\title{
NON-LINEAR ANALYSIS OF A NUCLEAR CONTAINMENT STRUCTURE UNDER HIGH INTERNAL PRESSURE
}

\author{
By \\ Ima Tavakkoli Avval \\ Master of Applied Science, Ryerson University, 2012 \\ Bachelor of Science, University of Tabriz, 2007
}

\author{
A dissertation \\ presented to Ryerson University \\ in partial fulfillment of the \\ requirements for the degree of \\ Doctor of Philosophy \\ in the program of \\ Civil Engineering
}

Toronto, Ontario, Canada, 2017

(C) Ima Tavakkoli Avval, 2017 


\section{AUTHOR'S DECLARATION}

I hereby declare that I am the sole author of this dissertation. This is a true copy of the dissertation, including any required final revisions, as accepted by my examiners.

I authorize Ryerson University to lend this dissertation to other institutions of individuals for the purpose of scholarly research.

I further authorize Ryerson University to reproduce this dissertation by photocopying or by other means, in total or in part, at the request of other institutions or individuals for the purpose of scholarly research.

I understand that my dissertation may be made electronically available to the public. 


\title{
ABSTRACT
}

\section{NON-LINEAR ANALYSIS OF A NUCLEAR CONTAINMENT STRUCTURE UNDER HIGH INTERNAL PRESSURE}

\author{
Ima Tavakkoli-Avval, Doctor of Philosophy, 2017 \\ Department of Civil Engineering \\ Ryerson University
}

The main objective of the current study is to investigate the response of an internally pressurized nuclear power plant containment structure at pressure values higher than design pressure, and is focused on the response of prestressed concrete containment to ultimate global structural failure. The containment structure consists of a prestressed concrete cylindrical perimeter wall, with a prestressed concrete tori-spherical dome, prestressed concrete ring beam, and conventionally reinforced concrete base slab. The finite element program ANSYS is used to predict the non-liner behaviour of the containment structure. Different techniques available in ANSYS program to model steel reinforcements for reinforced concrete and prestressed concrete is estimated to define a more suitable approach to model prestressing system. The approach proposed here is capable of incorporating parameters such as variation in tendon layout and non-uniform prestress losses in comparison to those done by other researchers. 
It is concluded that the design criteria for the containment structure are fully satisfied. No through crack was observed at design pressure. The first through crack develops in the dome at a pressure of 2.1 times the design pressure. There is no damage to be expected to the reactor systems up to a pressure well above design pressure. It is observed that the containment structure subject of this study meets the design requirement of the current standards and behaves linearly in excess of 1.5 times the design pressure. The response of the internally pressurized containment structure including the major openings is investigated. It is concluded that presence of openings does not have a significant effect on the pressure capacity of the containment structure. The minor differences in the responses are at pressure values beyond the linear limit and are less than $5 \%$. The response when openings are included are very similar to those without openings, except at the immediate neighboring of the equipment airlock opening. It is concluded that to predict the pressure response of containment structure, including the openings can be ignored. In case of need for a more exact response, only the equipment airlock can be included in the model. 


\section{TABLE OF CONTENTS}

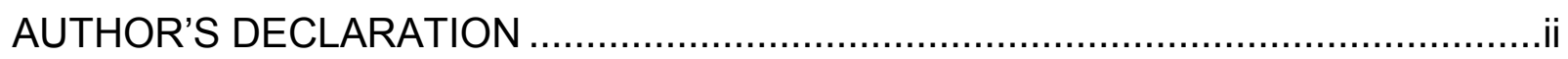

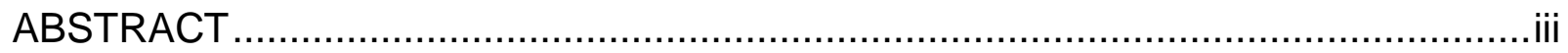

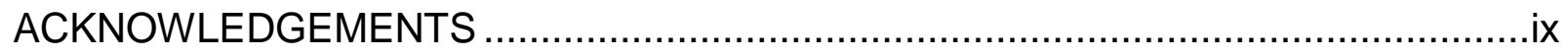

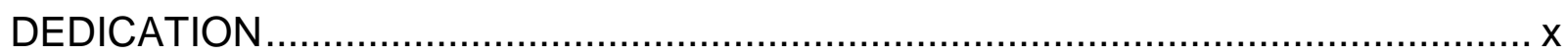

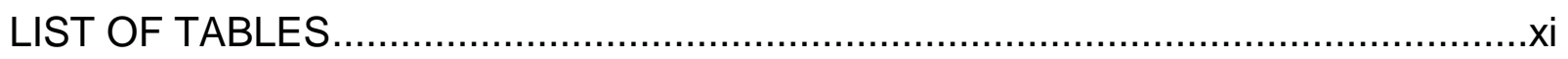

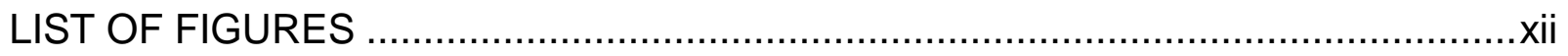

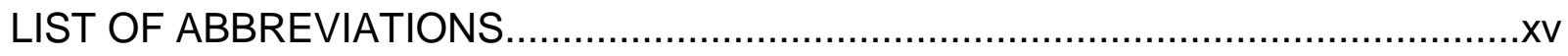

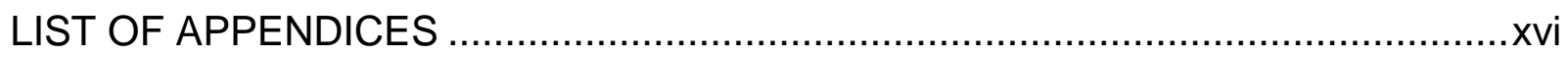

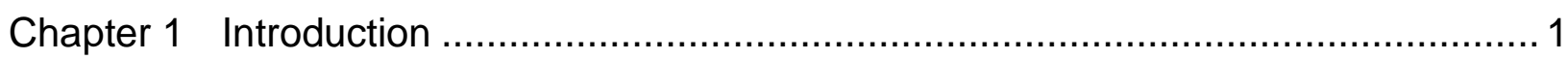

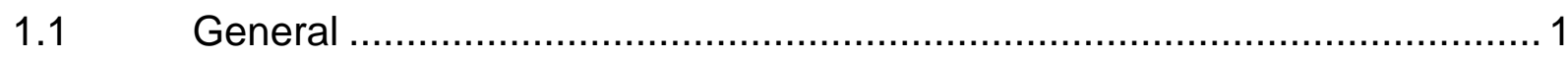

$1.2 \quad$ Nuclear Power Plant (NPP) Containment Structure ................................ 2

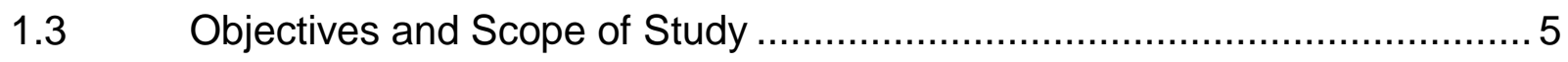

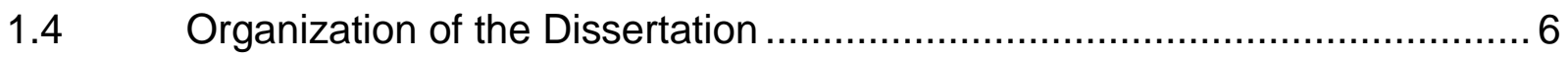

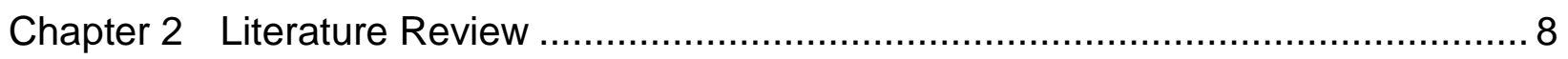

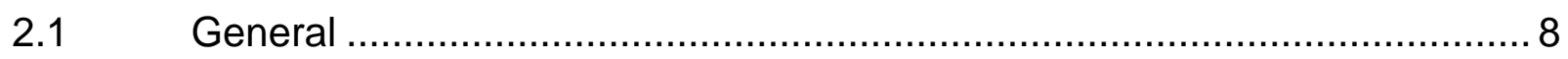

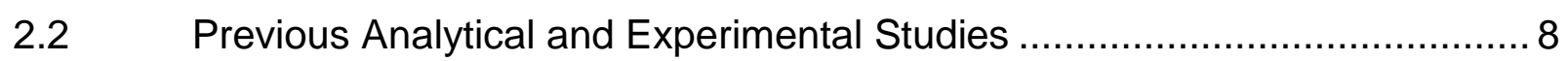

2.3 Applicable Codes and Standards ..................................................... 16

2.3.1 Design Load Considerations ........................................................... 16

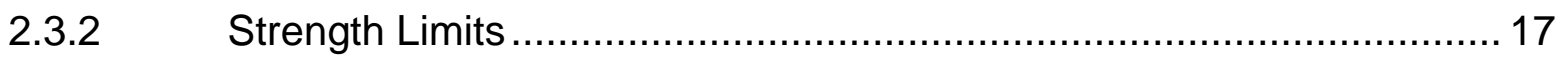

2.3.3 Permissible Stresses/Strains (PSS) ............................................ 17

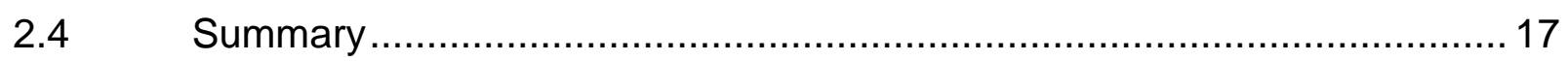

Chapter 3 Containment Structure Properties and Assumptions............................... 22

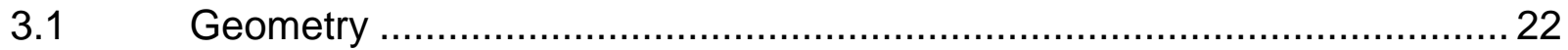

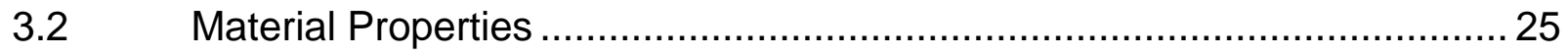

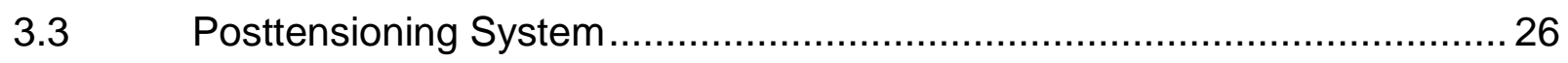

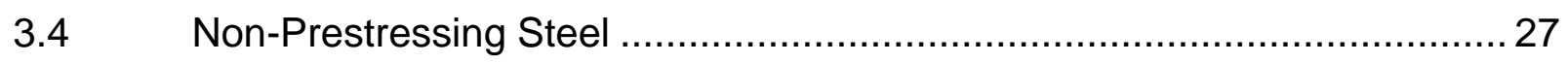

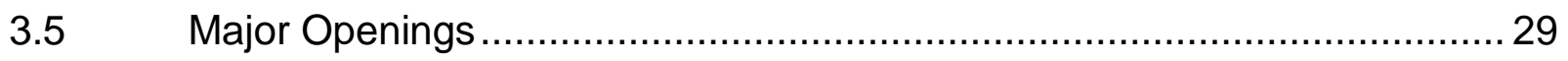

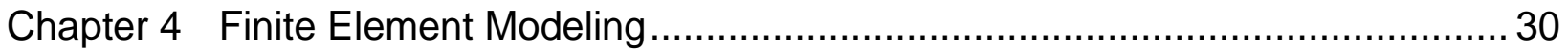

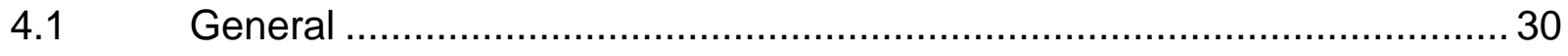




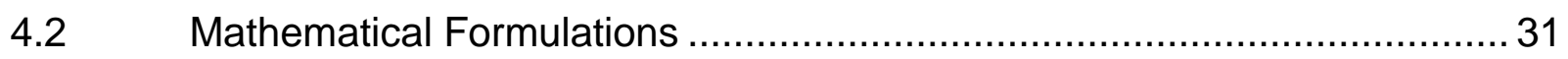

4.2.1 Concrete Material Model.............................................................. 31

4.2.2 Reinforced Concrete Element Selection ......................................... 34

4.2.3 Prestressing Tendon Element Selection ......................................... 39

4.3 Newton-Raphson Nonlinear Analysis ................................................. 43

4.4 Verification of the Finite Element Program ANSYS for Modelling CS ........ 43

4.4.1 Reinforced Concrete Beam .......................................................... 44

4.4.2 Mock-up prestressed containment structure …................................ 54

Chapter 5 Different Approaches to Model Prestressing System ................................ 64

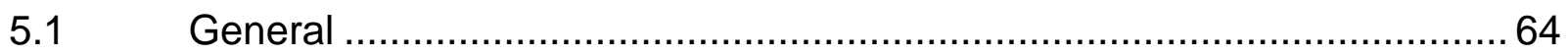

$5.2 \quad$ Development of Finite Element Models .................................................. 65

5.2.1 Material and Element Selection for Model 1 and Model 2 2....................65

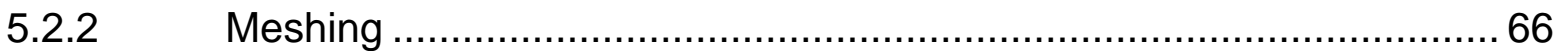

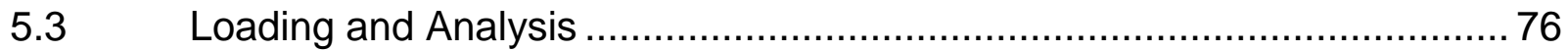

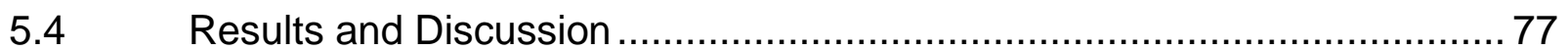

5.4.1 Overall Behaviour of Model 1 ............................................................ 77

5.4.2 Overall Behaviour of Model 2 ......................................................... 79

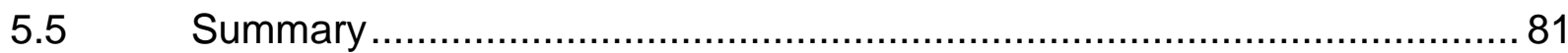

Chapter 6 Effects of Prestressing Losses on Response of Containment Structure .... 83

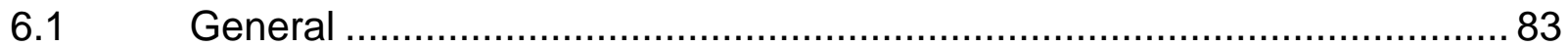

6.2 Analytical Calculation of Prestress Losses........................................... 83

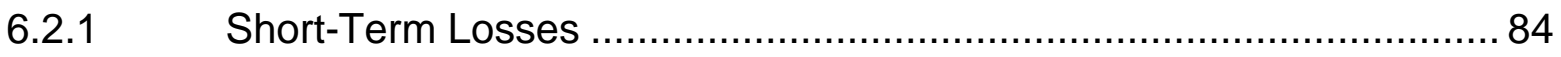

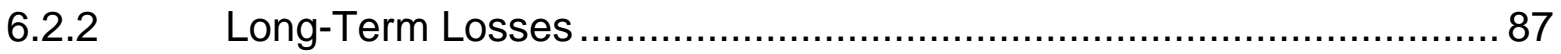

6.3 Modelling of the Containment Structure .............................................. 91

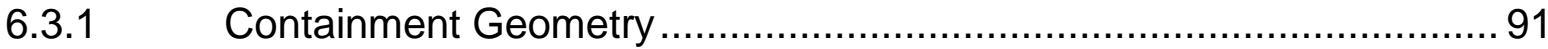

6.3.2 Material Model Selection................................................................. 92

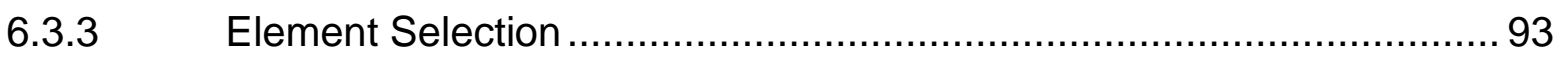

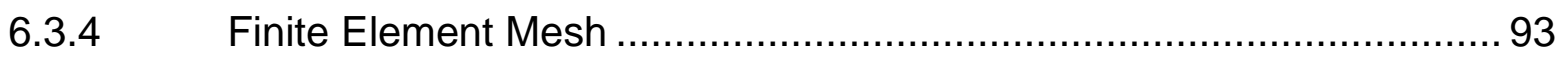

6.4 Introducing Prestressing Losses to FEM ............................................. 96

6.4.1 Geometry Dependent Losses ……............................................ 97

6.4.2 Time Dependent Losses ......................................................... 100 


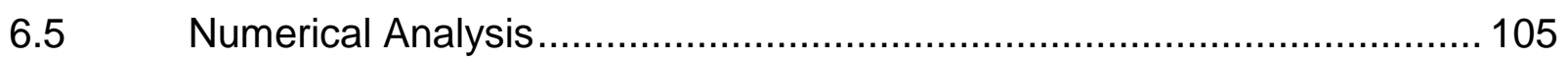

6.5.1 Analysis of the Containment under Internal Pressure ...................... 105

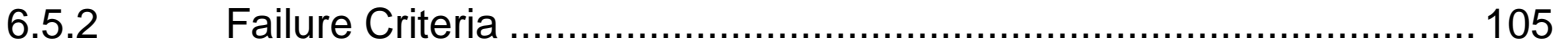

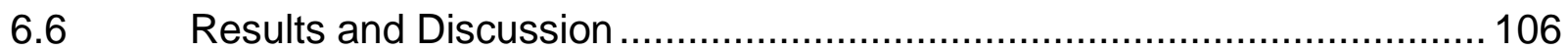

6.6.1 Overall Behaviour of the Containment Structure............................. 106

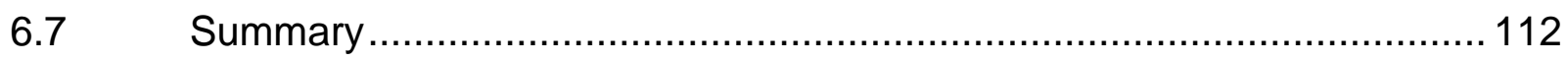

Chapter 7 Effects of Major openings on Response of Containment Structure .......... 114

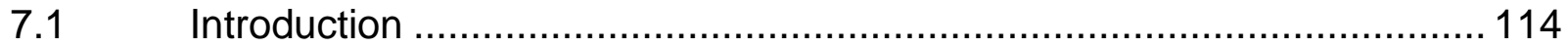

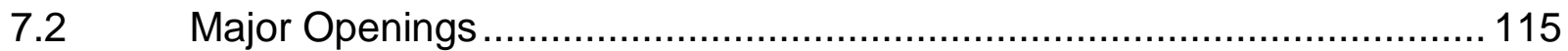

7.3 Finite Element Modelling of the Containment Structure ........................ 116

7.3.1 Material Model and Element Selection......................................... 116

7.3.2 Geometry Details of the Finite Element Models ............................. 116

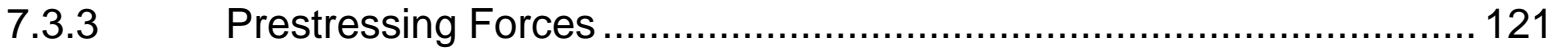

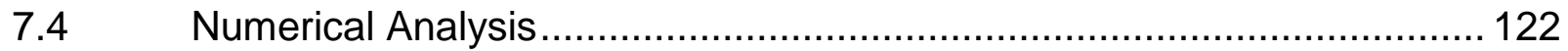

7.4.1 Analysis of Containment under Internal Pressure ........................... 122

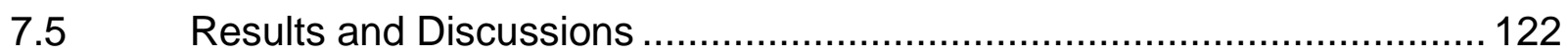

7.6 Assessment of Concrete Cracking …................................................. 126

7.7 Assessment of Non-Prestressing Steel and Prestressing Tendon Response

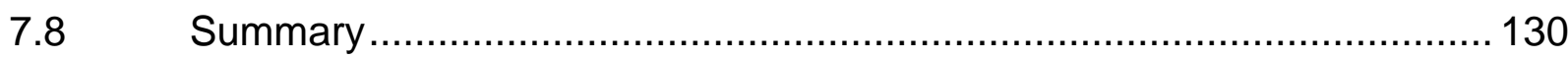

Chapter 8 Summary, Conclusions and Recommendations.................................. 133

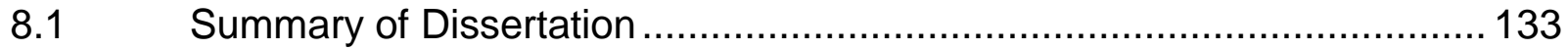

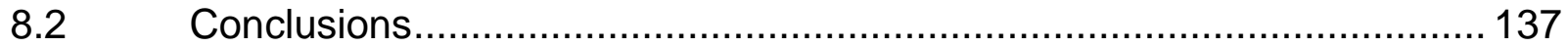

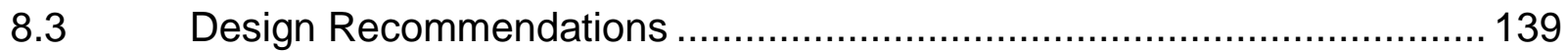

8.4 Recommendations for Future Studies ................................................ 140

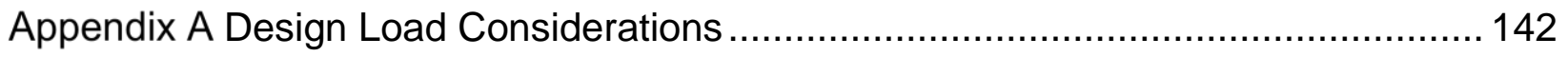

A.1 Factored Load Combinations ............................................................ 143

A.2 Un-factored Load Combinations..................................................... 144

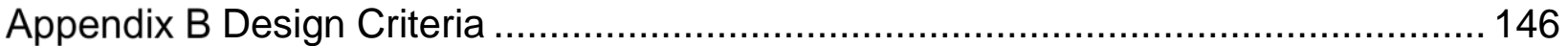

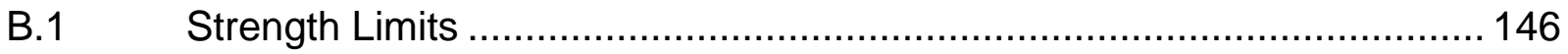

B.1.1 Flexure and Axial Loads ........................................................ 146

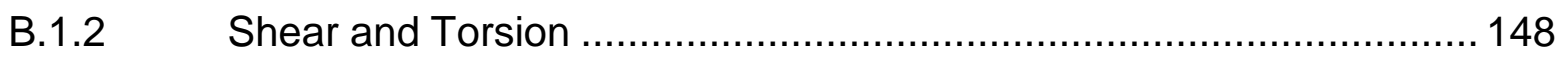


B.2 Permissible Stresses/Strains (PSS)

151

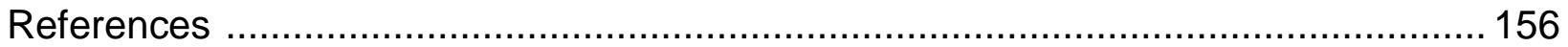

viii 


\section{ACKNOWLEDGEMENTS}

I would like to express my sincere gratitude to my instructors and research teammates who helped me complete this dissertation, and especially my supervisor, Dr. Reza Kianoush, for his consistent guidance throughout the duration of this research. Without his guidance and encouragement, it would not have been possible for me to complete this study with absolute success.

I would like to thank SNC Lavalin Inc., CANDU Energy Inc., MITACS Accelerate PhD program and Ryerson University for their financial support throughout this research study. I would also like to thank Dr. Homayoun Abrishami for his contributions and support during this period.

Last, but certainly not least, I recognize my husband, for his unconditional support in good and bad times. Without you, none of this would indeed be possible. 


\section{DEDICATION}

To

my daughter

Celine.

I love you! 


\section{LIST OF TABLES}

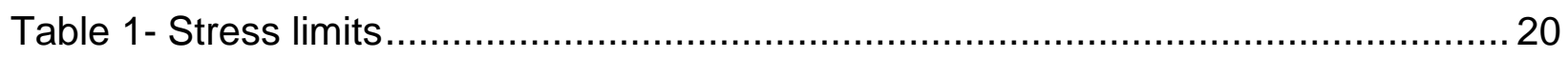

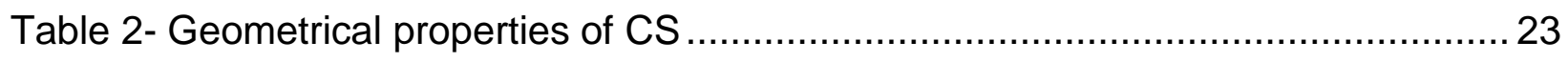

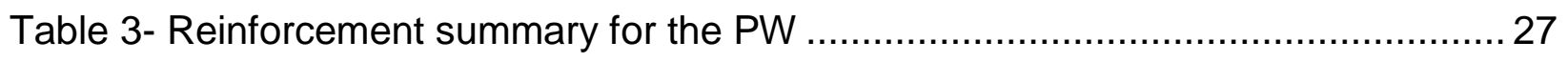

Table 4- Reinforcement summary for the Dome .................................................... 28

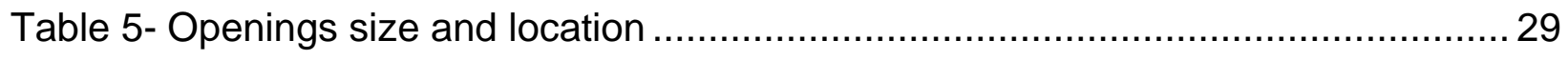

Table 6- Real constant sets for the reinforced concrete beam ................................... 47

Table 7- Real constant sets for reinforced concrete elements ................................... 58

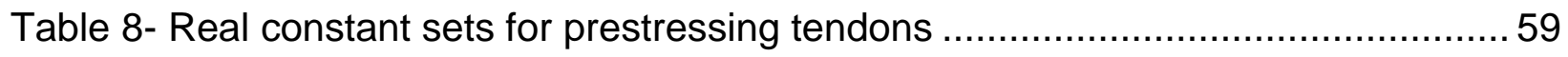

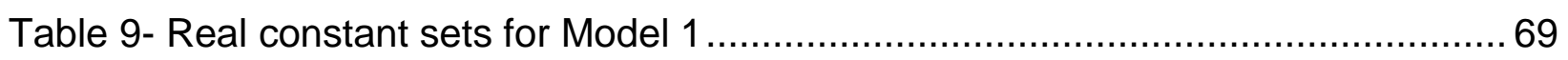

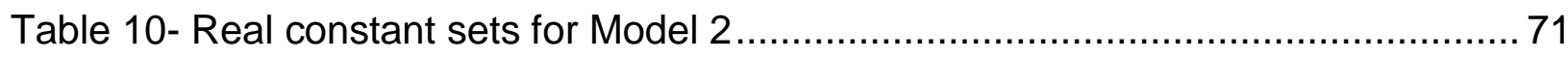

Table 11- Frictional coefficients summary for the cables......................................... 97

Table 12- Values for calculation of concrete creep for the cylindrical wall................... 103

Table 13- Values for calculation of concrete creep for the dome .............................. 103

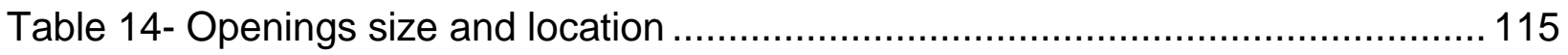




\section{LIST OF FIGURES}

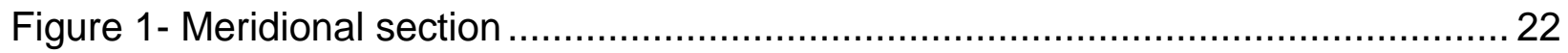

Figure 2- Horizontal cross-section of CS at elevation of equipment airlock................... 23

Figure 3- 3D schematic diagram of the containment structure .................................. 24

Figure 4- 3D schematic diagram of cross-section of the CS ..................................... 28

Figure 5- Concrete failure surface (source: [22]) ….................................................. 31

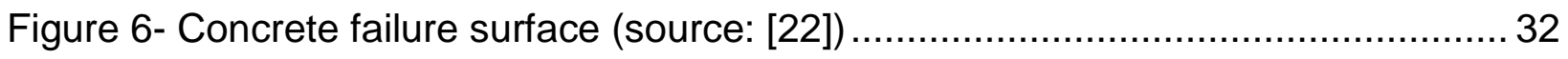

Figure 7- SOLID65 and reinforcement orientations (source: [22]) ….......................... 37

Figure 8- Strength of Cracked Condition (source: [22]) …........................................ 38

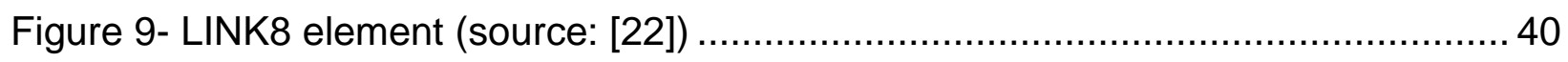

Figure 10- Reinforced concrete beam with loading ................................................. 44

Figure 11- Layout of reinforcements (source: [27]) ……....................................... 45

Figure 12- Reinforced concrete beam volume in ANSYS ........................................... 46

Figure 13- Strain-Stress curve for concrete material .............................................. 48

Figure 14- Strain-Stress curve for steel material ...................................................... 49

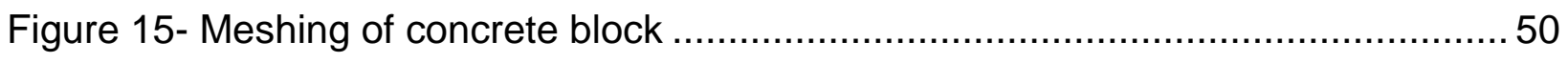

Figure 16- Reinforcement configuration in FE model .............................................50

Figure 17- Boundary condition at planes of symmetry ……................................... 51

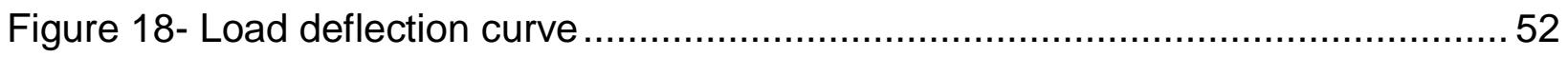

Figure 19- First crack at the constant moment region ........................................... 53

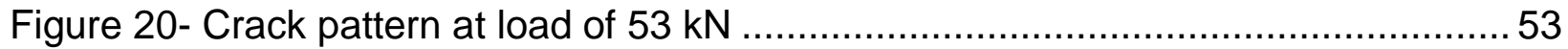

Figure 21- Vertical section of test structure (source: [28]) ….................................... 55

Figure 22- Non-prestressing reinforcement details (source: [28]) ….........................5 56

Figure 23- Real constant sets for containment structure cross-section ........................ 58

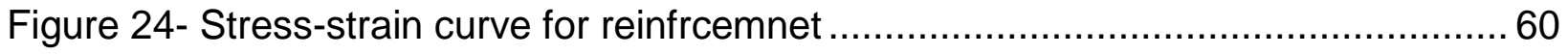

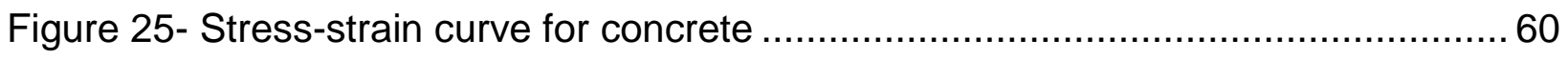

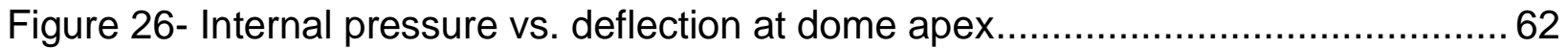

Figure 27- Finite element concrete elements and RC sets for Model 1 ........................6 68

Figure 28- Prestressing equivalent forces for Model 1 ............................................. 70

Figure 29- Finite element of prestressing tendons for Model 2: ............................... 72 
Figure 30- Concrete elements at dome of the CS …............................................ 73

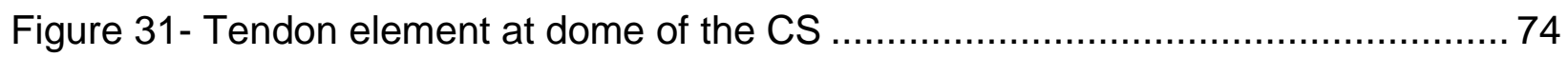

Figure 32- Nodes for concrete and tendon layer 1 element ................................... 74

Figure 33- Coupled nodes of concrete and tendon elements at dome ......................... 75

Figure 34- Internal pressure vs. normal displacement at dome apex.......................... 77

Figure 35- Stress state of a typical element at inner face of the dome for Model 1 at

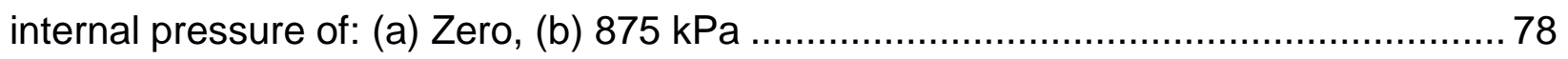

Figure 36- Location of the dome prestressing tendon that yields first in Model 2 .......... 80

Figure 37- Stress-strain relationship for bar element............................................. 80

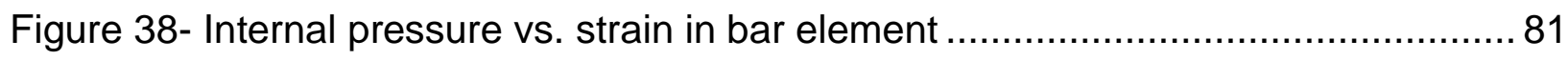

Figure 39- Frictional loss: (a) Curvature friction, (b) Wobble frictional (source: [21]) ..... 85 Figure 40- Finite elements: (a) reinforced concrete elements, (b) prestressing tendons 95

Figure 41- Prestressing force distribution along tendon length .................................98

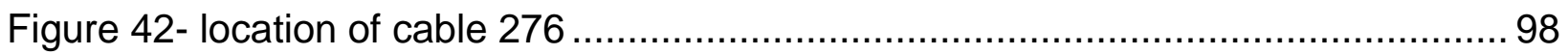

Figure 43- Variation of force in a typical wall horizontal tendon (Group1) .................. 100

Figure 44 - Prestressing tendon material properties in time ................................... 101

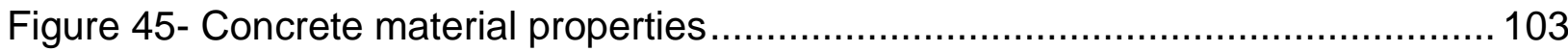

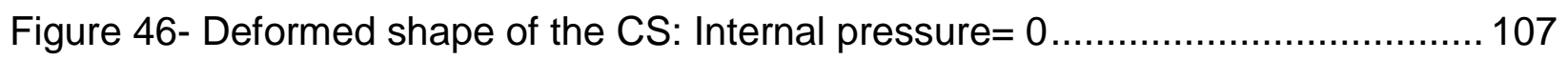

Figure 47- Internal pressure vs. normal displacement at dome apex ........................ 109

Figure 48- Internal pressure vs. normal displacement at wall mid-height.................... 109

Figure 49- Defromed shape of the containmnet strcuture at the end of analysis ........ 110

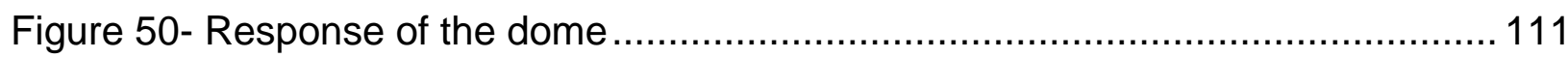

Figure 51- Response of the prestressing tendon at dome springing ........................111

Figure 52- Finite elements: (a) reinforced concrete elements, (b) prestressing tendons

Figure 53- Model 1: Horizontal cross-section of wall ............................................. 118

Figure 54- Model 2: CS and prestressing details around O1, O2 and O3 ................. 120

Figure 55- Model 2: Horizontal section of PW ...................................................... 121 
Figure 56- CS at internal pressure of zero: (a) Before application of prestressing forces

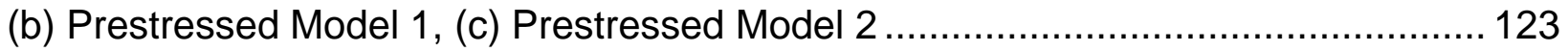

Figure 57- Deformed shape at internal pressure of 2.5DBA:.................................. 124

Figure 58- Internal pressure vs. normal displacement at dome apex (Point A) ........... 125

Figure 59- Internal pressure vs. normal displacement at Wall (Point B) ..................... 125

Figure 60- Internal pressure vs. strain in dome radial reinforcement......................... 128

Figure 61 - Internal pressure vs. strain in wall hoop reinforcement ............................ 128

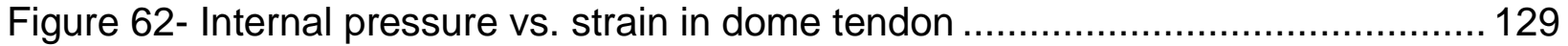

Figure 63- Model 2: Internal pressure against strain in hoop reinforcement above

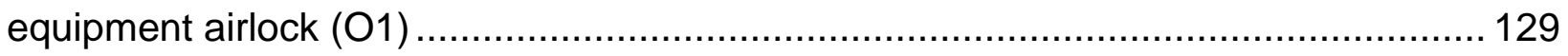

Figure 64- Internal pressure vs. strain in horizontal tendon of wall .......................... 130 


\section{LIST OF ABBREVIATIONS}

$\begin{array}{ll}\text { 2D } & \text { 2 Dimensional } \\ \text { 3D } & \text { Three-Dimensional } \\ \text { ACR } & \text { Advanced Candu Reactor } \\ \text { BDBA } & \text { Beyond Design Basis Accident } \\ \text { BWR } & \text { Boiling Water Reactor } \\ \text { CANDU } & \text { CANadian Deuterium Uranium } \\ \text { CS } & \text { Containment Structure } \\ \text { CSA } & \text { Canadian Standard Association } \\ \text { DBA } & \text { Design Basis Accident } \\ \text { DCEP } & \text { Design Change Engineering Program } \\ \text { DOF } & \text { Degree of Freedom } \\ \text { FEA } & \text { Finite Element Analysis } \\ \text { FEM } & \text { Finite Element Method } \\ \text { IS } & \text { Internal Structure } \\ \text { LOCA } & \text { Loss of Coolant Accident } \\ \text { MKIH } & \text { Multi Linear Kinematic Hardening } \\ \text { MSLB } & \text { Main Steam Line Break } \\ \text { NPP } & \text { Nuclear Power Plant } \\ \text { PCCM } & \text { Prestressed Concrete Containment Model } \\ \text { PHW } & \text { Pressurized Heavy Water } \\ \text { PSS } & \text { Permissible Stress Strain } \\ \text { PW } & \text { Perimeter Wall } \\ \text { PWR } & \text { Pressurized Water Reactor } \\ \text { RB } & \text { Reactor Building } \\ \text { RC } & \text { Reinforced Concrete } \\ \text { UDL } & \text { Uniformly Distributed Load } \\ \text { ULS } & \text { Ultimate Limit State } \\ \text { UPC } & \text { Ultimate Pressure Capacity } \\ & \end{array}$




\section{LIST OF APPENDICES}

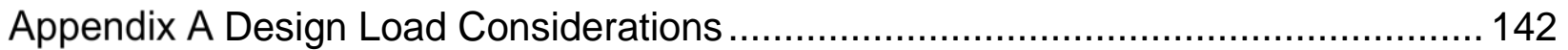

A.1 Factored Load Combinations ….......................................................... 143

A.2 Un-factored Load Combinations............................................................ 144

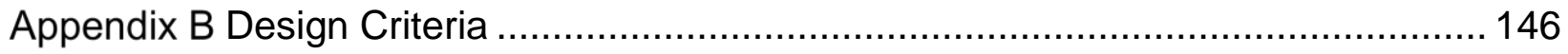

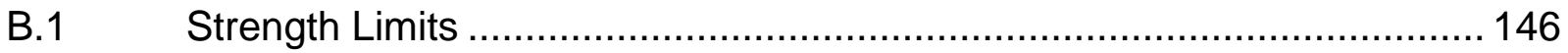

B.1.1 Flexure and Axial Loads ....................................................... 146

B.1.2 Shear and Torsion .................................................................... 148

B.2 Permissible Stresses/Strains (PSS) ............................................. 151 


\section{CHAPTER 1 INTRODUCTION}

\subsection{General}

The Nuclear Power Plant (NPP) containment system forms a continuous, pressure retaining envelope around the reactor core and the heat transport system. The containment structure (CS) is designed to protect the public and environment from all potential internal events. There is a demand in the nuclear power industry to investigate the response of containment structures to much higher internal pressures that could be encountered during a severe accident.

Under abnormal conditions, such as Loss of Coolant Accident (LOCA) or Main Steam Line Break (MSLB), the containment structure is subjected to an increasing internal pressure, and tensile stresses can be developed in significant parts of the containment structure. Due to its low tensile capacity, concrete cracks in such condition. By increasing the internal pressure, the cracks penetrate through the thickness of the wall in areas that are relatively weaker than the remaining parts of the containment. Then, the response of the containment structure is followed by possible yielding of the non-prestressing steel and prestressing tendons causing the loss of function and finally the overall failure of the structure.

The main objective of the current research study is to predict the pressure values at which the design conditions and limit states are met, which include; cracking and crushing of concrete, yielding of non-prestressing steel and prestressing tendon, and rupture of nonprestressing steel or prestressing tendon. Moreover, for prestressed concrete containments, the internal pressure capacity may be estimated based on satisfying both of the following strain limits defined in CSA N287.3 [1]: 
1) A total tensile average strain in tendons away from discontinuities of 0.8 percent; and

2) A global free-filed strain in reinforcements away from discontinuities of 0.4 percent.

One of the design requirements for the nuclear power plant containment structure is to have the ultimate pressure capacity (UPC) of at least twice the design pressure, and the structure to behave elastically to at least 1.5 times the design pressure [1].

It should be noted that the design of the reactor building in general must conform to the requirements of the Canadian Nuclear Safety Commission (REGDOC-2.5.2- CNSC) [2]. The containment structure falls under the jurisdiction of CSA N287.1 [3], CSA N287.2 [4] and CSA N287.3 [1]. These standards impose conditions in addition to those of conventional concrete design code CSA A23.3 [5].

\subsection{Nuclear Power Plant (NPP) Containment Structure}

The Reactor Building (RB) in NPP can be divided into two parts: the Containment Structure (CS) and the Internal Structure (IS). The CS houses the nuclear systems and the Internal Structure and supports them. The containment structure is the main component of the containment system. The CS should be designed in a way to provide sufficient strength, structural integrity, and required leak-tightness under operating and test conditions, postulated accident and environmental conditions. Moreover, the CS shall be designed to maintain their strength, serviceability and durability during the design life of the structure [1].

The design of the NPP containment structures must be carried out to ensure that any release of radioactive material to the environment is within the regulatory limits. Neutron radiation is an atomic particle that is emitted during nuclear reactor operation. Neutron radiation is not as readily absorbed as charged particle radiation, which makes this type highly penetrating [6]. Neutron can be shielded by water, concrete and materials 
containing large number of hydrogen molecules, accordingly, the NPP containments are reinforced concrete or prestressed concrete structures.

The major step in design of a containment structure is its shape and geometry. If the outward pressure from steam applied at inner face of the CS is the dominant force, containment tends to have a spherical design, on the other hand if the weight of the structure is the dominant force, containment tends to have a can shaped design. As the major functional requirement of the CS is to withstand the pressure loading of design basis accidents (DBA), the ideal shape of containment would be a spherical structure. Since a spherical structure is not suitable for equipment layout and is too expensive to build, the design results in combination of spherical and can shape. Therefore, containments usually adopt a cylindrical wall with flat bottom and a segmental spherical dome configuration.

The diameter of the cylindrical wall and the height of the CS are dictated by the equipment layout. Other parameter affecting the height and dimeter of the CS is the free building volume required to keep the accident pressure within a reasonable value. The thicknesses of the wall and dome are primarily determined by shielding requirements.

The containment structure subject of this study consists of a prestressed concrete cylindrical perimeter wall (PW), with a prestressed concrete tori-spherical dome, prestressed concrete ring beam, and conventionally reinforced concrete base slab. Properties of the CS subject of this study are explained in more details in Chapter 3.

The structure is prestressed to control the tensile stresses at the inside face of the containment boundary. This keeps it crack-free to help in the control of leakage. As the other major functional requirements of the CS is to limit the release of radioactive material to within the specified dose limits.

There is a demand in the nuclear power industry to investigate the response of containment structures Beyond Design Basis Accidents (BDBAs). BDBAs are accidents 
that are outside the limits of what the plant is designed to withstand. Beyond design-basis events are difficult to predict either because they have never occurred or have a low probability of occurring, but have potentially significant consequences. The consequence may be release of radioactive material that may exceed the dose limits for design basis accidents. A very good example is the Fukushima nuclear accident.

BDBAs are addressed by designing the plant to be strong through large margins for design basis accidents. The goal is to ensure that to the extent practicable, means are provided to mitigate the consequences and to minimize the probability of containment failure following a BDBA.

For BDBAs loads an assessment can be performed to ensure that the structural integrity of the CS is maintained. Plastic response due a BDBA, such as severe accident pressure, severe aircraft impact or blast would be acceptable as long as the overall structural integrity is not jeopardized. To achieve this goal, the CS should be of strong design with sufficient design margins so that it may survive following a BDBA.

BDBA load combinations are not specified in reference [1], but can be defined by analogy with load combinations for similar load categories and the requirements of NUREG-0800 [7]. For severe/extreme accident pressure, the load combination can be defined as follows:

$1.0 \mathrm{D}+1.0 \mathrm{~T}_{p}+1.0 \mathrm{P}_{\text {severe }}$

where,

D: Dead load;

$T_{p}$ : Effective prestressing load (short-term or long-term); and

Psevere: Severe accident pressure. 
It should be noted that, by analogy with 10CFR Part 50.34 [8] and NUREG-0800 [7], this load combination includes pressure loads ( $\left.P_{\text {severe}}\right)$ only in addition to permanent loads. Severe accident thermal loads will not be combined with permanent and pressure loads in this load combination.

According to CSA N287.3 Clause C.3.1 [1], safety margin of ultimate internal pressure capacity shall be at minimum of value of two. CSA N287.3 Clause C.3.2 requires that the failure mode of the CS to be identified in UPC assessment.

\subsection{Objectives and Scope of Study}

This research study aims to expand the understanding of the prestressed concrete containment structures that are subjected to internal pressure beyond the design pressure. The goal is to calculate the UPC of a specific nuclear power plant containment structure that is proposed to be built. Influence of different parameters on the UPC of the CS is studied. The particular aims of the current research study are to:

- Perform a realistic simulation of the prestressed concrete containment structure;

- Perform a realistic modelling of the prestressing effects and the associated losses;

- Determine the global UPC of the overall nuclear power plant containment without major openings; and

- Determine the UPC of the nuclear power plant containment accounting the effects of major openings.

Recent developments in computer technology and laboratory testing methods have helped to expand the knowledge of the ultimate response of the prestressed containment structures. For the purpose of the current study, the finite element program ANSYS is employed to simulate the response of the nuclear power plant containment structure.

Followings are the main steps throughout this research study: 
- Develop the finite elements models using the proper element types and material models; including the proper modeling of the concrete, reinforcement and prestressing tendons;

- Perform non-linear analysis on the model;

- Evaluate the response of the containment structure at DBA and UPC;

- Trace the major changes in structure responses;

- Monitor the progression of cracking;

- Monitor the stress level and yielding of the reinforcement and prestressing tendon; and

- Identify the failure modes and UPC of the Finite Element Model (FEM).

\subsection{Organization of the Dissertation}

This dissertation is divided into 9 chapters:

Previous research studies conducted as experimental tests and/or analytical analyses to investigate the failure and nonlinear response of prestressed containment structures are summarized in Chapter 2. Applicable codes and standards for design of such structures are discussed and explained in Chapter 2 as well.

The properties of the containment structure subject of the current study are described in details in Chapter 3.

Finite element modelling and mathematical formulation are summarized in Chapter 4 . The use and capabilities of the finite element program ANSYS to predict the nonlinear and failure response of reinforced concrete and prestressed concrete structures are verified. This includes response of a reinforced beam in section 4.4.1 and response of a mock-up prestressed containment structure in section 4.4.2. 
Chapter 5 explains and compares the different approaches to model the effects of prestressing system in containment structures and their effects on the pressure response and failure modes of the CS.

As follows, Chapter 6 explains the parameter affecting the prestressing forces in structures with complex geometry such as CS and provides approaches to accommodate the non-uniform prestressing losses in the finite element models.

Chapter 7 investigates the effects of major openings on the nonlinear response of the CS, and answers a key question if the major openings weakens the structure. Also, the approaches to accommodate the non-uniform prestress loss in a complicated model that includes several sources for non-axisymmetric behavior are described in this chapter.

Chapter 8 provides a summary of this dissertation, list of conclusions and design recommendations for similar structures as well as recommendations for future studies.

Afterwards, a list of references used within this dissertation is provided. Appendices $A$ and $B$ summarize the load cases and load combinations considered in the design of containment structures and design criteria according to applicable codes and standards, respectively. 


\section{CHAPTER 2 LITERATURE REVIEW}

\subsection{General}

There have been a number of analytical and experimental investigations to determine the pressure capacity of reinforced and prestressed containment structures. A summary of those studies are described in this section.

\subsection{Previous Analytical and Experimental Studies}

Rizkalla et al. [10] conducted an experimental study to evaluate the UPC of a prestressed CS patterned after the Canadian $C A N D U \otimes^{1}$ reactor containment. The dimension and other specifications were chosen to represent the CANDU CS with overall scale of 1:14. Only the elements contributing to resist the internal pressure loadings were in the model. Water was used to develop internal pressure in their test. This experimental investigation is used in the current study to verify the development of the finite element model of the CS.

They reported that the first crack developed at the pressure $210 \mathrm{kPa}$ at the inside face of the wall. At pressure of $260 \mathrm{kPa}$, visible meridional and circumferential cracks formed at the cylindrical wall and by the increase of pressure, cracks became wider and new cracks developed. Remarkable increase in wall deformation was observed associated with yielding of reinforcement and increase in ductility of the structure. At failure, the midheight of the perimeter wall deflected outward by $64 \mathrm{~mm}$, and the apex of the dome deflected upward by $76 \mathrm{~mm}$. Failure occurred when the prestressing tendon in both vertical and horizontal directions ruptured at the mid height of the wall.

\footnotetext{
$1 \AA$ Registered trademark of Atomic Energy of Canada Ltd. (AECL) used under exclusive licence by Candu Energy Inc.
} 
They concluded that the pattern of major cracks is affected by the location of the tendons in wall and dome and that cracks formed between the tendons and effected by the secondary reinforcement.

Rizkalla et al. [10] observed that the buttresses had introduced localized stiffness to the wall and in their study they indicated that the effect of the buttresses on non-axisymmetric behaviour of the CS should not be ignored [10].

Radulescu et al. [11] conducted an analytical work to obtain the UPC of the CANDU6® ${ }^{2}$ CS. The CANDU6 containment structure contains of cylindrical wall supported on a circular base slab and supporting a ring beam, lower dome and upper dome. The cylindrical wall, upper dome, ring beam and the base slab are prestressed concrete.

The computer program ANSYS [9] was used to model a 6 degree slice of the containment. Iso-parametric solid concrete elements were used to define the concrete wall and dome. Thickness of the cylindrical wall was modelled using seven Solid65, and the reinforcing bars and prestressing tendons are introduced using smeared capacity of the solid elements. For CANDU6 containment structure, the upper dome contains of 3 layers of prestressing tendons. Those were converted to the equivalent two layers of meridional and circumferential steels were added to the central layer of elements. The effects of the prestressing system in their study is introduced by two types of forces. First, the forced at anchorages of the cables which were presented as a lone load on the uniform magnitude around the circumference of the containment, second, the inward radial force due to cable curvature, which were introduced as uniformly distributed inward pressure.

The effects of temperature was not included in their study. They assumed that long term shrinkage and creep induced low level of stress in the containment structure except at

\footnotetext{
$2 \AA$ Registered trademark of Atomic Energy of Canada Ltd. (AECL) used under exclusive licence by Candu Energy Inc.
} 
the locations with high restraint condition such as at the springing of the upper dome and at the perimeter wall above the hinge. Those loads were not included in their study.

The non-linear analysis was conducted using the Newton-Raphson method by increasing the internal pressure. They concluded that up to pressure of $143 \mathrm{kPa}$ stresses were within the allowable limits both in compression and tension. No cracks in the wall were observed up to a pressure of $342 \mathrm{kPa}$. Afterwards, meridional cracks developed below the ring beam, and started to spread over the height of the wall and to penetrate through the $43 \%$ of thickness of the wall at pressure of $427 \mathrm{kPa}$. From $427 \mathrm{kPa}$ to $441 \mathrm{kPa}$ a nearly generalized hoop cracking pattern was developed. At $448 \mathrm{kPa}$, the reinforcing steel yields in the meridional direction. Then at pressure of $483 \mathrm{kPa}$, reinforcing steel yields in both directions at the apex of the dome and some regions in the perimeter wall. Finally, at 565 $\mathrm{kPa}$, the dome becomes simply a tensile membrane near final failure, the reinforcing steel had yielded and only the prestressing tendons were contributing to ultimate strength [11].

Smith [12] at Sandia National Laboratories prepared an extensive research study on the UPC of the CS subjected to prestress loss and tendon and reinforcing degradation. Using finite element program ABAQUS [13], they modelled the prestressed concrete containment structure with inside diameter of $42.67 \mathrm{~m}$, inside height of $64.62 \mathrm{~m}$ with wall thickness of $1.07 \mathrm{~m}$ and dome thickness of $0.81 \mathrm{~m}$. The cylindrical wall supported on a $2.74 \mathrm{~m}$ thick base mat. The steel liner had thickness of $6.35 \mathrm{~mm}$.

In their study, according to symmetry condition, a 30 degree slice of the CS was modelled. 20-node brick elements used to model the concrete and 8-node shell elements for the liner. Liner was attached to the concrete at coinciding nodes. The hoop and dome tendons were modelled as smeared reinforcing bars and fully bonded to the concrete. On the other hand, the vertical tendons were modelled as truss elements and were attached to concrete at four points along the height of the wall.

Comparing the results of the different reduced prestressing levels, they concluded that for the LOCA, uniform loss of prestressing in the vertical and hoop tendons did not have 
a significant effect on the calculated failure pressure of the vessel. However, it should be noted that frictional variation of prestress loss significantly affected the deformed shape of the containment, which influences the built up of the strain at liner anchors. Consequently, they concluded that to predict the failure of the CS, the effects of frictional prestress loss should be considered [12].

Saudy et al. [14] conducted UPC analysis on an Advanced Candu Reactor (ACR) ${ }^{\circledR} 3$ containment structure. This containment originally was designed to withstand internal pressure of $450 \mathrm{kPa}$ at LOCA. A 5 degree sector of the structure was modelled using ANSYS program. Similarly, they used Solid65 elements to model concrete material. The thickness of the wall, dome and base slab were divided to ten elements. Five elements were used along the circumferential direction of the wall, dome and slab base.

Shell43 elements were used to model reinforcing in their study. These elements were used for the reinforcing layers and had shared nodes with solid elements for the concrete layers. Two reinforcing layers were modelled to introduce meridional and hoop reinforcing. The amount of reinforcing in meridional and hoop directions were not identical and as a result, the layer introducing meridional reinforcement were modelled with small value for the modulus of elasticity in hoop direction and the layer representing the hoop reinforcement were modelled with small modulus of elasticity in meridional direction.

The 3D bar element referred to as LINK8 elements in ANSYS program, was used to model hoop tendons. Shell 43 elements were used to represent the vertical prestressing tendon with an orthotropic material with very small value for the modulus of elasticity in hoop direction. However, an isotropic materiel is used for the Shell elements that are used to introduce prestressing in dome. The shell elements in dome were defined to act in hoop and meridional directions as well as the vertical tendons. The effects of prestressing was

\footnotetext{
$3{ }^{\circledR}$ Registered trademark of Atomic Energy of Canada Ltd. (AECL) used under exclusive licence by Candu Energy Inc.
} 
introduces by applying differential temperature on the elements representing vertical and hoop prestressing tendons.

They observed a linear response up to pressure of $796 \mathrm{kPa}$. Beyond this point, softening of the structure and cracking happened. First cracking started at wall mid height in hoop direction, followed by cracks at inside face of the dome at spring line. At $1260 \mathrm{kPa}$, all the wall elements cracked in meridional, hoop and radial directions and the cracks in the dome extended towards the apex of the dome. At $1300 \mathrm{kPa}$, all the dome elements cracked in radial, meridional and hoop directions. At the inside face layer of the wall, hoop reinforcement started to yield at pressure of $1122 \mathrm{kPa}$, and the outside face tendons at pressure of $1138 \mathrm{kPa}$. For the meridional steel reinforcement, the yielding started at 1218 $\mathrm{kPa}$ at wall-base joint. The hoop tendons started to yield at pressure of $1260 \mathrm{kPa}$ and at $1300 \mathrm{kPa}$ the maximum elastic and plastic strains reached to $0.86 \%$ and $0.139 \%$, respectively. They concluded that the yielding of the hoop tendons governed the failure of the containment. At the UPC of $1300 \mathrm{kPa}$ which represents 2.89 times the deign pressure were calculated for ACR-700 containment structure [14].

Kwak and Kim [15] conducted numerical analysis on the 1/14 prestressed concrete containment model with internal bonded tendons that were tested by Rizakalla et al. [10]. Similarly the containment circular wall and the dome was modelled using finite element method via DIANA 8.1 software. They employed 3D layered shell elements in their model. Penetrations and equipment hatches were ignored. In total, 1380 eight-node layered shell elements for the wall and the lower part of the dome and 125 six-node layered shell elements for the upper part of the dome were used. The foundation and buttresses were modelled with twenty-node solid elements.

In their model, circumferential and vertical reinforcements were modelled as an equivalent steel layer. The internal tendons were also described by truss elements maintaining the placing space. They introduced the effects of tension stiffening to their model and compared the results with the experimental study performed on the 1/14 prestressed concrete containment model. The analytical study showed that the structure undergoes 
remarkable deformation which initiates from the wall-base connection. The vertical buttresses restricted the outward deformation of the wall.

With increase of the internal pressure, at $248 \mathrm{kPa}$, the circumferential cracking developed at the interior of the ring beam region along with exterior cracking at the mid height of the dome, followed by horizontal cracking at the wall of the CS. At $372 \mathrm{kPa}$, interior horizontal cracking and the vertical exterior cracking initiated at the buttresses and was distributed along the wall face between the pair of buttresses with increase of pressure. At the internal pressure of $620 \mathrm{kPa}$, remarkable outward deformation of the ring beam was observed. It was observed that the vertical buttresses and the ring beam anchored the prestressed pressure and maintained the membrane behaviour up to the ultimate pressure capacity. The model failed at $930 \mathrm{kPa}$, due to yielding of the reinforcement [15].

Moreover, Hu and Lin [16] conducted an analytical study using finite element to predict the ultimate pressure capacity of a Pressurized Water Reactor (PWR) CS. Similarly, the PWR prestressed containment is composed of a circular base, cylindrical wall and hemispherical dome. For PWR CS wall, the prestressing tendons are placed in meridional and circumferential directions. Moreover for the dome, the prestressing tendons are placed in circumferential direction and two perpendicular directions parallel to $\mathrm{X}$ and $\mathrm{Y}$ coordinates. For this CS, the design pressure was $476 \mathrm{kPa}$.

Due to placement of the tendon, the CS has four plane of symmetry, and $1 / 8$ of the CS was modelled. Symmetry boundary conditions were imposed at the two planes of symmetry. The eight-node shell elements with six DOF at each node, were employed to model the wall and dome of the CS. Moreover, the twenty-node solid elements were used to model the base slab. For simplicity, the lateral pressure applied to the base slab due to the soil was ignored. The prestressing tendons and reinforcing steel are modelled as uni axial materials that are smeared through the element section. The cross-sectional area, spacing, position and orientation of the prestressing tendons or the reinforcing steel were specified for each layer. 
A Mohr-Coulumb type compression surface with a crack detention surface was used to model the failure surface of the concrete material. Therefore, when the principal stresses are dominantly in compression, the response of the concrete is modelled by an elasticplastic theory. In tension, when the cracks occurs, the orientation of the cracks are preserved and the existing cracks are modelled by the damage elasticity. Also, tension stiffening is modelled by a simple descending line.

The prestressing forces of the tendons were applied by the initial strain to the CS. Then, the internal pressure was applied. With both material and geometry non-linearity, the ultimate pressure capacity of the CS was $886 \mathrm{kPa}$. To investigate the influence of the geometry non-linearity on the response of the CS, they compared the results of the geometric non-linearity formulation and those of the linear geometric formulation for the cases that the material are assumed to act linearly. They concluded that the results may deviate for the pressure beyond $1400 \mathrm{kPa}$ which is far beyond the failure of the CS. They stated that the deformation of the CS is still in small displacement stage when the containment fails and the effects of the geometry non-linearity is negligible.

Moreover, to investigate the effects of tension stiffening on the ultimate pressure capacity of the PWR containment structure, the results were compared for the case that no tension stiffening were introduced to the model. For the case that the strain at which the tensile strength of the concrete after cracking falls to the value of zero is set to a value close to the cracking strain, the value of UPC of the PWR containment structure was estimated as $848 \mathrm{kPa}$. They concluded that the effect of tension stiffening on the UPC is insignificant.

By comparing the results of the CS modelled including the base slab and the one without the base slab, they concluded that the model with the base slab is stiffer, however, the UPC of the two cases are almost the same. The crack pattern for the two cases were reported rather similar, however the model without the base has more cracks at the bottom of the cylindrical wall [16]. 
Hu and Liang [17] conducted numerical analyses to predict the pressure capacity and the failure mode of the Boiling Water Reactor (BWR) Mark III reinforced concrete containment using the finite element program ABAQUS [13]. They used 8-node shell elements to model the dome and cylinder wall, and 27-node solid elements to model the base slab. They concluded that when the reinforced concrete containment failed, extensive cracks took place at the apex of the dome, the intersection of the dome and the cylinder and the lower part of cylinder where there was a discontinuity in the thickness of the containment. In addition, the ultimate pressure capacity of the containment was calculated as 1.59 times the design pressure [17].

Kim and Lee [18] used the 9-node degenerated shell finite element to predict the UPC of nuclear containment building. The degenerated shell element was used to consider the shell's transverse strain effects. To calculate the stress through the thickness of the reinforced concrete layers, numerical integration is done through the thickness direction. Such formulation was then employed in modelling a standard Korean nuclear containment building with a hemispheric dome supported on cylindrical wall and a base slab. The structure was loaded with the associated dead load, prestressing load and internal pressure at the time of accident. In their study, the prestressing effect was introduced by an equivalent uniformly distributed pressure on the outer surface of the containment wall.

One quarter of the CS was modelled omitting the mat foundation. The wall and the dome of the CS was modelled using eight and five 9-node degenerated shell elements. In circular direction, the CS was divided to five elements. The degenerated shell element consisted of 8-concrete layers where the inner and the outer layers were the smeared steel layers. The responses of the structure were still in linear region prior to pressure of $0.83 \mathrm{MPa}$. Initial cracking was observed to be more excessive at the outer surface compared to the inner surface. With increase of the internal pressure, the cracks spread towards the upper part of the wall and the dome. Ultimately at the internal pressure of $1.14 \mathrm{MPa}$, the shear failure mode happened when the cracks had spread in all part of the CS [18]. 
Shokoohfar and Rahai [19] conducted numerical nonlinear analyses of a 1:4 scale model of a Prestressed Concrete Containment Vessel (PCCV) under pressure and high temperature effects comparing the results with those of the experimental analysis done by reference [20]. In their study, they concluded that the temperature has little impact on the ultimate pressure capacity of the prestressed concrete containment vessel. Moreover, the failure mode of the PCCV structure was not influenced by hoop tendons prestressing force variations, as those parameters were more significant under lower pressures [19].

\subsection{Applicable Codes and Standards}

As was mentioned before, the design of the reactor building in general must conform to the requirements of the Canadian Nuclear Safety Commission (REGDOC-2.5.2- CNSC, 2014) [2]. The containment structure falls under the jurisdiction of CSA N287.1 [3], CSA N287.2 [4] and CSA N287.3 [1]. These standards impose conditions in addition to those of conventional concrete design code CSA A23.3 [5].

The structural design shall be carried out according to the requirements stipulated in CSA A23.3 [5] and CSA N287.3 [1], and the requirements are:

a) Service category loads shall be examined under factored and un-factored conditions. The factored resistance of a section shall be greater than the effect of the factored loads. In addition, the stresses under un-factored loads shall be less than the allowable stresses.

b) Under the abnormal/environmental load category, the structure is to remain elastic.

\subsubsection{Design Load Considerations}

The load cases and load combinations that shall be considered in the design of the containment structures according to CSA N287.3 are summarized in Appendix A 


\subsubsection{Strength Limits}

The limit state design of the containment structure under factored service category loads shall be performed based on the CSA A23.3 [5]. Accordingly, the factored resistance of the section must be greater than or equal to the section forces under factored loads. The material resistance factors to be used for calculation of the factored resistance are as follows:

- $\phi_{c}=0.65$ Resistance factor for concrete (CSA A23.3 Clause 8.4.2 [5])

- $\phi_{s}=0.85 \quad$ Resistance factor for non-prestressed reinforcing bars (CSA A23.3 Clause 8.4.3[5])

- $\phi_{p}=0.90 \quad$ Resistance factor for prestressing tendon (CSA A23.3 Clause 8.4.3 [5])

These requirements are summarized in Appendix B .

\subsubsection{Permissible Stresses/Strains (PSS)}

In the CS, under the service category loads, the stresses shall remain below the permissible stresses. Moreover, under the abnormal/environmental load category, the structure is to remain elastic. The stresses in the sections under un-factored loads must be within the limits defined in Table 1.

The stress in prestressing tendon and non-prestressing steel can be calculated based on strain compatibility approach explained in Appendix B

\subsection{Summary}

Demand is increased in the nuclear power industry to investigate the response of containment structures during a LOCA and BDBA. Despite the wide range of studies on the UPC of the various CS, demand is specifically introduced for evaluation of the ultimate 
response of any new design nuclear power plant containment building beyond design basis accidents.

In internally pressurized containment structures, sources of non-axisymmetric behavior include; dome tendon layout, wall horizontal tendon buttresses and major openings. All the mentioned factors directly affect the deformed shape of the structure after transfer of prestressing forces as well as the stress distribution. These factors cannot be introduced if the CS is represented by an axisymmetric finite element model, or by a 3-dimensional (3D) repeating sector. To capture a more accurate behaviour of the CS, full 3D finite element models are prepared in the current study.

In most of preceding numerical studies, the prestressing tendons are modelled as smeared reinforcement or shell layers, and the effects of prestressing system are modelled using an equivalent approach. In those studies, the non-uniform prestressing losses are not fully considered.

The non-uniform variation of prestressing forces along the length of tendon affects stress distribution in the CS. In the current study, prestressing tendons are modelled with discrete bar elements, and the effects of prestressing system are added directly as initial strain to the bar elements. This approach enables the capability of the model to accommodate non-uniform prestressing force distribution by adding additional script to the program. The major challenge for modelling prestressing system is to accommodate parameters affecting prestressing forces. This includes: the geometry dependent changes along the tendon profile, changes due to incremental pressure and changes with time. To introduce these critical changes, the discrete elements are preferred in the current study.

Using the discrete elements, the tendon layout is modelled as close as possible to the designed layout and enables the model to capture the most accurate results of the prestressing system. This approach significantly increases the complexity of the 
modelling; however, it represents the most realistic modeling of the unsymmetrical tendon layout of the dome as well as of the perimeter wall.

In the current research study, detailed pressure analysis is presented for models prepared with discrete tendon elements. 
Table 1- Stress limits

\begin{tabular}{|c|c|c|c|}
\hline & Component & Compressive stress & Tensile Stress \\
\hline \multirow{3}{*}{$\begin{array}{c}\text { Service } \\
\text { Load } \\
\text { Category }\end{array}$} & concrete & $\begin{array}{l}0.35 f_{c}^{\prime} / 0.45 f_{c}^{\prime} \text { (Primary: membrane/membrane plus } \\
\text { bending) (N287.3 clause 8.2.1.3) } \\
0.45 f_{c}^{\prime} / 0.6 f_{c}^{\prime} \text { (Secondary: membrane/membrane plus } \\
\text { bending) (N287.3 clause 8.2.1.3) } \\
0.60 f_{c i}^{\prime} \text { (immediately after prestress transfer) (CSA } \\
\text { A23.3 Clause18.3.1.1) } \\
0.45 f_{c}^{\prime} \text { (after allowance for all prestress losses due to } \\
\text { sustained loads) (CSA A23.3 Clause18.3.2) } \\
0.6 f_{c}^{\prime} \text { (after allowance for all prestress losses due to all } \\
\text { loads) (CSA A23.3 Clause18.3.2) }\end{array}$ & $\mathrm{N} / \mathrm{A}$ \\
\hline & $\begin{array}{l}\text { non- } \\
\text { prestressed } \\
\text { main } \\
\text { reinforcement }\end{array}$ & $\begin{array}{l}0.50 f_{y} \text { (excluding temperature loads) } \\
0.65 f_{y} \text { (including temperature loads, using cross-ties) } \\
\text { (N287.3 Clause10.3.1) }\end{array}$ & $\begin{array}{l}0.50 f_{y} \text { (excluding temperature loads) } \\
0.65 f_{y} \text { (including temperature loads, using cross- } \\
\text { ties) (N287.3 Clause10.3.1) }\end{array}$ \\
\hline & $\begin{array}{c}\text { prestressing } \\
\text { tendon }\end{array}$ & $\mathrm{N} / \mathrm{A}$ & $\begin{array}{l}\min \left(0.85 f_{p u}, 0.94 f_{p y}\right) \text { (due to jacking force) } \\
\min \left(0.82 f_{p y}, 0.74 f_{p u}\right) \quad \text { (immediately after } \\
\text { prestress transfer) } \\
0.70 f_{p u} \text { (at anchor immediately after anchor set) } \\
\text { (CSA A23.3 Clause 18.4) }\end{array}$ \\
\hline
\end{tabular}




\begin{tabular}{|c|c|c|c|}
\hline & Component & Compressive stress & Tensile Stress \\
\hline \multirow{3}{*}{$\begin{array}{c}\text { abnormal/ } \\
\text { environm } \\
\text { ental } \\
\text { Load } \\
\text { Category }\end{array}$} & concrete & $\begin{array}{l}0.75 f_{c}^{\prime} \text { (primary) } \\
0.85 f_{c}^{\prime} \text { (including (primary plus secondary) } \\
\text { (CSA N287.3 Clause 10.3.2) }\end{array}$ & $\mathrm{N} / \mathrm{A}$ \\
\hline & $\begin{array}{l}\text { non- } \\
\text { prestressed } \\
\text { main } \\
\text { reinforcement }\end{array}$ & $0.90 f_{y}(\mathrm{CSA}$ N287.3 Clause 10.3.2) & $0.90 f_{y} \quad$ (CSA N287.3 Clause 10.3.2) \\
\hline & $\begin{array}{c}\text { prestressing } \\
\text { tendon }\end{array}$ & $\mathrm{N} / \mathrm{A}$ & $0.90 f_{p y}($ CSA N287.3 Clause 10.3.2) \\
\hline
\end{tabular}




\section{CHAPTER 3 CONTAINMENT STRUCTURE PROPERTIES AND ASSUMPTIONS}

\subsection{Geometry}

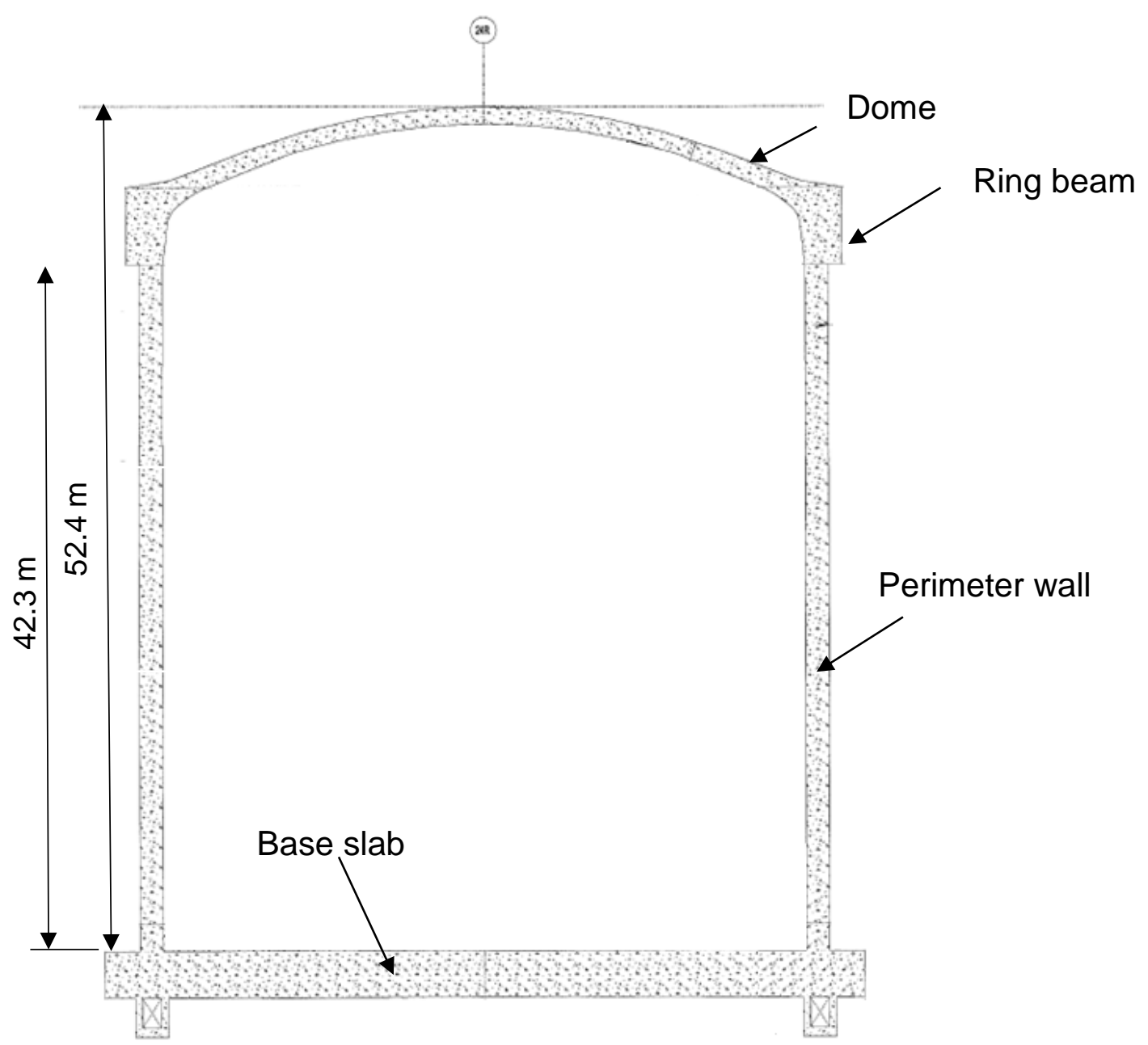

Figure 1- Meridional section

The containment structure selected for this study has dimensions and properties similar to one which is proposed to be built. The containment structure consists of a cylindrical perimeter wall, four buttresses at $90^{\circ}$ intervals, a tori-spherical dome, a ring beam, a base 
slab and a tendon gallery. The CS also contains of a steel liner at inner face of the PW and at the dome to provide additional leakage protection.

The meridional section and horizontal section of the containment are shown in Figure 1 and Figure 2, respectively. The four buttresses in the CS are named as buttresses 1, 2, 3 and 4, and hereafter are referred to as B1, B2, B3 and B4, respectively. These buttresses are shown in Figure 2.

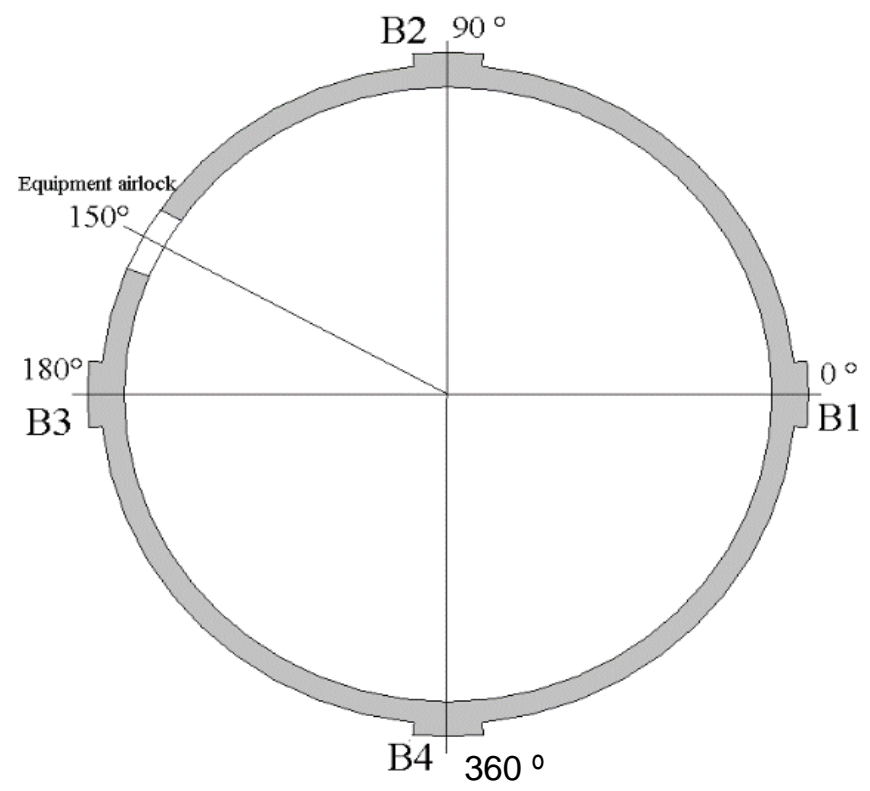

Figure 2- Horizontal cross-section of CS at elevation of equipment airlock

Table 2- Geometrical properties of CS

\begin{tabular}{|l|l|}
\hline Radius of perimeter wall interior surface & $20.7 \mathrm{~m}$ \\
\hline Radius of dome interior surface & $41.5 \mathrm{~m}$ \\
\hline Thickness of perimeter wall & $1500 \mathrm{~mm}$ \\
\hline Thickness of dome & $1100 \mathrm{~mm}$ \\
\hline Width of buttress & $5000 \mathrm{~mm}$ \\
\hline Thickness of buttress & $835 \mathrm{~mm}$ \\
\hline Thickness of ring beam & $2300 \mathrm{~mm}$ \\
\hline
\end{tabular}


The geometrical properties for the containment structure which are used in this study are summarized in Table 2. A schematic 3D diagram of the containment structure showing different components is presented in Figure 3.

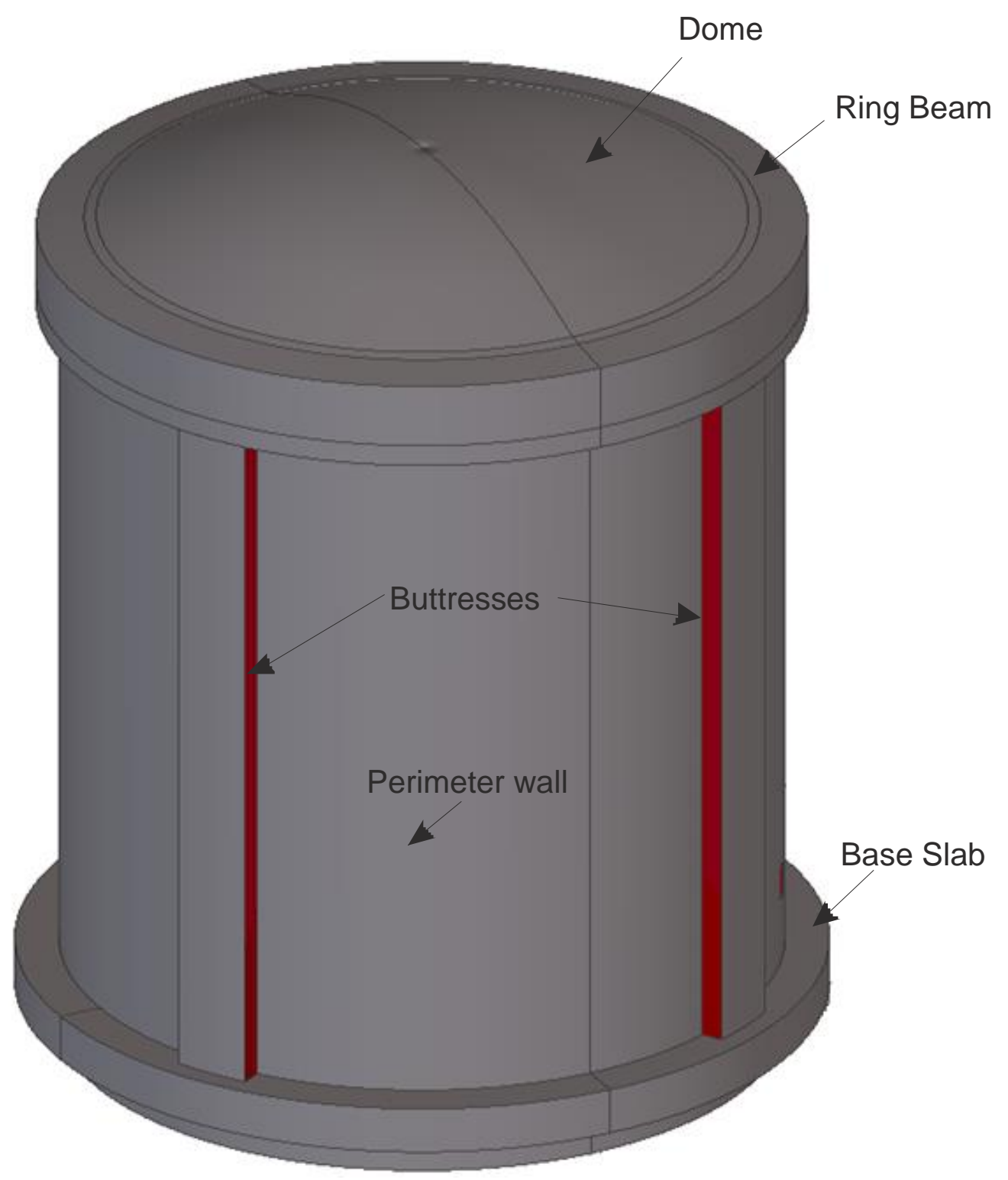

Figure 3-3D schematic diagram of the containment structure 


\subsection{Material Properties}

The structural materials used in the containment can be divided into three groups, which are non-prestressing steel bars, prestressing tendons and concrete.

The material properties for non-prestressing steel are as follows:

$\mathrm{E}_{\mathrm{s}}=200,000 \mathrm{MPa} \quad$ Modulus of elasticity of non-prestressing steel;

$f_{y}=400 \mathrm{MPa} \quad$ Yield strength of non-prestressing steel.

The material properties for prestressing tendons are as follows:

$E_{p}=195,000 \mathrm{MPa} \quad$ Modulus of elasticity of prestressing tendons;

$\mathrm{f}_{\mathrm{pu}}=1860 \mathrm{MPa} \quad$ Ultimate tensile strength of prestressing tendons;

$\mathrm{f}_{\mathrm{py}}=1670 \mathrm{MPa} \quad$ Yield strength of prestressing tendons.

The stress-strain curve for the prestressing tendons is defined based on the modified Ramberg-Osgood function by Mattock for low-relaxation strands from reference [21] as follows:

$$
f_{p}=E_{P} \varepsilon_{p f}\left\{0.025+\frac{1-0.0025}{\left[1+\left(118 \varepsilon_{p f}\right)^{10}\right]^{1 / 10}}\right\} \leq f_{p u}
$$

The material properties of concrete are defined as follows, where Equation (2) has been obtained from reference [21].
$\gamma_{c}=2400 \mathrm{~kg} / \mathrm{m}^{3}$
Density of concrete;
$f_{c}^{\prime}=50 \mathrm{MPa}$ Specified concrete compressive strength;
$E_{c}=32,000 \mathrm{MPa}$
Secant modulus of elasticity; 


$$
\begin{array}{ll}
E_{c}=\left(3300 \sqrt{f_{c}^{\prime}}+6900\right)\left(\frac{\gamma_{c}}{2300}\right) \cong 32,000 \mathrm{MPa} \\
\mathrm{V}_{\mathrm{c}}=0.15 & \text { Poisson's ratio for concrete; and } \\
\mathrm{\alpha}_{\mathrm{c}}=10 \times 10^{-6}\left({ }^{\circ} \mathrm{C}\right)^{-1} & \text { Coefficient of thermal expansion for concrete. }
\end{array}
$$

The tensile strength of the concrete is assumed $5 \mathrm{MPa}$.

\subsection{Posttensioning System}

The perimeter wall is prestressed with a total of 146 post-tensioning horizontal tendons. Horizontal tendons are anchored between opposite buttresses, meaning that each tendon has an overlapping angular length just above $90^{\circ}$ with another tendon. Average spacing of horizontal tendons is $600 \mathrm{~mm}$ and the first horizontal tendon starts at $3000 \mathrm{~mm}$ from the base of the wall. All the tendons are tensioned from both ends with jacking stress of $1520 \mathrm{MPa}$.

The perimeter wall is prestressed in meridional direction with a total number of 124 vertical post-tensioning tendons. These tendons are anchored at the bottom of the base slab in the tendon gallery and on top of the ring beam. All the tendons are tensioned only from one end from the top of the wall with jacking stress of $1400 \mathrm{MPa}$. Distance of center of vertical tendons in perimeter wall to interior surface of the containment is $750 \mathrm{~mm}$ with average spacing of $1100 \mathrm{~mm}$.

The tori-spherical dome is prestressed with a total of 141 post-tensioning tendons. These tendons are placed in three layers which are at a $120^{\circ}$ orientation with respect to each other. The distance of each layer of the tendon from each other is $135 \mathrm{~mm}$ at dome apex. All the tendons in one layer have the same center and radius of curvature. All the tendons are tensioned from both ends with jacking stress of $1510 \mathrm{MPa}$, and anchored at the vertical exterior side of the ring beam. Distance of the middle layer of the tendons to interior surface of the containment is $550 \mathrm{~mm}$ with average spacing of $950 \mathrm{~mm}$. 
The ring beam is prestressed in hoop direction with a total number of 16 horizontal tendons. All the tendons have angular length of just above $180^{\circ}$ and are tensioned from both ends with jacking stress of $1520 \mathrm{MPa}$.

\subsection{Non-Prestressing Steel}

In addition to prestressing tendons, the containment wall and the dome contain nonprestressing reinforcement. The wall contains hoop and meridional non-prestressing steel; also, dome contains hoop and radial non-prestressing steel. The amount of hoop and meridional non-prestressing reinforcement varies along the height of the perimeter wall, dividing the wall into 3 sections. Moreover, the amount of hoop and radial reinforcement for the dome varies along the height of the dome, dividing the dome to 2 sections along the arc of the dome.

The perimeter wall and the dome are also provided with 15M T-headed bars for the transverse shear at spacing of $150 \mathrm{~mm}$.

Table 3- Reinforcement summary for the PW

\begin{tabular}{|c|c|c|c|}
\hline & Face & Direction & $\begin{array}{c}\text { Reinforcement ratio } \\
\%\end{array}$ \\
\hline \multirow{4}{*}{ 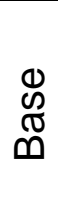 } & \multirow[t]{2}{*}{ Interior } & Hoop & 2.66 \\
\hline & & Meridional & 0.44 \\
\hline & \multirow[t]{2}{*}{ Exterior } & Hoop & 2.66 \\
\hline & & Meridional & 2.22 \\
\hline \multirow{4}{*}{ 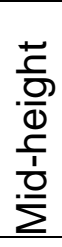 } & \multirow[t]{2}{*}{ Interior } & Hoop & 0.16 \\
\hline & & Meridional & 0.22 \\
\hline & \multirow[t]{2}{*}{ Exterior } & Hoop & 0.44 \\
\hline & & Meridional & 0.44 \\
\hline \multirow{4}{*}{ 응 } & \multirow[t]{2}{*}{ Interior } & Hoop & 0.16 \\
\hline & & Meridional & 0.16 \\
\hline & \multirow[t]{2}{*}{ Exterior } & Hoop & 0.44 \\
\hline & & Meridional & 0.75 \\
\hline
\end{tabular}




\begin{tabular}{|c|c|c|c|}
\hline & Face & Direction & $\begin{array}{c}\text { Reinforcement ratio } \\
\%\end{array}$ \\
\hline \multirow{4}{*}{$\frac{1}{\underline{t}} \frac{t}{\underline{c}}$} & \multirow[t]{2}{*}{ Interior } & Hoop & 0.15 \\
\hline & & Meridional & 0.15 \\
\hline & \multirow[t]{2}{*}{ Exterior } & Hoop & 0.45 \\
\hline & & \begin{tabular}{|l|} 
Meridional \\
\end{tabular} & 0.45 \\
\hline \multirow{4}{*}{ 용 } & \multirow[t]{2}{*}{ Interior } & Hoop & 0.15 \\
\hline & & \begin{tabular}{|l} 
Meridional \\
\end{tabular} & 0.15 \\
\hline & \multirow[t]{2}{*}{ Exterior } & Hoop & 0.30 \\
\hline & & \begin{tabular}{|l|} 
Meridional \\
\end{tabular} & 0.30 \\
\hline
\end{tabular}

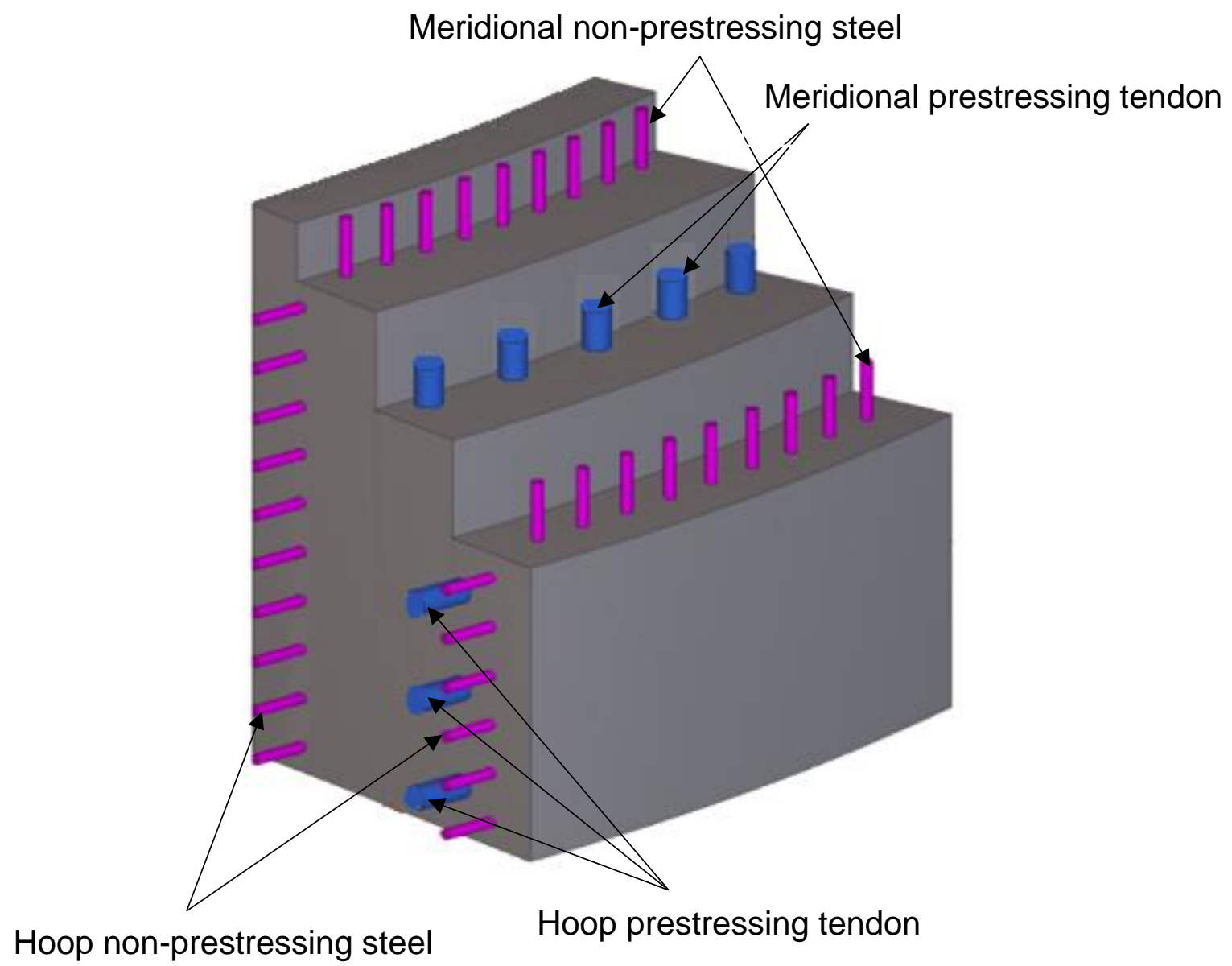

Figure 4- 3D schematic diagram of cross-section of the CS 
The reinforcement geometry of hoop and meridional sections of the containment are summarized in Table 3 and Table 4, for the perimeter wall and the dome, respectively. These locations are at the base, mid-height and top of the perimeter wall and at the midheight and apex of the dome. Figure 4 represents a 3D schematic diagram of the crosssection of the perimeter wall showing the prestressing tendons and non-prestressing reinforcements.

\subsection{Major Openings}

The major openings in this CS include; equipment airlock, containment passage, fuel transfer duet and personnel airlock. In the current study, these openings are referred to as $\mathrm{O} 1, \mathrm{O} 2, \mathrm{O} 3$ and $\mathrm{O} 4$, respectively.

The size and location of the openings are summarized in Table 5. The location of the openings are described as the angular distance of the vertical plane of symmetry of the opening from the centre of $\mathrm{B} 1$, and as distance from the base of the wall to bottom of the opening.

It should be noted that $\mathrm{O} 1, \mathrm{O} 2$ and $\mathrm{O} 3$ are located at the wall between $\mathrm{B} 2$ and $\mathrm{B} 3$, and $\mathrm{O} 4$ is located at the wall between B4 and B1. The effects of major openings on the response of the CS is discussed in detail in Chapter 7.

Table 5- Openings size and location

\begin{tabular}{|l|c|c|c|c|}
\hline \multicolumn{1}{|c|}{ Opening } & $\begin{array}{c}\text { Width } \\
(\mathrm{mm})\end{array}$ & $\begin{array}{c}\text { Height } \\
(\mathrm{mm})\end{array}$ & $\begin{array}{c}\text { Angular distance } \\
\text { from B1 }\left(^{\circ}\right)\end{array}$ & $\begin{array}{c}\text { Distance from } \\
\text { base }(\mathrm{m})\end{array}$ \\
\hline O1: Equipment airlock & 3960 & 4270 & 150 & 13.3 \\
\hline O2: Containment passage & 1070 & 2140 & 154 & 8.1 \\
\hline O3: Spent fuel transfer duet & 1520 & 1070 & 150 & 3.2 \\
\hline O4: Personnel airlock & 910 & 2130 & 295 & 4.3 \\
\hline
\end{tabular}




\section{CHAPTER 4 FINITE ELEMENT MODELING}

\subsection{General}

There is no explicit solution to predict the response of such complicated structure in nonlinear region. Finite element methods for structural analysis have been widely used in nuclear power industry. In finite element method, the overall behavior of the structure is determined by dividing the structure to finite number of small simple elements. This can be obtained only by knowing the distinct mechanical and physical properties of each element. This numerical method is widely applied to the prestressed and reinforced concrete structures based on the use of the nonlinear behavior of the materials.

Numerous general and specific finite element programs have been developed in the last few decades. Among these programs, ANSYS [9] is recommended as one of the most popular in both academic and commercial applications. ANSYS is widely used in nuclear industry. This software is improved compared to the traditional finite element computations in the elastic regime [22].

The current research study is focused on the response of prestressed concrete containment to ultimate global structural failure. The primary objective of this research study is to evaluate the UPC of the overall containment structure. This requires the finite element code to compute through severe concrete cracking and into the stage of widespread plastic rebar and tendon response.

In this chapter, application of the finite element program ANSYS is discussed to model the non-linear behaviour of the containment structure. 


\subsection{Mathematical Formulations}

\subsubsection{Concrete Material Model}

An appropriate model for the concrete material should be capable of presenting the mechanical behavior of concrete under compression and tension as well as the behavior after cracking.

Material model for concrete should account for both cracking and crushing parameters. In the current study, the tri-axial failure surface model developed by Willam and Warnke is employed [23]. This mathematical model considers a sextant of the principal stresses space assuming $\sigma_{1} \geq \sigma_{2} \geq \sigma_{3}$ (principal stresses). The failure surface in principal stressspace is shown in Figure 5.

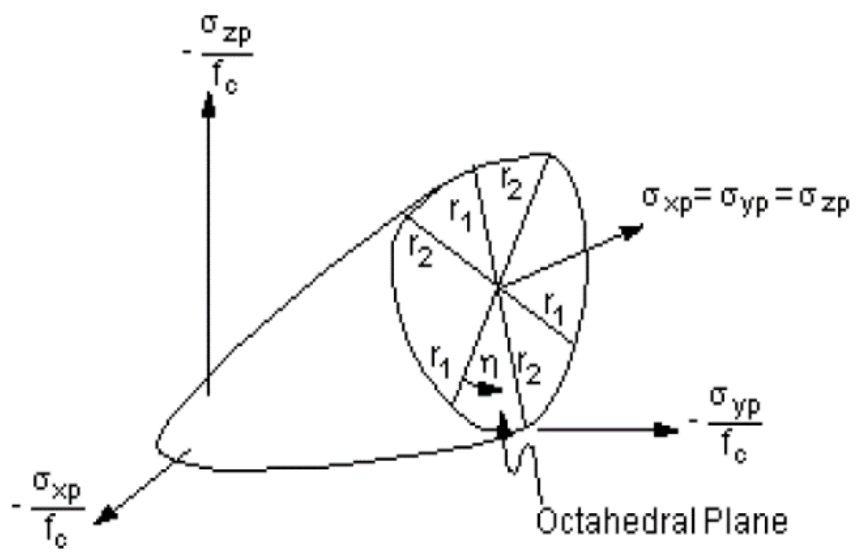

Figure 5- Concrete failure surface (source: [22])

The failure criterion for the concrete due to multi axial stress state is expressed by Equation (3).

$$
\frac{F}{f_{c}^{\prime}}-S \geq 0
$$

where, 
$\mathrm{F}=$ Function of principal stress state $\left(\sigma_{x p} ; \sigma_{y p} ; \sigma_{z p}\right)$;

$\mathrm{S}=$ Failure surface expressed in terms of the principal stresses and five input parameters

$f_{t} ; f_{c} ; f_{c b} ; f_{1}$ and $f_{2} ;$ (as shown in Figure 6)

$f_{c}^{\prime}=$ Uni-axial crushing strength;

$\sigma_{x p} ; \sigma_{y p} ; \sigma_{z p}=$ Principal stresses in principal directions;

$f_{t}=$ Uni-axial tensile cracking stress;

$f_{c}=$ Uni-axial crushing stress $\left(f_{c b}=1.2 f_{c}^{\prime}\right)$;

$f_{c b}=\mathrm{Bi}$-axial crushing stress;

$f_{1}=\mathrm{Bi}$-axial crushing stress under the ambient hydrostatic stress $\left(\mathrm{f}_{1}=1.45 f_{c}^{\prime}\right)$; and

$f_{2}=$ Uni-axial crushing stress under the ambient hydrostatic stress $\left(f_{2}=1.45 f_{c}^{\prime}\right)[23]$.

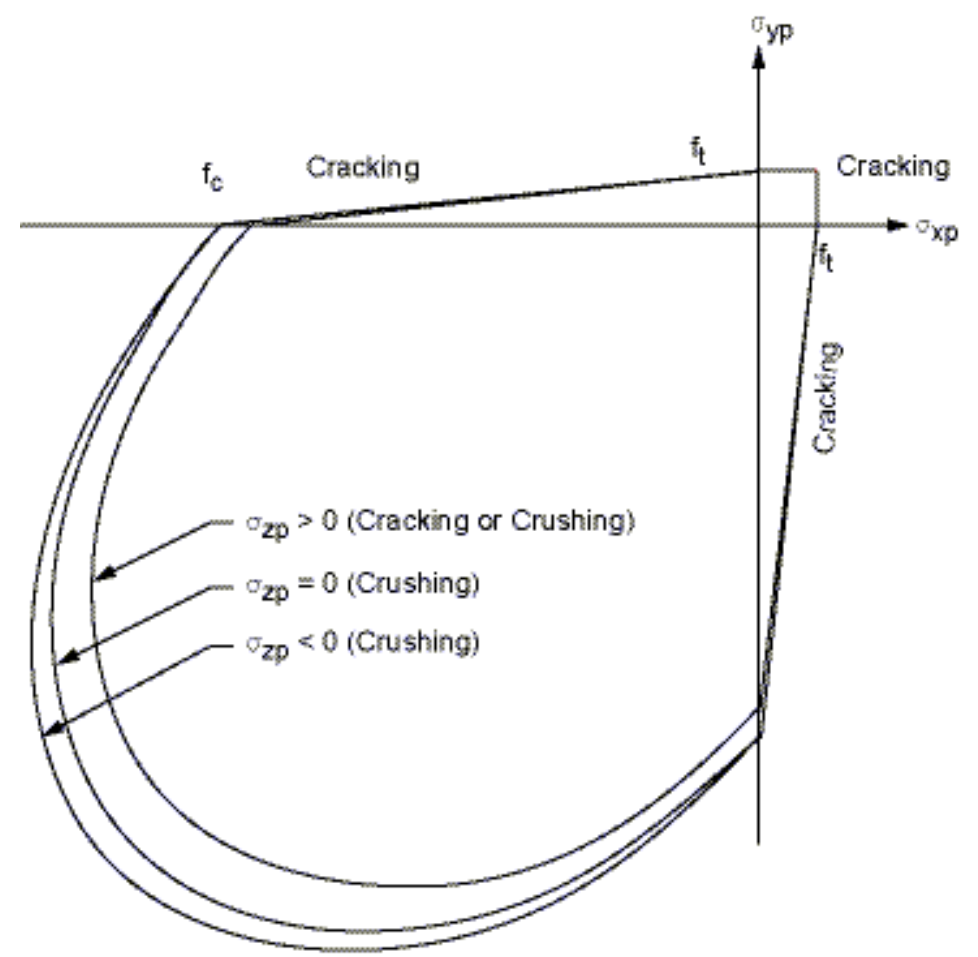

Figure 6- Concrete failure surface (source: [22])

Additional information that is needed for introducing the failure model is; shear transfer coefficients for an open crack and closed crack. In this study, these values are assumed to be 0.35 and 0.65 for open cracks and closed cracks, respectively. These values are suggested by references [24] and [25]. 
In compression-compression-compression regime $\left(0 \geq \sigma_{1} \geq \sigma_{2} \geq \sigma_{3}\right)$, $F$ (Function of principal stress state) takes the following form [22]:

$$
\mathrm{F}=F_{1}=\frac{1}{\sqrt{15}}\left[\left(\sigma_{1}-\sigma_{2}\right)^{2}+\left(\sigma_{2}-\sigma_{3}\right)^{2}+\left(\sigma_{3}-\sigma_{1}\right)^{2}\right]^{1 / 2}
$$

In a tension-compression-compression regime $\left(\sigma_{1} \geq 0 \geq \sigma_{2} \geq \sigma_{3}\right), F$ takes the following form [22]:

$$
\mathrm{F}=F_{2}=\frac{1}{\sqrt{15}}\left[\left(\sigma_{2}\right)^{2}+\left(\sigma_{2}-\sigma_{3}\right)^{2}+\left(\sigma_{3}\right)^{2}\right]^{1 / 2}
$$

If the failure criterion is satisfied, cracking occurs in the plane perpendicular to principal stress $\sigma 1$.

In a tension-tension-compression regime $\left(\sigma_{1} \geq \sigma_{2} \geq 0 \geq \sigma_{3}\right)$, F takes the following form [22]:

$$
\mathrm{F}=F_{3}=\sigma_{i} ; i=1,2
$$

If the failure criterion is reached in both $\mathrm{i}=1,2$, cracking occurs in the place perpendicular to principal stresses $\sigma_{1}, \sigma_{2}$. If the failure criterion is reached only for $i=1$, cracking occurs only on the plane normal to principal stress $\sigma_{1}$.

In tension-tension-compression regime $\left(\sigma_{1} \geq \sigma_{2} \geq \sigma_{3} \geq 0\right), F$ takes the following form [22]:

$$
\mathrm{F}=F_{4}=\sigma_{i} ; i=1,2,3
$$

If the failure criterion is satisfied in directions 1,2 , and 3 , cracking occurs in the planes perpendicular to principal stresses $\sigma_{1}, \sigma_{2}$, and $\sigma_{3}$. If the failure criterion is satisfied in directions 1 and 2, cracking occurs in the plane perpendicular to principal stresses $\sigma_{1}$ and 
$\sigma_{2}$. If the failure criterion is satisfied only in direction 1, cracking occurs in the plane perpendicular to principal stress $\sigma_{1}$.

It should be noted that the reinforced concrete elements available in ANSYS program is capable of modeling both cracking and crushing of concrete by using the tri-axial failure surface model by Willam and Warnke [23] and has been widely used in other research studies [11], [25] and [26].

\subsubsection{Reinforced Concrete Element Selection}

Two techniques are introduced in ANSYS program to model steel reinforcement for reinforced concrete. First is the smeared reinforcement approach, which assumes uniform distribution of reinforcing steel throughout the defined concrete elements. Second is the discrete model, where bar elements are used to model the reinforcement.

Smeared model is found to be more appropriate to model non-prestressing reinforcement in models with complicated geometry. Same approach can be used to model prestressing tendon, however, in this case, the prestressing forces should be applied as an equivalent forces or pressure to the finite element model. On the other hand, if the discrete approach is used to model the prestressing tendons, the prestressing forces can be applied directly to cables.

\subsubsection{Solid65- 3D Reinforced Concrete Solid}

Solid65 3D element is found to be the most appropriate element to model reinforced concrete, and is capable of modeling concrete material in compression and tension. Using this element, not only the cracking and crushing of the concrete can be modelled; the plasticity of the material using the Drucker-Prager failure surface can be correctly modelled in case plasticity is reached prior to cracking or crushing.

In this element cracking is permitted in three orthogonal directions in compare to shell element. If cracking occurs at integration point, the cracking is modelled through an 
adjustment of element stiffness, which means the model treats the cracking as "smeared crack" and not as discrete crack.

Moreover, for SOLID65 elements, in addition to concrete, three other independent materials can be introduced for reinforcement. The uniaxial stiffness of the reinforcement is added through the element in three independent directions by specifying the angle of orientation of the bars and reinforcements will be assumed smeared through the element [22].

The smeared reinforcement is introduced by Real Constant Set for Solid65 elements. Materiel number, volume ratio and orientation angel are the required input for this command. Where, material number refers to the type of the material for steel reinforcement. Volume ratio refers to the ratio the steel volume to concrete element. Moreover, the orientation angel refers to the orientation of the rebar in the smeared model. Each layer of reinforcing bars is assumed to be fully attached to the concrete element, providing displacement compatibility between bars and concrete. As a result, the Degree of Freedom (DOF) of the nodes at the rebar layer can easily be expressed in terms of the DOF of the nodes at the external layer through the tri-linear shape functions in the concrete element.

\subsubsection{Linear behaviour}

In the finite element model, initially, concrete is treated as an incrementally linear elastic material. The isotropic properties for the concrete material are defined as the modulus of elasticity and Poisson's ratio.

The general stress-strain matrix [D] for this element is defined as follows [22]:

$$
[D]=\left(1-\sum_{i=1}^{N_{r}} V_{i}^{R}\right)\left[D^{c}\right]+\sum_{i=1}^{N_{r}} V_{i}^{R}\left[D^{R}\right]_{i}
$$


$\mathrm{Nr}=$ number of reinforcing materials;

$\mathrm{V}_{\mathrm{i}}$ = ratio of volume of reinforcing material I to total volume of element ;

$\left[D^{c}\right]=$ stress-strain matrix for concrete; and

$[D]_{i}=$ stress-strain matrix for reinforcement $\mathrm{i}$.

The matrix $\left[D^{c}\right]$ for concrete as orthotropic material is defined as follows [22]:

$$
\left[D^{c}\right]=\frac{E}{(1+v)(1-2 v)}\left[\begin{array}{cccccc}
1-v & v & v & 0 & 0 & 0 \\
v & 1-v & v & 0 & 0 & 0 \\
v & v & 1-v & 0 & 0 & 0 \\
0 & 0 & 0 & \frac{1-2 v}{2} & 0 & 0 \\
0 & 0 & 0 & 0 & \frac{1-2 v}{2} & 0 \\
0 & 0 & 0 & 0 & 0 & \frac{1-2 v}{2}
\end{array}\right] \quad \text { Equation (9) }
$$

where:

$\mathrm{E}=$ Modulus of elasticity for concrete; and

$\mathrm{v}=$ Poisson's ratio for concrete.

The stress-strain matrix for reinforcement with respect to local coordinate system for reinforcement $\left(\mathrm{X}^{\mathrm{r}_{i}}, \mathrm{Y}_{\mathrm{i}}, \mathrm{Z}_{\mathrm{i}}\right)$ is as follows: $\left(\mathrm{X}_{\mathrm{i}}, \mathrm{Y}^{\mathrm{r}_{\mathrm{i}}}, \mathrm{Z}_{\mathrm{i}}\right)$ describes the coordinate system for reinforcement type $\mathrm{i}$ and the element coordinate system is denoted by $(X, Y, Z)$.

$$
\left\{\begin{array}{l}
\sigma_{x x}^{r} \\
\sigma_{y y}^{r} \\
\sigma_{z z}^{r} \\
\sigma_{x y}^{r} \\
\sigma_{y z}^{r} \\
\sigma_{x z}^{r}
\end{array}\right\}=\left[\begin{array}{cccccc}
E_{i}^{r} & 0 & 0 & 0 & 0 & 0 \\
0 & 0 & 0 & 0 & 0 & 0 \\
0 & 0 & 0 & 0 & 0 & 0 \\
0 & 0 & 0 & 0 & 0 & 0 \\
0 & 0 & 0 & 0 & 0 & 0 \\
0 & 0 & 0 & 0 & 0 & 0
\end{array}\right]\left\{\begin{array}{l}
\varepsilon_{x x}^{r} \\
\varepsilon_{y y}^{r} \\
\varepsilon_{z z}^{r} \\
\varepsilon_{x y}^{r} \\
\varepsilon_{y z}^{r} \\
\varepsilon_{x z}^{r}
\end{array}\right\}=\left[D^{r}\right]_{i}\left\{\begin{array}{l}
\varepsilon_{x x}^{r} \\
\varepsilon_{y y}^{r} \\
\varepsilon_{z z}^{r} \\
\varepsilon_{x y}^{r} \\
\varepsilon_{y z}^{r} \\
\varepsilon_{x z}^{r}
\end{array}\right\}
$$


$E^{r}=$ Modulus of elasticity for reinforcement type i.

The only nonzero stress component, $\sigma_{x x}^{r}$, is the axial stress in $\mathrm{Xr}_{i}$ direction of reinforcement type $i$. The reinforcement direction $X_{i}$ is related to element coordinate system $X, Y, Z$ through the following equation:

$$
\left\{\begin{array}{l}
X \\
Y \\
Z
\end{array}\right\}=\left\{\begin{array}{c}
\cos \theta_{i} \cos \Phi_{i} \\
\sin \theta_{i} \cos \Phi_{i} \\
\sin \theta_{i}
\end{array}\right\} X_{i}^{r}=\left\{\begin{array}{l}
l_{1}^{r} \\
l_{2}^{r} \\
l_{3}^{r}
\end{array}\right\} X_{i}^{r}
$$

where:

$\theta_{i}=$ angle between the projection of the $X^{r_{i}}$ axis on $X Y$ plane and the $X$ axis (shown in Figure 7)

$\phi_{i}=$ angle between the $X^{r_{i}}$ axis on $X Y$ plane and the $X$ axis (shown in Figure 7) $l_{i}=$ direction cosines between axis and element $X, Y, Z$ axes
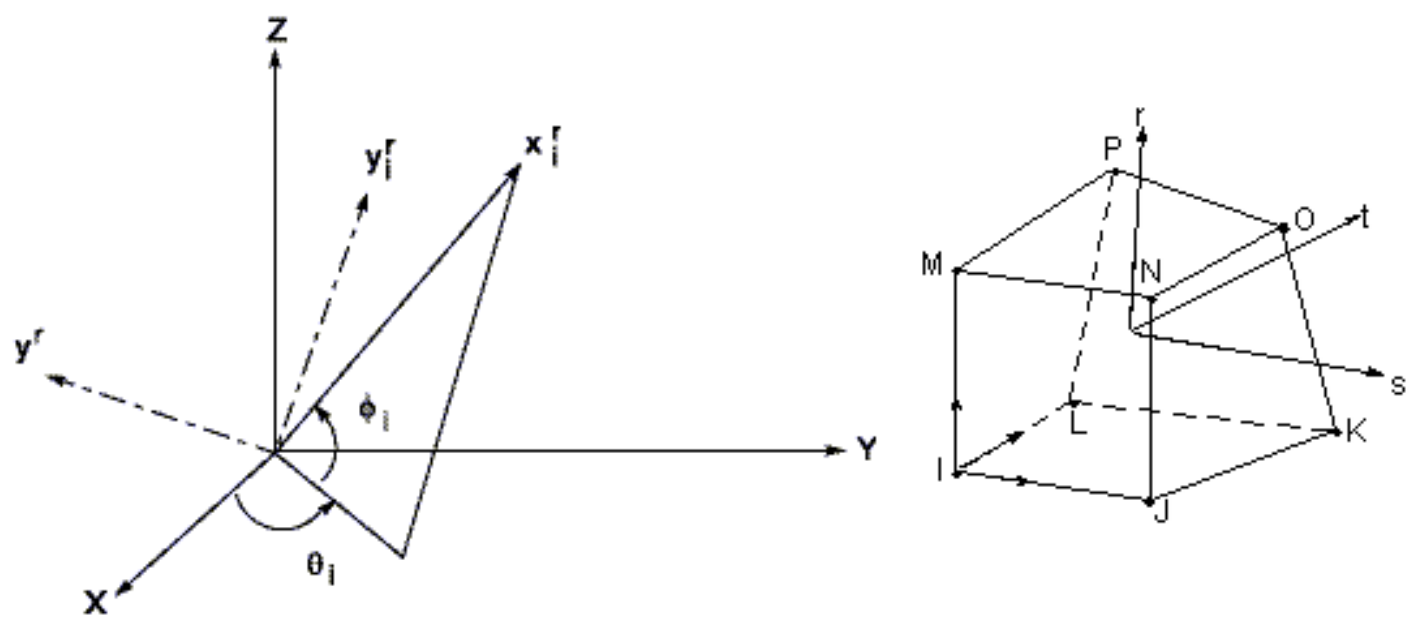

Figure 7- SOLID65 and reinforcement orientations (source: [22])

In order to express the material behaviour of the reinforcement in global coordinates, it is required to construct a transformation. 


\subsubsection{Non-linear behaviour}

As was mentioned before, by formation of crack at any integration point in the element, the stress-strain relations is modified by introducing plane of weakness in a direction normal to the crack face. Also a Shear transfer coefficient $\beta_{t}$ as shear strength reduction factor for the loads across the crack.

The stress-strain relations for a material that has cracked in one direction only become:

$$
\left[D_{c}^{c k}\right]=\frac{E}{1+v}\left[\begin{array}{cccccc}
\frac{R^{t}(1+v)}{E} & 0 & 0 & 0 & 0 & 0 \\
0 & \frac{1}{1-v} & \frac{v}{1-v} & 0 & 0 & 0 \\
0 & \frac{v}{1-v} & \frac{1}{1-v} & 0 & 0 & 0 \\
0 & 0 & 0 & \frac{\beta_{t}}{2} & 0 & 0 \\
0 & 0 & 0 & 0 & \frac{1}{2} & 0 \\
0 & 0 & 0 & 0 & 0 & \frac{\beta_{t}}{2}
\end{array}\right]
$$

where $R_{t}$ descents adaptively and diminish to zero as solution converges, and is defined based on Figure 8 . In the current study, value of 0.8 is used for $R_{t}$.

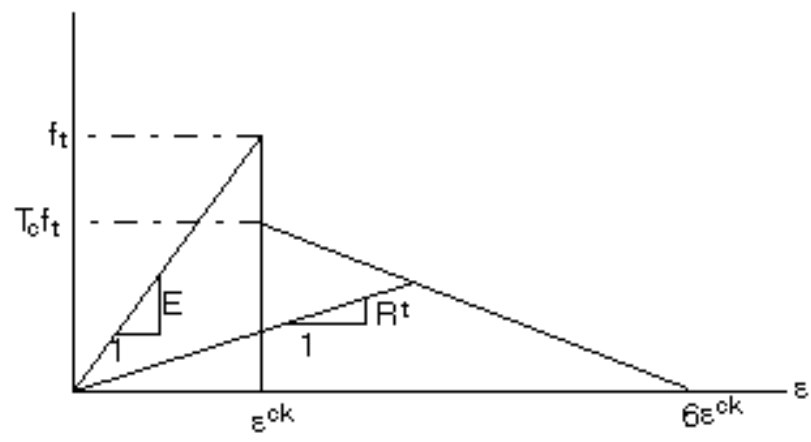

Figure 8- Strength of Cracked Condition (source: [22])

$\mathrm{f}_{\mathrm{t}}=$ uniaxial tensile cracking stress; and 
$T_{c}=$ multiplier for amount of tensile stress relaxation .

If the crack closes, all the compressive stresses normal to the crack plane are transmitted across the crack and only a shear transfer coefficient of $\beta_{c}$ is introduced for the closed crack. The stress-strain relations is changed as follows [22]:

$$
\left[D_{c}^{c k}\right]=\frac{E}{(1+v)(1-2 v)}\left[\begin{array}{cccccc}
1-v & v & v & 0 & 0 & 0 \\
v & 1-v & v & 0 & 0 & 0 \\
v & v & 1-v & 0 & 0 & 0 \\
0 & 0 & 0 & \frac{\beta c(1-2 v)}{2} & 0 & 0 \\
0 & 0 & 0 & 0 & \frac{(1-2 v)}{2} & 0 \\
0 & 0 & 0 & 0 & 0 & \frac{\beta c(1-2 v)}{2}
\end{array}\right]
$$

Equation (13)

If the material at any integration point fails in uniaxial, biaxial or tri-axial compression, the material is assumed to be crushed. Which is defined as complete deterioration of the structural integrity of the material. If the material has crushed, material strength is assumed to have degraded to an extent such that the contribution to the stiffness of the element at that integration point should be ignored.

\subsubsection{Prestressing Tendon Element Selection}

Another approach to model reinforcement and specifically the prestressing cables is the discrete model, where bar elements are used to model the reinforcement. In this model, bar elements are attached to concrete elements at coinciding nodes. Stiffness of the reinforcing bars is evaluated separately from that of the concrete element. These elements are produced with displacement compatibility between bars and concrete.

The drawback of these models is that the concrete mesh is restricted by the location of the reinforcements. Compare to smeared model, discrete method is the most suitable for prestressing tendons. 
LINK8 is a 3D spar element that can be used to model trusses, cables, spring, etc. This element is a uniaxial tension element with three degree of freedom at each node; transition in $\mathrm{X}, \mathrm{Y}$ and $\mathrm{Z}$ directions. It should be noted that this element cannot carry bending loads.

The element is defined by two nodes, the cross-sectional are and initial strain and material properties. The geometry, node locations and the coordinate system for this element is shown in Figure 9. The local $x$-axis is oriented along the length of the element from node I to node j. By applying initial strain on element, stress will be assumed uniform along the length of the element.
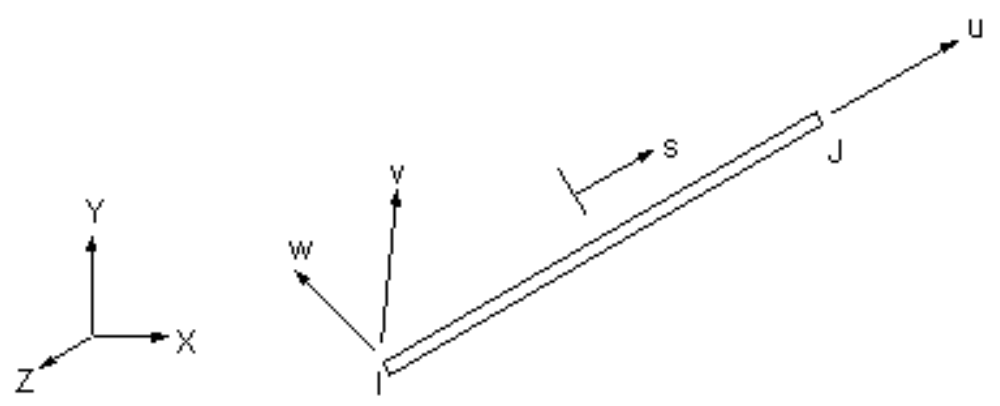

Figure 9- LINK8 element (source: [22])

The element stiffness matrix for LINK8 elements is according to Equation (14). Note that all the elements matrices are first generated in local coordinate system of the element and then are converted to global coordinate system [22].

$$
\left[K_{l}\right]=\frac{A E}{L}\left[\begin{array}{cccccc}
1 & 0 & 0 & -1 & 0 & 0 \\
0 & 0 & 0 & 0 & 0 & 0 \\
0 & 0 & 0 & 0 & 0 & 0 \\
-1 & 0 & 0 & 1 & 0 & 0 \\
0 & 0 & 0 & 0 & 0 & 0 \\
0 & 0 & 0 & 0 & 0 & 0
\end{array}\right]
$$

where: 
$A=$ element cross-sectional area;

$\mathrm{E}=$ Modulus of elasticity; and

$\mathrm{L}=$ element length.

The consistent element mass matrix is written according to Equation (15) [22]:

$$
\left[M_{l}\right]=\frac{\rho A L\left(1-\varepsilon^{i n}\right)}{6}\left[\begin{array}{cccccc}
2 & 0 & 0 & 1 & 0 & 0 \\
0 & 2 & 0 & 0 & 1 & 0 \\
0 & 0 & 2 & 0 & 0 & 1 \\
1 & 0 & 0 & 2 & 0 & 0 \\
0 & 1 & 0 & 0 & 2 & 0 \\
0 & 0 & 1 & 0 & 0 & 2
\end{array}\right]
$$

where:

$\rho=$ density; and

$\varepsilon^{i n}=$ initial strain.

The element stress stiffness matrix is [22]:

$$
\left[S_{l}\right]=\frac{F}{L}\left[\begin{array}{cccccc}
0 & 0 & 0 & 0 & 0 & 0 \\
0 & 1 & 0 & 0 & -1 & 0 \\
0 & 0 & 1 & 0 & 0 & -1 \\
0 & 0 & 0 & 0 & 0 & 0 \\
0 & -1 & 0 & 0 & 1 & 0 \\
0 & 0 & -1 & 0 & 0 & 1
\end{array}\right]
$$

where:

$F=A E \varepsilon^{\text {in }}$ for the first iteration, and the axial force for all subsequent iterations.

For a linear analysis or first iteration of a non-linear analysis [22]: 
$\varepsilon_{n}^{e l}=\varepsilon_{n}-\varepsilon_{n}^{t h}+\varepsilon^{i n}$

Equation (17)

where:

$\varepsilon_{n}^{e l}=$ elastic strain;

$\varepsilon_{n}=$ total strain $=\frac{\Delta u}{L} ;$

$u=$ difference of nodal displacement in axial direction; and

$\varepsilon_{n}^{\text {th }}=$ thermal strain.

For the subsequent iteration of nonlinear analysis [22]:

$\varepsilon_{n}^{e l}=\varepsilon_{n-1}^{e l}+\Delta \varepsilon-\Delta \varepsilon^{t h}-\Delta \varepsilon^{p l}-\Delta \varepsilon^{c r}-\Delta \varepsilon^{s w}$

Equation (18)

where:

$\Delta u=$ difference of nodal displacements increment in axial direction;

$\Delta \varepsilon^{\text {th }}=$ thermal strain increment;

$\Delta \varepsilon^{p l}=$ plastic strain increment;

$\Delta \varepsilon^{c r}=$ creep strain increment; and

$\Delta \varepsilon^{s w}=$ swelling strain increment.

The stress is [22]:

$$
\sigma=E \varepsilon^{a}
$$

where:

$\sigma=$ stress; and 
$\varepsilon^{a}=$ adjusted strain $=\varepsilon^{e l}+\Delta \varepsilon^{c r}+\Delta \varepsilon^{s w}$.

Thus, the strain used to compute the stress has the creep and swelling effects as of the beginning of the sub-step, not the end. Finally, force, $F$, is calculated based on Equation (20):

$$
F=A \sigma
$$

Equation (20)

\subsection{Newton-Raphson Nonlinear Analysis}

In the current study, Newton-Raphson approach is used to solve nonlinear problems. In this approach the load is divided into series of load increments, where the load increments can be applied in series of several load steps.

Before each solution, the Newton-Raphson method evaluates the out-of-balance load vector, which is the difference between the restoring forces and the applied loads. Then a linear solution is performed, using the out-of-balance loads, and the program checks for convergence. If convergence criteria are not satisfied, the out-of-balance load vector is re-evaluated, the stiffness matrix is updated, and a new solution is obtained. This iterative procedure continues until the problem converges [22].

\subsection{Verification of the Finite Element Program ANSYS for Modelling CS}

In this section, the capability of the finite element program, ANSYS, to model and predict the failure response of the reinforced concrete and prestressed concrete structures are investigated. For this purpose, the results of experimental research studies are compared to those of finite element analysis. Two experimental studies are chosen as references for this chapter. First is experimental data provided by Buckhouse [27], on a reinforced concrete beam tested to failure. Second is test structure of a containment subject of experimental study by Rizkalla et al. in [10]. 
Further analysis is conducted to verify the capability of the finite element program ANSYS to model the tension stiffening effect.

\subsubsection{Reinforced Concrete Beam}

A reinforced concrete beam with reinforcing steel modeled discretely is developed with results compared to the experimental work in reference [27]. The load-deflection response of the experimental beam is compared with that of finite element model in ANSYS.

\subsubsection{Experimental Reinforced Concrete Beam}

The reinforced beam under consideration has width and height of $254 \mathrm{~mm}$ (10in) and $457 \mathrm{~mm}$ (18in), respectively. The length of the beam is $4724 \mathrm{~mm}$ (186 in) with support located at $76 \mathrm{~mm}$ (3in) from each end of the beam, allowing a simply supported span on $4572 \mathrm{~mm}$ (180 in).

For the experimental test, two $222 \mathrm{kN}$ (50 kip) capacity cells were placed $1524 \mathrm{~mm}$ (60in) from the support of the beam. The beam was loaded with two symmetrically placed transverse loads as shown in Figure 10. The test beam was loaded for flexural failure.

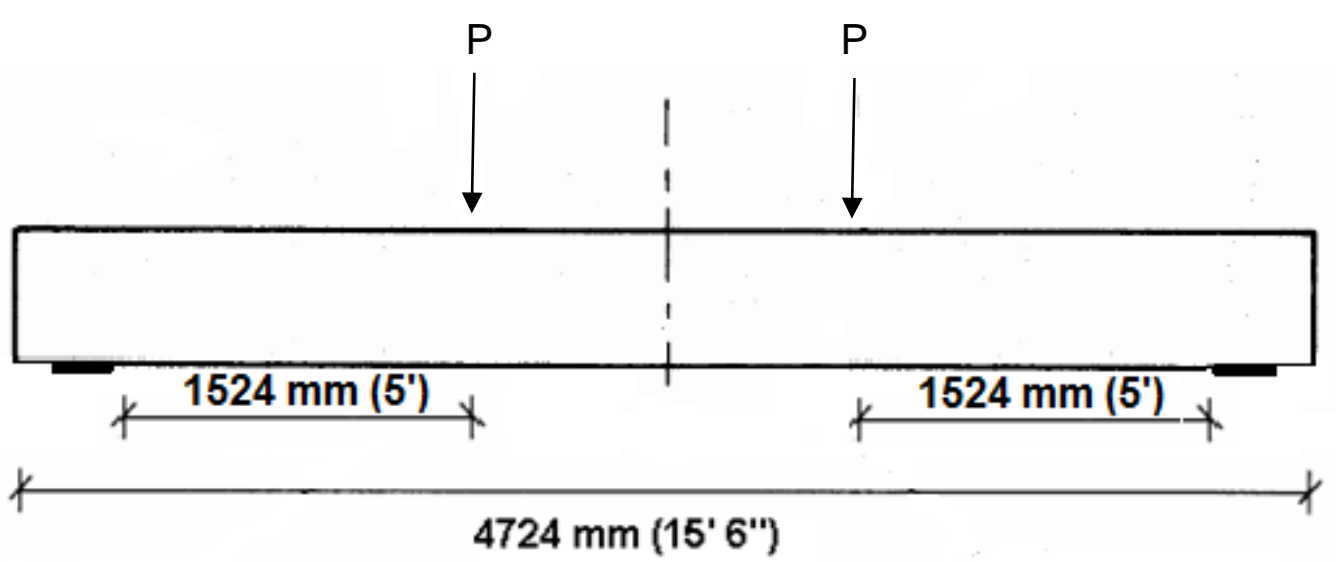

Figure 10- Reinforced concrete beam with loading 
The beam is reinforced with $3-15 \mathrm{M}(3 \# 5)$ bars for flexural reinforcement and $15 \mathrm{M} \mathrm{( \# 3)} \mathrm{U}$ bars for the shear reinforcements. A clear cover of $51 \mathrm{~mm}(2 \mathrm{in})$ is used in all directions. The layout of reinforcement is shown in Figure 11.

Mild-steel with yield strength of $410 \mathrm{MPa}(60000 \mathrm{psi})$ and the 28-day compressive strength of the concrete of $33 \mathrm{MPa}(4770 \mathrm{psi})$ are used in the test [27].

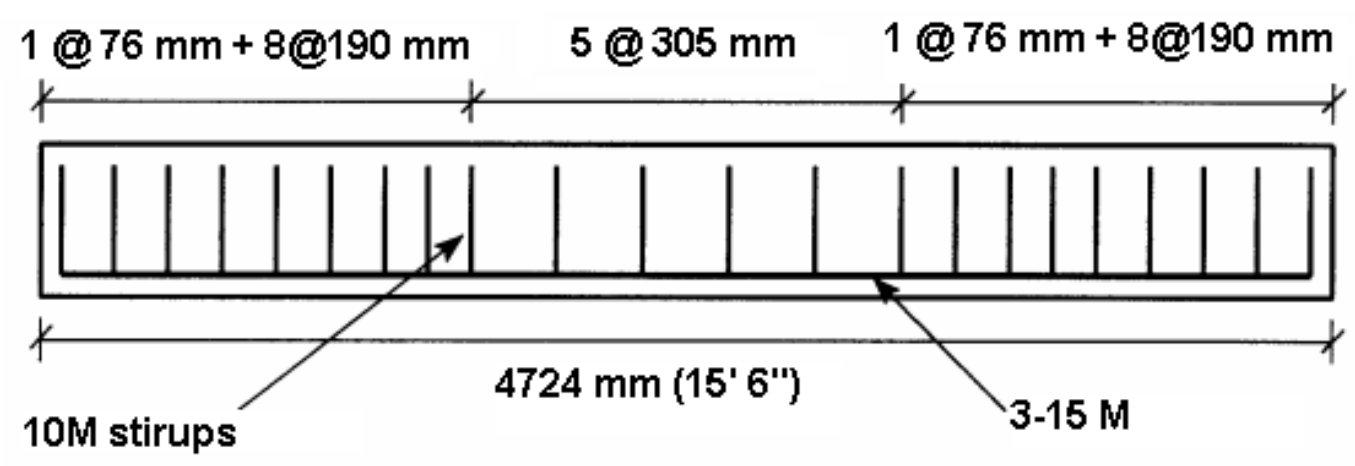

Figure 11- Layout of reinforcements (source: [27])

According to experimental test, the beam first cracked at load of $20 \mathrm{kN}$ (4500 lbs). The ultimate load $(P)$ for this simply supported beam was determined as $72 \mathrm{kN}$ (16310 lbs) and the average downwards centre line deflection was $93 \mathrm{~mm}$ (3.65 in) at failure. The beam behaved linearly before reaching the first cracking load $(20 \mathrm{kN})$. After the first cracking, the response was followed by a secondary linear region ending at a point that flexural reinforcements yield (close to $59 \mathrm{kN}(13,300 \mathrm{lbs})$ ). Finally, the beam failed reaching its ultimate flexural capacity.

\subsubsection{Finite Element Modelling for Reinforced Concrete Beam}

To verify the capability of ANSYS program to model the nonlinear behavior of the reinforced concrete beam, the beam tested by reference [27] is modelled. In this section, efforts are made to use similar approaches, element types and material properties as 
discussed previously that are found to be appropriate for modelling of the concrete containment structure.

Due to symmetry condition and to reduce computational efforts in finite element model, the beam is cut in half in longitudinal direction and again cut half in section; accordingly, only quarter of the beam is modelled. Accordingly, only one support and one loading location is required as shown in Figure 12.

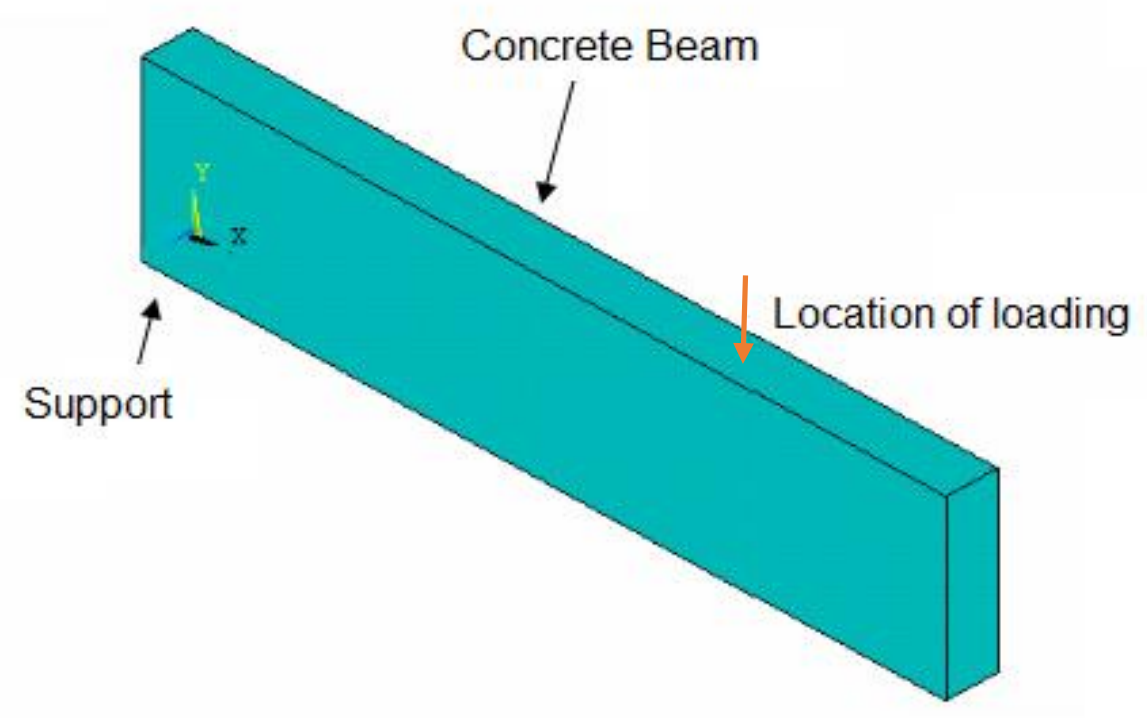

Figure 12- Reinforced concrete beam volume in ANSYS

To model concrete, solid65 element is used. Moreover, for both flexural and shear reinforcement Link8 elements with plastic deformation capacity are employed. In this model, to present shear and flexural reinforcements, the discrete approach is used.

The real constant values for the shear and flexural reinforcement are summarized in Table 6.

Real constant sets 1 and 2 are used to define the cross sectional area and the initial strain for the flexural reinforcement. It should be noted that one of the three flexural rebars located at plane of symmetry is cut in half. For this case, the cross sectional value for the 
flexural real constant set 1 is twice the one for set 2 (set 2 is used for the reinforcement at plane of symmetry).

Real constant sets 3 and 4 are used to define the cross-sectional area and the initial strain for the shear reinforcement. For similar reason as explained before, set 4 with half the cross-sectional of set 3 is used for the stirrups at the mid-span of the beam (plane of symmetry).

To define the concrete material for Solid65 element, modulus of elasticity of $27,228 \mathrm{MPa}$ $(3,949,076 \mathrm{psi})$ and Poisson's ratio of 0.2 are defined in the FEM. To properly model the behaviour of concrete material, a multi linear isotropic material is defined. To reduce the computational effort, a multi-linear curve is used which helps with the convergence of the nonlinear solution algorithm.

Table 6- Real constant sets for the reinforced concrete beam

\begin{tabular}{|c|c|c|c|c|}
\hline $\begin{array}{c}\text { Real } \\
\text { constant } \\
\text { set }\end{array}$ & Reinforcement & Element & & \\
\hline \multirow[t]{2}{*}{1} & \multirow[t]{2}{*}{ flexural reinforcement } & \multirow[t]{2}{*}{ LINK8 } & $\begin{array}{c}\text { Cross-sectional area } \\
\mathrm{mm}^{2}\left(\mathrm{in}^{2}\right)\end{array}$ & $\begin{array}{c}200 \\
(0.31)\end{array}$ \\
\hline & & & Initial strain & 0 \\
\hline \multirow[t]{2}{*}{2} & \multirow{2}{*}{$\begin{array}{l}\text { flexural reinforcement } \\
\text { at plane of symmetry }\end{array}$} & \multirow[t]{2}{*}{ LINK8 } & $\begin{array}{c}\text { Cross-sectional area } \\
\qquad \mathrm{mm}^{2}\left(\mathrm{in}^{2}\right)\end{array}$ & $\begin{array}{c}100 \\
(0.155)\end{array}$ \\
\hline & & & Initial strain & 0 \\
\hline \multirow[t]{2}{*}{3} & \multirow[t]{2}{*}{ shear reinforcement } & \multirow[t]{2}{*}{ LINK8 } & $\begin{array}{l}\text { Cross-sectional area } \\
\mathrm{mm}^{2}\left(\mathrm{in}^{2}\right)\end{array}$ & $71(0.11)$ \\
\hline & & & Initial strain & 0 \\
\hline \multirow[t]{2}{*}{4} & \multirow{2}{*}{$\begin{array}{l}\text { shear reinforcement } \\
\text { at plane of symmetry }\end{array}$} & \multirow[t]{2}{*}{ LINK8 } & $\begin{array}{c}\text { Cross-sectional area } \\
\mathrm{mm}^{2}\left(\mathrm{in}^{2}\right)\end{array}$ & $\begin{array}{c}35.5 \\
(0.055)\end{array}$ \\
\hline & & & Initial strain & 0 \\
\hline
\end{tabular}


In the current model, the nonlinear uni-axial compressive behavior of concrete is defined as follows:

$$
\begin{aligned}
& f=\frac{E_{c} \varepsilon}{1+\left(\frac{\varepsilon}{\varepsilon_{0}}\right)^{2}} \\
& \varepsilon_{0}=\frac{2 f_{c}^{\prime}}{E_{c}} \\
& E_{c}=4500 \sqrt{f_{c}^{\prime}}
\end{aligned}
$$

where,

$f=$ stress in concrete at strain $\varepsilon$;

$\varepsilon=$ strain at stress $f$

$\varepsilon_{0}=$ strain at ultimate compressive strength based of Equation (22); and $E_{c}=$ modulus of elasticity of concrete based on Equation (23).

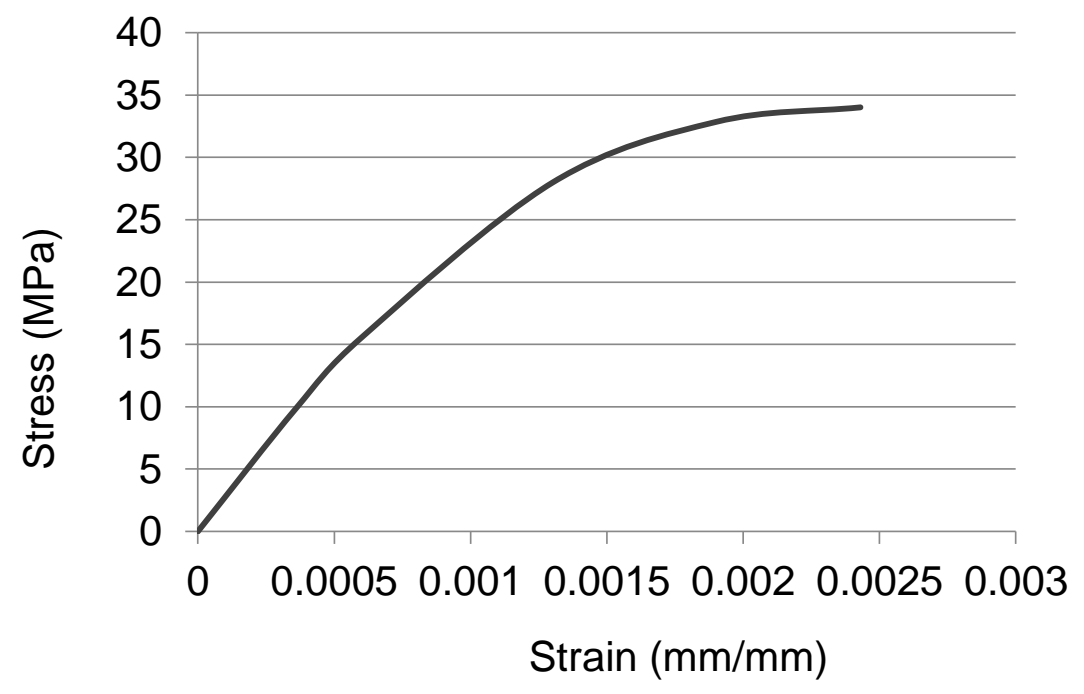

Figure 13- Strain-Stress curve for concrete material

The multi-linear stress-strain curve can be implemented in the model. The stress-strain plot for the concrete material under compression is shown in Figure 13. Note that the 
multi-linear isotropic material uses von Mises failure criterion as well as the WillamWarnke model [23] to define the failure of the concrete. Moreover, concrete is assumed to behave linearly before cracking up to tensile stress of 3.5 MPa.

The input implemented in the program to introduce the Willam-Warnke failure criterion for the concrete material, are summarized below. Appropriate values are introduced for shear transfer coefficient for open and close cracks in concrete as follows:

Shear transfer coefficient for open crack

For the reinforcing rebars, a bi-linear isotropic model is used. For the steel material, the yield stress of $410 \mathrm{MPa}(60000 \mathrm{ksi})$, modulus of elasticity of $200000 \mathrm{MPa}(29000 \mathrm{ksi})$ and the Poisson's ratio of 0.3 are defined in the FEM. The stress-strain plot for the steel material is shown in Figure 14. This model is also based on the von Mises failure criterion and is assumed to behave elastic-perfectly-plastic.

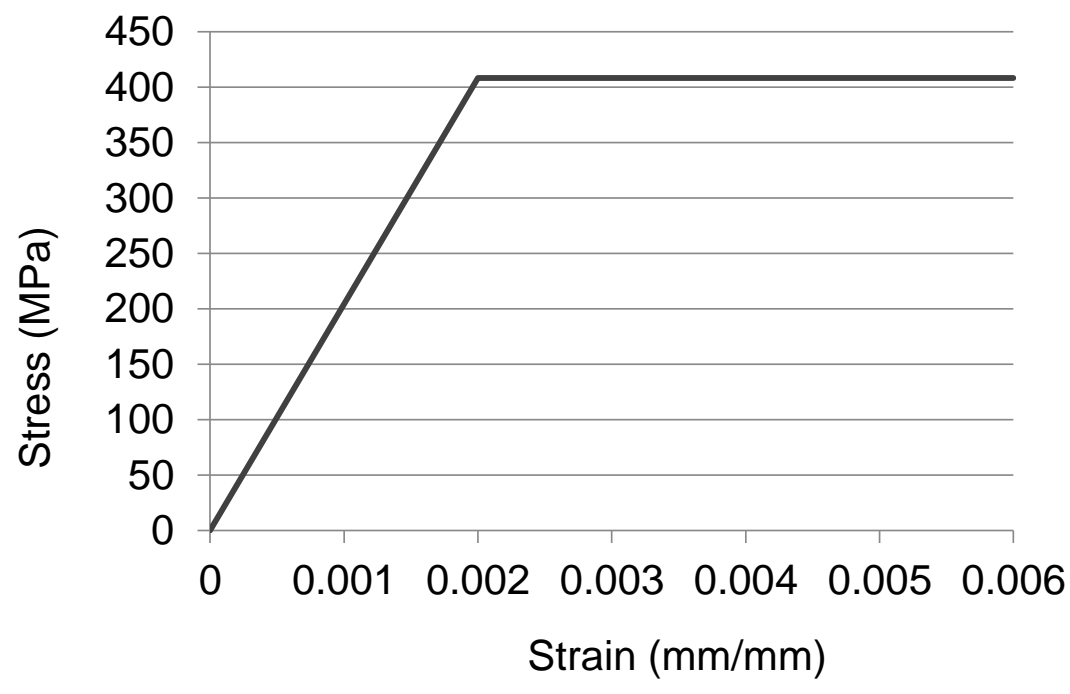

Figure 14- Strain-Stress curve for steel material

\subsection{Meshing}

The concrete block is divided into 3720 solid elements. Figure 15 shows the solid elements for the concrete block as well as the dimension of the elements. 


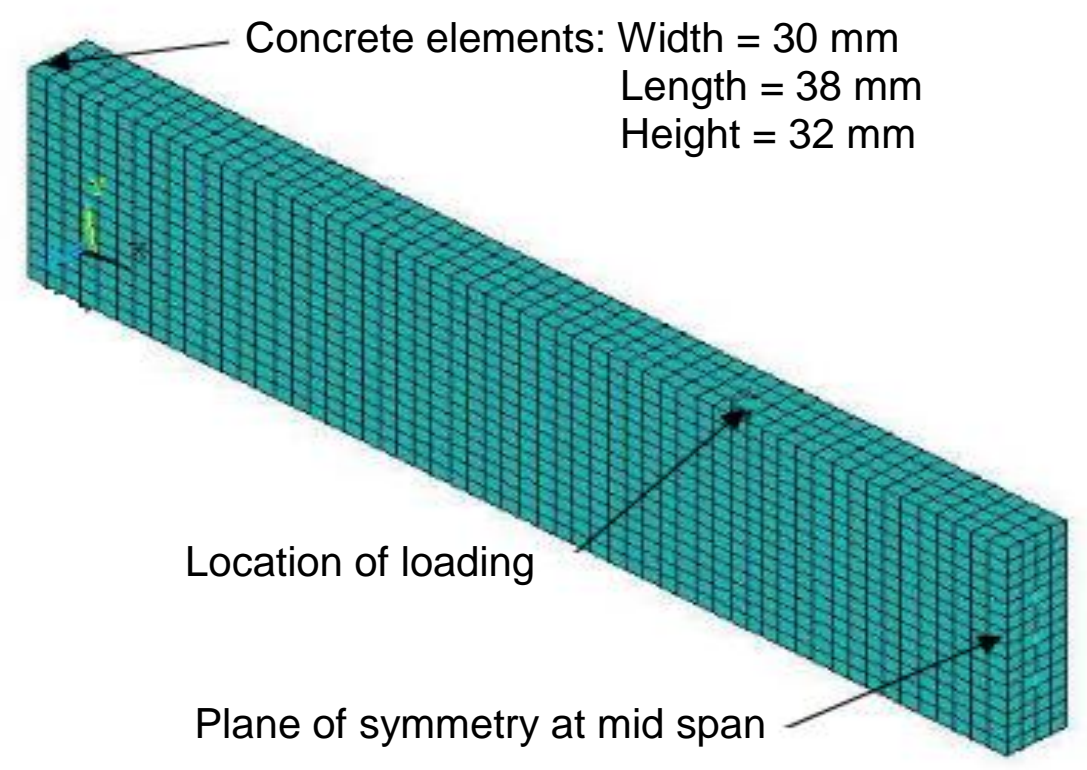

Figure 15- Meshing of concrete block

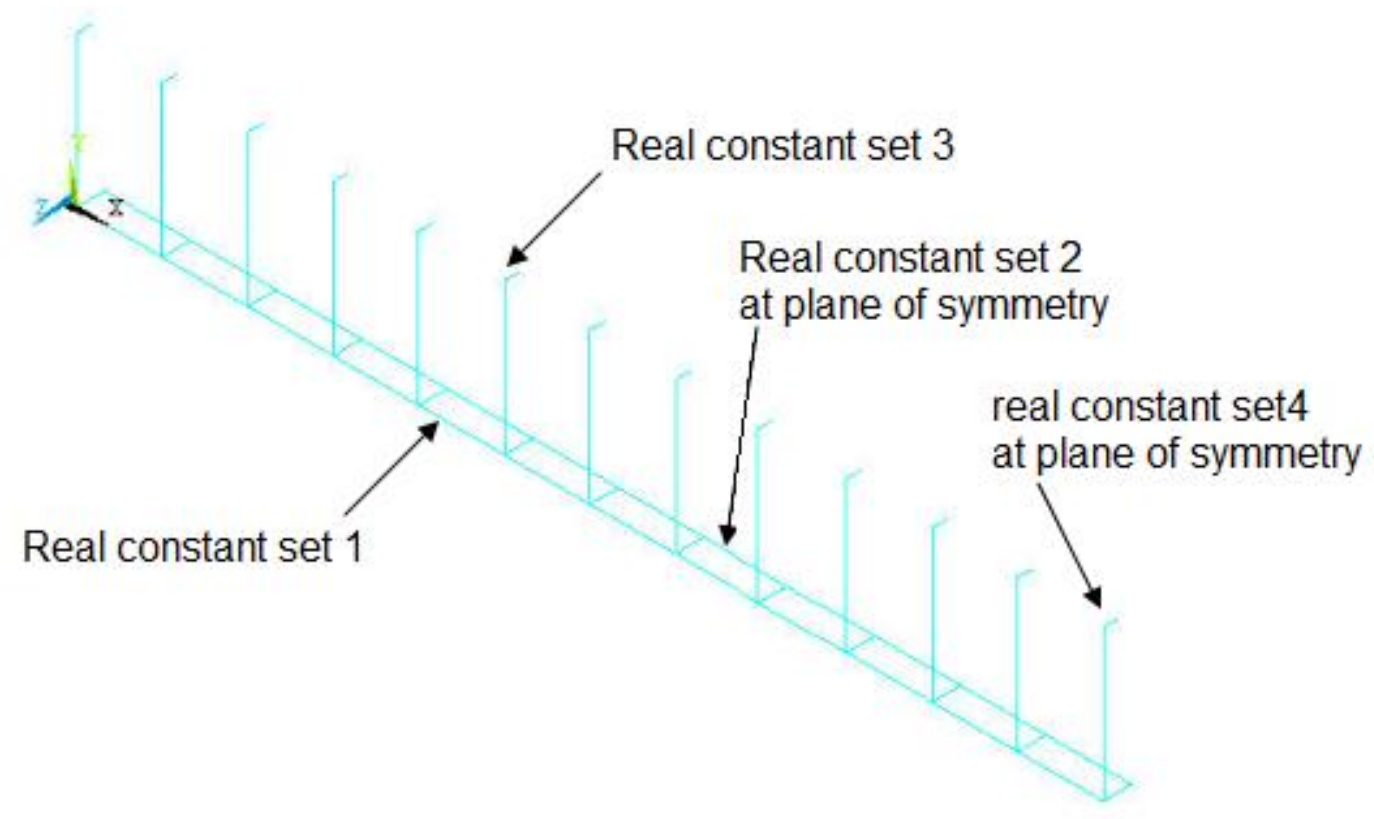

Figure 16- Reinforcement configuration in FE model 
The flexural rebars are divided to 62 elements with coinciding nodes with concrete each at $38 \mathrm{~mm}$ (1.5in) along its length. The stirrups are divided vertically to 11 elements with coinciding nodes with concrete element at each $30 \mathrm{~mm}$ (1.2in). Note that the first stirrup is located at the mid-span of the beam (plane of symmetry). Shear stirrups are located at coinciding nodes of the flexural rebars and concrete elements, with average spacing of $196 \mathrm{~mm}$ (7.75 in). Figure 16 shows the reinforcement configuration for the model.

\subsection{Boundary Condition}

To model the boundary condition at the support, the roller support condition, nodes at the bottom of the beam that are located at $76 \mathrm{~mm}$ (3in) from the end of the beam are constraint for the translation in $\mathrm{X}$ and $\mathrm{Y}$ directions.

The concrete beam model used is symmetric about two planes. The nodes located at the planes of the symmetry should be constraint in the direction perpendicular to the same plane of symmetry. As a result, nodes located at the mid-span of the beam are constraint for translation in $\mathrm{X}$ direction to get a unique solution. Nodes located at the other plane of symmetry which are located at $Z=0$, are constraint for translation in $Z$ direction. The boundary condition for the planes of symmetry and loading locations are shown in Figure 17.

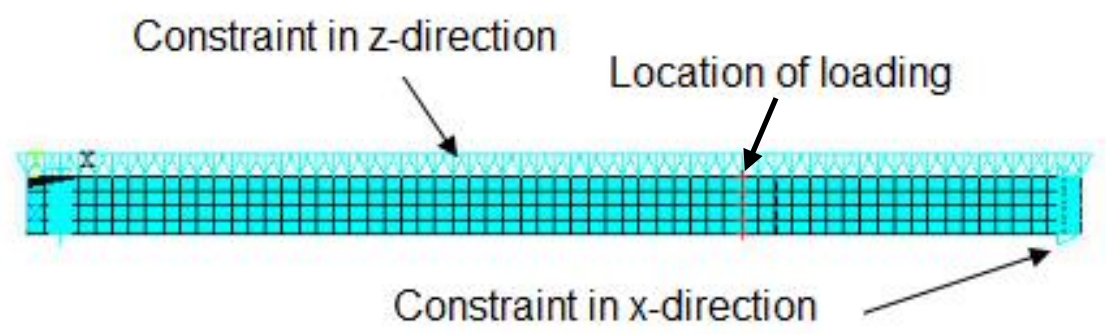

Figure 17- Boundary condition at planes of symmetry

The force, $\mathrm{P}$, is applied on the nodes at the top of the beam $1600 \mathrm{~mm}$ (63in) from the edge of the beam. Note that the load in distributed among several nodes to avoid premature failure. 


\subsubsection{Result and Discussion}

The results of the nonlinear finite element are presented in this section. It should be noted that the Newton-Raphson method of analysis is used to compute the nonlinear response. As a result, the load is applied incrementally to the beam up to the failure.

The full nonlinear load deformation response of the beam is captured in Figure 18. The results of the finite element analysis are shown by dashed line and are compared to that of experimental results. Three different behaviours of the beam are captured within the analysis: initial cracking, yielding of reinforcement and the strength limit state of the beam.

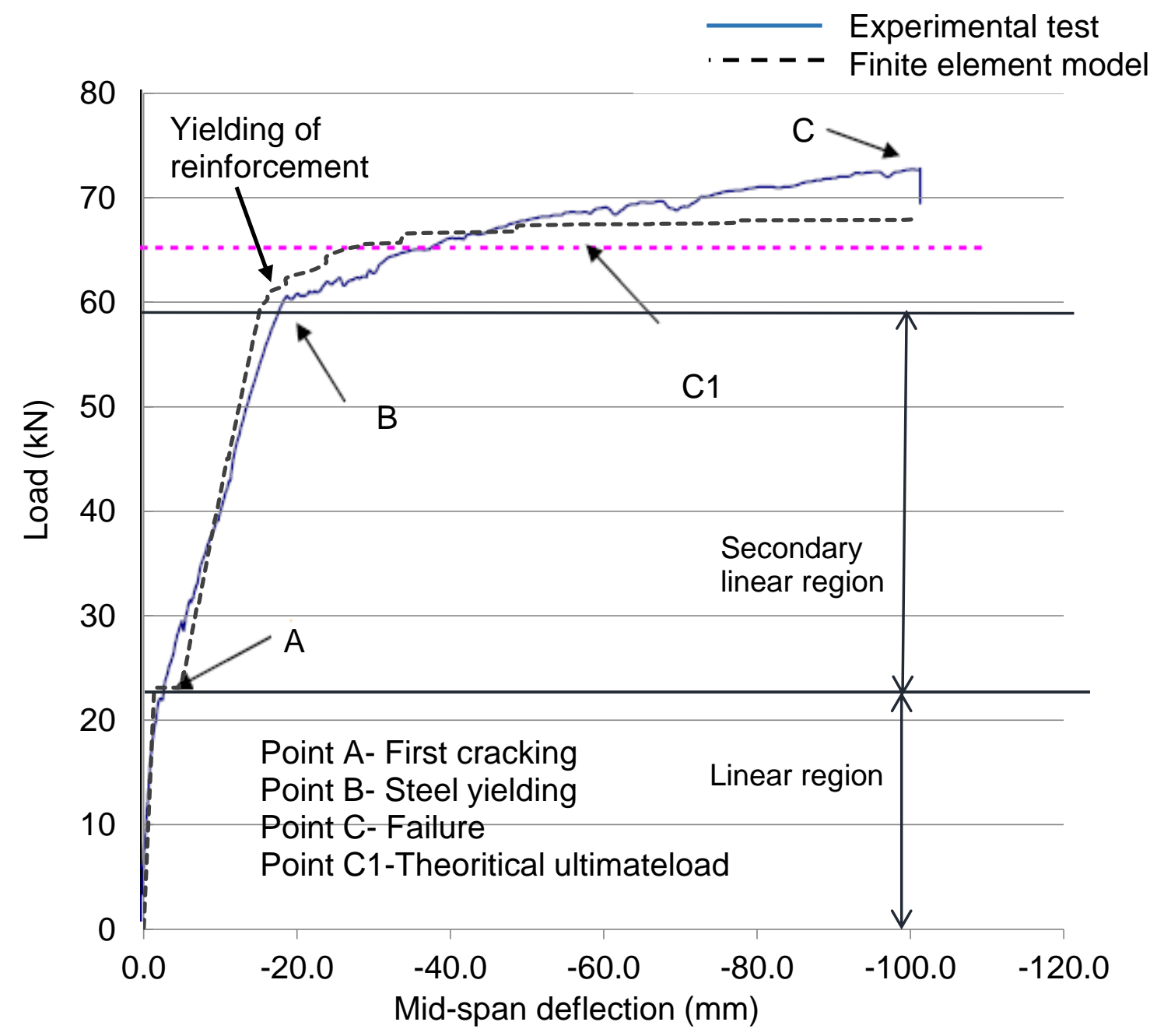

Figure 18- Load deflection curve 
The initial cracking of the beam in the finite element analysis happens when the applied load reaches the value of $23 \mathrm{kN}$ (5178 lbs). At this moment the flexural stress at the bottom fibre of the beam reaches the modulus of rupture of $3.5 \mathrm{MPa}(520 \mathrm{psi})$ over the constant moment region, and the beam cracks. This value compares well to $20 \mathrm{KN}$ (4500lbs) cracking load reported by Buckhouse [27]. Location of the first crack is shown in Figure 19. Significant flexural cracking is observed after the load of $53 \mathrm{kN}$ (12000 lbs) as shown in Figure 20.

Plane of symmetry

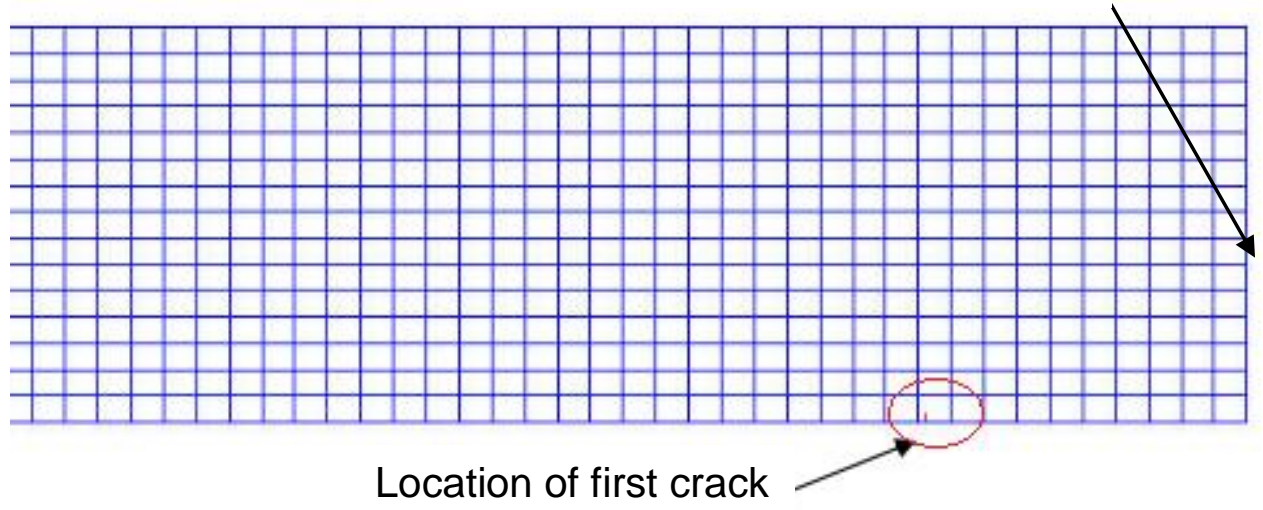

Figure 19- First crack at the constant moment region

Diagonal tension cracks

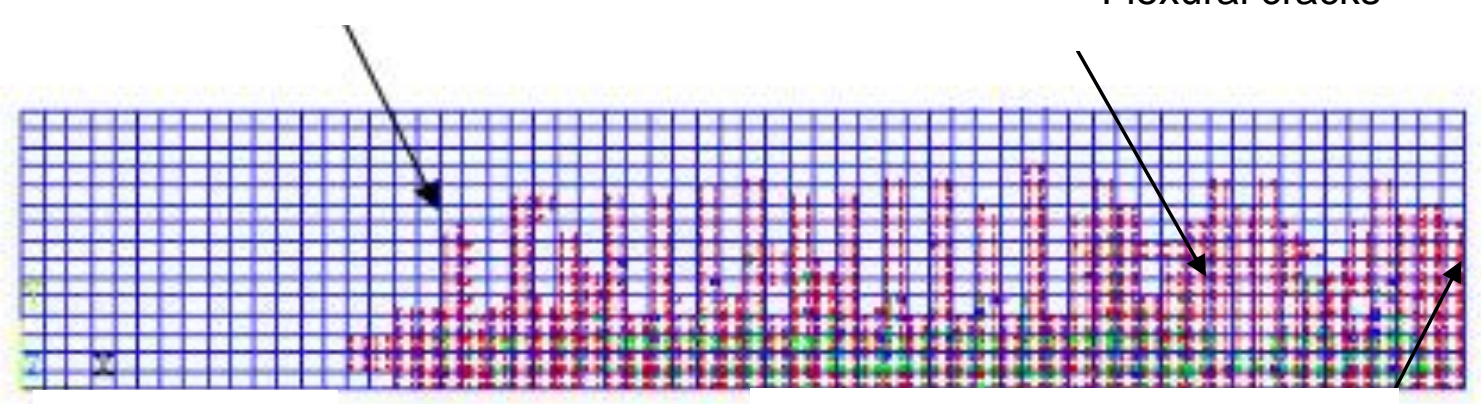

Flexural cracks

Plane of symmetry

Figure 20- Crack pattern at load of $53 \mathrm{kN}$

Yielding of the reinforcement occurs at the load of $59 \mathrm{kN}$ (13344 lbs) which is followed by successive cracking of the concrete beam. At $62 \mathrm{kN}(13,938 \mathrm{lbs})$, the beam has 
increasing flexural cracks, and diagonal tension cracks. Also, more cracks have now formed in the constant moment region. At $65 \mathrm{kN}$ (14612 lbs), cracking has reached the top of the beam, and failure is soon to follow.

At load $68 \mathrm{kN}$ (15287 lbs) the beam no longer can support any additional load as analysis stopped due to convergence failure. This value is compares very well with the value of $72 \mathrm{kN}$ (16310 lbs) failure load reported in reference [27].

It is observed that the finite element model is capable of practically predicting three essential nonlinear zones for the reinforced concrete beam. It is observed that the initial cracking of the concrete, yielding of the reinforcement and failure of the concrete beam can be captured by the finite element model.

\subsubsection{Mock-up prestressed containment structure}

The finite element model is prepared for the test structure subjected of experimental study by reference [10], [28] and [29].

\subsubsection{Test Structure}

The test structure which is patterned after the Canadian CANDU reactor containment included base slab, cylindrical wall, ring beam and spherical dome. Sections are proportioned with overall scale of 1:14 to have same sequence of cracking pattern under increasing internal pressure as the prototype.

To prevent explosive failure and to maintain a constant pressure with time, water is used rather air as the pressurizing medium. A plastic liner is added to inner face of the test structure to prevent leakage of water. Vertical section of the test structure and prestressing details is shown in Figure 21. Prestressing tendon details is shown in Figure 22.

The geometry properties of the model are summarized below. 
Radius of wall interior surface

$1473 \mathrm{~mm}$

Wall height

$3048 \mathrm{~mm}$

Thickness of wall

$127 \mathrm{~mm}$

Thickness of dome

$101.6 \mathrm{~mm}$

Thickness of ring beam

$419 \mathrm{~mm}$

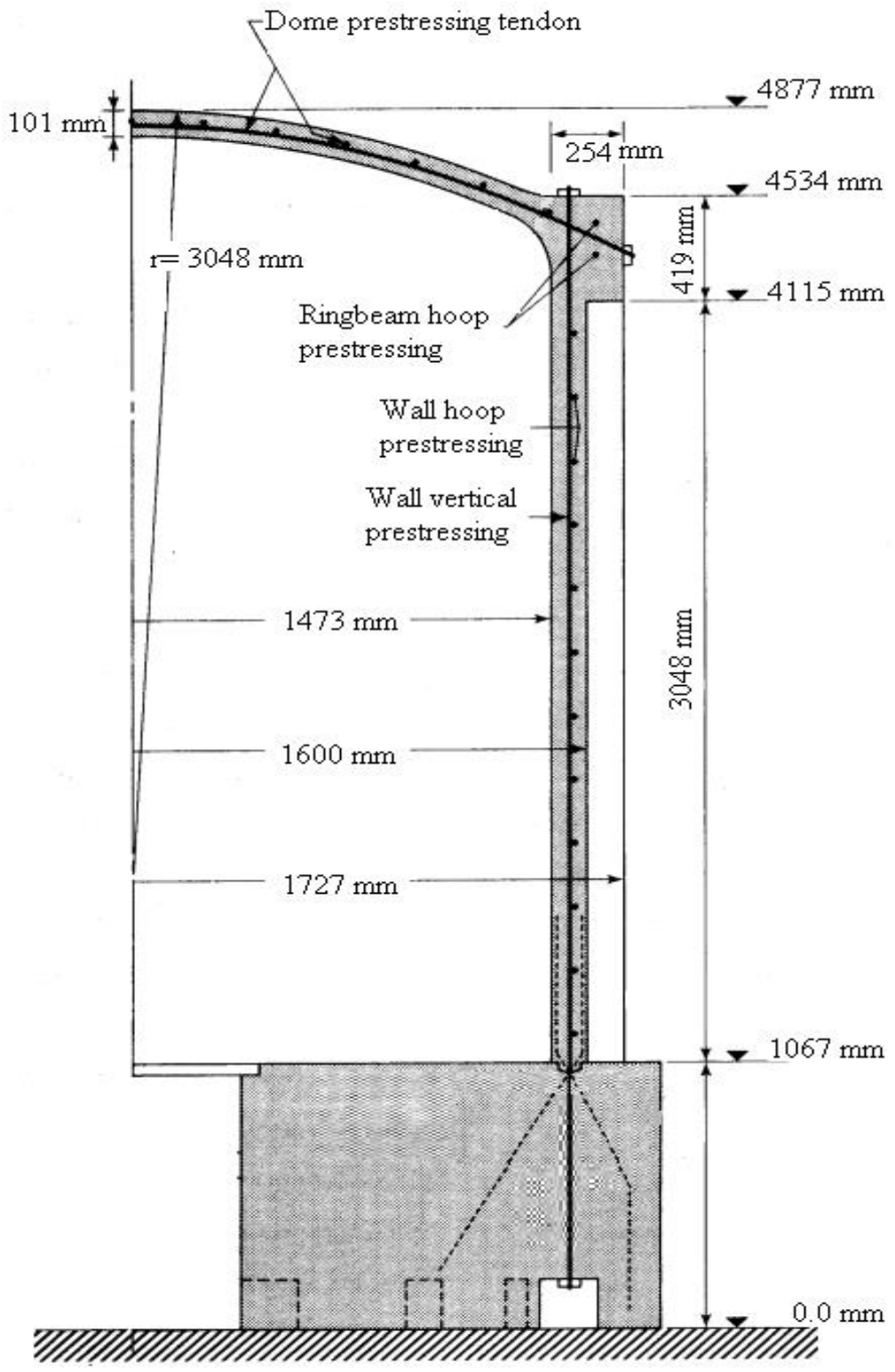

Figure 21- Vertical section of test structure (source: [28]) 


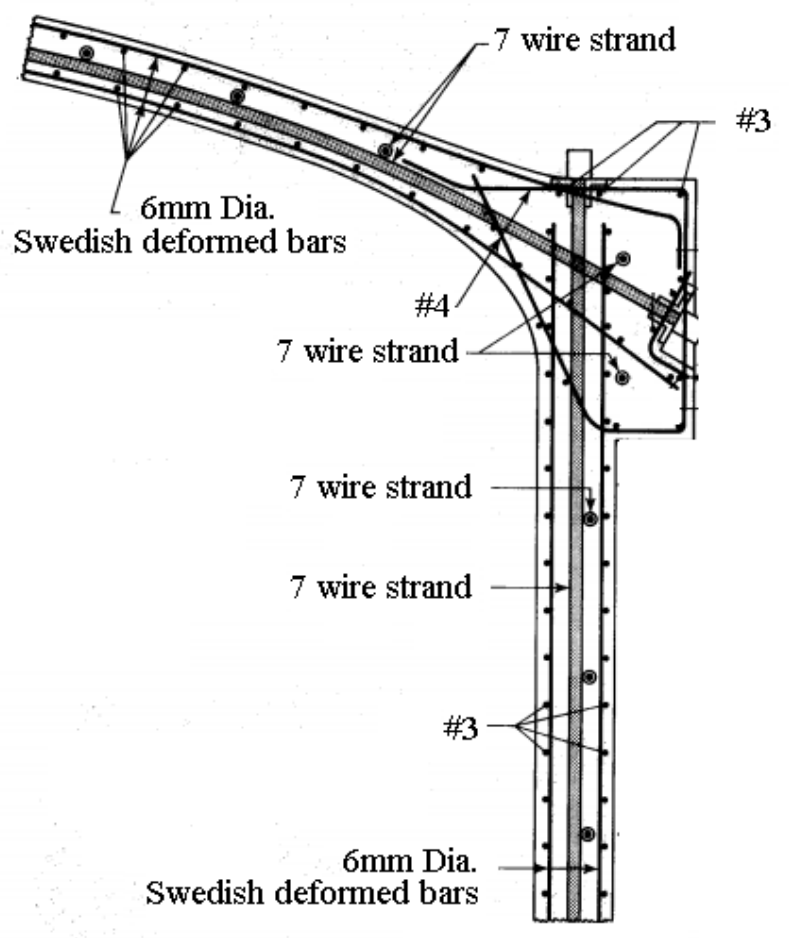

Figure 22- Non-prestressing reinforcement details (source: [28])

The circumferential steel in the wall is provided with $10 \mathrm{~mm}$ diameter (\#3) bars with spacing of $76 \mathrm{~mm}$. Vertical steel in the wall is provided by $6 \mathrm{~mm}$ diameter bars conforming to Swedish specifications. The yield stress for \#3 bars and $6 \mathrm{~mm}$ diameter Swedish bar are $345 \mathrm{MPa}$ and $482 \mathrm{MPa}$, respectively.

The cylindrical wall is prestressed with 24 horizontal tendons with vertical spacing of 254 $\mathrm{mm}$ and 20 vertical tendons with spacing of $483 \mathrm{~mm}$. The dome is prestressed with a layer of prestressing tendons of 11 tendons in each direction with a spacing of $254 \mathrm{~mm}$. Ring beam is prestressed with two 7 wire-strand tendons.

The material properties for prestressing tendons and rebars are as follows: Modulus of elasticity (MPa) Yield strength (MPa)

$6 \mathrm{~mm}$ rebar

(10 M) \#3 and \#4 rebar

Prestressing tendons
200,000

200,000

200,000
497 351

1670 
The material properties of concrete are defined as follows:

$\gamma_{c}=2400 \mathrm{~kg} / \mathrm{m}^{3} \quad$ Density

$f_{\mathrm{c}}^{\prime}=35 \mathrm{MPa} \quad$ Specified 28-day cylinder compressive strength

$f^{\prime} t=2.9 \mathrm{MPa} \quad$ Tensile strength of the concrete

$E_{c}=30000 \mathrm{MPa} \quad$ Secant modulus of elasticity

$\mathrm{v}_{\mathrm{c}}=0.15 \quad$ Poisson's ratio

\subsection{Testing}

Water is used as pressurizing agent to develop internal pressure on the CS. For the first loading sequence referred to as Test $F$, the internal pressure is increased up to value of $550 \mathrm{kPa}$ and terminated due excessive leakage of water because of cracks in concrete. After draining of the water and providing a new liner, Test $G$ is performed with increasing the internal pressure up to failure of the structure at value of $1100 \mathrm{kPa}$.

\subsection{Overall Behaviour of Test Structure}

The first crack developed at internal pressure of $210 \mathrm{kPa}$ at the inner face of the dome. First crack at the wall forms at internal pressure of $280 \mathrm{kPa}$. Failure of the test structure happens with rupture of three horizontal tendons at the wall and one vertical tendon at the wall.

\subsubsection{Finite Element Modelling}

Due to symmetry boundary condition, the finite element model is one quarter 3D model of the test structure. The real constant sets to introduce the reinforced concrete elements throughout the wall and dome of the CS is summarized in Table 7. For each section of the CS that are shown in Figure 23, the ratio of meridional, hoop and radial reinforcement are presented in Table 7. 


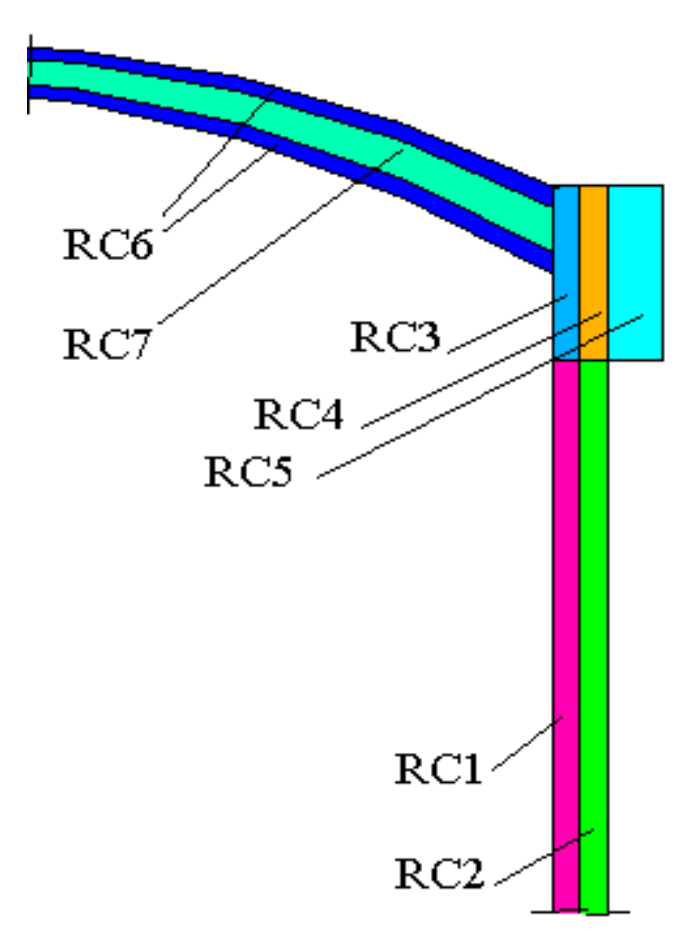

Figure 23- Real constant sets for containment structure cross-section

Table 7- Real constant sets for reinforced concrete elements

\begin{tabular}{|c|l|l|l|l|}
\cline { 3 - 5 } \multicolumn{2}{c|}{} & \multicolumn{3}{l|}{ Reinforcement ratio } \\
\hline $\begin{array}{c}\text { Real constant } \\
\text { set }\end{array}$ & & Meridional & Hoop & Radial \\
\hline RC set 1 & wall inner face & 0.00593 & 0.0147 & 0 \\
\hline RC set 2 & wall outer face & 0.00593 & 0.0147 & 0 \\
\hline RC set 3 & wall top inner face & 0.02193 & 0.0253 & 0 \\
\hline RC set 4 & wall top outer face & 0.02193 & 0.0253 & 0 \\
\hline RC set 5 & ring beam & 0.00133 & 0.0106 & 0.00266 \\
\hline RC set 6 & dome outer and inner faces & 0.00274 & 0.00274 & 0 \\
\hline RC set 7 & dome middle layer & 0 & 0 & 0 \\
\hline
\end{tabular}

The real constant sets to introduce the prestressing tendon elements and the prestressing forces of prestressing for the dome, wall and ring beam are summarized in Table 8 . The 
required information is area of the cable and strain in the cable which is calculated based on prestressing force available in reference [10].

Table 8- Real constant sets for prestressing tendons

\begin{tabular}{|l|l|l|l|}
\cline { 2 - 4 } \multicolumn{1}{l|}{} & Tendon & Area $\left(\mathrm{mm}^{2}\right)$ & Strain $(\mathrm{mm} / \mathrm{mm})$ \\
\hline RC set 11 & dome horizontal & 180.65 & 0.0047 \\
\hline RC set 12 & dome horizontal at plane of Sym. & 90.325 & 0.0047 \\
\hline RC set 13 & wall vertical & 98.7 & 0.0033 \\
\hline RC set 14 & wall vertical at plane of Sym. & 49.35 & 0.0033 \\
\hline RC set 15 & wall horizontal & 98.7 & 0.00476 \\
\hline RC set 16 & ring beam & 98.7 & 0.0048 \\
\hline
\end{tabular}

For simplification, the non-prestressing reinforcing steel are assumed to have an elasticperfectly plastic response with a bilinear kinematic hardening material model. The nonprestressing reinforcement steel in finite element models are introduced as smeared which assumes uniform distribution of reinforcing steel throughout the defined concrete elements.

For prestressing tendons, a multilinear kinematic hardening model is used. Cables are modelled by discrete bar elements. Link8 elements are used to model tendons which are uni-axial tension elements. The stress/strain curve of prestressing is defined based on the modified Ramberg-Osgood function by Mattock for low-relaxation strands from reference [21]. Stress-strain curves for all reinforcing material are shown in Figure 24.

For the concrete material, the tri-axial failure surface model developed by Willam and Warnke [23] is employed. Isotropic Solid-65 3D solid elements are used to model reinforced concrete. Stress-strain curve for concrete material is shown in Figure 25. 


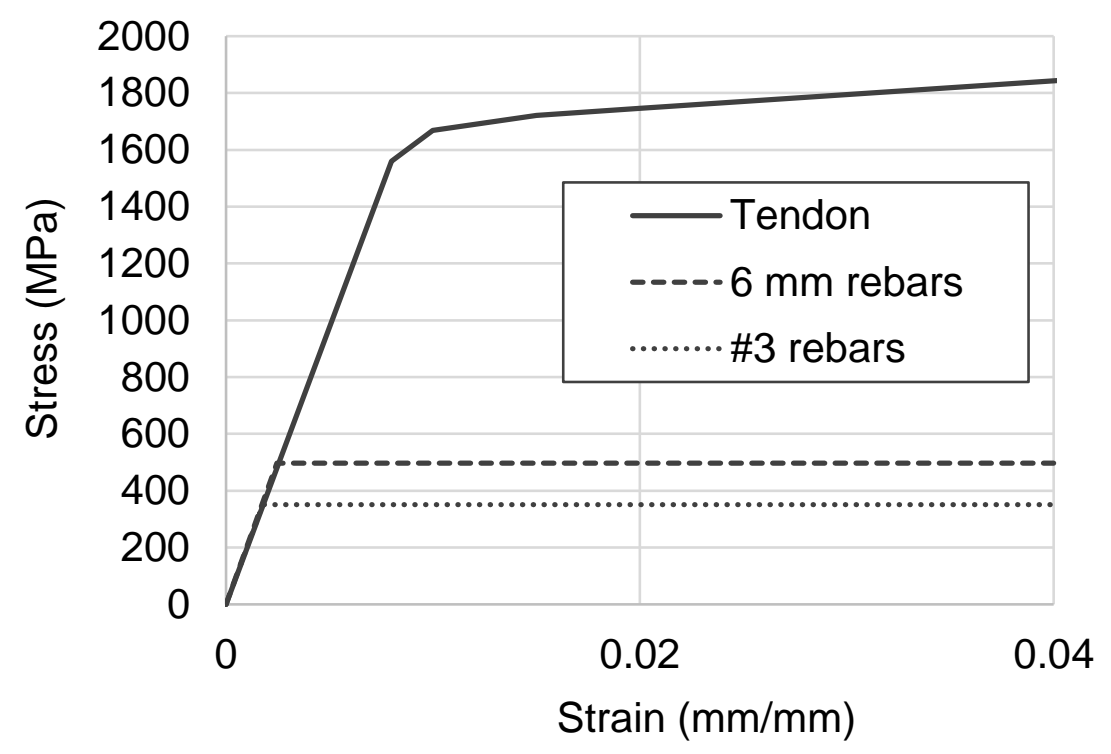

Figure 24- Stress-strain curve for reinfrcemnet

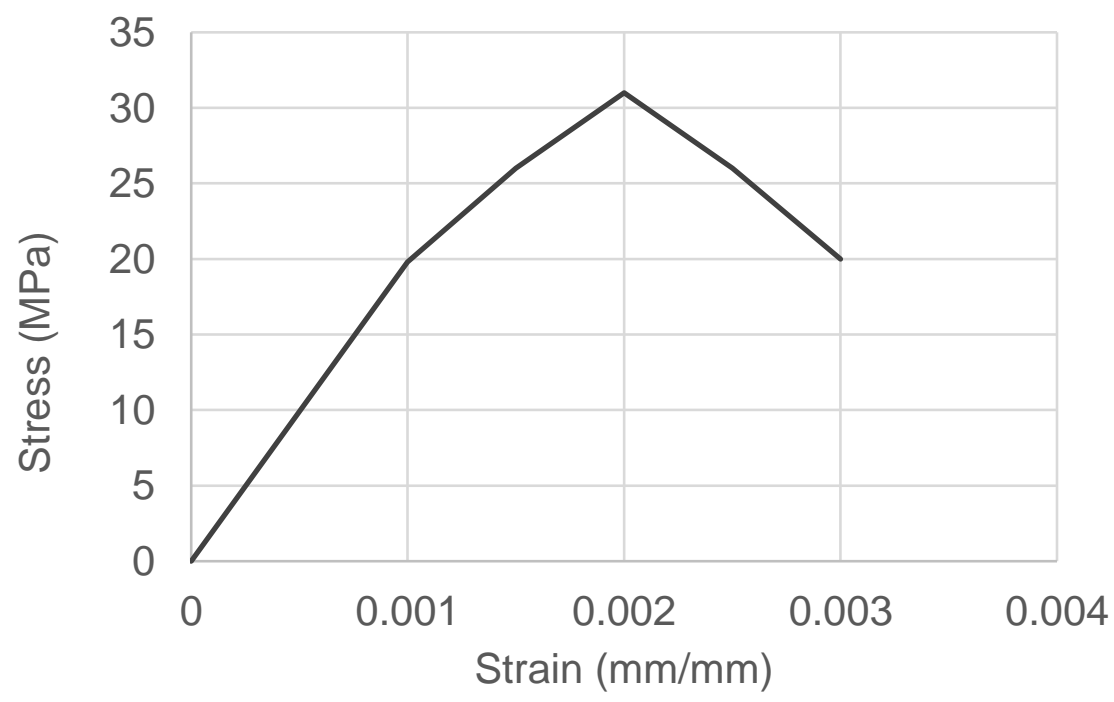

Figure 25- Stress-strain curve for concrete

To model the bond between concrete and prestressing tendon, nodes of bar elements are coupled with coinciding our neighboring nodes of concrete elements. It should be noted that these nodes are assumed $100 \%$ coupled. 
To add the effects of prestressing forces, strains are applied on the bar elements. The applied strain for each of the prestressing tendons can be calculated according the inservice force and properties of the tendon.

$$
\text { Strain }=\frac{\text { pretrssing force }}{A_{P} \times E_{P}}
$$

where $A_{p}$ is the cross-sectional area of tendon.

The in-service force is used to calculate the strain in the cables, and the prestressing losses are taken as an average through the length of the tendon. It should be noted that not enough information on prestressing losses of the tendons in the test structure is available in reference [10].

The analysis of the containment structure is conducted considering; dead loads, prestressing forces, and internal pressure. Dead loads contain self-weight of the structure including weight of the cylindrical wall, ring beam and the shallow dome. The CS model is loaded with a static internal pressure that increases incrementally.

For first step of analysis, a static analysis is conducted to apply the self-weight of the structure. For the next step, the prestressing effects are applied by adding an updated initial strain to the prestressing tendon elements as a separate load step.

A static nonlinear finite element analysis is conducted to estimate ultimate pressure capacity of the CS. It should be noted that the full Newton-Raphson method of analysis is used to compute the nonlinear response. The internal pressure is applied incrementally to the structure up to the failure.

4.4.2.2.1 Results and Discussions 
The results of the finite element analysis are compared with those of experimental tests in the form of deflection at the top of the dome as shown in Figure 26. Positive deflection in this graph represents an upward deflection.

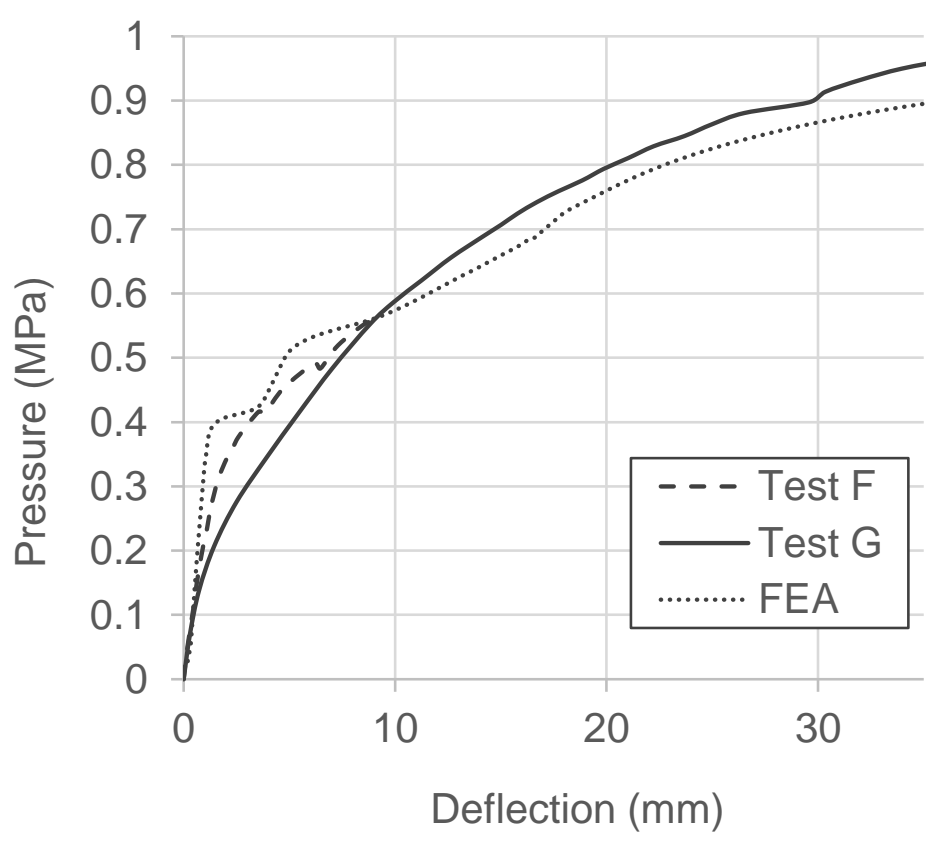

Figure 26- Internal pressure vs. deflection at dome apex

In Figure 26, the results are shown for finite element analysis (FEA) as well as test $F$ and test $G$ of the experimental study. The finite element analysis was carried out up to internal pressure of $899 \mathrm{kPa}$ and stopped at this point with convergence difficulties due to rupture of prestressing tendon at the wall.

It can be observed that the results of the FEA are in very good agreement with those of the experimental studies. The first crack in the FEM forms at internal pressure of $310 \mathrm{kPa}$ at the dome followed by a meridional crack and horizontal crack at the wall at internal pressure of $380 \mathrm{kPa}$ and $415 \mathrm{kPa}$, respectively.

The slight differences in the responses of the FEM and experimental tests are for the cracking loads which can be due to usage of two different concrete mix in the mock-up 
structures along the height of the wall, which is ignored in the FEM. In the FEM, same concrete material is used for all the volumes in CS.

Moreover, the detailed information on prestressing loss is not provided in the literature, and in the FEM the prestressing force loss is assumed uniform, which could results in variation in the cracking load due to the complicated geometry of the structure.

From the finding of the current chapter it is concluded that the nonlinear behaviour of the prestressed CS under internal pressure can be correctly simulated using ANSYS. As the geometry of the CS subject of this research study is very similar to this mock-up CS, similar modelling approaches is used to model prestressing as follows in Chapters 5, 6 and 7. 


\section{CHAPTER 5 DIFFERENT APPROACHES TO MODEL PRESTRESSING SYSTEM}

\subsection{General}

The primary objectives of this chapter are to compare the different approaches to model the containment structure and to investigate the response of a containment structure to much higher internal pressures that could be encountered during a severe accident.

Two models are prepared using different approaches to model the prestressing system in CS. Both models are discussed and the response of the structure and the results of UPC are compared. For the containment structure, the most detailed models are obtained by full 3D models.

In the first model, the effects of prestressing system on the CS is added as external forces applied at the outer surface of the CS and at tendon ends, in which prestressing tendons are modeled as smeared reinforcement. In the second model, the prestressing tendons are modelled as discrete elements and effects of prestressing forces are applied directly on the tendons as initial strain calculated based on tendon forces.

For comparison purpose, in both models, all the non-uniform prestressing losses are ignored in order to have equivalent forces. The effects of prestress losses are described in details in Chapter 6.

It should be noted that the first model has been used in several research studies; however, the second model has not been fully used by previous researchers to the extent of a complicated structure such as this containment. 


\subsection{Development of Finite Element Models}

The first step in the finite element modelling of the containment structure is to produce the proper geometry model for the structure.

It should be noted that in structures such as the containment structure, because of complication in geometry, the behaviour of the structure is non-axisymmetric. In CS, one of the sources of non-axisymmetric behaviours is dome tendon layout. As was mentioned before, the dome in this CS is prestressed with three layers of prestressing cables that are located $120^{\circ}$ apart from each other. This layout produces a more uniform pressure on the dome and as a result a more effective prestressing system.

Moreover, the PW is prestressed with two sets of horizontal tendons anchored at four buttresses at $90^{\circ}$ intervals. Each set of horizontal tendons has angular length of just above $180^{\circ}$ and are tensioned from both ends at alternate buttresses.

Due to tendons layout and horizontal wall tendon buttresses, the CS has no plane of symmetry, and to model the non-axis-symmetric behaviour of the CS, the most detailed model is obtained by a full 3D model.

To compare different approaches of modeling prestressing effects, two separate models are created in ANSYS. For both of the models, similar material properties, and similar element types and dimensions are used to model concrete and reinforcing steel. The differences between the models are the approaches to model the prepressing tendons and prestressing forces.

\subsubsection{Material and Element Selection for Model 1 and Model 2}

The CONCR model in ANSYS program enables the appropriate elements to account for both cracking and crushing parameters. For the CONCR model in ANSYS, the tri-axial failure surface model developed in reference [23] is employed. 
Additional information that is needed for introducing the failure model is shear transfer coefficients for an open crack and closed crack. In this study, these values are assumed to be 0.35 and 0.6 for open cracks and closed cracks, respectively. More detailed information can be found in literature by references [22] and [23].

Detailed information on nonlinear behaviour of concrete and application of smeared crack model for reinforced concrete and mass concrete can be found in references [30] and [31], respectively.

In both models, isotropic Solid-65 3D solid elements are used to model concrete. 3D solid elements are capable of modelling the nonlinear behaviour through thickness of the wall compared to conventional shell modelling.

For Model 1, the prestressing tendons are assumed to be smeared in SOLID65 concrete elements, and in Model 2, prestressing tendons are modelled with LINK8 elements.

To model the plastic behavior and large displacement for reinforcing steel and prestressing tendons, kinematic hardening model with Von-Mises failure criterion is employed. The isotropic properties to for reinforcing steel and prestressing tendon material are defined in the program which are the modulus of elasticity and passion ratio. The material properties used in the finite element models are as explained in Chapter 3.

\subsubsection{Meshing}

According to design specifications of this containment structure, the height of the PW is divided into three sections along the height of the wall. The amount of meridional, hoop and transverse reinforcement in these sections vary from each other; however, constant among the height of each section. Also, the reinforcing detail varies at inside face and outside face of the PW. Accordingly, the PW is divided into 3 volumes along the height of the wall and 3 volumes through the thickness of the wall. Wall is divided to 6 elements through the thickness and to 142 elements along the height. The amount of reinforcing 
steel at outer and inner volumes of the wall is calculated according to design specification of the containment structure. As explained in Chapter 3 , the vertical and meridional reinforcing steel are introduced as smeared reinforcement to the first two concrete elements at inner face and two concrete elements at outer face of the wall. The radial reinforcing steel are added as smeared reinforcement to all the elements for the PW.

The dome of the containment structure is divided into six volumes in thickness to introduce the reinforcement at inner and outer faces of the dome. Meridional, hoop and shear reinforcement are modelled with the same approach as the reinforcing steel for the PW. Dome is divided to 74 elements along the arc of the dome. The smeared meridional and radial reinforcement are added to the first two elements at inner face of the dome and the two elements at outer face of the dome using the calculated reinforcement ratio and steel material properties.

For Model 1, the amount of horizontal and vertical prestressing tendons for the wall is calculated. These elements are introduced by adding the reinforcement ratio for the smeared reinforcement to mid-section of the perimeter wall. For vertical tendons, the ratio is similar along the perimeter of the wall. For horizontal tendons, the ratio of the prestressing tendons is different along the height of the wall. The prestressing tendons are introduced starting $3000 \mathrm{~mm}$ from the base of the wall. To introduce the prestressing tendon for the shallow dome, the ratio of prestressing tendon is calculated and the value is assigned to mid-section of the dome. Finite element of the concrete material for Model 1 is shown in Figure 27. Using a wedge of the CS, variations of the RC sets along the height of the PW is also illustrated in the same figure. The real constant sets for Model 1 are summarized in Table 9.

For Model 1, the prestressing effects of wall horizontal tendons are introduced by applying a uniform external pressure acting normal to face of the PW. Moreover for the vertical tendons, forces are applied top of the PW at location of anchors. The effects of dome horizontal prestressing is added by applying a uniform external pressure acting normal to face of the dome and tendon end forces at location of anchors. 
At location of anchorages, steel plates are added to finite element model to prevent premature failure. A 2D solid45 element is used to model the plate. Additional pressure is introduced to CS at the outer face of the ring beam to consider the prestressing effects of the horizontal RB tendons.

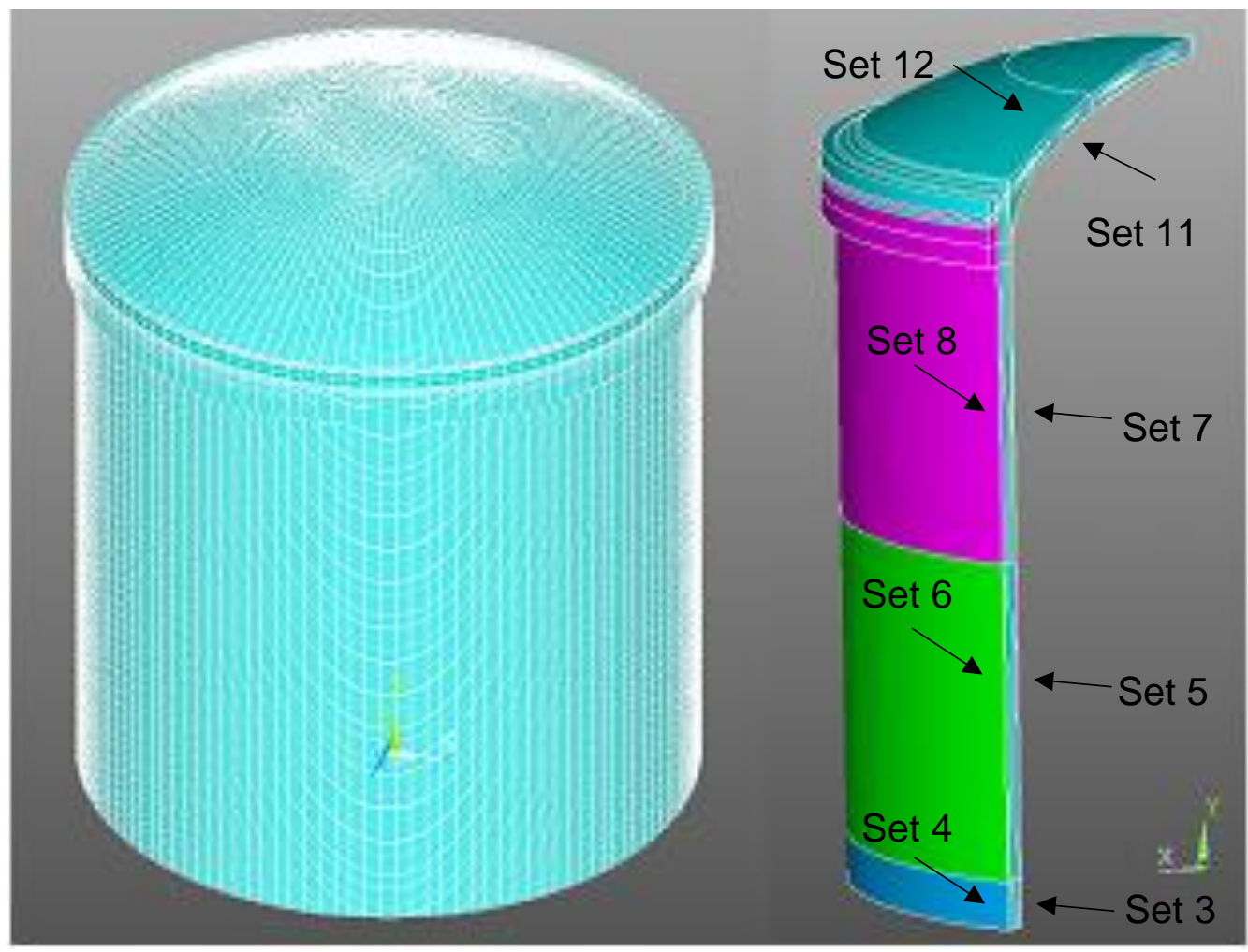

Figure 27- Finite element concrete elements and RC sets for Model 1

To model the effects of the prestressing system in Model 1, equivalent forces are applied at outer faces of the CS. For the PW horizontal tendons, the effects of the prestressing forces are applied as an external pressure acting normal at outer face of the wall. For the wall vertical tendons, the prestressing forces are applied as uniformly distributed load (UDL) applied at top of the wall. The load is applied as a downward load at middle of the wall. The forces of the ring beam horizontal tendons are applied as an external pressure applied normal at outer face of the RB. For the dome, the effects of the horizontal tendons are applied as an external pressure normal at outer face of the dome and as tendon end forces at location of anchors. 
Table 9- Real constant sets for Model 1

\begin{tabular}{|l|c|c|}
\hline Volume name & Location & RC set \\
\hline \multirow{2}{*}{ Volume 1 } & Inner face & Set\#3 \\
\cline { 2 - 3 } & Outer face & Set\#4 \\
\hline \multirow{2}{*}{ Volume 2 } & Inner face & Set\#5 \\
\cline { 2 - 3 } & Outer face & Set\#6 \\
\hline \multirow{2}{*}{ Volume 3 } & Inner face & Set\#7 \\
\cline { 2 - 3 } & Outer face & Set\#8 \\
\hline Dome & Inner face & Set\#11 \\
\cline { 2 - 3 } & Outer face & Set\#12 \\
\hline $\begin{array}{l}\text { Dome Horizontal tendon } \\
\text { (two layers at dome midsection) }\end{array}$ & Set\#14 \\
\hline $\begin{array}{l}\text { PW vertical and horizontal tendon } \\
\text { (two layers at volumes 1,2,3 midsection) }\end{array}$ & Set\#15 \\
\hline Plate at anchorage & Set\#32 \\
\hline
\end{tabular}

The equivalent pressures and forces that are used as input to the FE analysis of the CS in Model 1 (smeared tendon model) are based on information provided in Chapter 3 is summarized below:

PW external pressure

PW vertical UDL

RB external pressure

Dome external pressure

Dome meridional UDL at anchors
$800 \mathrm{kPa}$

$10200 \mathrm{kN} / \mathrm{m}$

$480 \mathrm{kPa}$

$850 \mathrm{kPa}$

$16500 \mathrm{kN} / \mathrm{m}$

It should be noted that for the equivalent forces mentioned above, all prestressing losses are ignored and it is assumed that the prestressing forces is applied uniformly on the CS. Those values are not the equivalent design values for this CS, and are calculated based on the jacking stresses without considering any losses. 
Figure 28 shows the equivalent external pressure and tendon end forces to model the effect of prestressing system in Model 1.

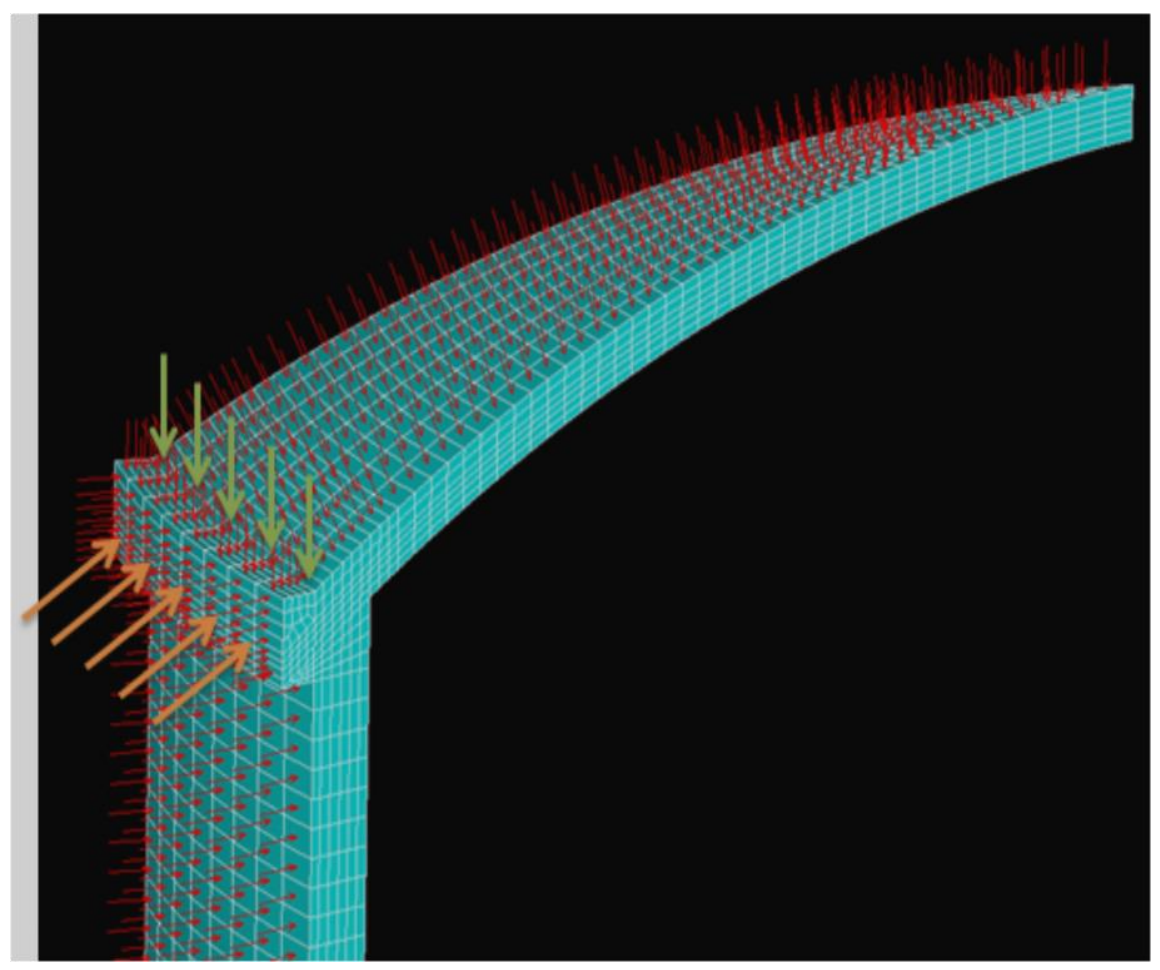

Figure 28- Prestressing equivalent forces for Model 1

Model 2: The concrete elements and real constant sets for reinforcing steel for the PW and the dome in Model 2 is similar to Model 1. However in Model 2, the prestressing tendons are represented by Link8 elements with uni-axial stiffness. The effect of prestressing is added as an initial strain on the elements. The real constant sets for prestressing tendons contains of the strain according to in-service tendon force and the area of the tendons.

Table 10 summarizes the Real Constant set assigned representing the smeared reinforcing steel at different location of the PW and the dome for Model 2. Figure 29(a) and Figure 29(b) show the finite element Model 2 for prestressing tendons using the Link8 elements for the perimeter wall, for the dome and for the ring beam tendons. As is shown in this figure, the prestressing system for the shallow dome consists of 3 layers of prestressing tendons that are located 120 degree apart from each other. 
Table 10- Real constant sets for Model 2

\begin{tabular}{|l|c|c|}
\hline Volume name & Location & RC set \\
\hline Volume 1,2,3 & Mid-Section & Set\#1 \\
\hline \multirow{2}{*}{ Volume 1 } & Inner face & Set\#3 \\
\cline { 2 - 3 } & Outer face & Set\#4 \\
\hline \multirow{2}{*}{ Volume 2} & Inner face & Set\#5 \\
\cline { 2 - 3 } & Outer face & Set\#6 \\
\hline \multirow{2}{*}{ Volume 3 } & Inner face & Set\#7 \\
\cline { 2 - 3 } & Outer face & Set\#8 \\
\hline \multirow{2}{*}{ Dome } & Inner face & Set\#11 \\
\cline { 2 - 3 } & Outer face & Set\#12 \\
\cline { 2 - 3 } & Mid-section & Set\#13 \\
\hline PW Vertical tendon & Set\#28 \\
\hline PW Horizontal tendon & Set\#29 \\
\hline Dome Horizontal tendon & Set\#30 \\
\hline Plate at anchorage & Set\#32 \\
\hline
\end{tabular}

The Link elements are coupled with concrete elements throughout the dome to assure that the prestressing forces are transferred to the dome structure. It should be noted that both models are fixed to the ground at the base.

The initial strain for the prestressing tendons at the wall and dome used in Model 2 (discrete tendon model) is summarized below:

PW horizontal tendon

PW vertical tendon

Ring beam tendons

Dome horizontal tendon
$7.4 \times 10^{-3} \mathrm{~mm} / \mathrm{mm}$

$6.7 \times 10^{-3} \mathrm{~mm} / \mathrm{mm}$

$7.4 \times 10^{-3} \mathrm{~mm} / \mathrm{mm}$

$7.6 \times 10^{-3} \mathrm{~mm} / \mathrm{mm}$ 
The above mentioned values are calculated based on the jacking forces and all prestressing losses are ignored.

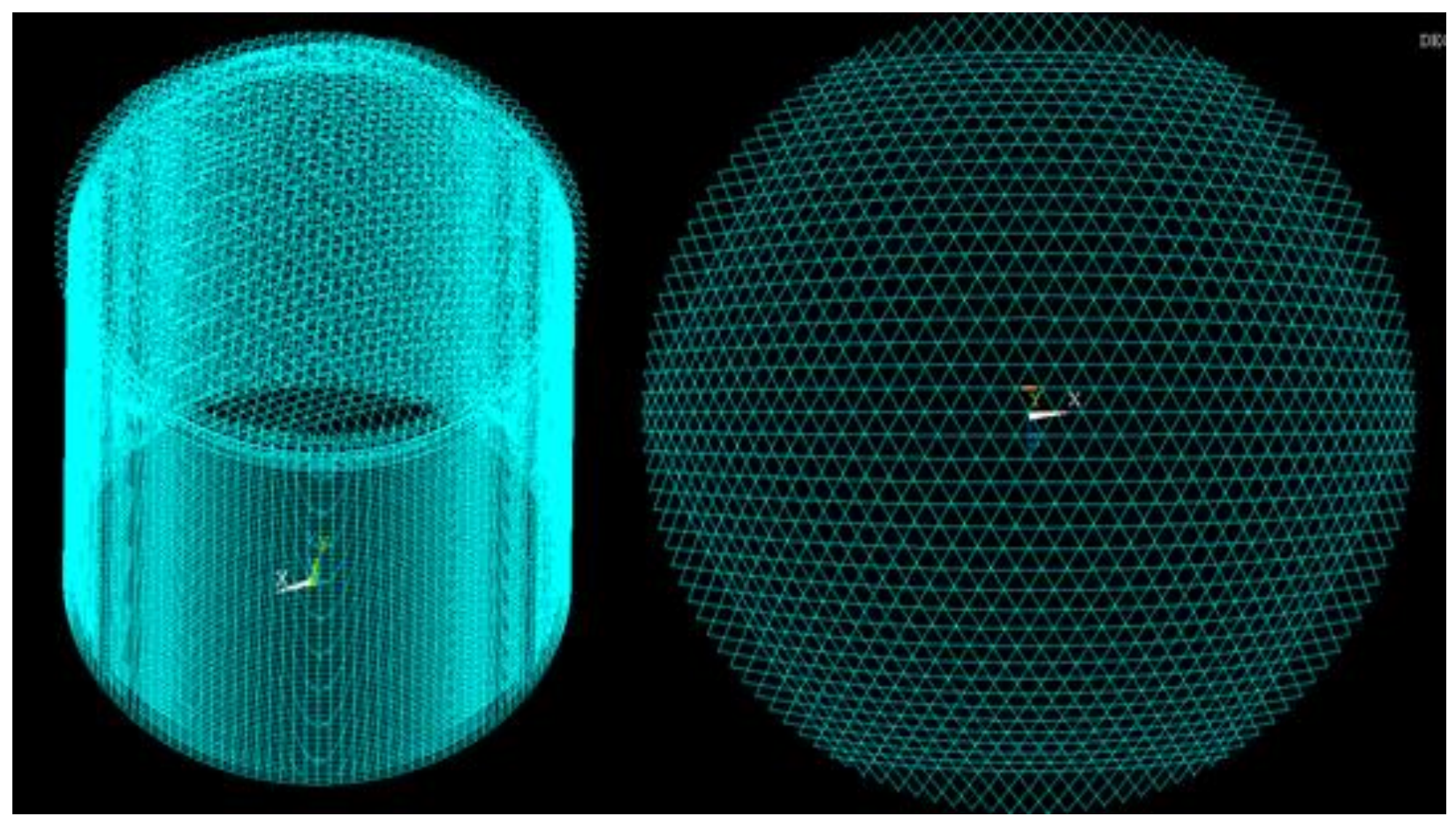

(a)

(b)

Figure 29- Finite element of prestressing tendons for Model 2:

(a) 3D model, (b) top view of the dome

As was mentioned before, one drawback of the discrete modeling is that the meshing of the concrete elements should be set initially as the location of the prestressing tendons. However, due to the nature of the geometry of the dome, the meshing cannot be matched with that of the prestressing system.

The ideal meshing for the dome is a symmetrical meshing system that will result in a more accurate values and will avoid any stress concentration in smaller elements. The orientation of the prestressing tendons at the dome, do not allow such a mesh for the bar elements, and will result in uneven element distribution for tendons.

To solve this problem, the prestressing tendon mesh and that of the concrete layers are produced separately. The meshing systems for a quarter of the concrete elements at the 
dome are shown in Figure 30. It can be observed that the lines to produce the concrete elements are located in radial and hoop directions and not match the direction of the prestressing tendons. However this meshing produces very accurate results compared to any meshing system that lacks order of coherence.

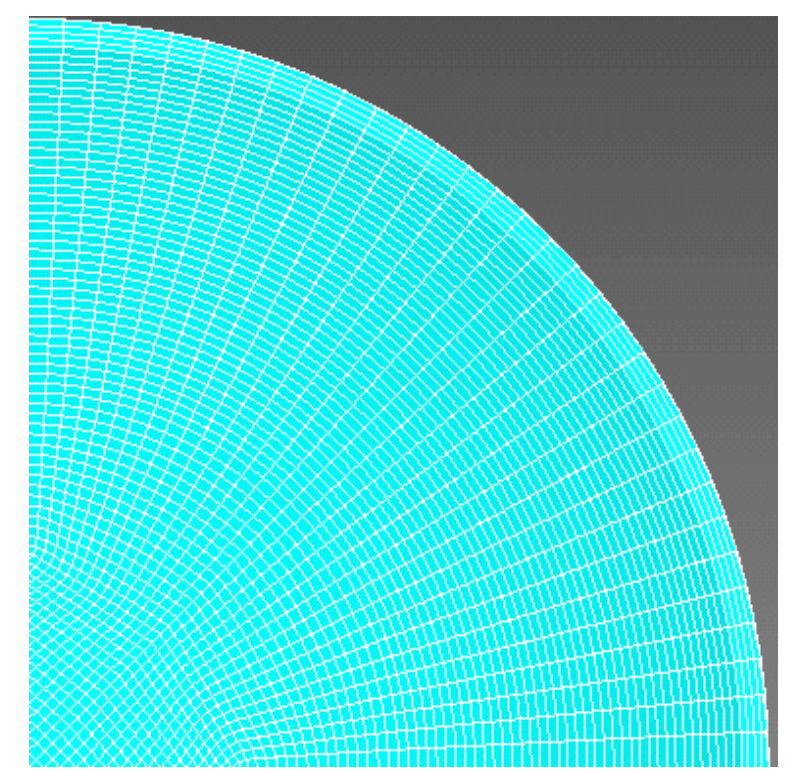

Figure 30- Concrete elements at dome of the CS

For the prestressing tendons, the tendons are divided in three groups. These are shown with different colors in Figure 31. Tendon layer one is located lowest elevation compared to the two other layers and is parallel to X-direction. Tendon layer 1 is shown with Cyan color. Tendon layer 3 is shown with Magnet color and is located at the higher layer compared the two other layers. Tendon layer 2 is shown with red color and is located at the middle layer of the dome. According to the design of this structure, the tendon layers are apart $135 \mathrm{~mm}$ in vertical direction and are located 120 degrees apart from each other. The lines representing the prestressing tendons are divided to 27 to 55 elements depending on the length of the tendon. The elements vary in lengths from $200 \mathrm{~mm}$ to 300 $\mathrm{mm}$ so that the location of the nodes are closer to nodes of the concrete elements. Link8 elements are attached together at the nodes. 
Figure 32 shows the nodes contributing to concrete elements and the link elements at location of tendon layer 1, nodes for concrete elements are shown by Cyan color and those for tendon elements by magnet color. It can be observed that despite several attempts to match the meshing of the two different components together, not all the nodes for these components coincide.

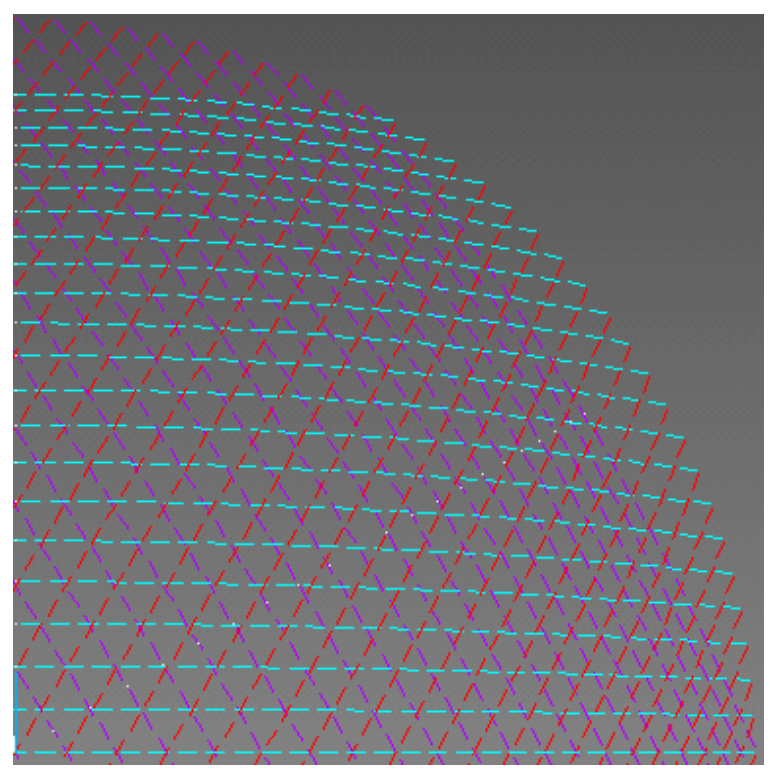

Figure 31- Tendon element at dome of the CS

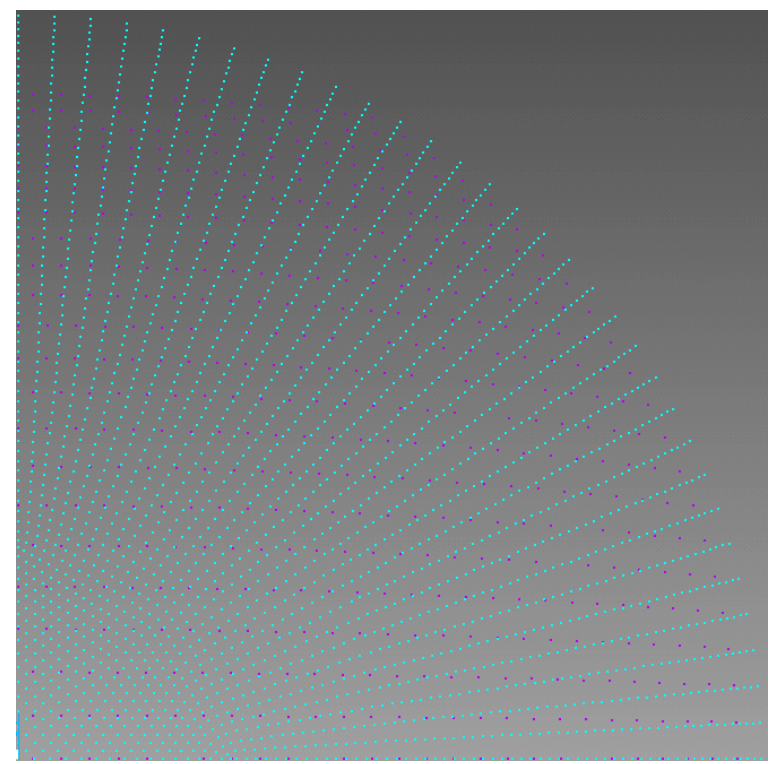

Figure 32- Nodes for concrete and tendon layer 1 element 
To model the bond between the prestressing tendons and concrete, the coinciding concrete and tendon nodes are coupled together. For the rest of the tendons nodes that are farther away from the concrete nodes from the specified logical distance, another method is employed. The displacement of the tendon element nodes is calculated from the average of the two or three concrete element nodes that are the closest to that node. These nodes are coupled to two or three nodes rather than one node to result in more accurate displacement.

The coupled nodes are attached assuming fully fixed condition. The tendon elements nodes that are coupled to one, two or three concrete elements nodes are assumed to have a $100 \%$ fixed connection which is appropriate for grouted tendons. For un-grouted tendon the same approach can be employed with reduction of the fixity of the connection between the tendon nodes and concrete nodes.

Figure 33 shows the coupled nodes for tendon Layer 1 and concrete elements. It can be observed that the pattern is more uniform at the apex of the dome as the concrete and tendon elements are smaller in that location to increase the accuracy of the results at this critical location.

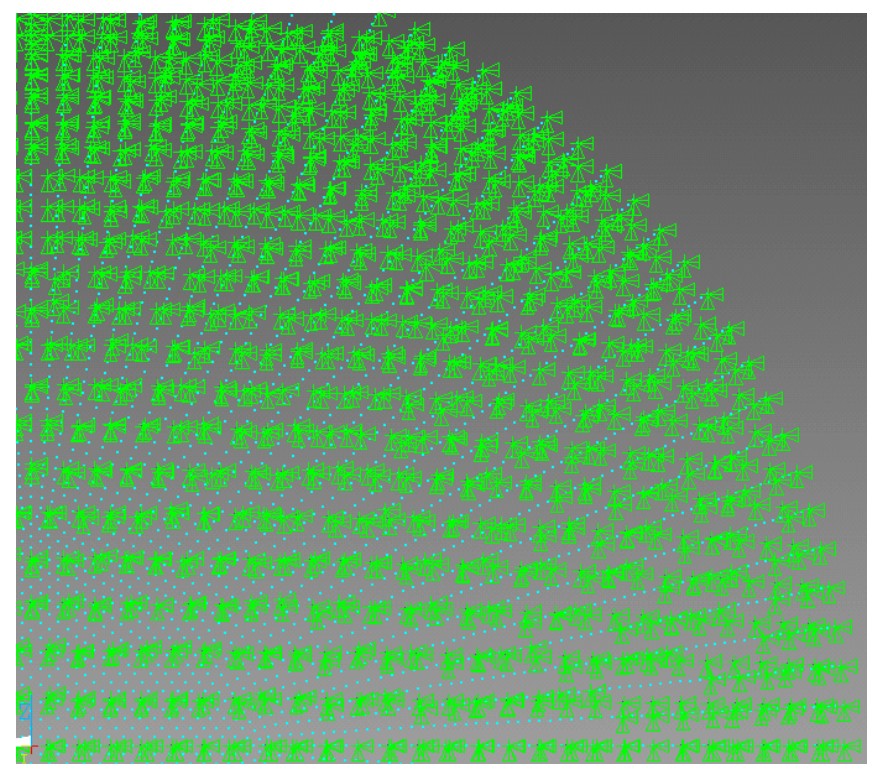

Figure 33- Coupled nodes of concrete and tendon elements at dome 
It should be noted that to prevent any premature failure due to stress concentration at locations of anchorage, a $300 \mathrm{~mm}$ thick steel plate is added to the finite element model to simulate the anchorage system. A 2D solid45 element is used to model the plate. This plate has same mesh size as the concrete it is connected to.

\subsection{Loading and Analysis}

The analysis of the containment structure is conducted considering; dead loads, prestressing forces, and internal pressure. Dead loads contain self-weight of the structure including weight of the cylindrical wall, ring beam and the shallow dome. Note that the effects of live loads are not considered during abnormal accident. The CS model was loaded with a static internal pressure that increased incrementally. Although many possible accident scenarios exist and are important near design pressures, for the calculation of ultimate capacity of the containment under internal pressure, the thermal loads are not included.

In both models, for first step of analysis, a static analysis is conducted to apply the selfweight of the structure. For the next step, the prestressing effects are applied for both models. For Model 1, the prestressing effects are added in a separate load step by applying the equivalent pressure and tendons end forces. For Model 2, the prestressing effects are applied by adding an initial strain to the prestressing tendon elements as a separate load step.

In both models, after application of static loads and prestressing forces, a uniform internal pressure is applied to the entire internal surface of the containment up to failure. The transient nature of the internal pressure is ignored as its period is much longer than that of the structure.

For both models, a static nonlinear finite element analysis is conducted to estimate

ultimate pressure capacity of the CS. Because of small displacement in concrete, geometry non-linearity or thinning of the wall need not to be accommodated in the models. 
It should be noted that the full Newton-Raphson method of analysis is used to compute the nonlinear response.

\subsection{Results and Discussion}

\subsubsection{Overall Behaviour of Model 1}

With application of prestressing effects on Model 1, the CS has a $20 \mathrm{~mm}$ downward deformation at dome apex and $5 \mathrm{~mm}$ inward deformation at wall mid-height. Model 1 behaves linearly under the explained loading condition.

For the next step, internal pressure is applied on Model 1 (smeared tendon model). The response of the structure in the form internal pressure against the normal displacement at dome apex for Model 1 is shown Figure 34. It is observed that the containment structure (CS) subject of this study meets the design requirement of the current standards and behaves linearly in excess of 1.5 times the design pressure of $400 \mathrm{kPa}$ (1.5 DBA). It should be noted that the internal pressure of $400 \mathrm{kPa}$ is equivalent of MSLB accident. The normal displacement at dome apex at the end of the linear response for Model 1 is $15 \mathrm{~mm}$.

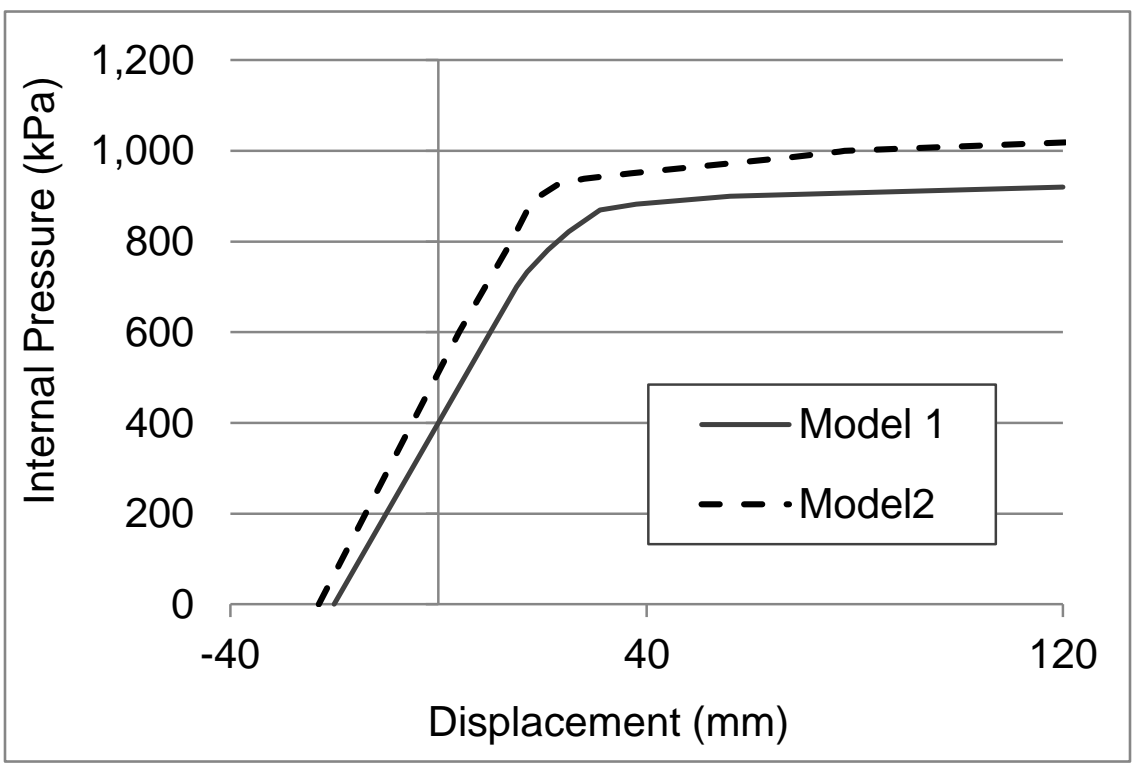

Figure 34- Internal pressure vs. normal displacement at dome apex 
First major crack forms at the wall outer face below the ring beam, which is due to meridional stresses at internal pressure of $680 \mathrm{kPa}$. At internal pressure of $780 \mathrm{kPa}$, cracks from at inner layer of the dome, which are due to radial stresses. The response is followed by yielding of radial reinforcement at inner layer of the dome at internal pressure of $875 \mathrm{kPa}$.

The stress state of a typical element at inner face of the dome at internal pressures of zero and $875 \mathrm{kPa}$ are shown in Figure 35. Finally, reinforcement yields in both radial and hoop directions throughout the dome, which results in excessive deformation at internal pressure of $905 \mathrm{kPa}$. At internal pressure of $905 \mathrm{kPa}$, Model 1 has outward deformation of $120 \mathrm{~mm}$ at crown of the dome. To reduce the computational efforts, the nonlinear analysis is not continued beyond this point.

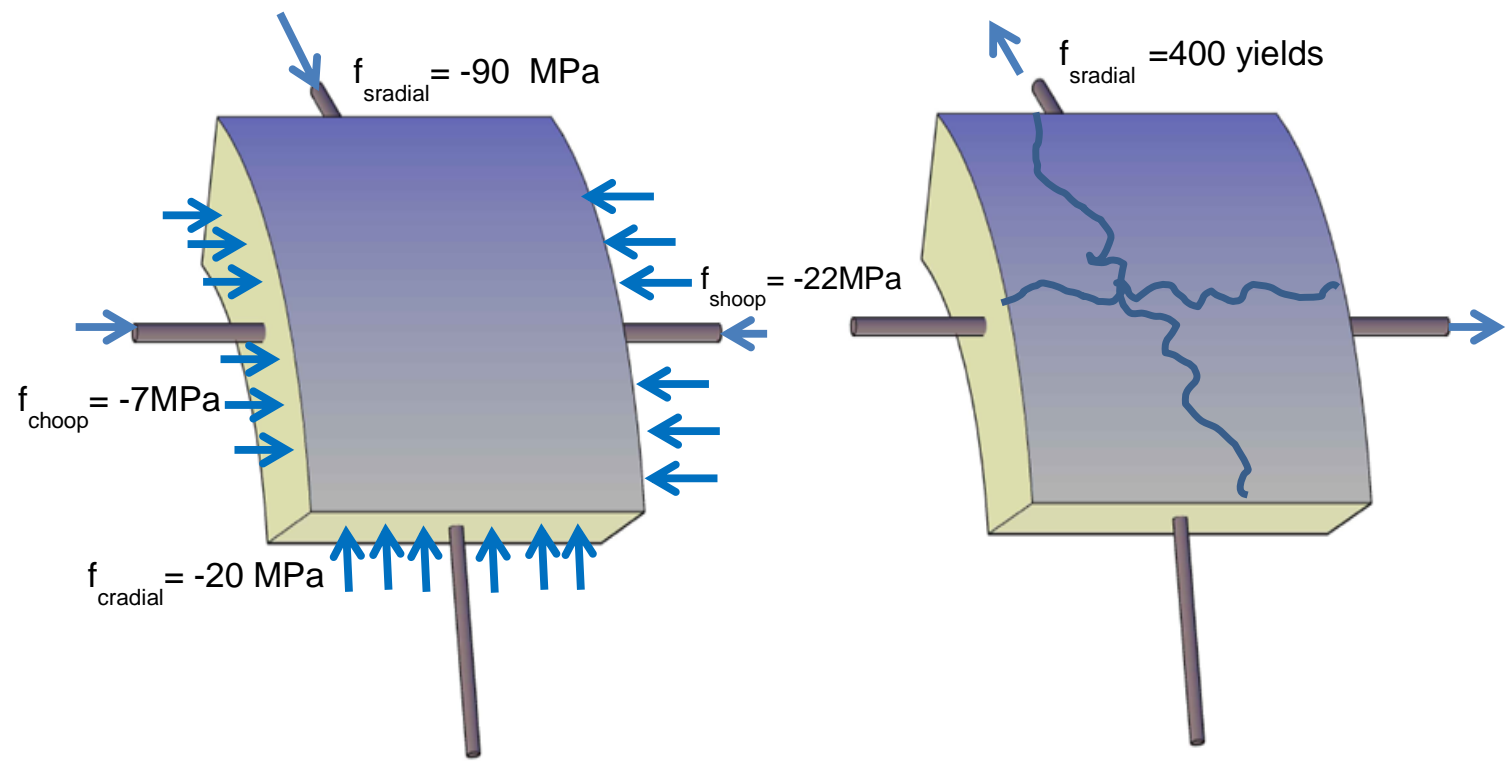

(a)

(b)

Figure 35- Stress state of a typical element at inner face of the dome for Model 1 at internal pressure of: (a) Zero, (b) $875 \mathrm{kPa}$

For a typical concrete element at mid-height of the dome, the element is at compressive stress of $20 \mathrm{MPa}\left(\mathrm{f}_{\mathrm{c}}{ }_{\mathrm{C}}=50 \mathrm{MPa}\right.$ ) in radial direction after transfer of prestressing effects. With increase of internal pressure, the concrete goes under tensile stress in radial direction 
and finally cracks at internal pressure of $830 \mathrm{kPa}$ when the tensile stress reaches the value of $5 \mathrm{MPa}$ in radial direction.

\subsubsection{Overall Behaviour of Model 2}

For Model 2, the effect of prestressing is added by an initial strain on the prestressing tendons. The response of the structure in the form of the normal displacement at dome apex of the containment structure is shown in Figure 34 as well. It can be observed that after application of all prestressing effects, the dome of the containment structure has a downward deformation of $25 \mathrm{~mm}$. With increase of internal pressure, the dome starts to have upward deformation and reaches the value of zero at internal pressure of $510 \mathrm{kPa}$.

Model 2 also behaves linearly under prestressing effect. For Model 2, there is an $18 \mathrm{~mm}$ outward deformation at the apex of the dome at the end of the linear response. Model 2 as well behaves linearly in excess of 1.5 times the design pressure and meets the design requirements.

Figure 36 shows top view of the prestressing tendons for the shallow dome. For the prestressing tendon located near the dome mid-height as shown in Figure 36, the tendon first reaches the mechanical strain of $0.8 \%$ at internal pressure of $890 \mathrm{kPa}$. Figure 37 and Figure 38 show the response of the prestressing tendon element in the form of stressstrain relationship and internal pressure against the strain in the element, respectively.

According to Figure 38, the tensile strain in the prestressing tendon reaches the value of $0.8 \%$ and prestressing tendon yields at internal pressure of $890 \mathrm{kPa}$.

One can conclude that the nonlinear response of the structure starts after formation of the cracks due to radial stresses and is followed by yielding of radial reinforcing steel. After yielding of the prestressing tendon, the response of the structure is followed by excessive deformation in both radial and vertical directions at internal pressure of 1030 $\mathrm{kPa}$. To reduce the computational efforts, the analysis is not continued beyond this point. 


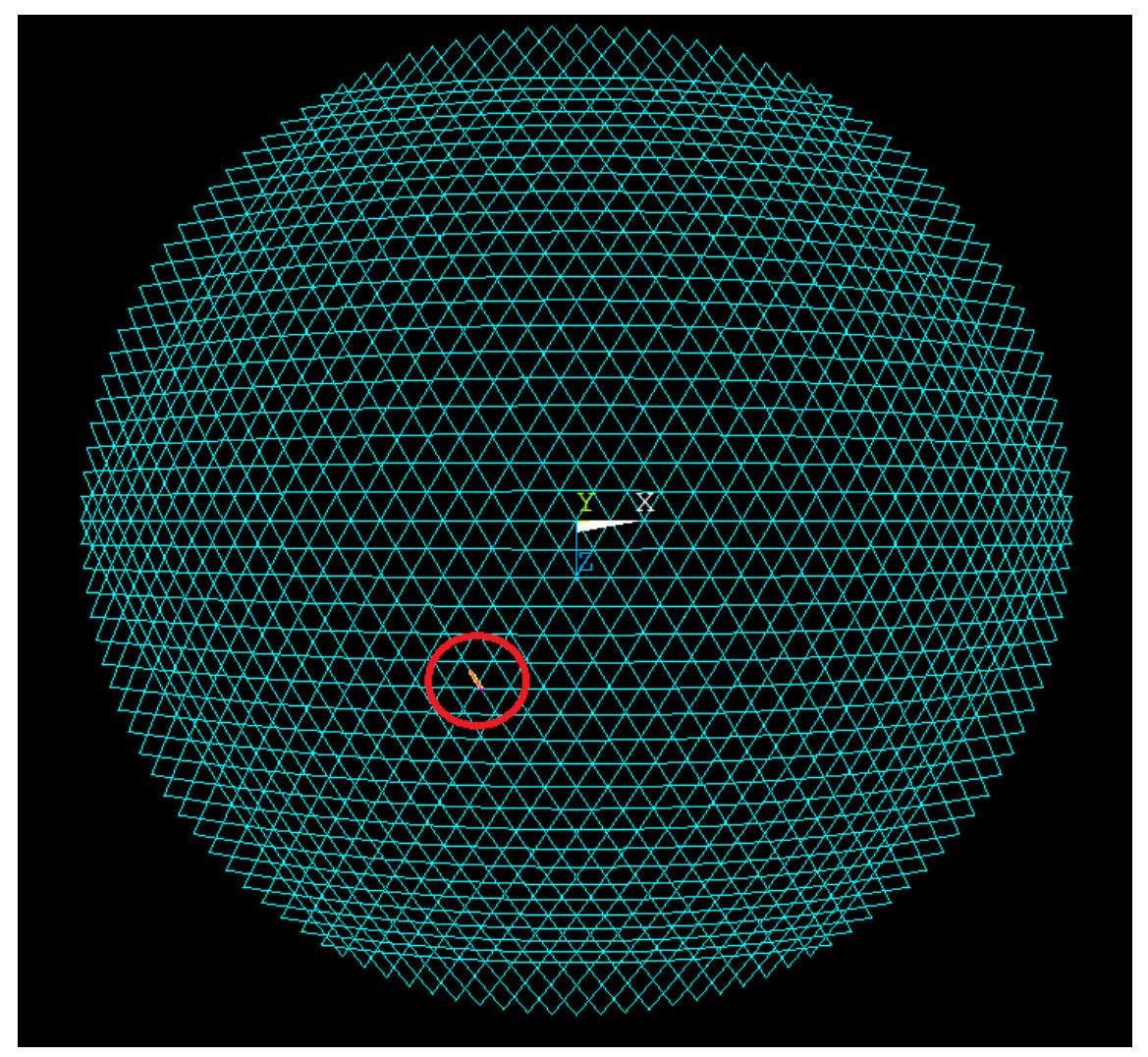

Figure 36- Location of the dome prestressing tendon that yields first in Model 2

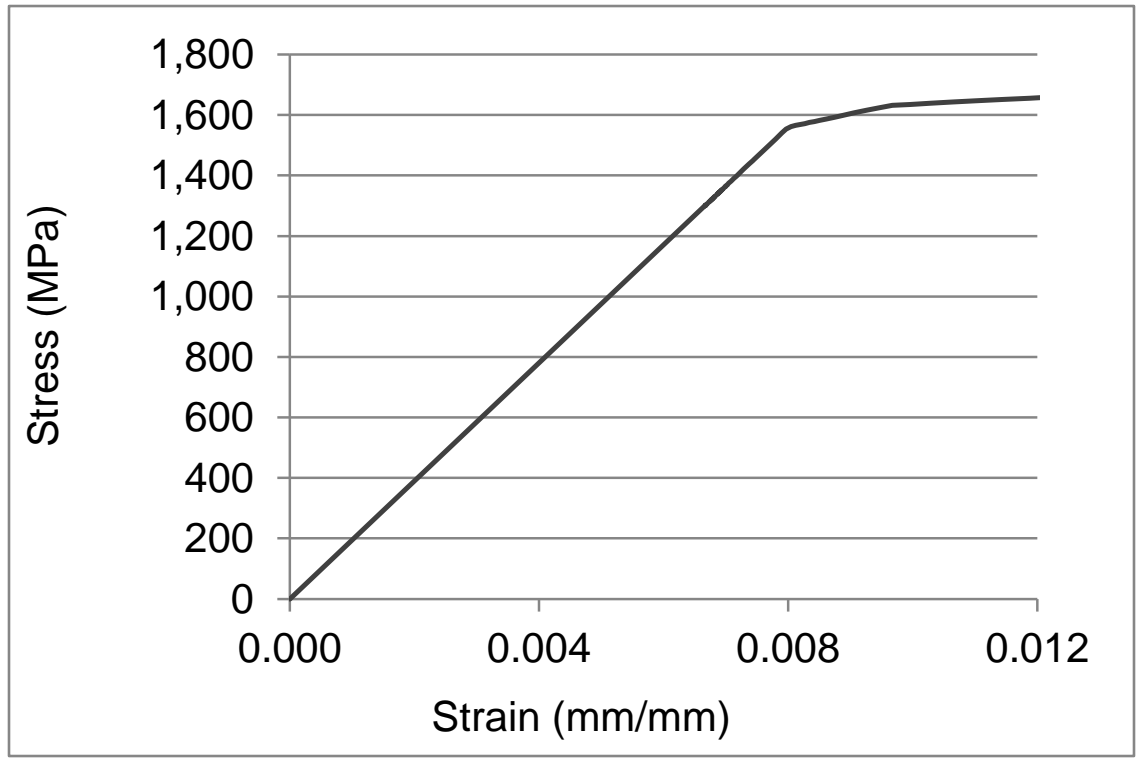

Figure 37- Stress-strain relationship for bar element 


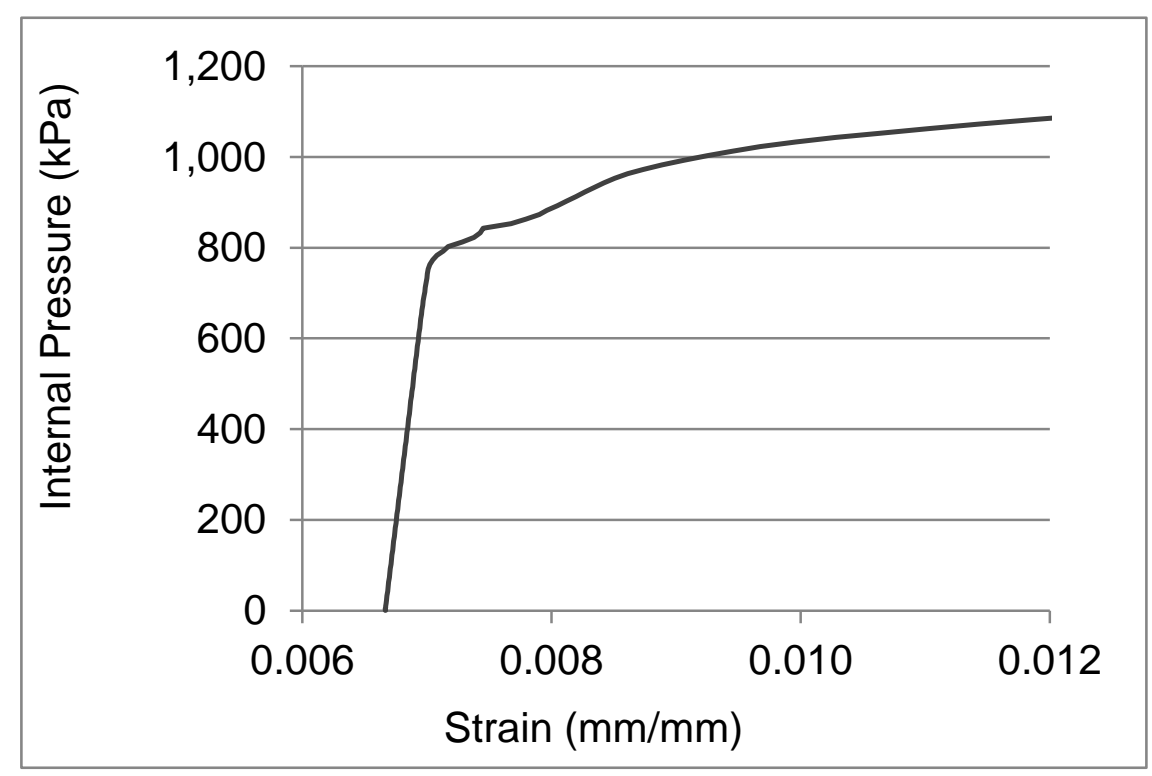

Figure 38- Internal pressure vs. strain in bar element

For Model 2, the vertical displacement of $120 \mathrm{~mm}$ at dome apex happens at internal pressure of $1030 \mathrm{kPa}$. In comparison with Model 1, the internal pressure is increased by $14 \%$ in Model 2.

\subsection{Summary}

In this chapter, two different models are prepared to compare different approaches to introduce the prestressing effects. For Model 1, the reinforcing steel and prestressing tendons are added as smeared reinforcement to concrete elements for both perimeter wall and the shallow dome. The effects of prestressing are added as equivalent pressure and tendon end forces.

For Model 2, bar elements are used for modelling the prestressing tendons. The major challenges for modelling prestressing tendon element are to accommodate parameters affecting prestressing forces. To introduce these critical changes, the discrete tendons elements are attached to concrete elements at coinciding nodes and the prestressing effects are added as an equivalent strain to the tendons in Model 2. This method is more appropriate in comparison to the equivalent force approach in the previous studies. This approach significantly increases the complexity of the problem; however, represent the 
most realistic modeling of the three layers of the prestressing system at the dome of the containment structure.

The response of the structure in the form of internal pressure versus normal displacement at dome apex is compared for the two approaches. It is concluded that using both models, the CS meets the design requirements for concrete containment structures and behaves linearly in excess of 1.5 times the design pressure of $400 \mathrm{kPa}$. For Model 2, the linear limit is 20 percent higher in comparison to Model 1 . The value of the pressure capacity is increased by 14 percent in comparison with the Model 1 .

It should be noted that in the smeared tendon model, as the effects of prestressing system is added as uniform pressure and tendons end forces of the CS, the non-uniform aspect of prestressing force distribution cannot be fully included in the model. As was mentioned before, the effects of horizontal tendons are added as a uniform pressure applied normal on the outer face of the wall. However, due to friction prestress loss, in reality the cables will not cause a uniform pressure on the wall. The three layers of dome tendons system are replaced with a uniform pressure applied normal on the outer face of the dome. However, due to geometry dependant nature of friction loss and anchorage set loss, the forces in the cables are not uniform along the length of the tendon.

It is concluded that the discrete model represent a more realistic model of the prestressing system. Using discrete model, the changes in the prestressing forces due to long-term and short-term losses can be added according to geometry of the tendons as explained in Chapter 6. 


\section{CHAPTER 6 EFFECTS OF PRESTRESSING LOSSES ON RESPONSE OF CONTAINMENT STRUCTURE}

\subsection{General}

The major challenges for modelling prestressing system are to accommodate parameters affecting prestressing forces. This includes: the geometry dependent changes along the tendon profile, changes due to incremental pressure and changes with time. In the current study, to introduce these critical changes, the discrete elements are used to model prestressing tendons. For discrete tendon elements, initial prestressing forces are addressed directly by an equivalent strain on each tendon element.

Using the discrete elements, the tendon layout is modelled as close as possible to the designed layout and enables the model to capture the most accurate results of the prestressing system. This approach significantly increases the complexity of the modelling; however, it represents the most realistic modeling of the unsymmetrical tendon layout of the dome as well as of the perimeter wall.

In the current chapter, analytical calculation of prestress losses, introduction of prestress losses in the FEM and detailed pressure analysis are presented for a model prepared with discrete tendon elements.

\subsection{Analytical Calculation of Prestress Losses}

Prestress losses in post-tensioned system are categorized as immediate and timedependent losses and both shall be considered in design of the containment structure.

According to N287.3 Clause 10.4 [1], special attention shall be given to the following:

a) the construction schedule and prestressing sequences for determining prestressing losses; 
b) the friction losses based on experimentally determined wobble and curvature coefficients and verified during stressing operations; and

c) the exposure conditions such as temperature and humidity.

The calculations of short-term and long-term losses are explained as follows based on methodology in references [21] and [32].

\subsubsection{Short-Term Losses}

\subsubsection{Elastic Shortening of Concrete}

In the calculations of the elastic shortening of concrete the maximum stress in concrete immediately after prestress transfer can be used conservatively. Also, the number of tendons that can create the full elastic shortening effect on each other, $n$, can be assumed to be the total number of tendons for each group of tendons.

Elastic shortening loss for tendon [5]:

$$
\Delta f_{p}=\frac{n-1}{2 n} \times \frac{E_{P}}{E_{c}} \times \frac{f_{p i} \cdot A_{p}}{t . s}
$$

$n=$ total number of posttensioning tendons for wall or ring beam;

$E_{P}=$ modulus of elasticity of tendon;

$E_{c}=$ modulus of elasticity of concrete;

$f_{P i}=$ stress in tendon right after transfer of prestressing forces,

$f_{P i}=\min \left(0.82 f_{P y}, 0.74 f_{P u}\right)[1] ;$

$f_{P y}=$ yield stress of prestressing tendon;

$f_{P u}=$ ultimate stress of prestressing tendon;

$A_{P}=$ Area of prestressing tendon;

$t=$ depth or thickness of the section; and 
$S=$ spacing of tendons.

\subsubsection{Loss due to Friction}

When a tendon is tensioned by a jack, in an unbounded tendon, the force produced is not constant along the length due to friction between the tendon and the duct. The change in prestressing forces is caused because of the curvature frictional loss and the wobble frictional loss, as are shown in Figure 39(a) and Figure 39(b), respectively [21].

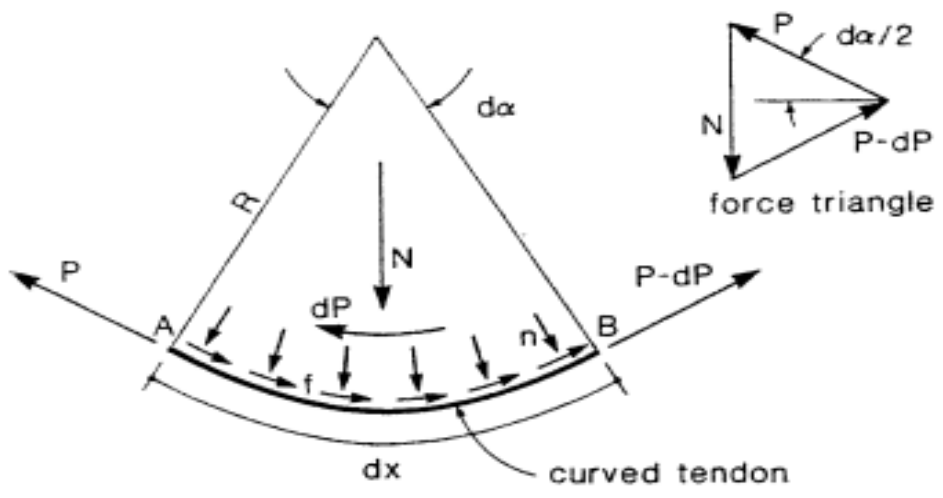

(a)

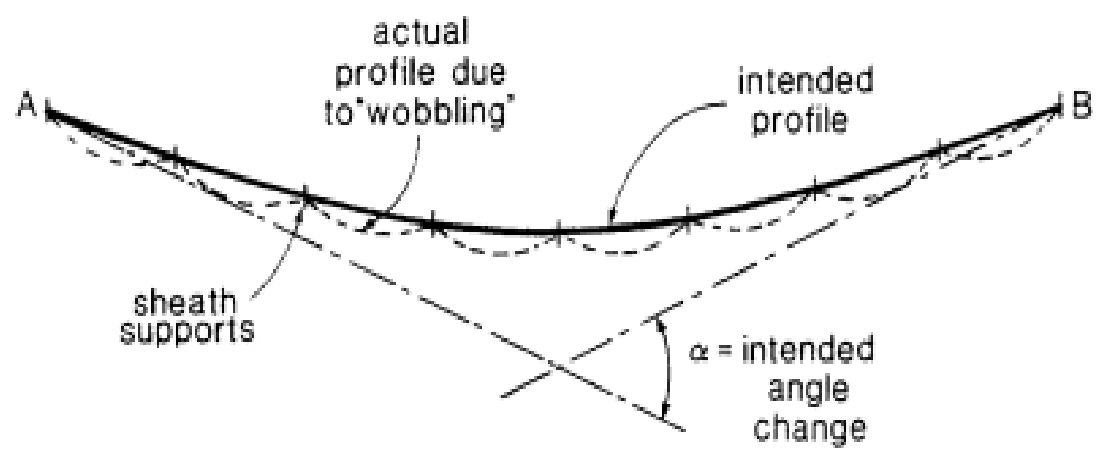

(b)

Figure 39- Frictional loss: (a) Curvature friction, (b) Wobble frictional (source: [21]) 
During stressing, the prestress loss at location $x$, along the tendon is given by Equation (26) [21]:

$$
\left(\Delta f_{p}, x\right)=f_{p j} \times\left[1-e^{-\mu(\alpha)-K(l)}\right]
$$

$f_{p j}=$ Jacking stress;

$\alpha=$ intended angle change;

$l=$ distance from anchorage;

$\mu=$ curvature friction coefficient of tendons; and

$\mathrm{k}=$ wobble friction coefficient of tendons.

\subsubsection{Loss to Anchorage Seating}

Moreover, the posttensioning system will result in additional losses in prestressing forces due to setting of the wedges at the anchorage. The length of the tendon affected by anchorage set is a function of the friction loss and can be calculated as follows:

Friction loss for a single tendon [21]:

$$
\left(\Delta f_{p}, x\right)=f_{p j} \times\left[1-e^{-\mu(\alpha)-K(l)}\right]
$$

$f_{p j}=$ Jacking stress;

$\alpha=$ intended angle change;

$l=$ distance from anchorage;

$\mu=$ curvature friction coefficient of tendons; and

$\mathrm{k}=$ wobble friction coefficient of tendons.

This is found by iterative procedure to satisfy: 


$$
\int_{0}^{l_{s e t}}\left(\Delta f_{p}, x\right) \cdot d x=E_{p} \cdot \Delta_{\text {set }} \rightarrow l_{\text {set }} \text { is found }
$$

$l_{s e t}=$ length of the tendon affected by anchorage set.

For $x \leq l_{\text {set }}$, total loss: (including friction loss and anchorage set loss)

$$
\left(\Delta f_{P-T}, x\right)=\left(\Delta f_{p}, x\right)-\left(\Delta f_{p}, l_{s e t}\right) \times \frac{l_{\text {set }}-l}{l_{\text {set }}}
$$

$l=$ distance to anchorage at location $\mathrm{x}$.

\subsubsection{Long-Term Losses}

\subsubsection{Tendon Relaxation}

Loss due to tendon relaxation can be found as follows [21]:

$$
\Delta f_{p}=f_{p i} \times \frac{\log \left(t_{\text {end }}-t_{p t}\right)}{45} \times\left(\frac{f_{p i}}{f_{p y}}-0.55\right)
$$

$t_{\text {end }}=$ time at the end of plant life;

$t_{p t}=$ elapsed time at prestressing;

$f_{p i}=$ stress in prestressing tendon immediately after prestress transfer; and $f_{p y}=$ yield stress of prestressing tendon. 


\subsubsection{Concrete Shrinkage}

It should be noted that at present the empirical formula given by reference [32] is widely used to predict shrinkage strain. Comparison of different models available to predict creep and shrinkage strain of concrete is available in reference [33]. Prestress loss due to concrete shrinkage can be calculated using Equation (31) to Equation (37) as follows [32]:

$\gamma_{R H}=\mid \begin{array}{clc}(1.4-0.0102 R H) & \text { if } & 40 \% \leq R H \leq 80 \% \\ (3-0.03 R H) & \text { if } & 80 \% \leq R H \leq 100 \%\end{array}$

Equation (31)

$\gamma_{R H}=$ correction factor for relative humidity greater than $40 \%$.

$\gamma_{v s}=\mid \begin{array}{cll}1.2 e^{\left(-0.00472 \text { ratio }_{-} s\right)} & \text { if } & \text { ratio_ } v s \leq 254 \mathrm{~mm} \\ 0.36 & \text { if } & \text { ratio_ } v s>254 \mathrm{~mm}\end{array}$

Equation (32)

$\gamma_{v s}=$ correction factor for volume to surface ratio other than $38 \mathrm{~mm}$.

$\varepsilon_{S H_{-} u}=780 \times 10^{-6} \gamma_{R H} \gamma_{v s}$

Equation (33)

$\varepsilon_{S H_{-} u}=$ ultimate shrinkage strain.

$\varepsilon_{S H_{-} e n d}=\varepsilon_{S H_{-} u} \frac{t_{\text {end }}-t_{c p}-7}{35+t_{\text {end }}-t_{c p}-7}$

Equation (34)

$\varepsilon_{S H_{-} \text {end }}=$ shrinkage strain at end of plant life.

$\varepsilon_{S H_{-} p t}=\varepsilon_{S H_{-} u} \frac{t_{p t}-t_{c p}-7}{35+t_{p t}-t_{c p}-7}$

Equation (35) 
$\varepsilon_{S H_{-} p t}=$ shrinkage strain at time of prestressing;

$t_{e n d}=$ elapsed time at end of plant life;

$t_{p t}=$ elapsed time at prestressing of; and

$t_{c p}=$ elapsed time at concrete pouring.

Shrinkage strain between the time of prestressing and the end of plant life:

$$
\varepsilon_{S H_{-} \text {send }}=\varepsilon_{S H_{-} e n d}-\varepsilon_{S H_{-} p t}
$$

Shrinkage loss:

$$
\Delta f_{p_{-} \text {shrnkage }}=\varepsilon_{S H_{-} \Delta e n d} E_{p}
$$

\subsubsection{Concrete Creep}

Prestress loss due to creep in concrete can be calculated based on requirements of references [21] and [32] using Equation (38) to Equation (44) as follows:

$$
\gamma_{R H}=1.21-0.0067 R H
$$

$\gamma_{R H}=$ Correction factor for relative humidity greater than $40 \%$; and

$\mathrm{RH}=$ relative humidity.

$$
\gamma_{v s}=\frac{2}{3} \cdot\left[1+1.13 e^{(-0.0213 \text { ratio_vs })}\right]
$$

$\gamma_{v s}=$ Correction factor for volume to surface ratio other than $38 \mathrm{~mm}$; and ratio_vs = volume to surface ratio. 
$\gamma_{l a}=1.25\left(t_{p t}-t_{c p}\right)^{-0.118}$

Equation (40)

$\gamma_{l a}=$ Correction factor for ages at application of load greater than 7 days for moist cured concrete or greater than I to 3 days for steam-cure;

$t_{p t}=$ elapsed time at prestressing; and

$t_{c p}=$ elapsed time at concrete pouring.

$C_{\text {ultimate }}=2.35 \gamma_{R H} \gamma_{v s} \gamma_{l o}$

Equation (41)

where:

$C_{\text {ultimate }}=$ ultimate creep coefficient.

$C_{t_{-} \text {end }}=C_{\text {ultimate }} \frac{\left(t_{\text {end }}-t_{p t}\right)^{0.6}}{10+\left(t_{\text {end }}-t_{p t}\right)^{0.6}}$

Equation (42)

$C_{t_{-} \text {end }}=$ creep coefficient at end of plant life;

$t_{\text {end }}=$ elapsed time at end of plant life;

$t_{p t}=$ elapsed time at prestressing of; and

$t_{c p}=$ elapsed time at concrete pouring.

Creep loss for wall:

$\Delta f_{p_{-} c r}=C_{t_{-} \text {end }} \frac{E_{p}}{E_{c}} \cdot \frac{F}{t}$

Equation (43)

$E_{P}=$ modulus of elasticity of tendon;

$E_{c}=$ modulus of elasticity of concrete; 
$t=$ depth or thickness of the section; and

$F=$ force per unit length after short-term losses.

Creep loss for dome:

$$
\Delta f_{p_{-} c r}=C_{t_{-} \text {end }} \frac{E_{p}}{E_{c}} \cdot \frac{P_{e q}}{2 t} \cdot R_{d}
$$

$E_{P}=$ modulus of elasticity of tendon;

$E_{c}=$ modulus of elasticity of concrete;

$t=$ depth or thickness of the dome;

$R_{d}=$ radius of the middle layer of dome tendons; and

$P_{e q}=$ pressure equivalent of prestressing after short-term losses.

\subsection{Modelling of the Containment Structure}

\subsubsection{Containment Geometry}

The geometry and material properties of the containment structure is similar to those explained in Chapter 3.

In internally pressurized containment structures, sources of non-axisymmetric behavior include; dome tendon layout, wall horizontal tendon buttresses and major openings. All the mentioned factors directly affect the deformed shape of the structure after transfer of prestressing forces as well as the stress distribution. These factors cannot be introduced if the CS is represented by an axisymmetric finite element model, or by a 3-dimensional repeating sector. To capture a more accurate behaviour of the CS, full 3D finite element model is prepared in the current study. The model in the current chapter includes the nonaxisymmetric tendon layout, tendon buttresses, but ignoring presence of openings. 
Moreover, the non-uniform variation of prestressing forces along the length of tendon affects stress distribution in CS. Prestressing tendons are modelled with discrete bar elements in both models, and the effects of prestressing system are added directly as initial strain to the bar elements. This approach enabled the capability of the model to accommodate non-uniform prestressing force distribution by adding additional script to the program.

In most of preceding numerical studies, the prestressing tendons are modelled as smeared reinforcement or shell layers, and the effects of prestressing system are modelled using an equivalent approach. In those studies, the non-uniform prestressing losses are not fully considered.

\subsubsection{Material Model Selection}

The structural materials used in the containment can be divided into three groups, which are non-prestressing steel bars, prestressing tendons and concrete.

As the strain limit for pressure capacity defined by reference [1] for reinforcing steel is within the yield zone of the stress-strain curve of this material, an elasto-perfectly-plastic behaviour is used for the stress/strain curve of the reinforcing bar. An elasto-perfectlyplastic behaviour is also used for the stress/strain curve of prestressing tendons.

To model the plastic behavior and large displacement for both non-prestressing steel bars and prestressing tendons, kinematic hardening model with von-Mises/Hill failure criterion is used. The isotropic properties for non-prestressing steel and prestressing tendon materials are defined as the modulus of elasticity and Poisson ratio.

The material properties of concrete are defined as follows:

$f_{\mathrm{c}}^{\prime}=50 \mathrm{MPa}$

$\mathrm{E}_{\mathrm{c}}=32,000 \mathrm{MPa}$
Specified 28-days concrete compressive strength; Secant modulus of elasticity of concrete; 
$\mathrm{V}_{\mathrm{c}}=0.15 \quad$ Poisson's ratio for concrete; and

$\alpha_{c}=10 \times 10^{-6}\left({ }^{\circ} \mathrm{C}\right)^{-1} \quad$ Coefficient of thermal expansion of concrete.

The tensile strength of the concrete is assumed as $5 \mathrm{MPa}$.

\subsubsection{Element Selection}

3D SOLID65 reinforced concrete elements are employed for reinforced concrete elements. In the current chapter, the non-prestressing steel bars are modelled as smeared reinforcement and prestressing tendons are modelled with discrete elements. Link8 elements are used to model tendons which are uni-axial tension elements.

\subsubsection{Finite Element Mesh}

\subsubsection{Reinforced Concrete}

The perimeter wall is divided into 6 elements through the thickness and to 142 elements along the height. The hoop and meridional non-prestressing steel are introduced as smeared reinforcement to the first two concrete elements at inner face and two concrete elements at outer face of the wall. The shear reinforcing steels are added as smeared reinforcement to all the elements for the PW.

The dome of the containment structure is divided into six elements in thickness and 74 elements along the arc of the dome. Meridional, hoop and shear reinforcement are modelled as smeared reinforcement for the dome. The smeared meridional and hoop reinforcement are added to the first two elements at inner face of the dome and the two elements at outer face of the dome. Figure 40(a) shows the finite elements for reinforced concrete for the wall, the dome as well as the ring beam. 


\subsubsection{Prestressing Tendons}

For the perimeter wall, 124 lines corresponding to the perimeter wall meridional cables are added with distance of $750 \mathrm{~mm}$ to interior surface and spacing of $1088 \mathrm{~mm}$. Also, horizontal tendons are modelled with distance of $1250 \mathrm{~mm}$ to interior surface of the perimeter wall. The finite element model also includes four buttresses at $90^{\circ}$ intervals at which the horizontal tendons are anchored. Bar elements are connected at both ends to alternate buttresses meaning that each tendon has an angular length just above $180^{\circ}$. Vertical spacing of the horizontal tendons in the FEM is $600 \mathrm{~mm}$.

For the dome, tendons are placed in three layers which are at $120^{\circ}$ orientation with respect to each other. All the tendons in one layer have the same center and radius of curvature. All the lines representing the tendons are fixed from both ends to the vertical exterior side of the ring beam. Distance of the middle layer of the tendons in dome to interior surface of the containment is $550 \mathrm{~mm}$. The distance of each layer of the tendon from each other is $135 \mathrm{~mm}$. The average spacing of the tendons in the FEM at the dome apex is $1100 \mathrm{~mm}$, which is $916 \mathrm{~mm}$ in the CS itself. An equivalent tendon cross-sectional area is calculated to account for this change in the FEM.

To model the bond between the concrete and the prestressing tendons, nodes of the bar elements are coupled with the coinciding or neighboring nodes of the concrete elements. It should be noted that these nodes are assumed $100 \%$ coupled.

Figure 40 (b) shows the finite elements for reinforced concrete for the wall, the dome as well as the ring beam.

To add the effects of prestressing forces, strains are applied directly on the bar elements. The applied strain for each of the prestressing tendons can be calculated according the jacking force or in-service force, and the properties of the tendons. 


$$
\text { Strain }=\frac{\text { pretrssing force }}{A_{P} \times E_{P}}
$$

where $A_{p}$ is the cross-sectional area of the tendon.

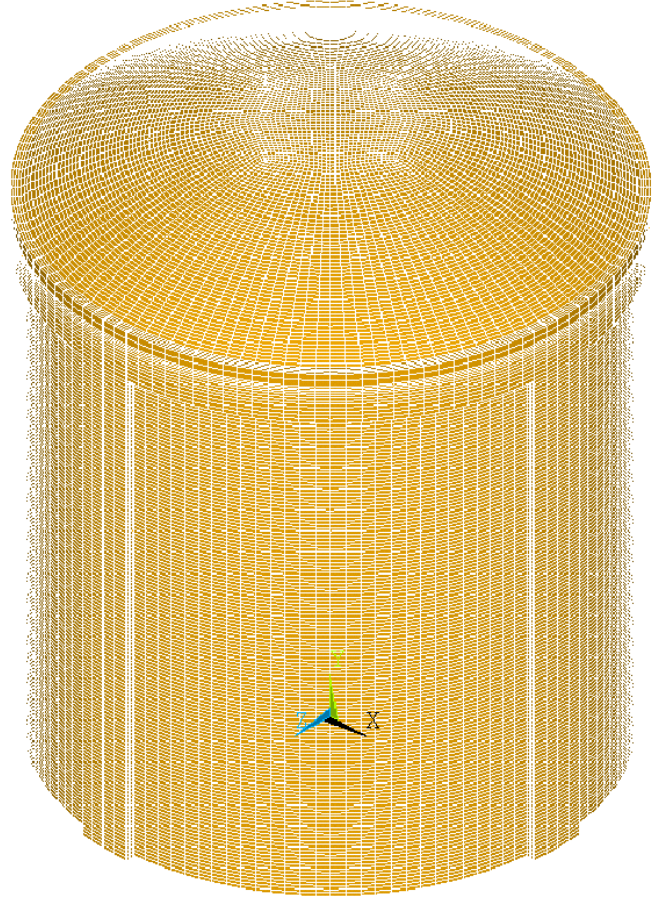

(a)

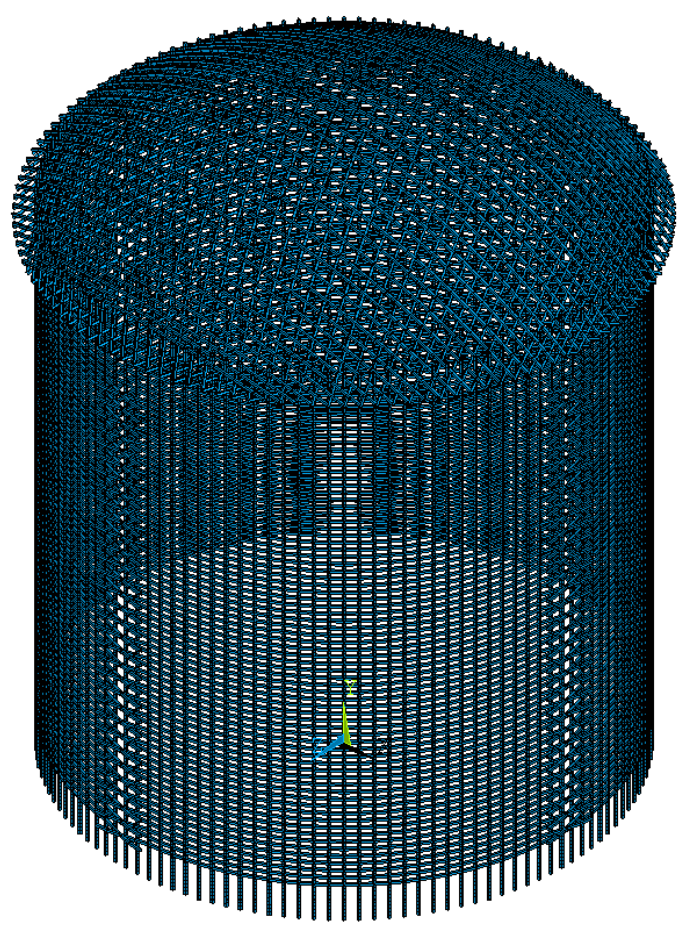

(b)

Figure 40- Finite elements: (a) reinforced concrete elements, (b) prestressing tendons

The primary strains in the tendon elements are first calculated based on the jacking force (primary strain), then, are updated based on the estimated prestressing losses (reduced strain).

The strain for the prestressing tendons at the wall, ring beam and dome is summarized below and calculated based on jacking forces.

PW horizontal tendon

PW vertical tendon
$7.4 \times 10^{-3} \mathrm{~mm} / \mathrm{mm}$

$6.7 \times 10^{-3} \mathrm{~mm} / \mathrm{mm}$ 
Ring beam tendons

Dome horizontal tendon
$7.4 \times 10^{-3} \mathrm{~mm} / \mathrm{mm}$

$7.6 \times 10^{-3} \mathrm{~mm} / \mathrm{mm}$

Similar to Chapter 5, to prevent any premature failure due to stress concentration at locations of anchorage, a $300 \mathrm{~mm}$ thick steel plate is added to the finite element model to simulate the anchorage system. 2-Dimensional (2D) solid45 elements are used to model the plate.

\subsection{Introducing Prestressing Losses to FEM}

As was mentioned before, the prestressing force can be added according to the jacking force or the in-service force. If the in-service force is used to calculate the initial strain in the tendon elements, the prestressing losses are taken as an average through the length of the tendon and the non-uniform geometry dependent prestressing losses cannot be included. In this chapter, the strains in the tendon elements are calculated based on the jacking forces (or jacking stresses). Then, they are updated based on the estimated prestressing losses.

The prestressing losses in tendons are categorized as immediate losses and timedependant losses. The immediate losses are elastic shortening of the concrete, anchorage set loss and friction loss in tendons and are non-uniform and geometry dependent. The time dependent losses are dependent on the material behaviour such as creep and shrinkage of the concrete and relaxation of the prestressing tendons. In the finite element model, the effects of elastic shortening of the concrete are introduced automatically after application of the prestressing forces. On the other hand, other losses are introduced by the user. 


\subsubsection{Geometry Dependent Losses}

\subsubsection{Friction Loss}

During stressing, the percentage of prestress loss at location $x$, along the tendon is given by Equation (46):

Friction loss $(x) \%=e^{-\sum(\mu \alpha+K l)}$

Equation (46)

In equation (5), $\mu$ and $\mathrm{K}$ are frictional coefficients [21]. Curvature coefficient and wobble coefficient for dome and wall tendons are summarized in Table 11.

Table 11- Frictional coefficients summary for the cables

\begin{tabular}{|l|c|c|}
\cline { 2 - 3 } \multicolumn{1}{c|}{} & Curvature friction & Wobble coefficient \\
\hline Perimeter wall horizontal tendon & 0.20 & $0.000 \mathrm{~m}^{-1}$ \\
\hline Perimeter wall vertical tendon & 0.18 & $0.000 \mathrm{~m}^{-1}$ \\
\hline Dome horizontal tendon & 0.18 & $0.010 \mathrm{~m}^{-1}$ \\
\hline
\end{tabular}

For each cable, the first node is set as the anchor. The distance from the anchor is calculated based on the distance from centroid of the element. $l$ in Equation (46), is the distance from centroid of each elements from centroid of the previous element, and to find the distance from anchor, the value of $l$ is added to that of previous elements. $\alpha$ in Equation (46) is the angle between the each tendon element and the previous element, and to calculate the intended angle change along the length of the cable, the value is added to the values of the previous elements.

To introduce the variation of the prestressing forces along the length of the tendon, additional scripts are added to the finite element program to change the prestressing force of each element according to its geometry. 
The variation of prestressing forces along the length of a typical dome tendon is shown in Figure 41. Forces are represented as percentage of jacking force considering frictional losses only. The location of the tendon subject of Figure 41, is shown in Figure 42. This cable is the longest cables at the dome and contributes to tendon layer1.

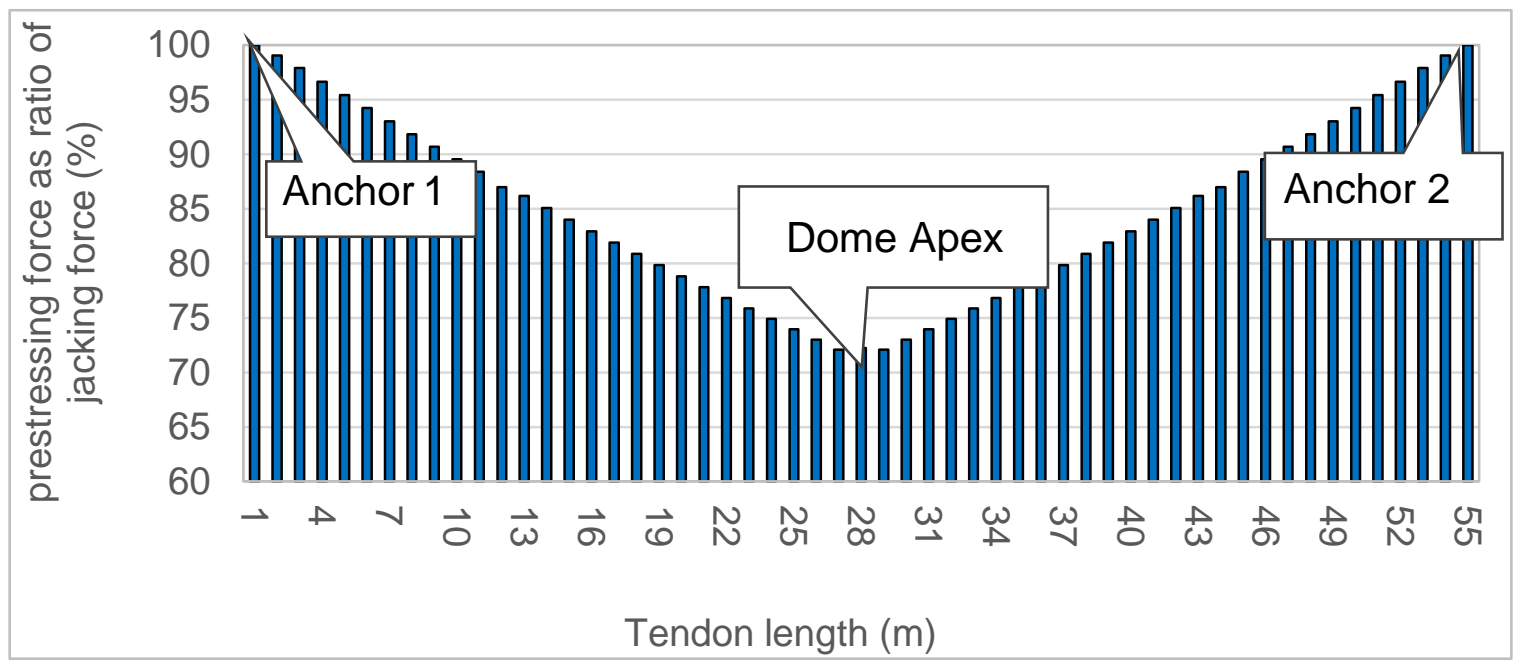

Figure 41- Prestressing force distribution along tendon length

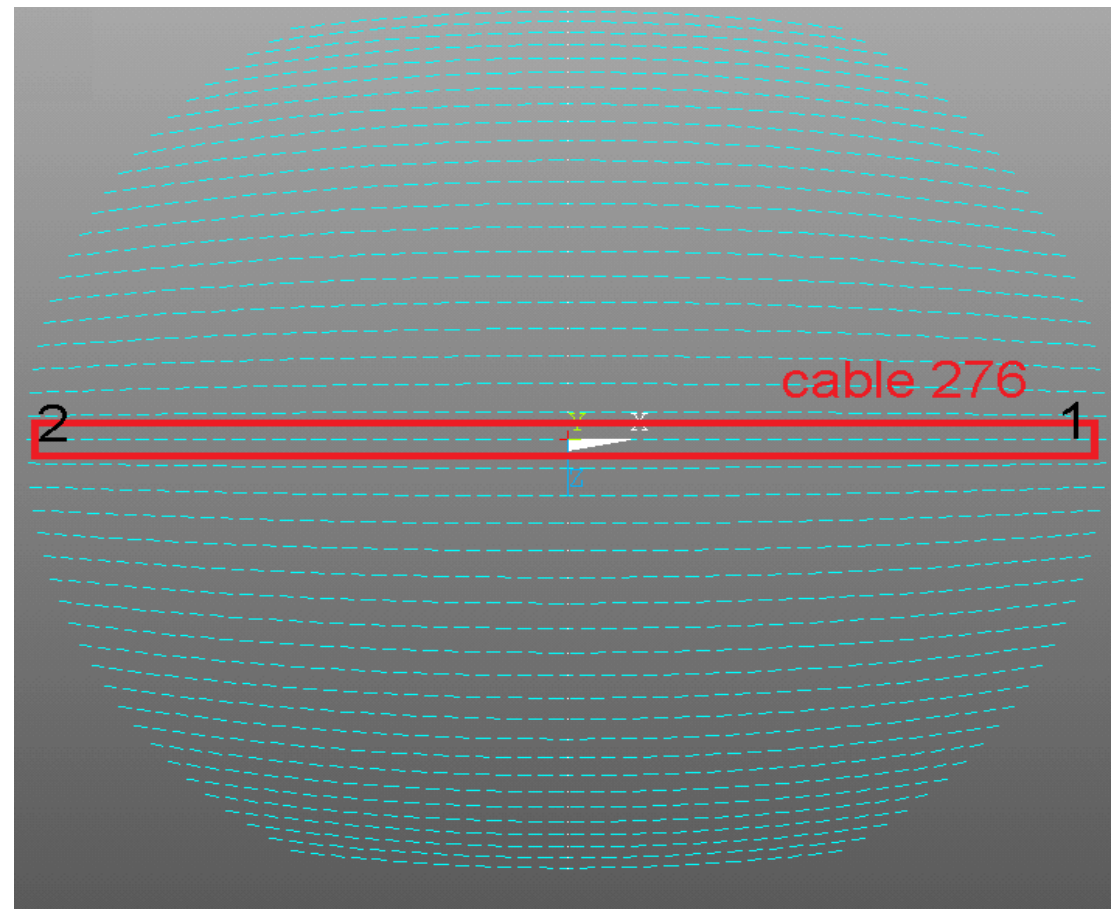

Figure 42- location of cable 276 
Similar approach is used to address friction loss for wall vertical tendons and horizontal tendons.

\subsubsection{Anchorage Seating Loss}

Moreover, the posttensioning system will result in additional losses in prestressing forces due to setting of the wedges at the anchorage. The length of the tendon affected by anchorage set is a function of the friction loss. If the friction is low, the length affected is larger. The effected length is calculated according to Equation (47) [21]:

$$
l_{\text {set }}=\sqrt{\frac{\Delta_{s e t} A_{p} E_{p}}{p}}
$$

where $p$ is the average prestressing force loss due to friction per unit length, $\Delta_{\text {set }}$ is the anchorage set. Values $p$ are calculated from finding of section 6.4.1.1. The anchorage set for this case is $6 \mathrm{~mm}$ and the effected length $\left(l_{\text {set }}\right)$ is $10 \mathrm{~m}, 9.5 \mathrm{~m}$ and $16 \mathrm{~m}$ for dome tendons, wall horizontal and vertical tendons, respectively.

Losses in prestressing forces due to setting of the wedges is also geometry dependent and is addressed by introducing a script to finite element program. If the distance of element centroid from anchor is larger than $l_{\text {set }}$, the total geometry dependant losses is same as friction loss. If the distance is smaller than $l_{\text {set }}$, then the percentage of the total geometry dependant loss at location $x$ along the tendon length is updated according to Equation (48) :

Geometry dependant loss $(x) \%=$ friction loss $(x) \% \times \frac{2 p}{\text { jacking froce }} *\left(l_{\text {set }}-x\right)$ Equation (48)

Reduced strain for each element is then obtained from Equation (49): 
When the amount of losses is calculated along the length of the tendon, the primary strain values are updated with the reduced strain for each element.

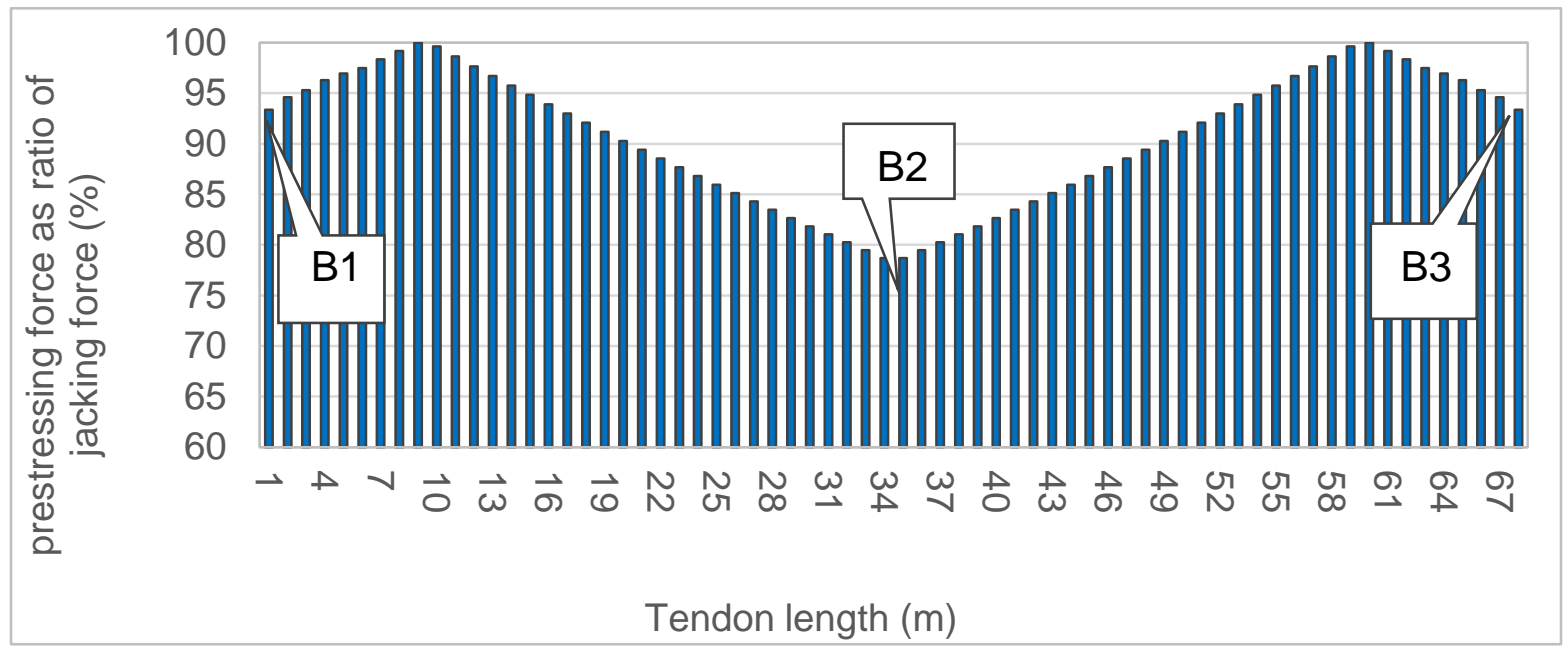

Figure 43- Variation of force in a typical wall horizontal tendon (Group1)

The variation of prestressing force as percentage of jacking force along the length of a typical wall horizontal tendon, taking to account effects of both friction and anchorage set, is shown in Figure 43. The cable subject of Figure 43 contributes to wall horizontal tendon group1 and is the first cable starting from the base of the wall. It should be noted that the percentage of the tendon force to jacking force along the length of the cable is identical in all wall horizontal tendons, because the presence of the openings are ignored.

\subsubsection{Time Dependent Losses}

\subsubsection{Relaxation of Prestressing Tendons}

To introduce the time dependent prestressing force losses, a simplified approach is used in this study. Relaxation of the low relaxation tendons varies in an approximately linear function with the log of the time under stress. Relaxation of the steel is accounted by using 
a reduced stiffness of the steel, $E_{p, \text { eff. }}$ The reduced stiffness is calculated from Equation (50).

$$
E_{p, e f f}=\left[1-\frac{\log t}{45}\left(\frac{f_{p i}}{f_{p y}}-0.55\right)\right] E_{p}
$$

where $t$ is the time under loads in hours, $f_{p i}$ and $f_{p y}$ are the initial stress and the yield stress of the tendon [21].

For this study, the long term losses are calculated at the end of plant life 60 years. Comparison of the stress-strain curve for the prestressing tendons at the time of prestressing and at the end of plant life is shown in Figure 44.

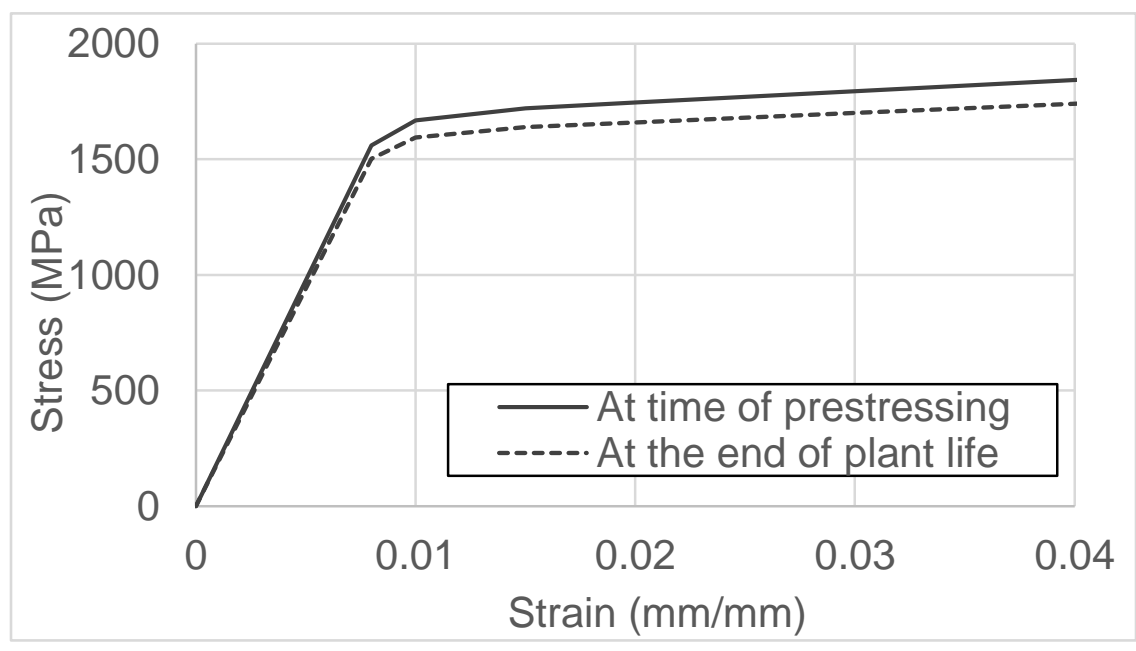

Figure 44 - Prestressing tendon material properties in time

\subsubsection{Creep in Concrete}

The mechanical behaviour of the concrete in compression depends on the rate of loading and time history of loading. If the stress is held constant for some length of time, the strain increases. If the containment is left under prestressing forces, creep of concrete will result in changes of behaviour of the structure with time. The effect of creep is accounted by reducing the initial stiffness of concrete on the stress strain curve. 
Creep coefficient at the end of plant life, $C_{t_{-} e n d}$, is calculated according to Equation (51):

$$
C_{t_{\_} \text {end }}=\frac{\left(t_{\text {end }}-t_{p t}\right)^{0.6}}{10+\left(t_{\text {end }}-t_{p t}\right)^{0.6}} \times 2.35 \gamma_{l a} \times \gamma_{R H} \times \gamma_{v s}
$$

where:

$\gamma_{l a}=$ correction factor for lading age later than 7 days Equation (40);

$\gamma_{R H}=$ correction factor for relative humidity greater than $40 \%$ Equation (38);

$\gamma_{v s}=$ correction factor for volume to surface ratio other than $38 \mathrm{~mm}$ Equation (39);

$t_{p t}=$ the loading age; and

$t_{\text {end }}=$ time at the end of plant life.

In addition to Equation (38) to Equation (40), Equation (52) and Equation (53) are required to calculate creep coefficient at the end of plant life Equation (52):

For the cylindrical wall:

$$
\operatorname{ratio}_{v S}=\frac{\pi\left((r+d)^{2}-r^{2}\right)}{2 \pi(r+d)}
$$

$r=$ inner radius of the wall; and

$\mathrm{d}=$ depth of the wall.

For the dome:

$$
\text { ratio }_{v s}=\frac{\frac{4 \pi}{3}\left((r+d)^{3}-r^{3}\right)}{4 \pi(r+d)^{2}}
$$

$r=$ inner radius of the dome; and

$d=$ depth of the dome. 
Effective stiffness $\left(E_{c, \text { eff }}\right)$ at time $t_{\text {end }}$ (at the end of plant), is $E_{c, \text { eff }}=\frac{E_{c i}}{1+C_{t_{-} \text {end }}}$ [21] and [32].

The values used to calculate the effective stiffness are summarized in Table 12 and Table 13 , for the wall and the dome, respectively. As an average, the creep coefficient is taken as 0.88. Comparison of the stress-strain curve for the prestressing tendons at the time of prestressing and at the end of plant life is shown in Figure 45.

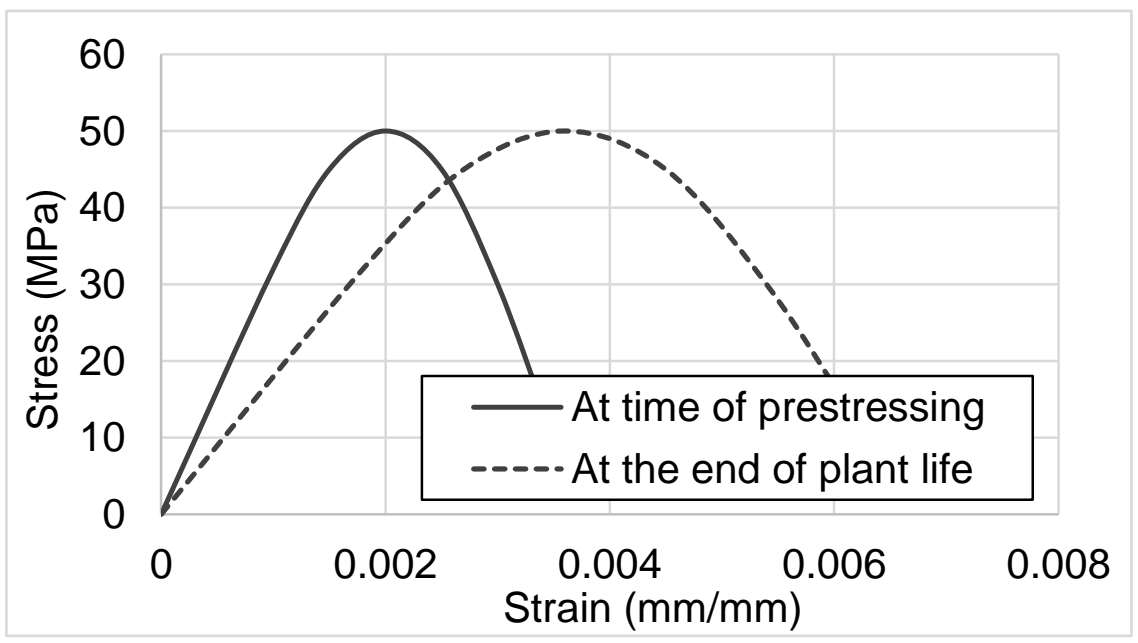

Figure 45- Concrete material properties

Table 12- Values for calculation of concrete creep for the cylindrical wall

\begin{tabular}{|l|c|}
\hline Correction factor for relative humidity greater than $40 \%$ & 0.83 \\
\hline Volume surface ratio & $1.45 \mathrm{~m}$ \\
\hline Correction factor for volume-to-surface ratio greater than $38 \mathrm{~mm}$ & 0.67 \\
\hline Correction factor for loading age later than 7 days & 0.70 \\
\hline Creep coefficient at the end of plant life & 0.89 \\
\hline
\end{tabular}

Table 13-Values for calculation of concrete creep for the dome

\begin{tabular}{|l|c|}
\hline Correction factor for relative humidity greater than $40 \%$ & 0.83 \\
\hline Volume surface ratio & $1.07 \mathrm{~m}$ \\
\hline Correction factor for volume-to-surface ratio greater than $38 \mathrm{~mm}$ & 0.67 \\
\hline Correction factor for loading age later than 7 days & 0.70 \\
\hline Creep coefficient at the end of plant life & 0.88 \\
\hline
\end{tabular}




\subsubsection{Shrinkage in Concrete}

Shrinkage is a time-dependent moisture loss and as a result of this process, the volume of concrete is reduced. A simplified approach is used to account for shrinkage of concrete in the FE model. An equivalent negative temperature is applied on the concrete volume which is calculated according to Equation (54) [21] and [32].

$$
\varepsilon_{s h}=\gamma_{v S} \times \gamma_{R H} \times\left(\frac{\left(t_{\text {end }}-t_{c p}-7\right)}{35+\left(t_{\text {end }}-7\right)}\right) 0.78 \times 10^{-3}
$$

$\gamma_{v s}=$ correction factor for volume surface ratio Equation (32);

$\gamma_{R H}=$ correction factor for relative humidity greater than $40 \%$ Equation (31);

$t_{\text {end }}=$ time at the end of plant life; and

$t_{c p}=$ time at the concrete pouring.

For both dome and the cylindrical wall, correction factors for relative humidity and volumeto-surface ratio and are taken as 0.74 and 0.36 , respectively.

Shrinkage strain is calculated according the shrinkage between the time of prestressing and at the end of plant life. The shrinkage strains are $43.06 \times 10^{-6}$ and $38.84 \times 10^{-6}$ for the perimeter wall and the dome, respectively.

An equivalent negative temperature is applied on the concrete volume which is calculated according to Equation (55).

$$
\Delta T=\frac{-\varepsilon_{s h}}{\alpha}
$$

where $\alpha$ is the coefficient of thermal expansion for concrete. 


\subsection{Numerical Analysis}

\subsubsection{Analysis of the Containment under Internal Pressure}

Similarly, the analysis of the containment structure is conducted considering; dead loads, prestressing forces, and internal pressure. The CS model was loaded with a static internal pressure that increased incrementally.

For first step of analysis, a static analysis is conducted to apply the self-weight of the structure. For the next step, the prestressing effects are applied by adding an initial strain to the prestressing tendon elements as a separate load step. After application of static loads and prestressing forces, a uniform internal pressure is applied to the entire internal surface of the containment up to failure. The transient nature of the internal pressure is ignored as its period is much longer than that of the structure.

A static nonlinear finite element analysis is conducted to estimate ultimate pressure capacity of the CS. Because of small displacement in concrete, geometry non-linearity or thinning of the wall need not to be accommodated in the model. It should be noted that the full Newton-Raphson method of analysis is used to compute the nonlinear response. The Newton-Raphson method is an iterative process of solving the nonlinear equations. This method updates the stiffness matrix at each iteration. As a result, the load is applied incrementally to the structure up to the failure.

\subsubsection{Failure Criteria}

Determining failure of the containment requires monitoring the concrete, reinforcing bars, and tendons closely. A strain-based failure criterion was selected and applied to the reinforcing bars and tendons. The strain-based failure is reached when the calculated strains exceed the following strain limits [1]:

1. Total tensile average strain in tendons away from discontinuities of 0.8 percent;

2. Global free-field strain for reinforcing steel of 0.4 percent. 
At ultimate pressure capacity, the CS loses its structural integrity due to crushing of the concrete or rupture of prestressing tendon.

\subsection{Results and Discussion}

\subsubsection{Overall Behaviour of the Containment Structure}

The following definitions are used to define the cracking directions for the wall: a horizontal crack is caused principally by meridional stresses and a vertical crack by hoop stresses. For the dome: a hoop crack is caused principally by radial stresses and a radial crack by hoop stresses.

The response of the containment structure under the described loading is summarized as follows:

1. After application of all prestressing forces including long-term and short-term losses, the dome of the containment structure has a downward deformation of 33 $\mathrm{mm}$. Perimeter wall also has an inward deformation of $16 \mathrm{~mm}$. Deformed shape of the containment structure after application of prestressing forces is shown in Figure 46.

2. With increase of internal pressure, dome starts to undergo upward deformation and the PW an outward deformation. The decompression internal pressure for the containment structure is around $750 \mathrm{kPa}$. At internal pressure of $124 \mathrm{kPa}$, corresponding to LOCA with total loss of dousing, the maximum concrete tensile stresses in the dome and the perimeter wall are $4.5 \mathrm{MPa}$ and $3.4 \mathrm{MPa}$, respectively, and both are lower than the tensile strength of the concrete $(5 \mathrm{MPa})$.

3. Except locally at the inside face at lower elevation of the dome, there are no cracks in the containment at a pressure of $670 \mathrm{kPa}$. These cracks spread rapidly along the face of the dome at pressure of $770 \mathrm{kPa}$. While these cracks are propagating 
into the thickness, they never reach the outside face where a narrow compressive region persists all along the pressure capacity analysis of the containment.

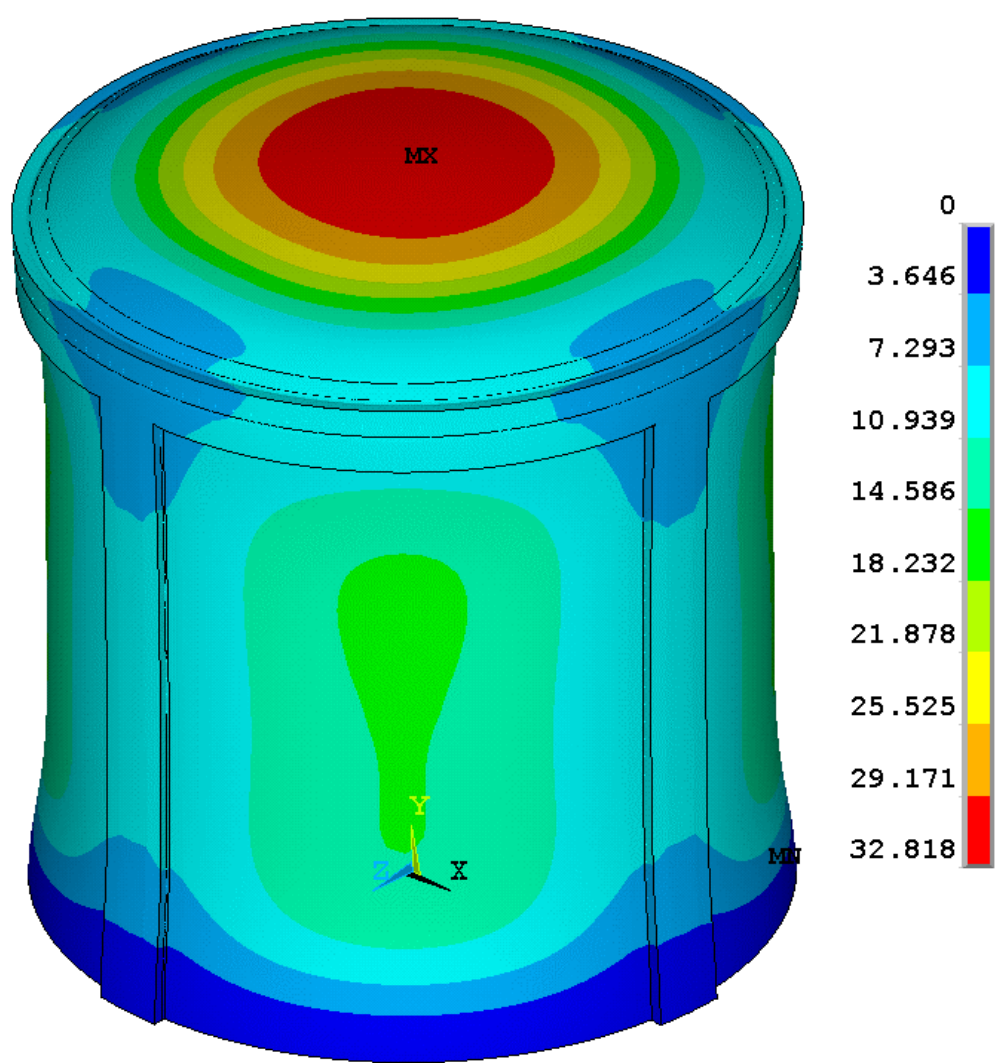

Figure 46- Deformed shape of the CS: Internal pressure $=0$

4. The first through-crack, initiates from the outside face and caused by the radial stresses, occurs in the dome at $830 \mathrm{kPa}$. These cracks are located close to the dome apex.

By increasing the pressure from $830 \mathrm{kPa}$ to $930 \mathrm{kPa}$ a critical point in the global behaviour of the containment is reached. The dome cracks first due to the hoop stresses, and a secondary quasi-generalized meridional cracking pattern develop over the entire dome, except at the outside face of the dome springing. 
At pressure of $830 \mathrm{kPa}$, vertical cracking develop at the top and bottom of the perimeter wall. These cracks initiate close to the buttresses. At internal pressure of $930 \mathrm{kPa}$ vertical cracks develop over the entire height. Moreover, additional cracks initiate at the base of the wall between the buttresses due to meridional stresses.

At $1040 \mathrm{kPa}$, the wall crack pattern progress towards the base, except at the immediate connection of the buttress and the base at outer face.

5. The reinforcing steel first yields at internal pressure of $830 \mathrm{kPa}$ in radial direction at the inner face, at lower level of the dome and near dome apex.

Further, at $930 \mathrm{kPa}$ the reinforcing steel yields in both directions at the crown of the dome.

Near $1008 \mathrm{kPa}$, the dome is fully cracked in all directions. The reinforcing steel yields and only the prestressing cables contribute to the ultimate strength.

Between pressure of $964 \mathrm{kPa}$ and $1040 \mathrm{kPa}$, hoop reinforcements of the $\mathrm{PW}$ yield. These elements are located close to buttress.

6. At $1070 \mathrm{kPa}$, a prestressing tendon at dome ruptures. This element is located at middle layer of prestressing tendons and is located at lower elevation of the dome. The yielding of this tendon initiates at pressure of $930 \mathrm{kPa}$.

The responses of the containment structure are shown in Figure 47 and Figure 48 in the form of the internal pressure versus normal displacement at the dome and at the wall, respectively. It should be noted that the positive normal displacement at dome apex is upward deformation and positive normal displacement at wall mid-height is an outward deformation. 


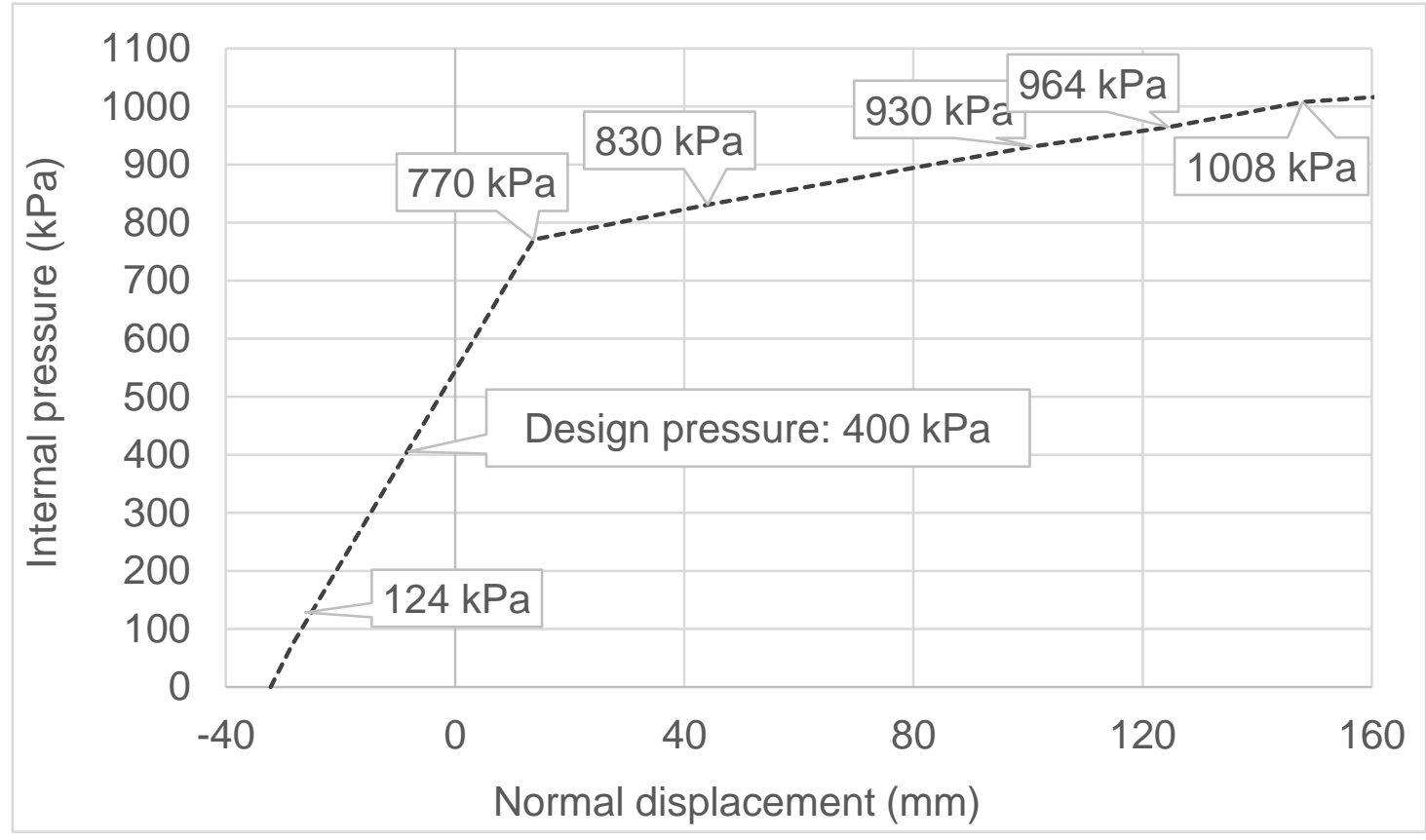

Figure 47- Internal pressure vs. normal displacement at dome apex

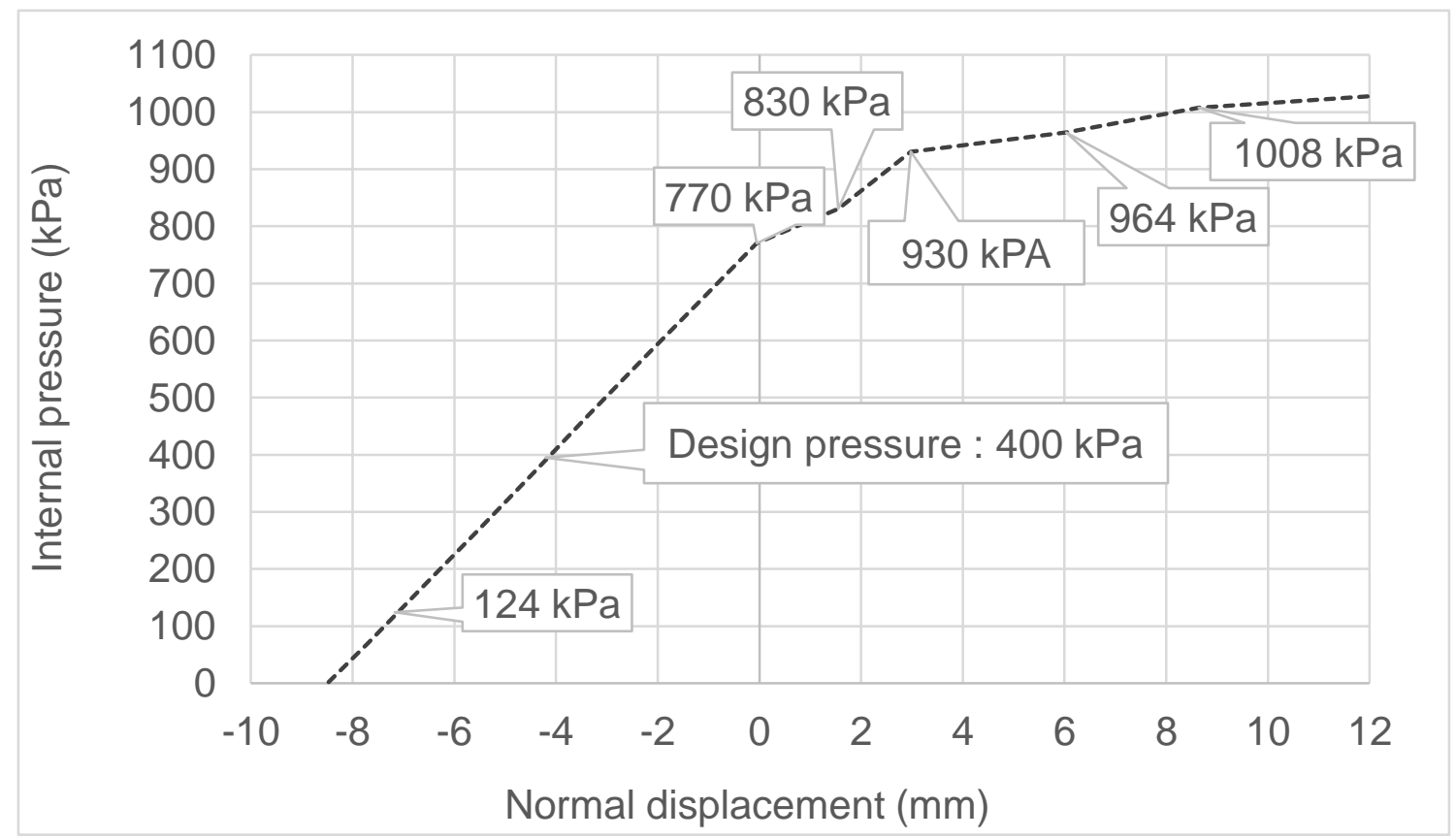

Figure 48- Internal pressure vs. normal displacement at wall mid-height

The internal pressures at which there is a change in radial, hoop or vertical stiffness of the containment structure, are summarized below. These values are represented as ratios of design basis accident (DBA): 
1.9 DBA: Hoop cracks at lower level of the dome due to radial stress (Linear Limit)

2.1 DBA: Through crack at dome close to apex due to radial stress

2.3 DBA: Dome tendon yields located at lower elevation of the dome

2.4 DBA: Wall meridional tendon yields at mid-height of the wall

2.7 DBA: Prestressing tendon ruptures (UPC)

The finite element analysis terminates at internal pressure of $1070 \mathrm{kPa}(2.7 \mathrm{DBA})$ when the value of the strain in prestressing tendon exceed the limiting defined strain. Deformed shape of the containment structure at the end of analysis is shown in Figure 49.

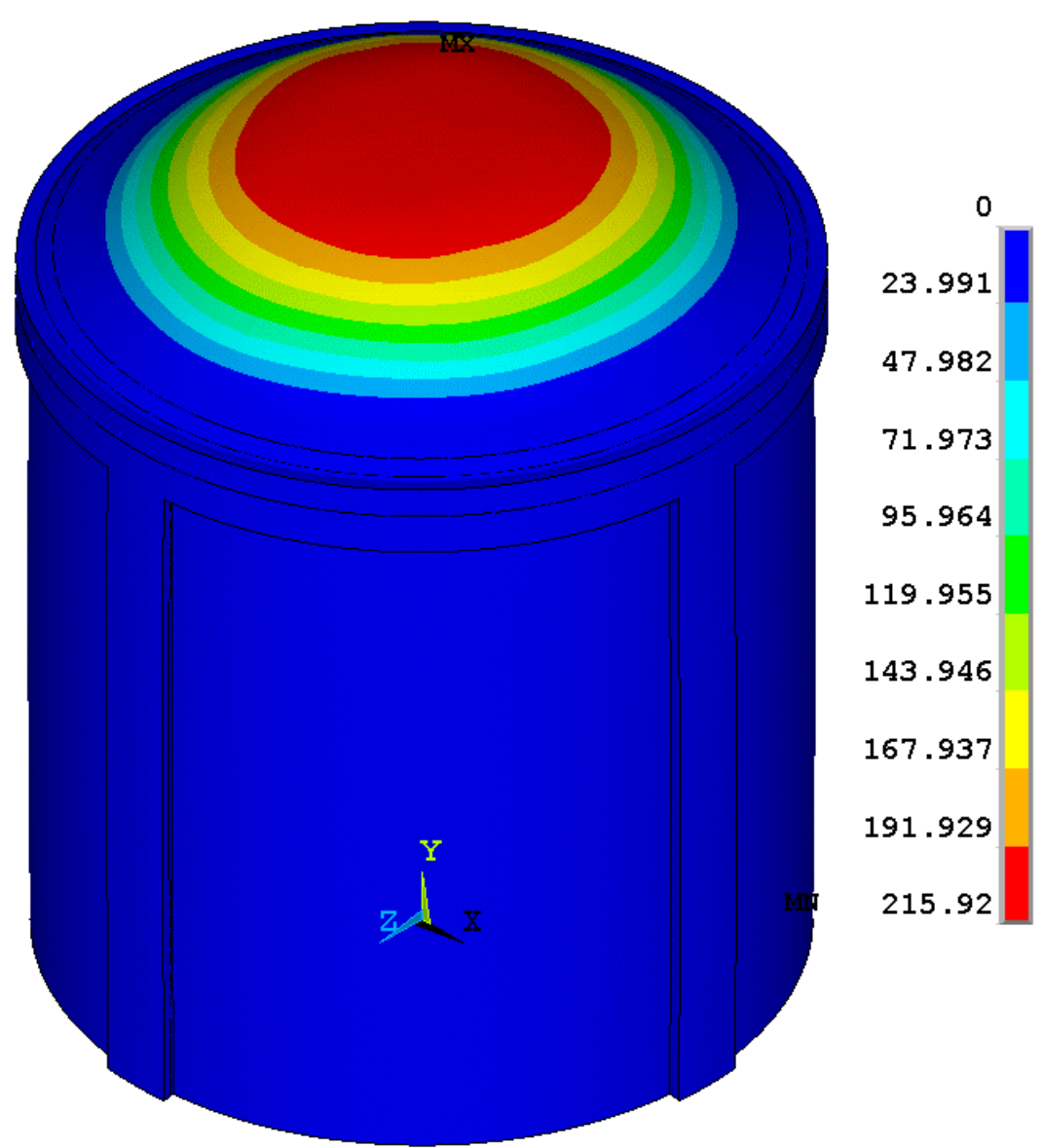

Figure 49- Defromed shape of the containmnet strcuture at the end of analysis

The response of the dome in the form of internal pressure versus the strain in reinforced concrete elements at two critical locations of dome apex and dome springing; is shown in Figure 50. 
During the analysis, the tensile strain of 0.4 percent is reached at internal pressure of 870 $\mathrm{kPa}$. Moreover, the first tendon yields at internal pressure of $930 \mathrm{kPa}$ when the strain in the prestressing tendon exceeds 0.8 percent. This tendon is located at lower elevation of the dome (dome springing). Response of this element in the form of internal pressure against total mechanical strain is shown in Figure 51. These limits for the wall are reached at much higher pressure.

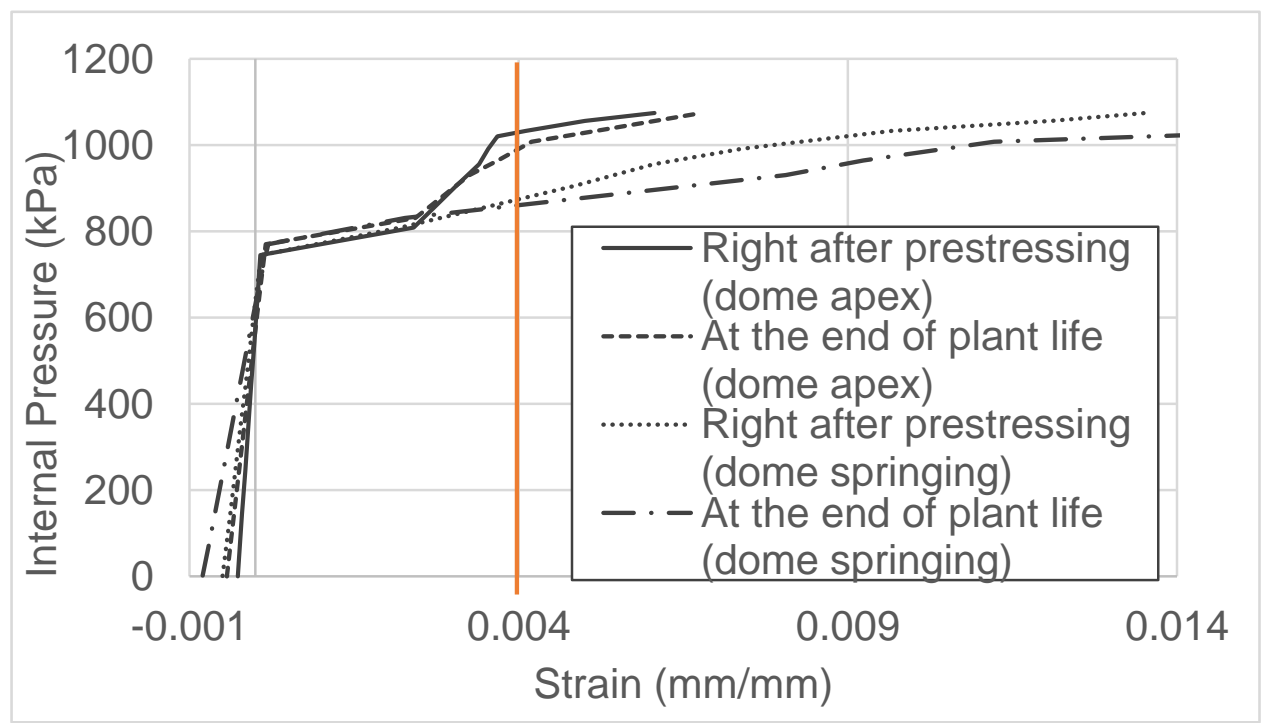

Figure 50- Response of the dome

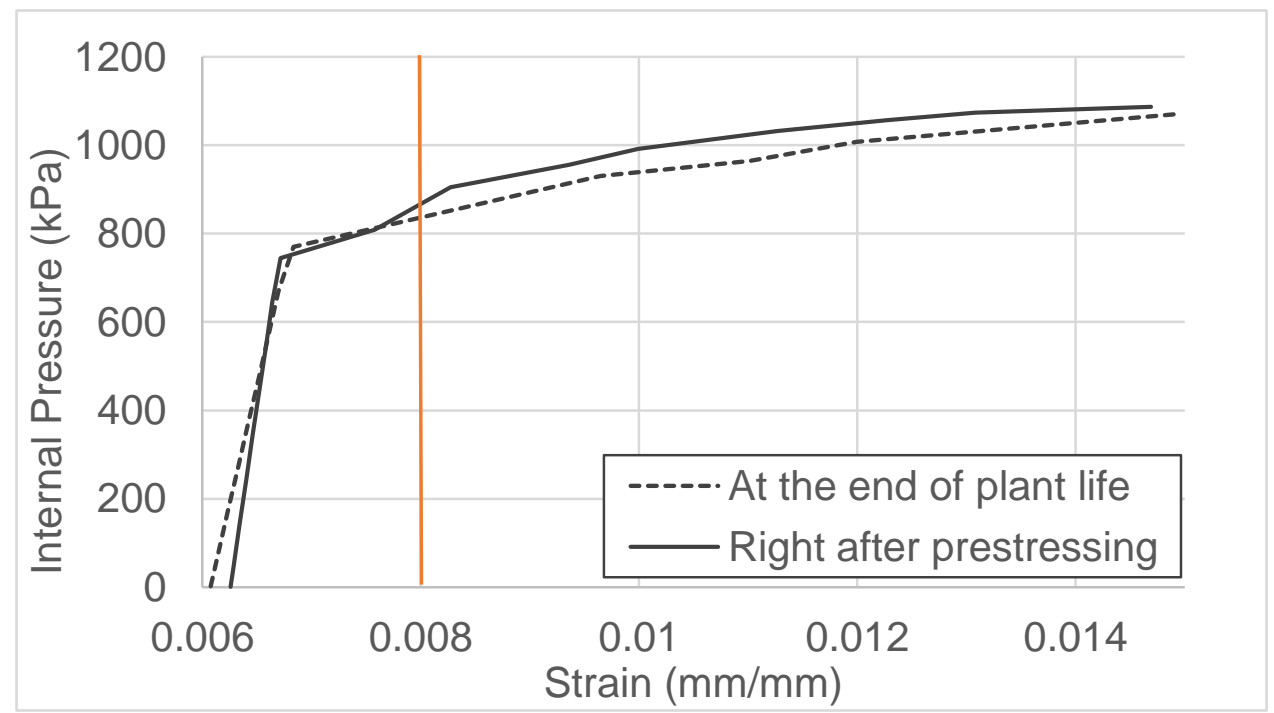

Figure 51- Response of the prestressing tendon at dome springing 
The functional integrity limit for the containment structure is $870 \mathrm{kPa}$ and the structural integrity limit for containment structure is $1070 \mathrm{kPa}$.

\subsection{Summary}

The objective of this chapter is to investigate the response of a containment structure to much higher internal pressures that could be encountered during a severe accident. The major challenges for modelling prestressing tendon element are to accommodate parameters affecting prestressing forces.

In research studies by others, the prestressing system is modelled using an equivalent pressure and tendon end forces to represent the prestressing forces and tendons are modelled as smeared reinforcement in the concrete element. This approach presents no difficulty in modelling the prestressing system; however, any non-uniform changes in the prestressing forces cannot be directly accommodated.

In this study, an alternative approach is introduced to capture the prestressing system, in which the prestressing tendons are modelled using discrete elements. This method is more appropriate when the tendons are not located in an axisymmetrical or symmetrical fashion; also the proposed approach is capable of accommodating the non-uniform losses in prestressing forces.

On the basis of the above findings, it is concluded that the design criteria for the containment structure are fully satisfied. At $124 \mathrm{kPa}$ (equivalent of LOCA), stresses are found to be within allowable values both in tension and compression. Also, no through crack was observed at $400 \mathrm{kPa}$ (design pressure). The first through crack develops in the dome at a pressure of $830 \mathrm{kPa}$. This gives a factor of safety against through cracking of $830 / 400=2.1$. There is no damage to be expected to the reactor systems up to a pressure well above $400 \mathrm{kPa}$. 
It is observed that the containment structure subject of this study meets the design requirement of the currents standards and behaves linearly up to pressure of $770 \mathrm{kPa}$ (almost 2 times of the design pressure). The reinforcing steel and prestressing tendon at the dome yield at internal pressure of $830 \mathrm{kPa}$ and $930 \mathrm{kPa}$, respectively.

Under the ultimate pressure condition, cracks are likely to occur near the apex of the dome, the dome springing and the bottom of the perimeter wall. Excessive deformation of the dome starts with yielding of the reinforcement at the dome and is followed by yielding of the prestressing tendons at the dome close to the ring beam (dome springing).

The structural integrity limit for pressure capacity of this containment structure is 1070 $\mathrm{kPa}$ and happens when the prestressing tendon ruptures at dome of the containment structure. 


\section{CHAPTER 7 EFFECTS OF MAJOR OPENINGS ON RESPONSE OF CONTAINMENT STRUCTURE}

\subsection{Introduction}

The main objective of this chapter is to investigate the response of an internally pressurized containment structure when major opening are considered in the FEM. The key technical question is whether major openings weaken the containment structure. For this purpose, two models are prepared using the finite element program, ANSYS, to predict the response of the structure beyond linear limit. In Model 1, openings are ignored and in Model 2, major openings including; equipment airlock, containment passage, fuel transfer duet and personnel airlock are incorporated. Both Models 1 and 2 are full three dimensional representation of the containment structure.

The objective is to determine the values of internal pressure at which design conditions and state limits are met. These include cracking and crushing of concrete, yielding of nonprestressing steel and prestressing tendon, and rupture of non-prestressing steel or prestressing tendon.

In internally pressurized CS, sources of non-axisymmetric behavior include; dome tendon layout, wall horizontal tendon buttresses and major openings. All the mentioned factors directly affect the deformed shape of the structure after transfer of prestressing forces as well as the stress distribution. These factors cannot be introduced if the CS is represented by an axisymmetric finite element model, or by a 3-dimensional (3D) repeating sector. To capture a more accurate behaviour of the CS, two full 3D finite element models are prepared in the current study. Model 1 that includes the non-axisymmetric tendon layout, tendon buttresses, but ignoring presence of openings; and Model 2, includes all the above mentioned factors. 
Moreover, the non-uniform variation of prestressing forces along the length of tendon affects stress distribution in CS. In the current study, prestressing tendons are modelled with discrete bar elements in both models, and the effects of prestressing system are added directly as initial strain to the bar elements. This approach enabled the capability of the model to accommodate non-uniform prestressing force distribution by adding additional script to the program as explained in Chapter 6.

\subsection{Major Openings}

As was mentioned in Chapter 3, the major openings in this CS include; equipment airlock, containment passage, fuel transfer duet and personnel airlock. The size and location of the openings are summarized in Table 14. The locations of the openings are described as the angular distance of the vertical plane of symmetry of the opening from the centre of B1, and as distance from the base of the wall to bottom of the opening.

The four buttresses in the CS are named as buttresses 1, 2, 3 and 4, and in this article, and are referred to as B1, B2, B3 and B4, respectively. Openings 1, 2 and 3 are located at the quadrant of the wall between $\mathrm{B} 2$ and $\mathrm{B} 3$, and opening 4 is located at the quadrant of the wall between B4 and B1.

Table 14- Openings size and location

\begin{tabular}{|l|l|l|l|l|}
\hline \multicolumn{1}{|c|}{ Opening } & \multicolumn{1}{|l|}{$\begin{array}{c}\text { Width } \\
(\mathrm{mm})\end{array}$} & $\begin{array}{c}\text { Height } \\
(\mathrm{mm})\end{array}$ & $\begin{array}{c}\text { Angular } \\
\text { distance } \\
\text { from B1 }\left(^{\circ}\right)\end{array}$ & $\begin{array}{c}\text { Distance from } \\
\text { base }(\mathrm{m})\end{array}$ \\
\hline O1: Equipment airlock & 3960 & 4270 & 150 & 13.3 \\
\hline O2: Containment passage & 1070 & 2140 & 154 & 8.1 \\
\hline O3: Spent fuel transfer duet & 1520 & 1070 & 150 & 3.2 \\
\hline O4: Personnel airlock & 910 & 2130 & 295 & 4.3 \\
\hline
\end{tabular}




\subsection{Finite Element Modelling of the Containment Structure}

\subsubsection{Material Model and Element Selection}

The same material model as described in chapters 5 and 6 is also used in this chapter for the concrete. For simplification, the non-prestressing reinforcing steel is assumed to have an elastic-perfectly plastic response with a bilinear kinematic hardening material model.

For prestressing tendons, a multilinear kinematic hardening model is used. Initially, the isotropic properties for the prestressing tendon are defined as the modulus of elasticity and Poisson's ratio. For the prestressing tendons, cables are modelled by discrete bar elements and Link8 elements are used.

\subsubsection{Geometry Details of the Finite Element Models}

For this containment, the most detailed representations are obtained by full 3D model to predict the non-axisymmetric behaviour of the structure. As follows, the geometry properties and meshing of the two models are described.

\subsubsection{Model 1}

The perimeter wall is divided into 6 elements through the thickness and 142 elements along the height. The hoop and meridional non-prestressing steel are introduced as smeared reinforcement to the first two concrete elements at inner face and two concrete elements at outer face of the wall. The shear reinforcing steels are added as smeared reinforcement to all the elements of the PW.

The dome is divided into six elements in thickness and into 74 elements along the arc of the dome. The smeared radial and hoop reinforcements are added to the first two elements at inner face of the dome and the two elements at outer face of the dome. The 
shear reinforcing steel is added as smeared reinforcement to all the dome concrete elements.

For the finite element model, the same layout as was described in section 3.1 is used for the horizontal prestressing tendons. Horizontal tendons are divided into two groups; group 1 where tendons are anchored at buttresses 1 and 3 and group two where tendons are anchored at buttresses 2 and 4 . Tendons in group 1 and group 2, have vertical spacing of $1200 \mathrm{~mm}$.

For finite element Model 1, 128 vertical lines are used in axisymmetrical fashion with average spacing of $1100 \mathrm{~mm}$. As the original layout of the vertical prestressing in the PW contains 124 tendons as described in Chapter 3, an equivalent area of $7990 \mathrm{~mm}^{2}$ is adopted for these elements to match that of the CS vertical tendons.

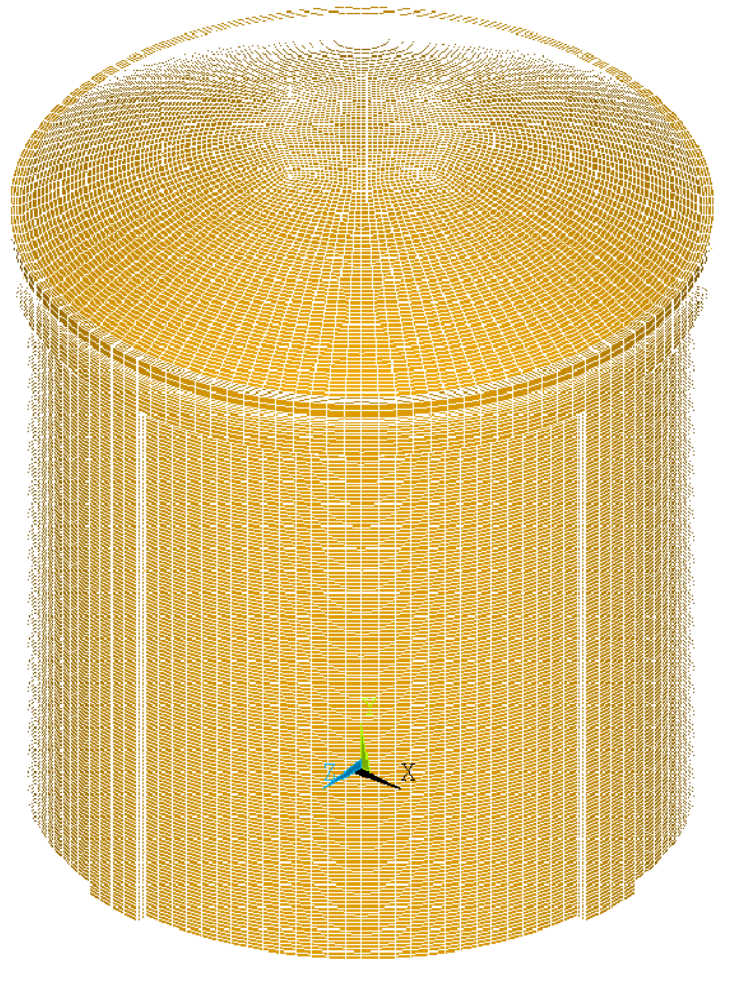

(a)

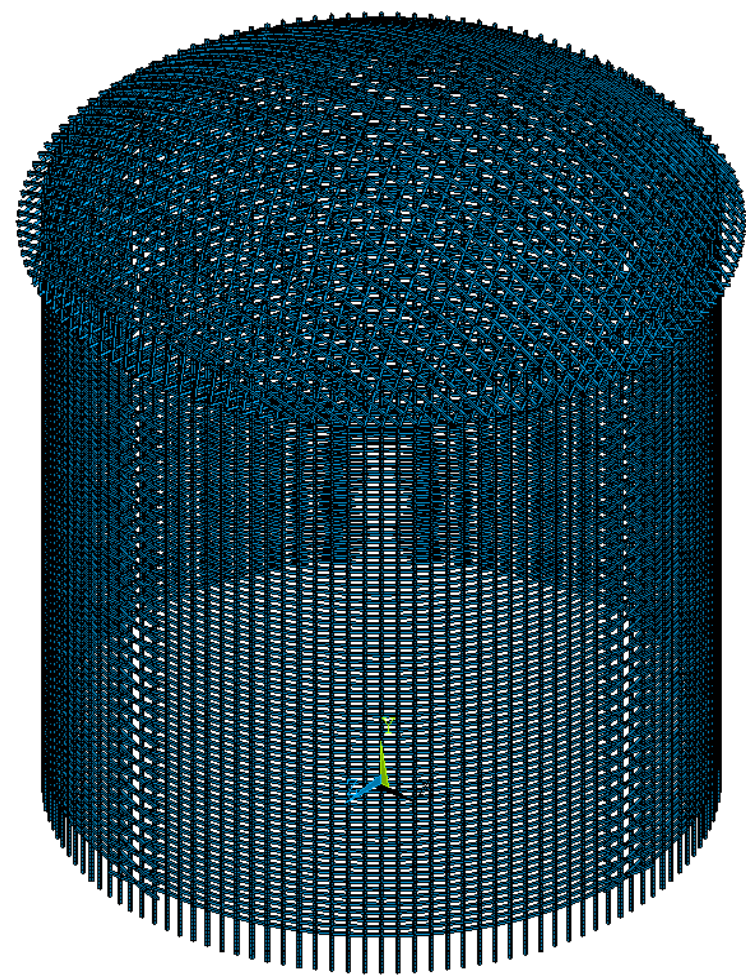

(b)

Figure 52- Finite elements: (a) reinforced concrete elements, (b) prestressing tendons 
Finite element models for reinforced concrete elements and prestressing tendon elements are shown in Figure 52. Figure 53 shows a horizontal cross section of the PW of Model 1, including two typical horizontal tendons attributing to group1 and vertical tendons.

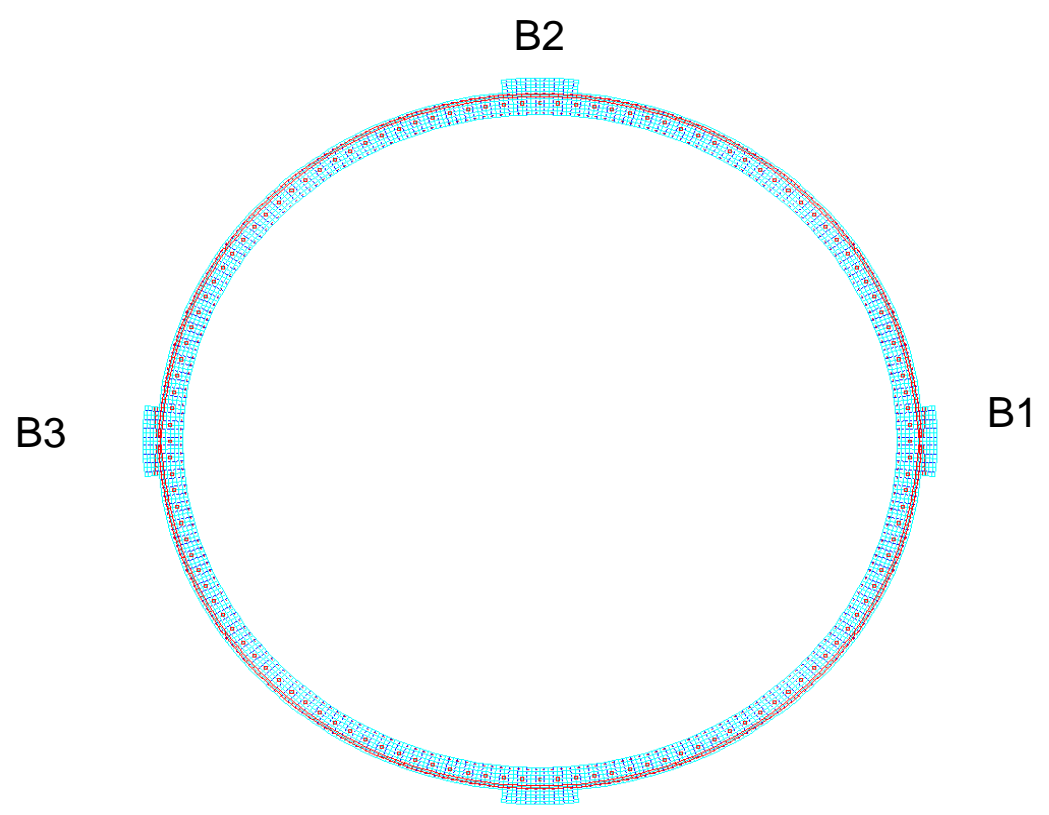

B4

Figure 53- Model 1: Horizontal cross-section of wall

For the dome, there are 3 layers of prestressing and all the tendons in each layer have the same center and radius of curvature. All the lines representing the tendons are fixed at both ends to the vertical exterior side of the ring beam. In the finite element model, the spacing of the tendons at dome apex is higher than that of the actual layout. To compensate for this change, the area of the tendons that are passing through the apex of the dome are changed. In actual layout, spacing is $916 \mathrm{~mm}$, where finite element model at dome apex is this spacing is $1088 \mathrm{~mm}$, accordingly the area five of the longest tendons in each layer is adjusted.

For the finite element mode, 8 lines are used in hoop direction to represent the ring beam tendons, and the area of these elements are set twice the area of the ring beam tendon to create an equivalent model. 


\subsubsection{Model 2}

For Model 2, same dimensions are used for the containment structure and properties of non-prestressing reinforcement are identical to those of Model 1. Layout of prestressing tendons at dome and ring beam remains unchanged.

As was mentioned before, among the four opening, $\mathrm{O} 1, \mathrm{O} 2$ and $\mathrm{O} 3$ are located at quadrant of the wall between B2 and B3. O1 is the largest openings, and intersects with four vertical tendons. Moreover, the personnel opening (O4) is located between B1 and B4. O4, is the narrowest of the four opening and intersects with two vertical tendons. For the vertical tendons, the two tendons intersecting with $\mathrm{O} 4$ are shifted to the sides of the opening, and the four tendons intersecting with $\mathrm{O} 1, \mathrm{O} 2$ and $\mathrm{O} 3$ are removed. Therefore, in Model 2, there are 124 vertical tendons with cross-sectional area of $8250 \mathrm{~mm}^{2}$.

In the original layout for this containment structure, the layout of the horizontal tendons is changed around the openings. In the original layout some horizontal tendons around openings are not anchored at alternate buttress and have different vertical spacing. As was mentioned before, the PW is prestressed with total of 146 horizontal tendons. One hundred and eighteen tendons are long tendons which cover half of the circumference of the wall and are anchored at diametrically at opposite buttresses. Twenty-eight tendons are short tendons which cover a quarter of the circumference and are anchored at two adjacent buttresses. The short tendons are used where large openings prevent the use of a $180^{\circ}$ tendon. Horizontal tendons are deflected either up or down to clear the large permanent openings, while vertical tendons are shifted to the sides of the permanent openings.

or Model 2, the change in layout of horizontal tendons is ignored and tendons are anchored at opposite buttresses. Tendons in two groups 1 are anchored at B1 and B3 and tendons at group 2 are anchored at B2 and B4. The tendons intersecting with vertical sides of $\mathrm{O} 1, \mathrm{O} 2$ and $\mathrm{O} 3$ are removed around the openings to keep the same number of prestressing tendons as Model 1. The tendons are now located at spacing of $304 \mathrm{~mm}$ 
around the openings as shown in Figure 54. Away from discontinuities, the layout and spacing of prestressing tendons in Model 2 are identical to those of Model 1.

Figure 55 shows a horizontal cross section of the PW in Model 2, including two typical horizontal tendons attributing to group1 as well as the vertical tendons.

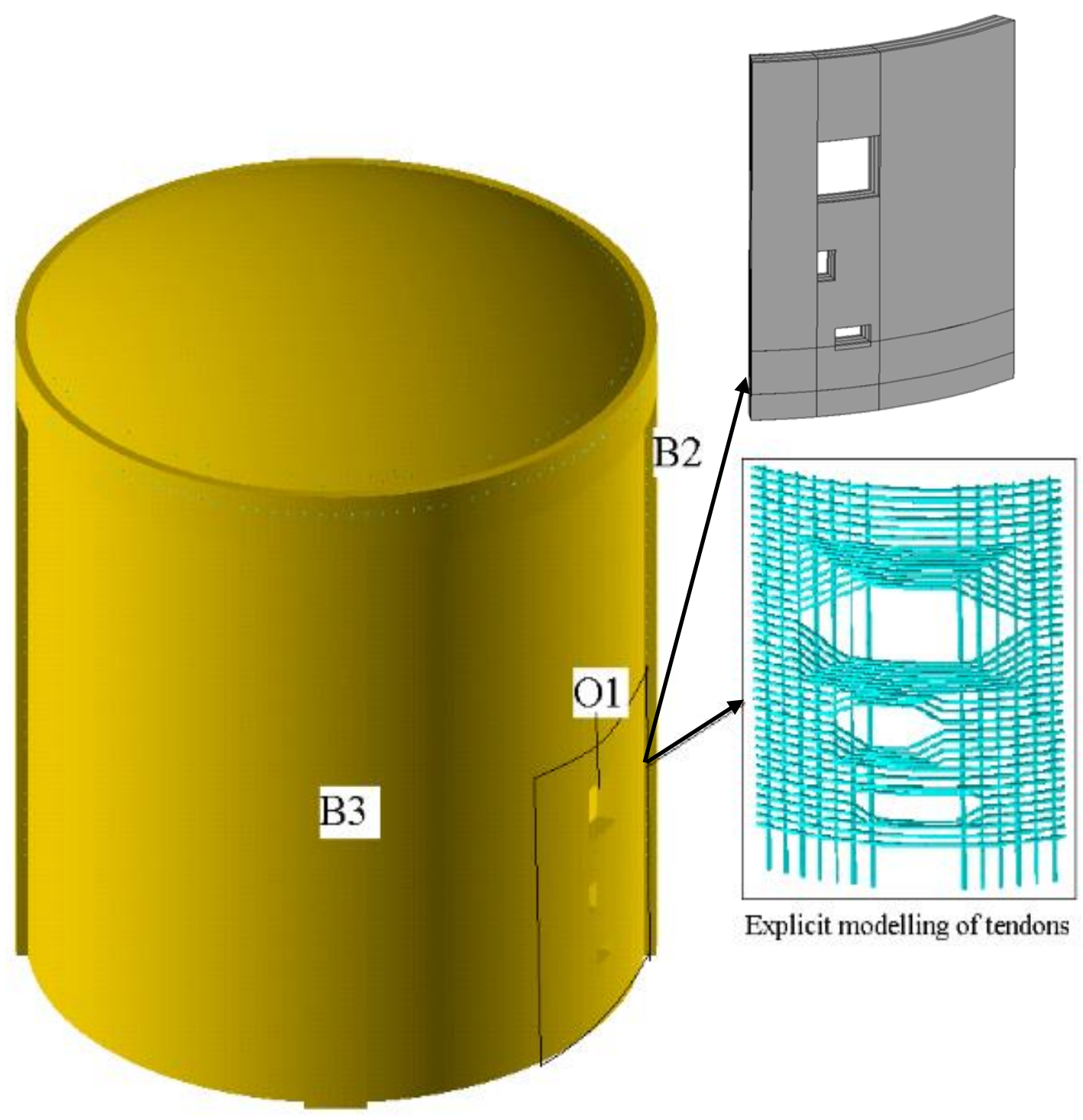

Figure 54- Model 2: CS and prestressing details around $\mathrm{O} 1, \mathrm{O} 2$ and $\mathrm{O} 3$ 


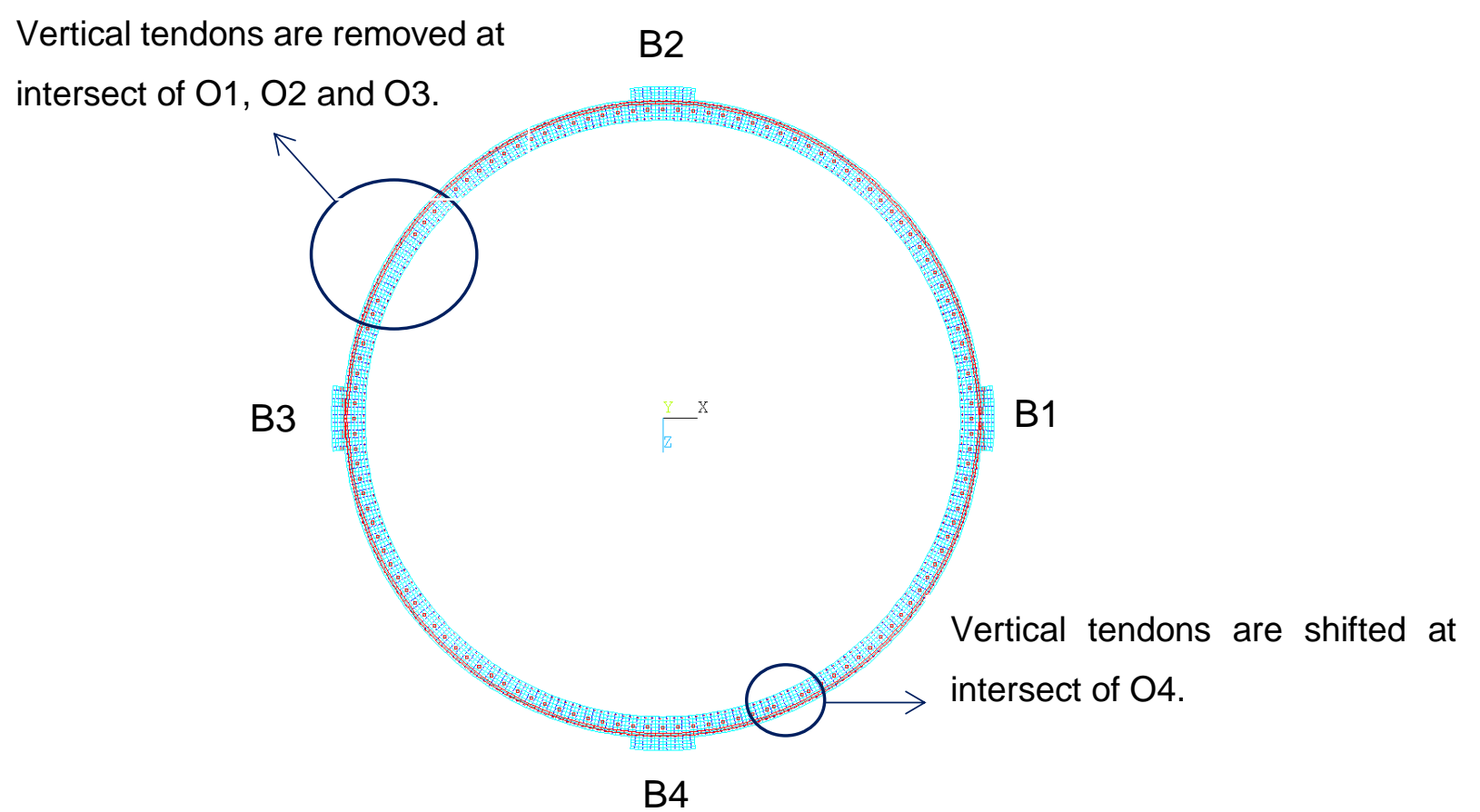

Figure 55- Model 2: Horizontal section of PW

\subsubsection{Prestressing Forces}

To model the bond between the concrete and the prestressing tendons, nodes of the bar elements are coupled with the coinciding or neighboring nodes of the concrete elements. It should be noted that these nodes are assumed $100 \%$ coupled.

To add the effects of prestressing forces, strains are applied directly on the bar elements. In the current study, the strains in the tendon elements are first calculated based on the jacking force (primary strain), then, are updated based on the estimated prestressing losses (reduced strain). Similar approaches to Chapter 6 are used to introduce the prestressing loss to the models. Curvature coefficient of 0.18 and wobble coefficient of $0.003 \mathrm{~m}^{-1}$ are used for both the dome and the wall tendons are used for calculation of friction losses. 


\subsection{Numerical Analysis}

\subsubsection{Analysis of Containment under Internal Pressure}

The analysis of the containment structure is conducted considering; dead loads, prestressing forces, and internal pressure. Dead loads contain self-weight of the structure including weight of the cylindrical wall, ring beam and the shallow dome. Note that the effects of live loads are not considered during abnormal accident. The CS is subjected to a static internal pressure that increased incrementally. Although many possible accident scenarios exist and are important near design pressures, for the calculation of ultimate capacity of the containment under internal pressure, the effects thermal loads are not included as suggested by reference [1].

In both models, after application of static loads and prestressing forces, a uniform internal pressure is applied to the entire internal surface of the containment up to failure.

A static nonlinear finite element analysis is conducted to estimate ultimate pressure capacity of the CS. Because of small displacement in concrete, geometry non-linearity or thinning of the wall need not to be accommodated in the models. It should be noted that the full Newton-Raphson method of analysis is used to compute the nonlinear response.

\subsection{Results and Discussions}

The deformed shape of the CS after transfer of prestressing forces including all immediate and long-term losses is shown in Figure 56. Moreover, deformed shape at internal pressure of approximately 2.5 times the design pressure is shown in Figure 57.

It is observed that the maximum displacement is at the dome and is close to the dome apex (Point A). Based on the deformed shape of the wall at the end of the analysis, the maximum radial displacement is not at mid-height of the wall in Model 2, as was observed in Model 1. In Model 2, the radial displacement at neighboring of the $\mathrm{O} 1$ is much higher (Point B). 


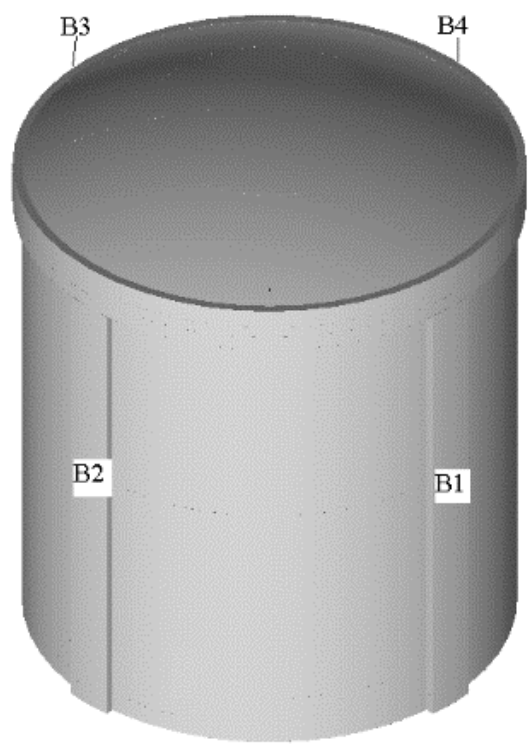

(a)

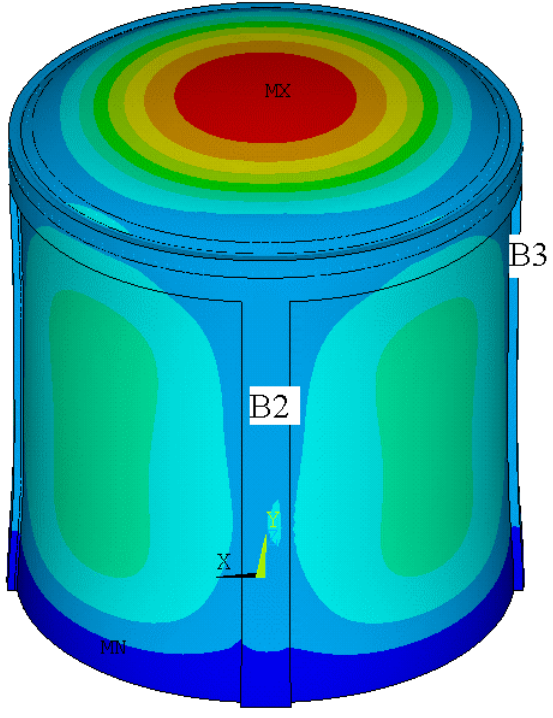

(b)

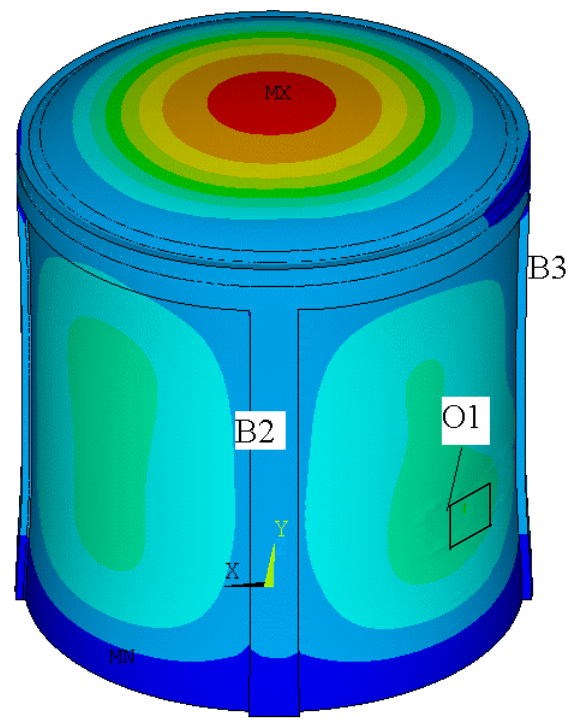

(c)

Figure 56- CS at internal pressure of zero: (a) Before application of prestressing forces (b) Prestressed Model 1, (c) Prestressed Model 2 


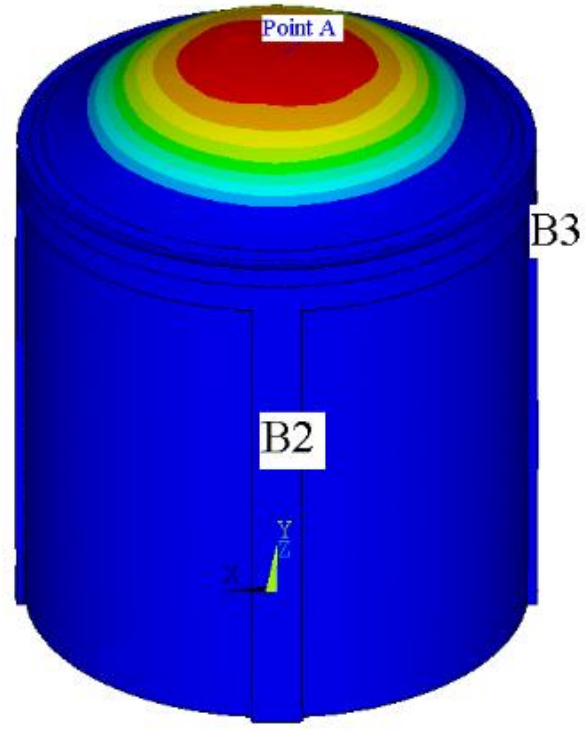

(a)

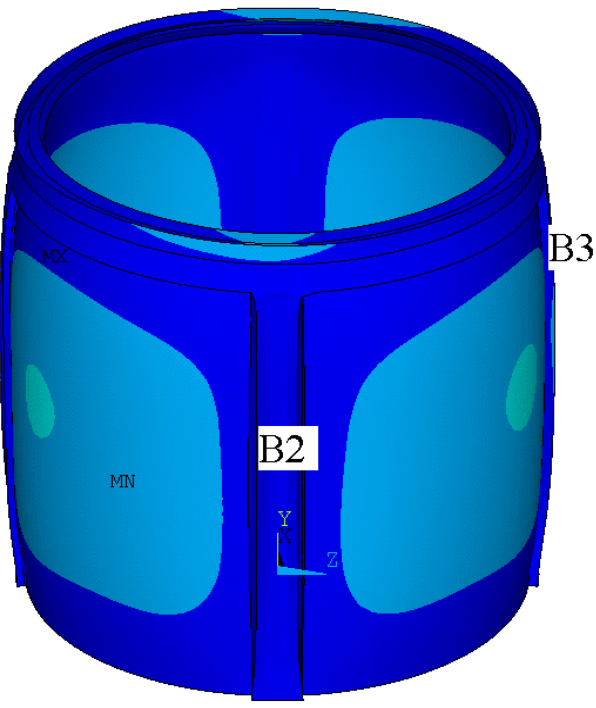

(c)

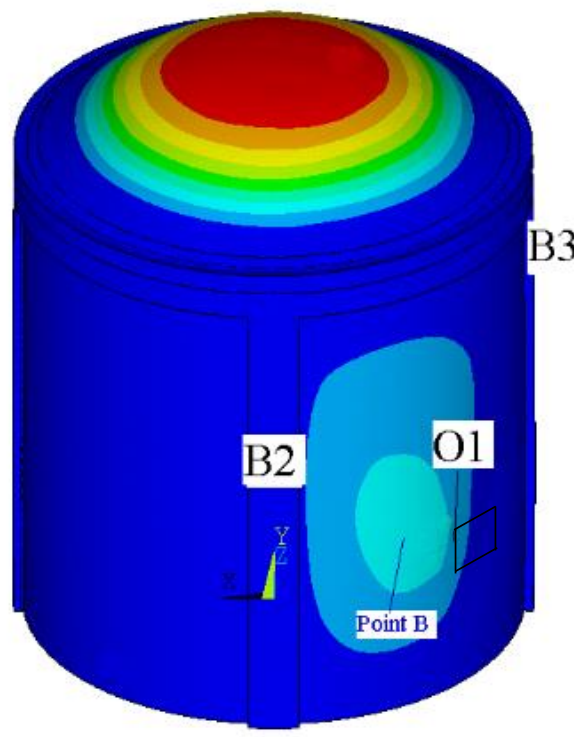

(b)

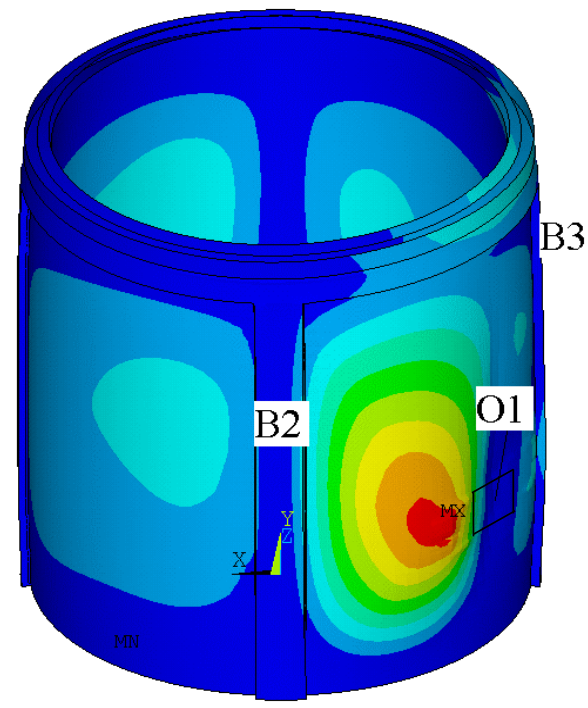

(d)

Figure 57- Deformed shape at internal pressure of 2.5DBA: (a) Model 1, (b) Model 2, (c) PW: Model 1, (d) PW: Model 2.

Responses of the models in the form of internal pressure versus the normal displacement at dome apex (Point A) are compared in Figure 58. It should be noted that positive normal displacement at the dome is an upward deformation. 
The responses of the CS in the form of internal pressure against radial displacement at Point B at the PW are compared in Figure 59. It should be noted that positive normal displacement at the wall is an outward radial deformation.

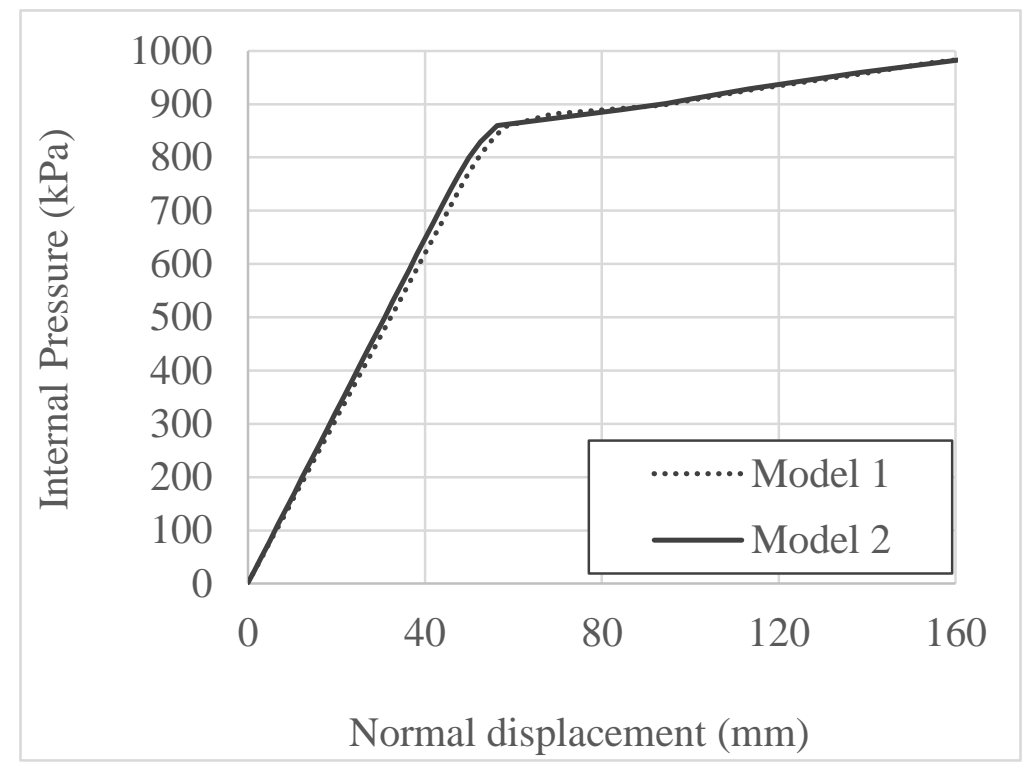

Figure 58- Internal pressure vs. normal displacement at dome apex (Point A)

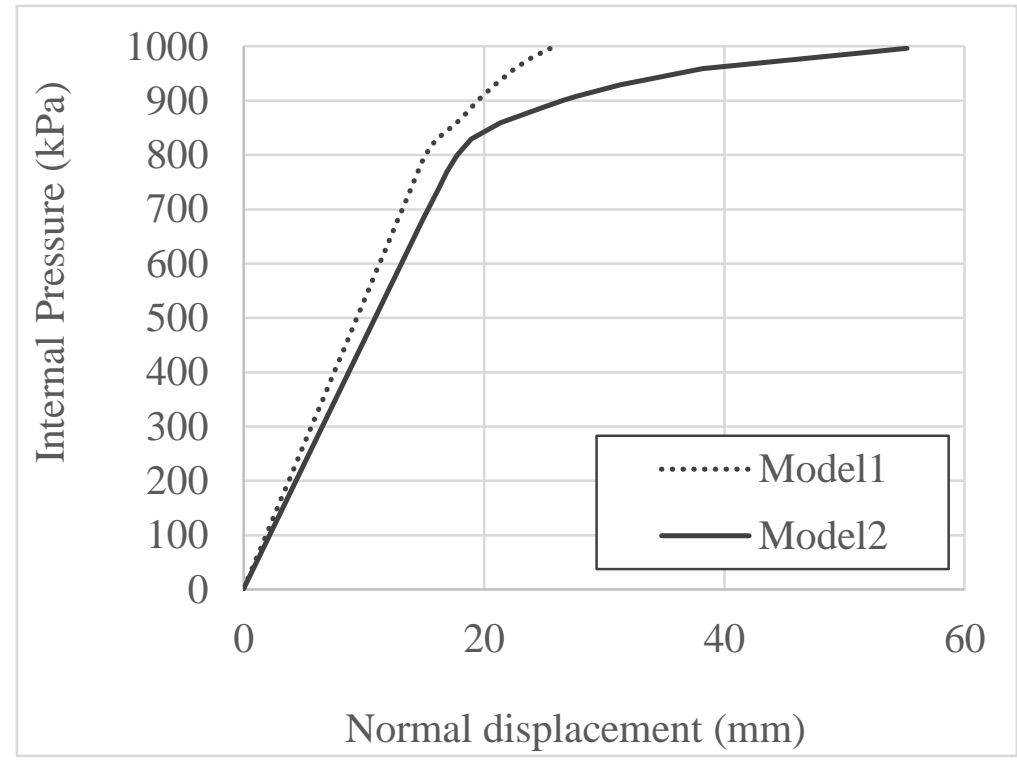

Figure 59- Internal pressure vs. normal displacement at Wall (Point B)

According to findings of Chapter 6, the structural integrity limit for this containment structure reaches at internal pressure of $1070 \mathrm{kPa}(2.7 \mathrm{DBA})$, with rupture of prestressing 
tendon at the dome. Because the strain limits (Failure criteria were defined in section 6.5.2 based on requirement of CSA N287.3 [1]) are reached at lower pressure than 2.7DBA, the pressure analyses are conducted up to internal pressure of $1000 \mathrm{kPa}$ (2.5DBA) to reduce computational effort. For both models the analysis can be continued above the value of internal pressure of $1000 \mathrm{kPa}$.

\subsection{Assessment of Concrete Cracking}

The following definitions are used to define the cracking directions for the wall: a horizontal crack is caused principally by meridional stresses and a vertical crack by hoop stresses. For the dome: a hoop crack is caused principally by radial stresses and a radial crack by hoop stresses.

1. Except locally at the inside face at lower elevation of the dome, there are no cracks in the containment at a pressure of $0-730 \mathrm{kPa}$ in both models. These local cracks are due to radial stresses and at internal pressure of $740 \mathrm{kPa}$, start to spread in hoop direction. By increase of internal pressure to $770 \mathrm{kPa}$, these cracks spread rapidly along the lower face of the dome and propagate in thickness. While these cracks are propagating into the thickness, they never reach the outside face where a narrow compressive region persists all along the analysis of the containment.

2. At internal pressure of $770 \mathrm{kPa}$, in both models, some vertical cracks form at approximately mid-height of the wall behind the buttresses. With increase of internal pressure to $800 \mathrm{kPa}$ theses cracks spread along the height of the wall and propagate in thickness.

3. At internal pressure of $800 \mathrm{kPa}$, hoop cracks form at the bottom of the wall at approximately $45^{\circ}$ angular distance from buttresses. These cracks are formed due to meridional stresses. 
4. Between internal pressure of $860 \mathrm{kPa}$ to $880 \mathrm{kPa}$, through crack forms at the dome due to radial stresses, in both models. Additional cracks also form at the dome due to hoop stresses.

5. The difference in crack pattern in the two models are visible after internal pressure of $830 \mathrm{kPa}$. In Model 2, there are some cracks due to hoop stresses at immediate neighboring of opening1 at internal pressure of $830 \mathrm{kPa}$, while no crack were observed in Model 1 under this pressure.

6. For Model 1, with increase of internal pressure from $830 \mathrm{kPa}$ to $930 \mathrm{kPa}$, more vertical cracks form at either side of the buttresses. Moreover, horizontal cracks at top of the wall attached to ring beam form in the area between the buttresses. For Model 2, with increase of internal pressure from $830 \mathrm{kPa}$ to $930 \mathrm{kPa}$, in addition to crack pattern in Model 1, the vertical cracks around Opening 1 start to spread toward the top and bottom of the wall. Moreover, additional cracks form at top of the wall below ring beam due to meridional stresses.

\subsection{Assessment of Non-Prestressing Steel and Prestressing Tendon Response}

1. For both models, the next critical change in stiffness of the structure happens at internal pressure of $830 \mathrm{kPa}$, with yielding of radial non-prestressing reinforcement at inner face of the dome. This element is located at quadrant of the CS between buttresses 1 and 4 and is close to dome springing. The location of these elements in the two models are almost identical.

The response of the structure in the form of internal pressure versus the strain in the dome radial reinforcement is shown in Figure 60, for both models.

2. At internal pressure of $860 \mathrm{kPa}$, in both models, hoop non-prestressing reinforcement yields at inner face of the wall at area behind the buttresses approximately at mid-height of the wall. The response of the structure in the form 
of internal pressure against strain in wall hoop reinforcement is shown in Figure 61 for both models. The locations of these elements in the two models are almost identical.

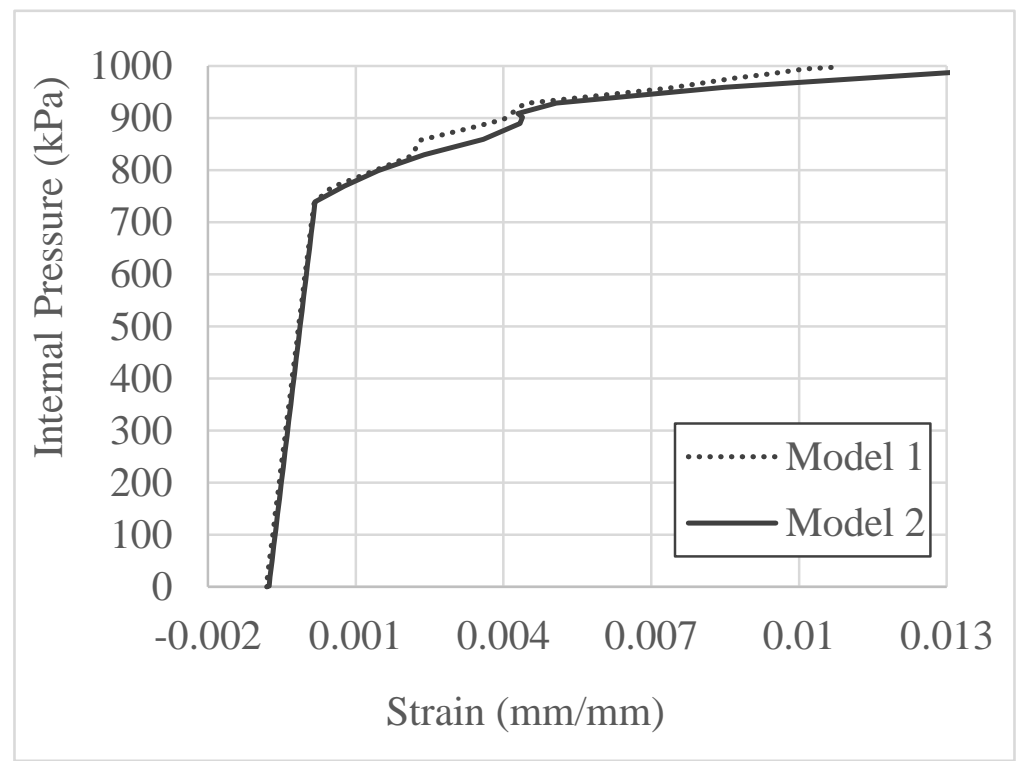

Figure 60- Internal pressure vs. strain in dome radial reinforcement

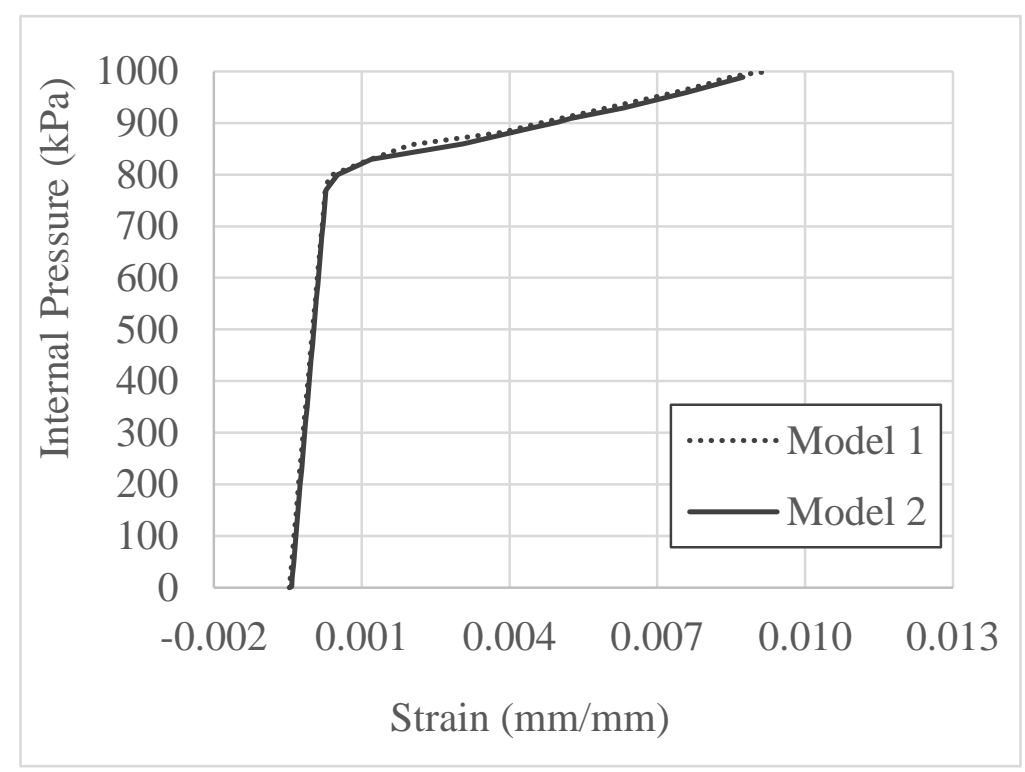

Figure 61- Internal pressure vs. strain in wall hoop reinforcement

3. For both models, at internal pressure of $880 \mathrm{kPa}$, prestressing tendon yields at the dome. This tendon attributes to tendon layer 2 and is located at the quadrat of the 
dome between buttresses 2 and 3 . The response of the structure in the form of internal pressure against strain in dome tendon is shown in Figure 62.

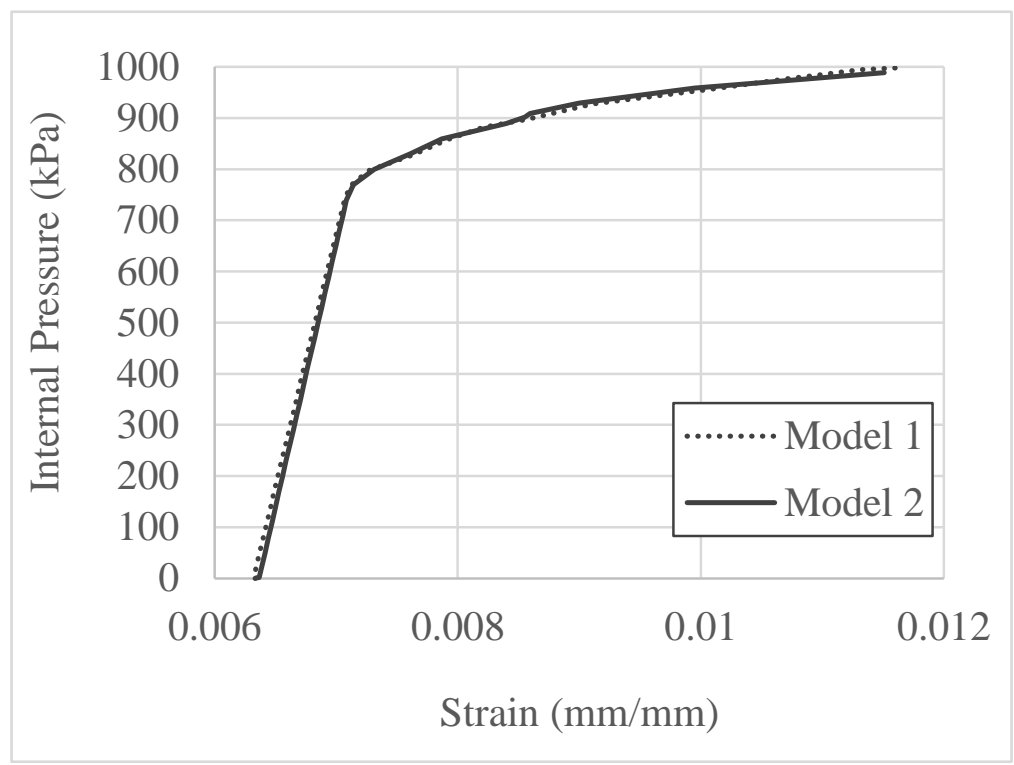

Figure 62- Internal pressure vs. strain in dome tendon

4. For Model 2, at internal pressure of $908 \mathrm{kPa}$, hoop reinforcement yields at immediate neighboring of opening1, whereas in Model 1, this element remains elastic until the end of the analysis.

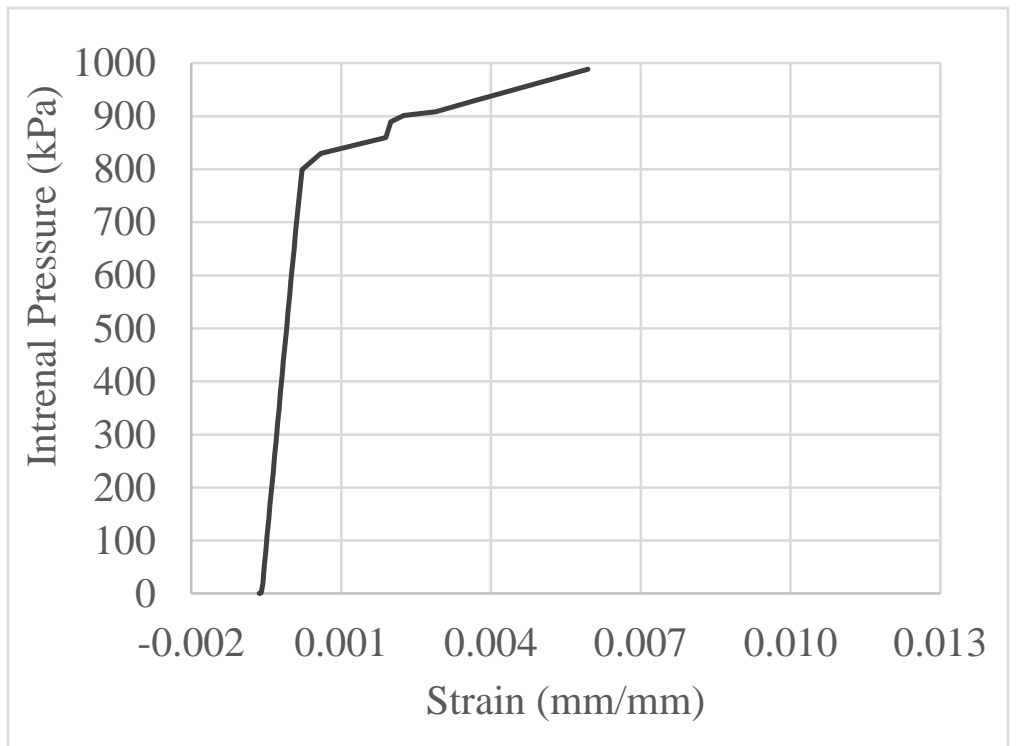

Figure 63- Model 2: Internal pressure against strain in hoop reinforcement above equipment airlock (O1) 
Figure 63 shows the relationship between internal pressure and strain in hoop reinforcement above $\mathrm{O} 1$ in Model 2. At internal pressure of $960 \mathrm{kPa}$, vertical reinforcement yields at top of the wall at quadrant of the CS located between B2 and B3, in Model 2.

5. For Model 1, wall horizontal tendon yields at internal pressure of $998 \mathrm{kPa}$, located at neighboring of B1 and approximately at mid-height of the wall. For Model 2, wall horizontal tendon yields at internal pressure of $988 \mathrm{kPa}$. These tendons are not exactly the same in the two models and the response of the containment in the form pressure versus strain in theses tendons is shown in Figure 64.

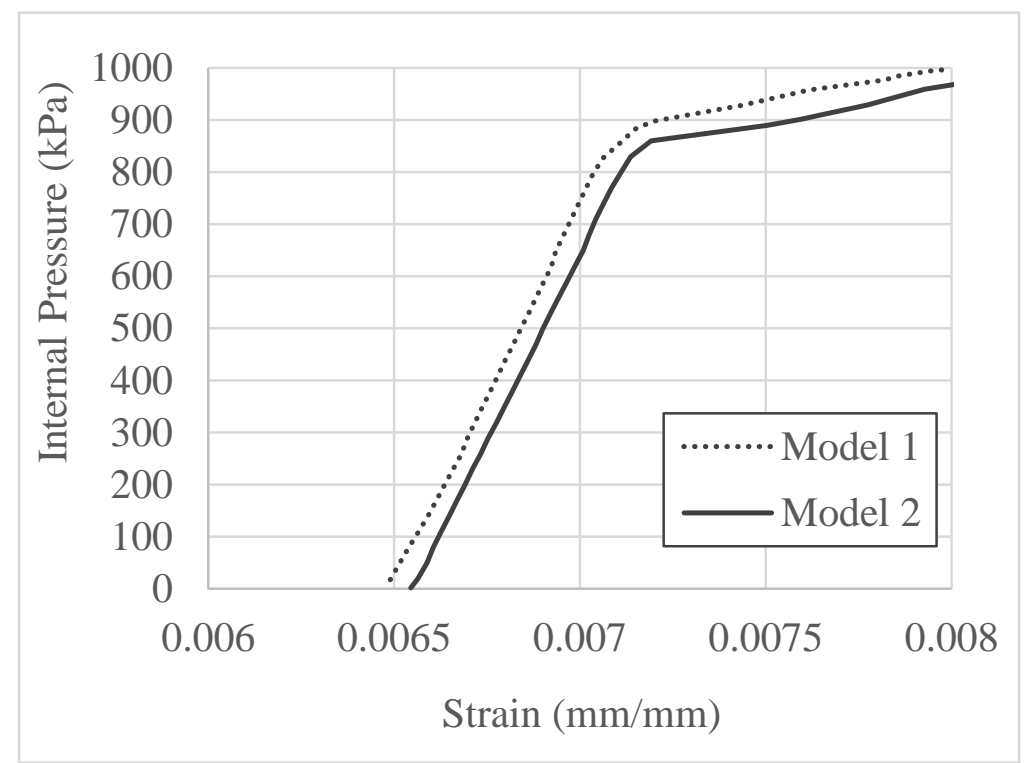

Figure 64- Internal pressure vs. strain in horizontal tendon of wall

\subsection{Summary}

The currents chapter investigates the response of an internally pressurized containment structure, and the main objective is to answer a key technical question whether major openings weaken the containment structure. To predict the non-linear response of the containment structure, two separate models are prepared in ANSYS program. 
To include parameters effecting the non-axisymmetric behaviour of the structure such as dome tendon layout, hoop tendon buttresses and major openings, both models are full three dimensional representation of the containment. In Model 1, openings are ignored and in Model 2, major openings including; equipment airlock, containment passage, fuel transfer duet and personnel airlock are added to the model.

The values of internal pressures at which deign conditions and state limits are met in the two models are compared. These include cracking, yielding of non-prestressing and prestressing tendon. It is observed that in both finite element models, the structure remains linear-elastic up to internal pressure of 1.8 DBA. Cracking starts in both models at inner face of the dome, close to dome springing, with increase of internal pressure, theses cracks spread in hoop direction and propagate in thickness of the dome, but never become through crack because of a narrow compressive region at outer face of the dome at same location all along the analysis.

At internal pressure of 1.9 DBA, vertical cracks form at wall in both models behind buttresses at mid-height of the wall. The difference in crack patterns in the two models starts at internal pressure of 2.07 DBA with formation of vertical cracks at immediate neighboring of equipment airlock, which spread towards the top and bottom of the wall with increase of internal pressure. First through crack form at internal pressure of 2.1DBA at the dome mid-height due to radial stresses.

For both models, another critical change in stiffness of the CS happens with yielding of dome radial reinforcement at internal pressure of 2.1D BA. At internal pressure of 2.15 DBA, hoop reinforcement yields at the PW. With increase of internal pressure to $2.2 \mathrm{DBA}$, prestressing tendon yields at the dome in both models followed by yielding of horizontal tendon at 2.5 DBA in Model 1 and 2.47 DBA in Model 2. According to design requirements for concrete containment structures for nuclear power plants, the pressure capacity of the containments may be estimated as 2.15 DBA on satisfying strain limits for prestressing tendon and non-prestressing steel. 
It is concluded that presence of openings does not have significant effect on pressure capacity of the containment structure. Behaviour of the containment is almost identical in both models within the linear elastic response, and beyond the linear elastic limit, the difference is at neighboring of the equipment airlock. A localized model of neighboring of airlock opening can be prepared for a more detail analysis.

It is concluded that to predict the pressure response of this containment structure, modeling of the openings can be ignored. In case of need to for a more exact response, only the equipment airlock can be included in the model. 


\section{CHAPTER 8 SUMMARY, CONCLUSIONS RECOMMENDATIONS}

\subsection{Summary of Dissertation}

The main objective of the current study is to investigate the response of an internally pressurized nuclear power plant containment structure at pressure values higher than design pressure. This study is focused on the response of a prestressed concrete containment to ultimate global structural failure. This is due to a demand in nuclear industry to investigate response of containment structures Beyond Design Basis Accidents (BDBAs). These are accidents that are outside the limits of what the plant is designed for to withstand under normal operating condition. If a speculated accident occurs, the plant should remain safe and secure.

The containment structure subject of this study consists of a prestressed concrete cylindrical perimeter wall, with a prestressed concrete tori-spherical dome, prestressed concrete ring beam, and conventionally reinforced concrete base slab. The structure is prestressed to control the tensile stresses of the containment boundary.

One of the design requirements for the nuclear power plant containment structure (CS) is to have the ultimate pressure capacity of at least twice the design pressure, and the structure to behave elastically to at least 1.5 times the design pressure [1]. Moreover, for prestressed concrete containments, the pressure capacity may be estimated based on satisfying of the strain limits as required in CSA N287.3 Annex C [1]. These limits are checked for the CS subject of the current study.

One of the main objectives of the current study is set to prepare a realistic finite element model of the containment structure. The finite element model includes properties of the concrete containment, prestressing tendons and non-prestressing steel. In the FEM developed in the current study, an appropriate model for the concrete material is used 
which is capable of presenting the mechanical behavior of concrete under compression and tension as well as the behavior after cracking. Moreover, material used for nonprestressing steel and prestressing tendon is capable of representing the responses of the material beyond yield point.

Two techniques are introduced in ANSYS program to model steel reinforcement for reinforced concrete. First is the smeared reinforcement approach, which assumes uniform distribution of reinforcing steel throughout the defined concrete elements. Second is the discrete model, where bar elements are used to model the reinforcement.

Smeared model is found to be more appropriate to model non-prestressing reinforcement in models with complicated geometry. Same approach can be used to model prestressing tendon, however, in this case, the prestressing forces should be applied as an equivalent force to model. If the discrete approach is used to model the prestressing tendons, the prestressing forces can be applied directly to the tendons. In the current study, the nonprestressing steels are modelled as smeared reinforcement. But, for prestressing tendon, both approaches are used and their responses are compared.

In this study, the objective is set to compare the responses of the CS when the prestressing effects are modelled using smeared model and discrete model. Two models are prepared and their responses are compared. In both models, the prestressing forces are applied ignoring all losses. In the first model, the prestressing is added as smeared reinforcement, and the effects of prestressing system are added as equivalent pressure and forces. In the other model, the prestressing tendons are modelled with discrete elements and the forces are applied directly on the elements. Static nonlinear finite element analysis is conducted to estimate ultimate pressure capacity of the CS. The full Newton-Raphson method of analysis is used to compute the nonlinear response where the load is applied incrementally to the structure up to the failure.

The next objective is to propose an approach to include all the parameters affecting the prestressing forces. The major challenges for modelling prestressing system are to 
accommodate parameters affecting prestressing forces. This includes: the geometry dependent changes along the tendon profile, changes due to incremental pressure and changes with time. The prestressing losses in tendons are categorized as short-term and long-term losses. The short-term losses are elastic shortening of the concrete, anchorage set loss and friction loss in tendons. Prestressing force losses due to friction and anchorage set are non-uniform and geometry dependent. The long-term losses are time dependent, also dependent on the material behaviour such as creep and shrinkage of the concrete and relaxation of the prestressing tendons.

When a tendon is tensioned by a jack, the force produced is not constant along the length of the tendon due to friction between tendon and duct. The change in prestressing forces is caused because of the curvature frictional loss and the wobble frictional loss which is not uniform. In this study, to introduce the variation of the prestressing forces along the length of the tendon, additional scripts are added to the finite element program to change the prestressing force of each element according to the geometry of the element. For each cable, the geometry of the nodes of each element is read, and according to distance and angle change from the location of the anchor, the reduced force is calculated. Then the primary value (primary value was based on jacking force) is updated with the new value.

Moreover, the posttensioning system will result in additional losses in prestressing forces due to setting of the wedges. The length of the tendon affected by anchorage set is a function of the friction losses. If the friction is low, the length affected is larger. Losses in prestressing forces due to setting of the wedges are also geometry dependent and are addressed by introducing a script to finite element program.

To introduce the time dependent prestressing losses, a simplified approach is used in this study. Relaxation of the low relaxation tendons varies in an approximately linear function with the log of the time under stress. Relaxation of the steel is accounted by using a reduced stiffness of the steel. The effect of creep is accounted by reducing the initial 
stiffness of concrete on the stress strain curve. The reduced modulus of elasticity at the end of plant is used to address creep losses.

Two models are prepared in which the tendons are modelled with discrete elements and prestressing forces are applied directly on the tendon elements. In one model, the prestressing losses are calculated right after transfer of prestressing forces (only shortterm losses) and another model in which the prestressing losses are calculated at the end of plant life (short-term + long-term losses). Static nonlinear finite element analysis is conducted to predict responses of these models.

A strain-based failure criterion is selected and applied to the reinforcing bars and tendons. This limit is given for strain away from discontinuities meaning locations away from buttresses and/or large openings [1].

At ultimate pressure capacity, the CS loses its structural integrity due to crushing of the concrete or rupture of prestressing tendon. All these parameters are checked at the time of prestressing and at the end of plant life (60 years).

The next objective is to investigate the response of an internally pressurized containment structure when major openings are considered in the finite element model. The key technical question is whether major openings weaken the containment structure. For this purpose, two other models are prepared using the finite element program, ANSYS, to predict the response of the structure beyond linear limit. Full 3D models of the CS to introduce all sources of non-axisymmetric behavior including; dome tendon layout, wall horizontal tendon buttresses and major openings. In one model, openings are ignored and in the other model, major openings including; equipment airlock, containment passage, fuel transfer duet and personnel airlock are incorporated. For both models, prestressing tendons are modelled as discrete elements and prestressing forces are applied directly on the tendon elements. The short-term and long-term prestressing losses are introduced to the models. 


\subsection{Conclusions}

The conclusions of the current study is summarized as follows:

Conclusions on different models for the restressing systems in FEM:

- When the prestressing tendons are modelled as smeared reinforcement and the effects of the prestressing system is added as external forces on the CS, the nonuniform distribution of the prestressing force cannot be introduced. Also, models prepared using this approach is not capable of presenting the exact layout of prestressing tendons.

- Discrete modelling of the prestressing tendons enables the user to accommodate the exact layout of prestressing tendons (and if required non-prestressing steel) to take into account the sources of non-axisymmetric behavior of the CS. Using this approach, the parameters effecting the changes in prestressing forces can be introduced to the finite element model.

- Between the two approaches available to model the prestressing system in the CS, discrete model results in higher value for both linear limit and pressure capacity. When both approaches are compared within the liner limits, there is a difference of $20 \%$ in pressure capacity.

- Due to complexity of discrete modelling of the prestressing tendons, user may choose to use the simplified approach, and model the prestressing system as smeared reinforcement. As it is concluded that using both approaches, the CS meets the design requirements, therefor for design purposes the simplified approach is found more appropriate.

Conclusions on prestressing losses:

- To introduce non-uniform distribution of prestressing forces along the tendon length, discrete tendon elements should be used. The forces applied on the tendon 
are updated based on location of each element to accommodate geometry dependant losses. The geometry dependant losses are introduced by adding a script to the program based on coordinates of the elements.

- For the CS model considering all losses, it is observed that the design criteria for the containment structure are fully satisfied. For the CS model including all losses, at internal pressure of $124 \mathrm{kPa}$, within the concrete stresses are found to be within allowable values both in tension and compression. For the CS model including all losses, the factor of safety against through the thickness cracking is 2.1 .

- During the analysis, the tensile strain of 0.4 percent is reached at internal pressure of 2.2 DBA. Moreover, the first tendon yields at internal pressure of 2.3 DBA when the strain in the prestressing tendon exceeds 0.8 percent. Accordingly, the CS meets the design requirements of CSA N287.3 [1] and has pressure capacity of more two times the design pressure.

- The CS model including all losses behaves linearly up to almost two times of the design pressure, and again the CS meets the design requirements of CSA N287.3 [1] and behaves linearly in excess of 1.5 times the design pressure.

- The structural integrity limit reaches at 2.7 DBA, with rupture of prestressing tendons at the dome.

Conclusions on effects of major openings:

- Presence of openings do not have a significant effect on the pressure capacity of the containment structure. The minor differences in the responses when the major openings are included in the model are at pressure values beyond the linear limit and are less than $5 \%$. 
- The response of the CS when the major openings are included in the model does not vary significantly, except at the immediate neighboring of the equipment airlock opening. For both models (including or ignoring openings), failure initiates by formation of cracks at the dome, followed by yielding of the radial reinforcement at the dome, and yielding of hoop reinforcement at the perimeter wall, then by yielding of prestressing tendon at the dome and horizontal tendon at the perimeter wall.

- To predict the pressure response of containment structure, modeling of the openings can be ignored for the size of the opening considered in the current study. In case of a need for a more exact response, only the equipment airlock (3960 mm by $4270 \mathrm{~mm}$ opening) can be included in the model.

\subsection{Design Recommendations}

In the current study, it is observed that the dome in CS is one of the critical elements in CS. Non-linear behaviour of the CS initiated at the dome due to formation of cracks and yielding of reinforcement. Accordingly, it is recommended to increase the amount of radial and meridional reinforcement at the dome to enhance the response of the CS under high internal pressures.

The amount of dome prestressing can also be increased for the same purpose. With increase of jacking force within the permissible limits, or increase of number of tendons, the amount of compressive stress introduced at the dome due to transfer of prestressing can be increased which will result in enhancement in the behaviour of the dome.

Moreover, by reduction of the amount of prestressing forces at the perimeter wall in horizontal direction, the wall can be made less stiff in comparison to the dome. Which will result in more radial deformation at wall which will reduce the upward deflection of the dome. 
In the CS subject of the current study, the wall and base slab connection is assumed as fixed. This is to accommodate steel liner at inner face of the CS and to prevent the rupture of the liner because of rotation at the connection in case of hinge connection. It should be noted that moments at the fixed connection result in requiring additional reinforcement at the base of the wall. The amount of the reinforcement at the base of the wall should be within the code limits.

Enhancement of the neighbouring of large penetrations with additional reinforcement is recommended due to concentration of the stresses around the openings and changes in layout of prestressing tendons.

\subsection{Recommendations for Future Studies}

In the current study, the effect of the major openings on the response of the CS is investigated for which the major openings are included in the global model of the CS. Future studies can be carried out on the effects of the openings including:

- Localized models of major openings to predict the behaviour of neighbouring of the openings taking into account the following parameters:

$\circ$ the stress concentrations and local strengthening around the major openings;

o the effects imposed by the curved arrangement of the reinforcement or prestressing system around the openings or penetrations;

o the thermal effects on the local penetration area caused by process piping passing through; and

o the impulse or impact effects in the vicinity of penetration.

In the current study, the presence of the steel liner at the inner face of the CS is ignored and its behaviour is not thoroughly investigated. Future studies can be carried out on the behaviour of steel liner system including: 
- Non-linear finite element analysis on global model of the CS including the liner plate and stiffeners to predict the response of the liner system

- Experimental investigation on localized model of the liner system including the liner plate and stiffeners to calibrate the finite element model.

Moreover, future studies can be carried out to investigate the effects of thermal loading on the CS including:

- Time-dependent heat transfer analysis of the containment structure under severe accident temperature conditions. 


\section{Appendix A DESIGN LOAD CONSIDERATIONS}

This appendix describes the load cases and load combinations that shall be considered in the design of the containment structure according to CSA N287.3 [1].

The load cases are defined as follows:

D: Dead load;

L: Live load;

$\mathrm{Pa}$ : Internal accident pressure due to LOCA (loss-of-coolant accident) or MSLB (main steam line break);

Pr: Reduced accident pressure;

Pv: Negative pressure load due to any cause including negative pressures caused by inadvertent opening of pressure relief valves;

$P_{\text {vo: }}$ Loads due to operating negative pressure that may exist continuously throughout the entire operating, shutdown, or test period;

$P_{\text {severe: }}$ Severe accident pressure;

$\mathrm{T}_{\mathrm{a}}$ : Summer or winter accident temperature loads (transient or steady-state);

To: Summer or winter normal operation temperature loads (transient or steady-state);

Summer or winter start-up temperature loads (transient or steady-state);

$T_{p}$ : Effective prestressing load (short-term or long-term);

$T_{\text {sc: }}$ Load effects due to shrinkage and creep (short-term or long-term);

QACcsevere/extreme: Severe/Extreme aircraft crash;

Qed: Seismic load due to DBE (Design Basis Earthquake);

Qes: Seismic load due to SDE (Site Design Earthquake);

Qt: Loads due to design tornado;

$Q_{w}$ : Loads generated by the design wind specified for the site;

$\mathrm{R}$ : Loads generated by the rupture of a high-energy pipe during accident;

Ro: Pipe reactions during normal operating or shutdown conditions;

Ra: Pipe reactions from thermal expansion during accident; and

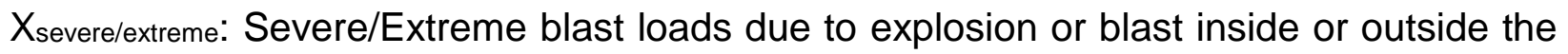
reactor building. 
Load combinations considered for concrete section design are based on Table 7.1 of CSA N287.3 [1]. These load combinations and the corresponding factors are summarized in as follows:

It should be noted that the load factors of 0.85 for $D$ and 0.0 for $L$ shall be used in all cases if the effects are reduced.

\section{A.1 FACTORED LOAD COMBINATIONS}

The most severe factored load combinations that shall be used for ultimate limit state design are as follows:

a) Service Load Category

All combinations of loads that may act simultaneously during construction, pre-operational proof pressure testing or normal plant operation:

\section{Construction period}

1.4D

$1.25 \mathrm{D}+1.50 \mathrm{~L}+1.00 \mathrm{~T}_{\mathrm{p}}+1.25 \mathrm{~T} s \mathrm{sc}+1.25 \mathrm{~T}_{\mathrm{o}}+0.40 \mathrm{Q}_{\mathrm{w}}+1.50 \mathrm{R}_{\mathrm{o}}$

$1.25 \mathrm{D}+0.50 \mathrm{~L}+1.00 \mathrm{~T}_{\mathrm{p}}+1.25 \mathrm{~T} \mathrm{sc}+1.25 \mathrm{~T}_{\mathrm{o}}+1.40 \mathrm{Q}_{\mathrm{w}}+1.00 \mathrm{R}_{0}$

$1.25 \mathrm{D}+0.50 \mathrm{~L}+1.00 \mathrm{~T}_{\mathrm{p}}+1.25 \mathrm{~T}_{\mathrm{sc}}+1.25 \mathrm{~T}_{\mathrm{o}}+1.00 \mathrm{Q}_{\mathrm{w}}+1.00 \mathrm{R}_{0}$

Test load combinations

$1.25 \mathrm{D}+1.50 \mathrm{~L}+1.00 \mathrm{~T}_{\mathrm{p}}+1.25 \mathrm{~T}_{\mathrm{sc}}+1.45 \mathrm{P}_{\mathrm{a}}+1.25 \mathrm{~T}_{\mathrm{o}}+0.40 \mathrm{Q}_{\mathrm{w}}+1.50 \mathrm{R}_{0}$

$1.25 \mathrm{D}+1.50 \mathrm{~L}+1.00 \mathrm{~T} p+1.25 \mathrm{~T} s+1.50 \mathrm{P}_{\mathrm{v}}+1.25 \mathrm{~T} o+0.40 \mathrm{Q}_{\mathrm{w}}+1.50 \mathrm{R}_{\mathrm{o}}$

$1.25 \mathrm{D}+1.50 \mathrm{~L}+1.00 \mathrm{~T}_{\mathrm{p}}+1.25 \mathrm{~T}_{\mathrm{sc}}+1.50 \mathrm{P}_{\mathrm{vo}}+1.25 \mathrm{~T}_{\mathrm{o}}+0.40 \mathrm{Q}_{\mathrm{w}}+1.50 \mathrm{R}_{0}$

Normal load combinations

$1.25 \mathrm{D}+1.50 \mathrm{~L}+1.00 \mathrm{~T}_{\mathrm{p}}+1.25 \mathrm{~T}_{\mathrm{sc}}+1.50 \mathrm{P}_{\mathrm{v}}+1.25 \mathrm{~T}_{\mathrm{o}}+1.50 \mathrm{Q}_{\mathrm{es}}+1.50 \mathrm{R}_{\mathrm{o}}$

$1.25 \mathrm{D}+1.50 \mathrm{~L}+1.00 \mathrm{~T}_{\mathrm{p}}+1.25 \mathrm{~T}_{\mathrm{sc}}+1.50 \mathrm{P}_{\mathrm{v}}+1.25 \mathrm{~T}_{\mathrm{o}}+1.50 \mathrm{Q}_{\mathrm{w}}+1.50 \mathrm{R}_{0}$

$1.25 \mathrm{D}+1.50 \mathrm{~L}+1.00 \mathrm{~T}_{\mathrm{p}}+1.25 \mathrm{~T}_{\mathrm{sc}}+1.50 \mathrm{P}_{\mathrm{vo}}+1.25 \mathrm{~T}_{\mathrm{o}}+1.50 \mathrm{Q}_{\mathrm{es}}+1.50 \mathrm{R}_{\circ}$

$1.25 \mathrm{D}+1.50 \mathrm{~L}+1.00 \mathrm{~T}_{\mathrm{p}}+1.25 \mathrm{~T}_{\mathrm{sc}}+1.50 \mathrm{P}_{\mathrm{vo}}+1.25 \mathrm{~T}_{o}+1.50 \mathrm{Q}_{w}+1.50 \mathrm{R}_{\circ}$ 
b) Abnormal/Environmental Load Category

All combinations of loads that may act simultaneously during a postulated accident and/or during an extreme environmental event:

Abnormal load combinations

$1.00 \mathrm{D}+1.00 \mathrm{~L}+1.00 \mathrm{~T}_{\mathrm{p}}+1.00 \mathrm{~T}_{\mathrm{sc}}+1.50 \mathrm{P}_{\mathrm{a}}+1.00 \mathrm{~T}_{\mathrm{a}}+1.00 \mathrm{R}_{\mathrm{a}}+1.00 \mathrm{R}+1.00 \mathrm{R}_{o}$

$1.00 \mathrm{D}+1.00 \mathrm{~L}+1.00 \mathrm{~T}_{\mathrm{p}}+1.00 \mathrm{~T}_{\mathrm{sc}}+1.00 \mathrm{P}_{\mathrm{vo}}+1.00 \mathrm{~T}_{\mathrm{o}}+1.00 \mathrm{R}_{0}+1.00 \mathrm{X}$

$1.00 \mathrm{D}+1.00 \mathrm{~L}+1.00 \mathrm{~T}_{\mathrm{p}}+1.00 \mathrm{~T}_{\mathrm{sc}}+1.00 \mathrm{P}_{\mathrm{vo}}+1.00 \mathrm{~T}_{\mathrm{o}}+1.00 \mathrm{R}_{\mathrm{o}}+1.00 \mathrm{Q}_{\mathrm{ACC}}$

Environmental load combinations

$1.00 \mathrm{D}+1.00 \mathrm{~L}+1.00 \mathrm{~T}_{\mathrm{p}}+1.00 \mathrm{~T}_{\mathrm{sc}}+1.00 \mathrm{P}_{\mathrm{vo}}+1.00 \mathrm{~T}_{\mathrm{o}}+1.00 \mathrm{Q}_{\mathrm{ed}}+1.00 \mathrm{R}_{\mathrm{o}}$

$1.00 \mathrm{D}+1.00 \mathrm{~L}+1.00 \mathrm{~T}_{\mathrm{p}}+1.00 \mathrm{~T}_{\mathrm{sc}}+1.0 \mathrm{P}_{\mathrm{vo}}+1.00 \mathrm{~T}_{\mathrm{o}}+1.00 \mathrm{Q}_{\mathrm{t}}+1.00 \mathrm{R}_{\mathrm{o}}$

Abnormal/environmental load combinations

$1.00 \mathrm{D}+1.00 \mathrm{~L}+1.00 \mathrm{~T}_{\mathrm{p}}+1.00 \mathrm{~T}_{\mathrm{sc}}+1.00 \mathrm{Pr}+1.00 \mathrm{~T}_{\mathrm{o}}+1.00 \mathrm{Q}_{\mathrm{ed}}+1.00 \mathrm{R}_{\mathrm{a}}$

$1.00 \mathrm{D}+1.00 \mathrm{~L}+1.00 \mathrm{~T}_{\mathrm{p}}+1.00 \mathrm{~T}_{\mathrm{sc}}+1.00 \mathrm{P}_{\mathrm{v}}+1.00 \mathrm{~T}_{\mathrm{o}}+1.00 \mathrm{Q}_{\mathrm{ed}}+1.00 \mathrm{R}_{\mathrm{a}}$

\section{A.2 UN-FACTORED LOAD COMBINATIONS}

The most severe un-factored load combinations that shall be used for the permissible stress/strain design are as follows:

a) Service Load Category

Pressure test

$1.0 \mathrm{D}+1.0 \mathrm{~L}+1.0 \mathrm{~T}_{\mathrm{p}}+1.0 \mathrm{~T}_{\mathrm{sc}}+1.15 \mathrm{~Pa}+1.0 \mathrm{~T}_{\mathrm{o}}$

Normal operation

$1.0 \mathrm{D}+1.0 \mathrm{~L}+1.0 \mathrm{~T}_{\mathrm{p}}+1.0 \mathrm{~T}_{\mathrm{sc}}+1.0 \mathrm{~T}_{\mathrm{o}}+1.0 \mathrm{Q}_{\mathrm{es}}+1.0 \mathrm{R}_{\mathrm{o}}$

b) Abnormal/Environmental Load Category

Abnormal event

$1.0 \mathrm{D}+1.0 \mathrm{~L}+1.0 \mathrm{~T}_{\mathrm{p}}+1.0 \mathrm{~T}_{\mathrm{sc}}+1.5 \mathrm{P}_{\mathrm{a}}+1.0 \mathrm{~T}_{\mathrm{a}}+1.0 \mathrm{R}_{\mathrm{a}}+1.0 \mathrm{R}$

Environmental event

$1.0 \mathrm{D}+1.0 \mathrm{~L}+1.0 \mathrm{~T}_{\mathrm{p}}+1.0 \mathrm{~T}_{\mathrm{sc}}+1.0 \mathrm{~T}_{\mathrm{o}}+1.0 \mathrm{Q}_{\mathrm{ed}}+1.0 \mathrm{R}_{\mathrm{o}}$ 
$1.0 \mathrm{D}+1.0 \mathrm{~L}+1.0 \mathrm{Tp}+1.0 \mathrm{Tsc}+1.0 \mathrm{To}+1.0 \mathrm{Qt}+1.0 \mathrm{Ro}$

Abnormal/environmental event

$1.0 \mathrm{D}+1.0 \mathrm{~L}+1.0 \mathrm{~T}_{\mathrm{p}}+1.0 \mathrm{~T}_{\mathrm{sc}}+1.0 \mathrm{P}_{\mathrm{r}}+1.0 \mathrm{~T}_{\mathrm{o}}+1.0 \mathrm{Q}_{\mathrm{ed}}+1.0 \mathrm{R}_{0}$ 


\section{Appendix B DESIGN CRITERIA}

B.1

STRENGTH LIMITS

The limit state design of the containment structure under factored service category loads shall be performed based on the CSA A23.3 [5]. Accordingly, the factored resistance of the section must be greater than or equal to the section forces under factored loads. It should be noted that for limit state design of CS, the load combinations and their corresponding factors are according to N287.3 [1] as explained in Appendix A

\section{B.1.1 FLEXURE AND AXIAL LOADS}

For the factored service load category, the design shall also meet the requirements of CSA A23.3 [5]. For sections under bending moments and axial forces the requirements of CSA A23.3 Section 10 will be applied. Accordingly, the following requirements will be addressed:

$$
M_{r} \geq M_{f}
$$

where;

$M_{f}=$ factored bending moment (including in-plane torsional moment); and

$M_{r}=$ factored bending moment resistance.

$$
\varepsilon_{c} \leq \varepsilon_{c c_{-} \max }=0.0035
$$

where;

$\varepsilon_{c}=$ concrete strain; and

$\varepsilon_{c c_{-} \max }=$ maximum compressive strain due to stress in concrete extreme fibre (CSA A23.3 Clause 10.1.3). 


$$
N_{r} \geq N_{f}
$$

where;

$N_{f}=$ factored axial force (including in-plane shear force); and

$N_{r}=$ factored axial resistance .

$$
N_{f} \leq P_{r, \max }
$$

where;

$P_{r, \max }=$ maximum factored axial resistance in compression (CSA A23.3 Clause 10.10.4 for sections tied as columns), where,

$$
P_{r, \max }=0.80 \times\left\{\alpha_{1} \phi_{c} f_{c}^{\prime}\left(A_{g}-A_{s t}-A_{p}\right)+\phi_{s} f_{y} A_{s t}-f_{p r} A_{p}\right\}
$$

where;

$$
\alpha_{1}=0.85-0.0015 f_{c}^{\prime} \geq 0.67(\text { CSA A23.3 Clause 10.1.7) }
$$

$f_{c}^{\prime}=$ specified compressive strength of concrete;

$A_{g}=$ gross area of section;

$A_{s t}=$ total area of longitudinal reinforcement;

$A_{p}=$ area of prestressing tendons;

$f_{y}=$ specified yield strength of non-prestressed reinforcement; and

$f_{p r}=$ stress in prestressing tendons at factored resistance. 


\section{B.1.2 SHEAR AND TORSION}

For sections under transverse shear forces the requirements of CSA A23.3 Section 11 shall be applied. Accordingly, the following requirements shall be addressed:

$$
A_{v} \geq A_{v_{-} \min }
$$

where;

$A_{v}=$ area of transverse shear reinforcement;

$A_{v_{-} \text {min }}=$ minimum area of transverse shear reinforcement (CSA A23.3 Clause 11.2.8.2), where,

$$
A_{v_{-} \min }=0.06 \sqrt{f_{c}^{\prime}} \frac{b_{w} s}{f_{y}}
$$

where;

$b_{w}=$ minimum effective web width $(\mathrm{mm}) ;$

$s=$ spacing of transverse shear reinforcement $(\mathrm{mm})$; and

$f_{c}^{\prime}$ and $f_{y}$ are in MPa.

$$
s \leq s_{\text {max }}
$$

where;

$S_{m s x}=$ maximum spacing of transverse shear reinforcement (CSA A23.3 Clauses 11.3.8.1 and 11.3.8.3), where, 
$s_{\max }=\left\{\begin{array}{l}\text { smaller of } 0.7 d_{v} \text { and } 600 \mathrm{~mm} \text { if } V_{f}-V_{p} \leq 0.5\left(V_{r_{-} \max }-V_{p}\right) \\ \text { smaller of } \frac{0.7 d_{v}}{2} \text { and } 300 \mathrm{~mm} \text { if } V_{f}-V_{p}>0.5\left(V_{r_{-} \max }-V_{p}\right)\end{array}\right.$

Equation (65)

$V_{r_{-} \max }=$ maximum possible factored shear resistance, where,

$V_{r_{-} \max }=0.25 \phi_{c} f_{c}^{\prime} b_{w} d_{v}+V_{p}$

Equation (66)

where;

$d_{v}=$ effective shear depth, taken as the greater of $0.9 d$ or $0.72 h$;

$d=$ distance from extreme compression fibre to centroid of longitudinal tension reinforcement;

$h=$ overall thickness or height of member; and

$V_{p}=$ component in the direction of the applied shear of the effective prestressing force factored by $\phi_{p}$, positive if resisting applied shear.

$V_{r} \geq V_{f}$

Equation (67)

where;

$V_{f}=$ factored transverse shear force;

$V_{r}=$ factored shear resistance (CSA A23.3 Clause 11.3.3), where,

$V_{r}=V_{c}+V_{s}+V_{p}$

Equation (68)

$V_{r} \leq V_{r_{-} \max }$

Equation (69)

where;

$V_{c}=$ shear resistance attributed to the concrete factored by $\phi_{c}$, where, 
$V_{c}=\phi_{c} \lambda \beta \sqrt{f_{c}^{\prime}} b_{w} d_{v}$

Equation (70)

Where, $\sqrt{f_{c}^{\prime}} \leq 8\left(f_{c}^{\prime}\right.$ in MPa) (CSA A23.3 Clause 11.3.4);

$\lambda=$ factor to account for low density concrete;

$\beta=$ factor accounting for shear resistance of cracked concrete, where,

$\beta=\frac{0.40}{\left(1+1500 \varepsilon_{x}\right)} \cdot \frac{1300}{\left(1000+s_{z e}\right)}($ CSA A23.3 Clause 11.3.6.4);

Equation (71)

$\varepsilon_{x}=$ longitudinal strain at mid-depth of the member due to factored loads (positive when tensile), where,

$\varepsilon_{x}=\frac{M_{f} / d_{v}+V_{f}-V_{p}+0.5 N_{f}-A_{p} f_{p o}}{2\left(E_{s} A_{s}+E_{p} A_{p}\right)} \quad$ no through crack;

Equation (72)

$\varepsilon_{x}=2 \frac{M_{f} / d_{v}+V_{f}-V_{p}+0.5 N_{f}-A_{p} f_{p o}}{2\left(E_{s} A_{s}+E_{p} A_{p}\right)}$ with through crack;

Equation (73)

$0 \leq \varepsilon_{x} \leq 0.003$

Equation (74)

$f_{p o}=$ stress in prestressing tendons when strain in the surrounding concrete is zero,

where;

$f_{p}=E_{p} \varepsilon_{p}=E_{p}\left(\varepsilon_{c}+\Delta \varepsilon_{p}\right) \rightarrow f_{p o}=E_{p}\left(0+\Delta \varepsilon_{p}\right)=E_{p} \Delta \varepsilon_{p}$

Equation (75)

$\Delta \varepsilon_{p}=$ difference between the total strain in concrete and the total strain in tendon; 
$E_{s}=$ modulus of elasticity of non-prestressed reinforcement;

$A_{s}=$ area of longitudinal reinforcement on the flexural tension side;

$E_{p}=$ modulus of elasticity of prestressing tendons;

$s_{z e}=$ equivalent value of crack spacing parameter $\left(s_{z}\right)$ that allows for the influence of aggregate size $(\mathrm{mm})$ (taken to be $300 \mathrm{~mm}$ as $A_{v_{-} \text {min }}$ is provided);

$\theta=$ angle of inclination of diagonal compressive stresses $\left(\theta=29+7000 \varepsilon_{x}\right)$; and

$V_{s}=$ shear resistance provided by transverse shear reinforcement factored by $\phi_{s}$, where,

$V_{s}=\frac{\phi_{s} A_{v} f_{y} d_{v} \cot \theta}{s}(\mathrm{CSA}$ A23.3 Clause 11.3.5.1)

Equation (76)

\section{B.2 PERMISSIBLE STRESSES/STRAINS (PSS)}

In the CS, under the service category loads, the stresses shall remain below the permissible stresses. Moreover, under the abnormal/environmental load category, the structure is to remain elastic. The stresses in the sections under un-factored loads must be within the permissible limits as defined previously in Table 1 in Chapter 2.

The stress in prestressing tendon and non-prestressing steel can be calculated based on strain compatibility approach. In this approach, stresses are calculated on the basis of the concrete remaining uncracked and material stress-strain relationships being linear. This approach can be expanded to cracked and/or non-linear stress-strain relationships as well.

The total strain in concrete is found by calculating strain at the centroid of the transformed section, and curvature [21].

This procedure is explained as follows: 


$$
\begin{gathered}
\varepsilon_{c e n}=\frac{N-N_{o}}{E_{c} A_{\text {trans }}} \\
\phi=\frac{M-M_{o}}{E_{c} I_{\text {trans }}}
\end{gathered}
$$

where,

$\varepsilon_{c e n}=$ strain at centroid of the transformed section;

$\phi=$ curvature;

$M=$ applied moment (shall be checked for both hoop and meridional directions);

$\mathrm{N}_{0}=$ decompression axial force;

$\mathrm{M}_{0}=$ decompression moment;

$\mathrm{E}_{\mathrm{C}}=$ modulus of elasticity of concrete;

$A_{\text {trans }}=$ Transformed the cross section; and

Itrans $=$ moment of inertia of a transformed section.

The decompression actions, $\mathrm{N}_{0}$ and $\mathrm{M}_{0}$, account for influence of prestressing. In determining the concrete stresses under long-term action creep in concrete and relaxation in prestressing tendons are accounted by effective modulus of elasticity, $E_{c, \text { eff }}$

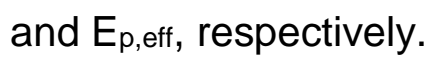

$$
N_{0}=E_{p, e f f} \Delta \varepsilon_{p} A_{p}-E_{c, e f f} \varepsilon_{c o} A_{c}
$$

where;

$E_{p, e f f}=$ effective modulus of elasticity of tendon;

$\mathrm{E}_{\mathrm{c}, \text { eff }}=$ effective modulus of elasticity of concrete;

$A_{p}=$ cross-section area of tendon;

$\mathrm{A}_{\mathrm{c}}=$ cross-section area of concrete; 
$\varepsilon_{c o}=$ thermal strain in concrete;

$\Delta \varepsilon_{p}=$ difference between the total strain in concrete and the total strain in tendon: (evaluated immediately after prestress transfer for convenience);

$$
\Delta \varepsilon_{p}=\varepsilon_{p i}-\varepsilon_{c i} \rightarrow \varepsilon_{p i}=\varepsilon_{c i}+\Delta \varepsilon_{p}
$$

$\varepsilon_{p i}=$ total strain in tendon immediately after prestress transfer; and

$\varepsilon_{c i}=$ total strain in concrete immediately after prestress transfer.

$$
M_{0}=-\left\lfloor E_{p, e f f} \Delta \varepsilon_{p} A_{p}\left(y_{b t}-y_{b s}\right)-E_{c, e f f} \varepsilon_{c o} A_{c}\left(y_{b g}-y_{b t}\right)\right\rfloor
$$

where;

$\mathrm{y}_{\mathrm{bt}}=$ distance of centre of transformed section from bottom fibre;

$\mathrm{y}_{\mathrm{bs}}=$ distance of centre of tendons from bottom fibre; and

$\mathrm{ybg}=$ centre of gravity of the section.

Once $\varepsilon_{c e n}$ and $\phi$ are found, the distribution of total concrete strain across the section is identified according to following equation:

$$
\varepsilon_{c}=\varepsilon_{c e n}-\phi y
$$

where;

$y=$ distance from centre of transformed section.

The strain in concrete caused by stress can be found by subtracting the shrinkage strain and thermal strain from total concrete strain according to following equation:

$$
\varepsilon_{c f}=\varepsilon_{c}-\varepsilon_{c o}
$$


The strain in prestressing tendon can be found according to following equation:

$$
\varepsilon_{p f}=\varepsilon_{c}-\Delta \varepsilon_{p}
$$

When the strains are known, the stress in the material can be easily found based on the stress-strain relationship. These values shall be checked to be within permissible limits. 


\section{REFERENCES}

[1] CSA N287.3, Design requirements for concrete containment structures for nuclear power plants (CSA N287.3-14), Torotno, Canada: Canadian Standards Association, 2014.

[2] Canadian Nuclear Safety Commission (CNSC), Design of Reactor Facilities: Nuclear Power Plants (REGDOC-2.5.2), Ottawa, Canada: Canadian Nuclear Safety Commission , 2014.

[3] CSA N287.1, General requirements for concrete containment structures for nuclear power plants (CSA N287.1-14), Toronto, Canada: Canadian Standards Association, 2014.

[4] CSA N287.2, Material requirements for concrete containment structures for CANDU nuclear power plants (CSA N287.2-08), Toronto, Canada: Canadian Standards Association, R2013.

[5] CSA A23.3, Design of Concrete Structures (CSA A23.3-14), Canadian Standards Association: Toronto, Canada, 2014.

[6] Thomas, D. J., "Neutron spectrometry for radiation protection," Radiation Protection Dosimetry, vol. 110, no. 1-4, pp. 141-149, 2004.

[7] NUREG 0800, Standard Review Plan, Office of Nuclear Reactor Regulation, U.S. Nuclear Regulatory Commission, Section 3.8.5, 2014.

[8] 10 CFR Part 50.34, Contents of Applications; Technical Information, U.S Nuclear Regulatory Commission, 2007. 
[9] ANSYS software (Version 12.1), Penn.: ANSYS Inc., 2010.

[10] Rizkalla, S. H., Simmonds, S. H., and MacGregor, J.G., "Prestressed concrete containment model," Journal of Structural Engineering, vol. 110, no. 4, pp. 730-743, 1984.

[11] Radulescu, J.P., Pradolin, L., and Mamet, J.C., "Ultimate pressure capacity of CANDU6 Containment structure," in The Power Canada's Future Conference, Toronto, Canada, 1997.

[12] Smith, J.A., Capacity of Prestressed Concrete Containment Vessels with Prestressing Loss, SAND2001-1762, Sandia National Laboratories, Albuquerque, NM, 2001.

[13] ABAQUS 6.9 User Documentation, Internet Manual. Simulia. Retrieved 10 September, 2011.

[14] Saudy, A.M., Awad, A., and Elgohary, M.M., "Ultimate pressure capacity of ACR® containment structure," in 18th International Conference on Structural Mechanics in Reactor Technology, Beijing, China, 2005.

[15] Kwak, H. G. and Kim, S. P., "Nonlinear analysis of RC beams based on momentcurvature relation," Comput Struct, vol. 80, pp. 615-628, 2005.

[16] Hu, H.T., and Lin, Y.H., "Ultimate analysis of PWR prestressed concrete containment subjected to internal pressure," International Journal of Pressure Vessels and Piping, vol. 83, no. 3, pp. 161-167, 2006.

[17] Hu, H. T., \& Liang, J. I., "Ultimate analysis of BWR Mark III reinforced concrete containment subjected to internal pressure." Nuclear Engineering and Design, vol. 195, no. 1, pp. 1-11, 2000. 
[18] Kim, K.S., and Lee, D.H., "Nonlinear analysis method for continuous post-tensioned concrete members with unbonded tendons," Engineering Structures, vol. 40, pp. 487$500,2012$.

[19] Shokoohfar, A., \& Rahai, A., "Nonlinear analysis of pre-stressed concrete containment vessel (PCCV) using the damage plasticity model." Nuclear Engineering and Design, vol. 298, pp. 41-50, 2016.

[20] Hessheimer, M.F., and Dameron, R.A., "Containment Integrity Research at Sandia National Laboratories. Division of Fuel, Engineering \& Radiological Research, Office of Nuclear Regulatory Research," US Nuclear Regulatory Commission, 2006.

[21] Collins, M.P., and Mitchell, D., Prestressed concrete structures, Englewood Cliffs, NJ: Prentice Hall, 1991.

[22] ANSYS Inc., ANSYS help manual (Version 11.1), Penn.: ANSYS Inc., 2004.

[23] Willam, K.J., and Warnke, E.P., "Constitutive model for the triaxial behavior of concrete," in International Association for Bridge and Structural Engineering, Bergamo, Italy, 1975.

[24] Ru-deng, L. U. O., "Values of shear transfer coefficients of concrete element Solid65 in Ansys [J]." Journal of Jiangsu University (Natural Science Edition) vol. 2, no. 018, 2008.

[25] Wolanski, A. J., "Flexural behavior of reinforced and prestressed concrete beams using finite element analysis." Diss. Faculty of the Graduate School, Marquette University, (2004). 
[26] Radulescu, J. P., Pradolin, L., and Mamet, J. C., "Ultimate pressure capacity of CANDU 6 containment structures. Proceedings Annu Conf Can Nucl Soc. Vol. 2., (1997).

[27] Buckhouse, E. R., "External flexural reinforcement of existing reinforced concrete beams using bolted steel channels", Doctoral dissertation, Marquette University, (1997).

[28] McGregor, J.G., Simmonds, S.H., and Rizkalla S.H., "Test of a Prestressed Concrete Secondary Containment Structure", A Technical Report to the Atomic Energy Control Board, Structural Engineering Report No. 85, University of Alberta, Department of Civil Engineering, Edmonton, AB. 1980.

[29] Murray, D.W., Wong C., Simmonds S.H. and MacGregor J.G., "An Inelastic Analysis of The Gentilly-2 Secondary Containment Structure", A Technical Report to the Atomic Energy Control Board, Structural Engineering Report No. 86, University of Alberta, Department of Civil Engineering, Edmonton, AB. 1980.

[30] Elmorsi, M., Kianoush, M.R., and Tso, W.K., "Nonlinear analysis of cyclically loaded reinforced concrete structures," ACI Structural Journal, vol. 95, no. 6, pp. 725-739, 1998.

[31] Hariri-Ardebili M.A., Seyed-Kolbadi S.M., and Mirzabozorg H.A., "Smeared crack model for seismic failure analysis of concrete gravity dams considering fracture energy effects," Struct Eng Mech, vol. 48, pp. 17-39, 2013.

[32] ACI Committee 209, "Guide for Modeling and Calculating Shrinkage and Creep in Hardened Concrete (ACl209.2R-08)," American Concrete Institute, Farmington Hills, MI, 2008. 
[33] Tia M, Hossiney N, Bekoe P., "Modulus of Elasticity, Creep and Shrinkage of Concrete: Phase II", Department of Civil and Coastal Engineering, University of Florida, Gainesville, Florida, 2009. 